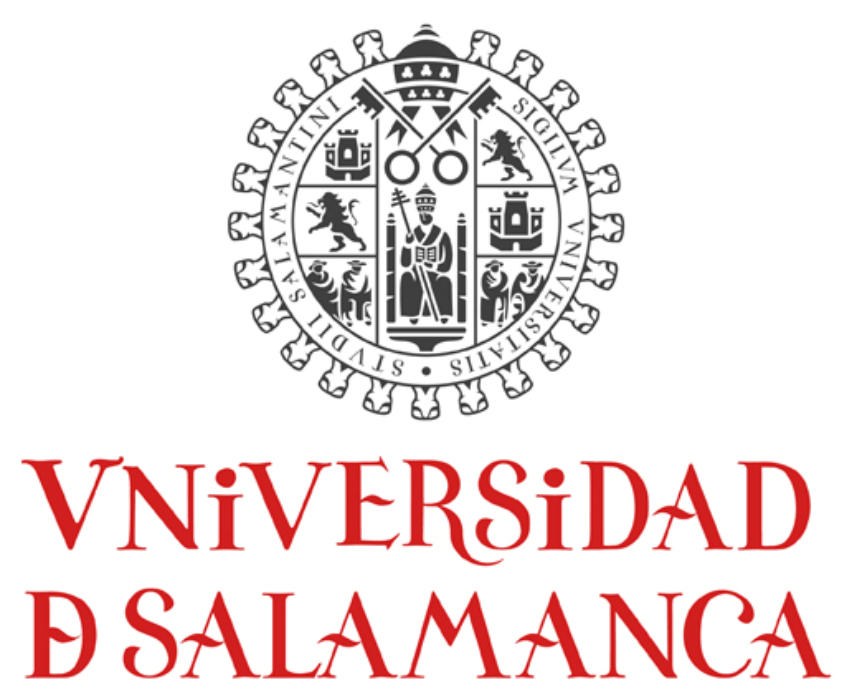

CAMPUS DE EXCELENCIA INTERNACIONAL

\author{
FACULTAD DE DERECHO \\ DEPARTAMENTO DE DERECHO PÚBLICO GENERAL \\ ÁREA DE CIENCIA POLÍTICA Y DE LA ADMINISTRACIÓN
}

TESIS DOCTORAL

\title{
ELITES PARLAMENTARIAS Y DEMOCRACIA EN AMÉRICA LATINA
}

\author{
Presentada por: \\ Cristina Rivas Pérez \\ Director: \\ Manuel Alcántara Sáez, Universidad de Salamanca
}

Salamanca, 2015 
La presente tesis doctoral corresponde a la modalidad de compendio de trabajos previamente publicados. En ella se recogen dos artículos de revistas y dos capítulos de libro todos ellos relacionados con el proyecto de tesis: "Elites parlamentarias y democracia en América Latina”. La referencia completa de la revista y editoriales de los libros, así como los autores y su afiliación se detalla a continuación:

Capítulo 1: "Patrones socioeconómicos de la elite legislativa y democracia en América Latina”. 2009. En Fátima Anastasia, Araceli Mateos Díaz, Magna Inácio y Marta Mendes da Rocha (org.). Elites Parlamentares na América Latina. Belo Horizonte: Argumentum Editora, pp.131-177.

Autores: Francisco Sánchez (Universidad de Valencia)

Cristina Rivas Pérez (Instituto de Iberoamérica, Universidad de Salamanca)

Artículo 1: "La educación como elemento de calidad de los políticos latinoamericanos”, en Política y Gobierno, Vol. XVII, número 2, México D.F. II Semestre 2010, pp. 279-319.

Autores: Cristina Rivas Pérez (Instituto de Iberoamérica, Universidad de Salamanca)

Purificación Vicente (Universidad de Salamanca)

Francisco Sánchez (Universidad de Valencia)

Capítulo 2: “The dimensions of Polarization in Parliaments". 2008. En Manuel Alcántara Sáez (ed.). Politicians and Politics in Latin America. United of States of America: Lynne Rienner Publishers, Inc., pp.139-160.

Autores: Cristina Rivas Pérez (Instituto de Iberoamérica, Universidad de Salamanca)

Artículo 2: "Las dimensiones de la polarización partidista en América Latina”, en Política y Gobierno, Vol. XIV, número 2, México D.F. II Semestre 2007, pp. 349-390. Autores: Manuel Alcántara Sáez (Universidad de Salamanca) Cristina Rivas Pérez (Instituto de Iberoamérica, Universidad de Salamanca) 


\section{AGRADECIMIENTOS}

En este camino que inicié hace ya muchos años he contado con el apoyo de diversas personas e instituciones a quienes quiero agradecer que me hayan acompañado en este largo trayecto. En primer lugar quiero dar las gracias al director de esta tesis, Manuel Alcántara, por la oportunidad que me dio en 1996 de formar parte del equipo de personas que integraban el Instituto de Iberoamérica del que por aquel entonces era director. Gracias a él aprendí a enamorarme de una región como América Latina a la que permanezco unida desde ese momento. Él me brindó la oportunidad de ser parte del Proyecto de Elites Parlamentarias en América Latina, un proyecto al que he dedicado mi vida en cuerpo y alma, el que me ha dado tantas satisfacciones y a la vez tantos quebraderos de cabeza...Por todo ello, y por seguir contando conmigo para todo aquello que puedes, igracias!.

Durante mi andadura en estos años de investigación he contado con el apoyo de muchos compañeros y amigos que han hecho posible que, por fin hoy, esté presentando esta tesis doctoral. Por ello quiero dar las gracias a todos los miembros que integran el Instituto de Iberoamérica y el Área de Ciencia Política de la Universidad de Salamanca. De todas las personas que conocí quiero destacar a Araceli, Mercedes, Pato, Ceci, Mar, Leticia, Elena, Flavia y Patricia Otero, y muy especialmente a tres personas que en estos últimos meses me han dedicado su tiempo a pesar de no tenerlo, Francisco Sánchez, por su perseverancia, a Fátima García por sus consejos y Ana Belén Benito, por sus comentarios y apoyo desde la distancia, ellos me han empujado en estos últimos meses para que esta tesis sea hoy una realidad.

Agradezco a mi madre su apoyo y su espíritu de lucha, porque aunque ella no lo sepa ha sido un ejemplo de fortaleza para sus hijas. Gracias mamá por el tiempo dedicado a mis hijos, sin tu ayuda hoy no hubiera podido poner fin a esta etapa de mi vida. Gracias también a mi hermana por creer en mí y apoyarme en todo momento, por poner esa nota de color y alegría en mi vida. A mi abuelo, que a sus 92 años, es todo un ejemplo de vitalidad. Y gracias a mi padre por acompañarme en todos estos años desde algún pequeño rincón del cielo, se que hoy estarías orgullosa de mi. 
Y por último, pero no menos importante, agradezco a Alberto por su paciencia y comprensión todos estos años, que se han traducido en un apoyo incondicional en todo lo que he hecho, apostando y confiando en mi. Y como no, a mis dos pequeños, Irene y Pablo, que han cambiado mi vida por completo dándoles un sentido que nunca antes pude imaginar. A ellos quiero, en primer lugar, pedirles perdón por el tiempo de juego que les he robado y, en segundo lugar les agradezco su cariño, sus besos, abrazos y alegría que me hacen olvidar todos los momentos difíciles atravesados en este largo camino.

A todos...GRACIAS. 


\section{ÍNDICE}

INTRODUCCIÓN........................................................ 1

1. Introducción........................................................ 1

2. Antecedentes del objeto de estudio.................................. 4

3. Estructura de la tesis................................................ 11

4. Objetivo, preguntas e hipótesis del trabajo............................. 13

5. Metodología de investigación.......................................... 16

6. Conclusiones........................................................ 21

Bibliografía.......................................................... 24

CAPÍTULO 1: Patrones socio económicos de la elite legislativa y democracia en América Latina.................................................... 30

1. Introducción..................................................... 31

2. Elites, democracia y desigualdad................................. 34

3. Desigualdad y elite política........................................ 39

4. Elites políticas y características de la democracia...................... 59

5. A manera de conclusión........................................... 70

Bibliografía........................................................... 71

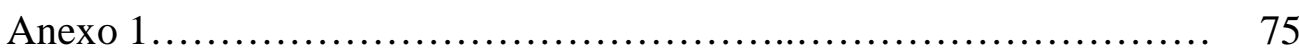

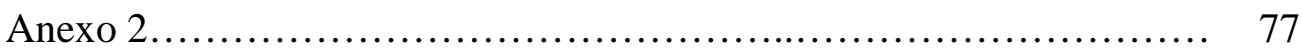

CAPÍTULO 2: La educación como elemento de calidad de los políticos latinoamericanos............................................................ 79

1. Introducción........................................................... 80

2. ¿Cómo se ha valorado la calidad de los políticos?..................... 82

3. ¿Cómo valorar las características de la democracia?.................... 88

4. Nuestra propuesta de estudio............................................... 91

5. Metodología para el análisis de los datos...................................... 95

6. Educación de los diputados y características de la democracia........... 98 
7. Educación, características de la democracia y desigualdad social........ 105

8. Conclusiones................................................... 113

Referencias bibliográficas...................................... 114

CAPÍTULO 3: The Dimensions of Polarization in Parliaments................... 120

Resumen en castellano............................................. 121

1. The Dimensions of Polarization in Parlaments........................ 127

2. Left and Right Parties in Latin American Parliaments................. 128

3. The Main Dimensions of Polarization in Latin American Parliaments..... 129

4. Conclusion........................................................ 141

Appendix....................................................... 143

Bibliography................................................ 149

CAPÍTULO 4: Las dimensiones de la polarización partidista en América Latina 169

1. Introducción................................................. 170

2. Izquierda y derecha, el reto de su medición........................ 172

3. Principales dimensiones de la polarización en los actuales Parlamentos latinoamericanos............................................... 175

4. Evolución de los partidos políticos en las principales dimensiones ideológicas respecto a la legislatura anterior........................ 194

5. Conclusiones............................................... 198

Referencias bibliográficas........................................ 203

Apéndice metodológico.......................................... 206 


\section{ÍNDICE DE CUADROS Y TABLAS}

\section{INTRODUCCIÓN}

Cuadro I: número de entrevistas realizadas

CAPÍTULO 1: Patrones socio económicos de la elite legislativa y democracia en América Latina

Tabla 1: Correlación entre nivel de estudios del padre, de la madre y del diputado por países

Tabla 2: Correlación entre nivel de estudios del padre, de la madre y del diputado con el nivel de ingresos de los parlamentarios por países.

Tabla 3: Contribuciones relativas del factor al elemento de la Figura 1

Tabla 4: Clasificación de la elite parlamentaria Latinoamericana según sus características socio económicas.

Tabla 5: Países que forman los clusters y características socio económicas....

Tabla 6: Medias de los clusters en las variables socio económicas

50

Tabla 7: Contribuciones relativas del factor al elemento para los diputados e indicadores socio económicos.

Tabla 8: Correlaciones entre características de las elites e indicadores de desigualdad social y educación.

Tabla 9: Países que forman los clusters y características socio económicas.....

Tabla 10: Medias de los clusters en las variables de desigualdad social y características socio económicas de los diputados latinoamericanos (16 países)

Tabla 11: Correlaciones entre variables socio económicas e indicadores de democracia y buen gobierno.

Tabla 12: Contribuciones relativas del Factor al Elemento para las características socio económicas de los diputados e indicadores de la democracia.

Tabla 13: Países que forman los clusters según características socio económicas y de la democracia.

Tabla 14: Medias de los clusters en las variables socio económicas y democracia.

ANEXO 1

Cuadro: Número de entrevistas. 
CAPÍTULO 2: La educación como elemento de calidad de los políticos latinoamericanos

Cuadro 1: Contribuciones relativas del factor al elemento para el nivel educativo de los diputados latinoamericanos y características de la democracia.....

Cuadro 2: Contribuciones relativas del factor al elemento para el nivel de estudios de los diputados y características de la democracia....

Cuadro 3: Clusters de clasificación según nivel educativo de los diputados y características de la democracia.....

Cuadro 4: Contribuciones relativas del factor al elemento para el nivel educativo de los diputados latinoamericanos, características de la democracia e indicadores de desigualdad y movilidad social.

Cuadro 5: Contribuciones relativas del factor al elemento para los países latinoamericanos....

Cuadro 6: Clusters de clasificación según nivel educativo de los diputados latinoamericanos, características de la democracia e indicadores de desigualdad y movilidad social.

CAPÍTULO 3: The dimensions of Polarization in Parliaments

Tabla 1: Familias partidistas según su posicionamiento en las dimensiones de polarización programática.

Table 6.1: Classification of Latin American Parties by ideology. ... 129

Table 6.2: Variables in the Analysis. 130

Table 6.3: Analysis of Rotated Factors.

Table 6.4: Proportion of Cumulative Variability Absorbed.

Table 6.5: Relative Contributions of the Factors to the Programmatic Dimensions.

Table 6.6: Relative Contributions of the Factors to Political Parties

Table 6.6: Proportion of Cumulative Variability Absorbed....

Table 6.7: Classification of Political Parties in the Religion and Values Dimension....

Table 6.8: Classification of Political Parties in the State Intervention Dimension 
Table 6.9: Classification of Political Parties in the Democracy Dimension...............................................................

Table 6.10: Classification of Political Parties in the Social Background Dimension

Table 6.11: Classification of Political Parties in the Armed Forces Dimension....

Table 6.12: Party Placement and Individual Self-Placement in the Left-Right Dimension.

Table 6.13: Results of Factor Analysis (total variance explained)

Table 6.14: Questions Used.

CAPÍTULO 4: Las dimensiones de la polarización partidista en América Latina

Cuadro 1: Clasificación de los partidos políticos latinoamericanos por su ideología

Cuadro 2: Variables en el análisis

Cuadro 3: Dimensiones de polarización (variables ordenadas según su contribución a la formación del factor).....

Cuadro 4: Clasificación de los partidos políticos en la dimensión intervención estatal........................................................

Cuadro 5: Clasificación de los partidos políticos en la dimensión

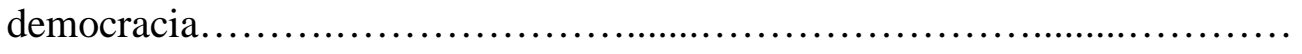

Cuadro 6: Clasificación de los partidos políticos en la dimensión valores.

Cuadro 7: Clasificación de los partidos políticos en la dimensión imagen de los Estados Unidos.

Cuadro 8: Clasificación de los partidos políticos en la dimensión fuerzas armadas

Cuadro 9: Resumen de resultados.

\section{ANEXO}

Cuadro 1: Absorción de inercia

Cuadro 2: Contribuciones relativas para las dimensiones de polarización....... 208

Cuadro 3: Contribuciones relativas para los partidos políticos. ... 209 


\section{ÍNDICE DE GRÁFICOS Y FIGURAS}

CAPÍTULO 1: Patrones socio económicos de la elite legislativa y democracia en América Latina

Figura 1: Representación gráfica de los países de acuerdo a las características socio económicas de los diputados a partir del análisis HJ-Biplot...

Figura 2: Dendograma de agrupación de los países según variables socio económicas.

Figura 3: Representación gráfica de los países, nivel de elitismo de los diputados latinoamericanos e indicadores socio económicos y educativos a partir del análisis HJ-Biplot

Figura 4: Representación gráfica de los países, características socio económicas de los diputados e indicadores sobre la democracia a partir del análisis HJ-Biplot

Figura 5: Representación gráfica de los países, características socio económicas de los diputados e indicadores sobre la democracia a partir del análisis $H J$-Biplot

CAPÍTULO 2: La educación como elemento de calidad de los políticos latinoamericanos

Gráfica 1: Representación de los países, nivel de estudios de los diputados latinoamericanos y características de la democracia a partir del análisis HJBiplot.

Gráfica 2: Dendograma de agrupación de los países según nivel educativo de los diputados latinoamericanos y características de la democracia.

Gráfica 3: Representación de los países para el nivel educativo de los diputados latinoamericanos, características de la democracia e indicadores de desigualdad y movilidad social.

Gráfica 4: Dendograma de agrupación de los países según nivel educativo de los diputados latinoamericanos, características de la democracia e indicadores de desigualdad y movilidad social.

CAPÍTULO 3: The dimensions of Polarization in Parliaments

Figure 6.1: Representation of the Polarization Dimensions, HJ-Biplot Axes 1 and 2 .

Figure 6.2: Representation of the Polarization Dimensions, HJ-Biplot Axes 1 and 3. 
CAPÍTULO 4: Las dimensiones de la polarización partidista en América Latina

Figura 1: Representación HJ-Biplot de la matriz de datos (eje 1 y 2)............ 184

Figura 2: Representación HJ-Biplot de la matriz de datos (eje 1 y 3)............ 185

Figura 3: Representación HJ-Biplot de la matriz de datos conjuntos (eje 1 y 2) 197

Figura 4: Representación HJ-Biplot de la matriz de datos conjuntos (eje 1 y 3) 197 


\section{INTRODUCCIÓN}

Esta tesis doctoral es el resultado de la compilación de dos artículos publicados en la Revista Política y Gobierno y dos capítulos de libros editados por Argumentum Editora y Lynne Rienner Publishers ${ }^{1}$ entre los años 2007 y 2010, que abordan el estudio de la elite parlamentaria en América Latina y su relación con la democracia.

Las diferentes aproximaciones teóricas y metodológicas desde las que se ha estudiado el ejercicio de la política han considerado a los políticos actores relevantes y desde los inicios de la disciplina, la academia ha prestado atención a cómo éstos eran reclutados y qué virtudes debían poseer aquellos que aspiraban a gestionar la cosa pública. Sin embargo, con el fin de los procesos de transición en América Latina en la década de 1980, el debate en torno a las bondades o peligros del presidencialismo frente al parlamentarismo (Linz y Valenzuela, 1994; Jones, 1995) centró la atención de la academia. Estas discusiones sobre el diseño institucional y otras polémicas acerca de los mecanismos de representación, sirvieron para avalar la ola de reformas que se implementaron en la región (Molina, 2000; Payne et al, 2002; Mainwaring y Pérez-Liñán, 2005; García Díez, 2005) sin prestar especial atención a los políticos.

De la misma manera, en la década de 1990 la Ciencia Política se centró en el estudio de los partidos, los sistemas en los que interactuaban y las instituciones que albergaban a los representantes latinoamericanos. Esta mirada a las instituciones -en una región harta de explicar su desarrollo político por visiones estructuralistas (donde las clases sociales tenían un papel estelar) o dependentistas (donde factores económicos externos prevalecían)- aportó una frescura inédita al entendimiento de la política en el continente latinoamericano. La nueva década del 2000 dará paso a los estudios sobre la calidad de la

\footnotetext{
${ }^{1}$ Las referencias bibliográficas de los artículos y capítulos de libro son: Rivas Pérez, Cristina, Vicente Purificación y Sánchez Francisco. "La educación como elemento de calidad de los políticos latinoamericanos”, en Política y Gobierno, Vol. XVII, número 2, México D.F. II Semestre 2010, pp. 279319.

Alcántara Sáez Manuel y Rivas Pérez Cristina. "Las dimensiones de la polarización partidista en América Latina”, en Política y Gobierno, Vol. XIV, número 2, México D.F. II Semestre 2007, pp. 349-390.

Sánchez Francisco y Rivas Pérez Cristina. 2009. "Patrones socioeconómicos de la elite legislativa y democracia en América Latina”. En Fátima Anastasia, Araceli Mateos Díaz, Magna Inácio y Marta Mendes da Rocha (org.). Elites Parlamentares na América Latina. Belo Horizonte: Argumentum Editora, pp.131177.

Rivas Pérez Cristina. 2008. “The dimensions of Polarization in Parliaments”. En Manuel Alcántara Sáez (ed.). Politicians and Politics in Latin America. United of States of America: Lynne Rienner Publishers, Inc., pp.139-160.
} 
democracia con los trabajos seminales de autores como O’Donnell (2004) o Diamond y Morlino (2004 y 2005).

Tras décadas de estudio de las instituciones y su rendimiento surge la necesidad de una nueva mirada bajo la premisa de que si las instituciones importan, los políticos importan tanto o incluso más. En palabras de Olson (1994:13) "la dimensión humana de las legislaturas es particularmente visible y notoria en países de democratización reciente”. Con esta afirmación se pone de manifiesto la preocupación por la incidencia que las habilidades de los legisladores, sus expectativas, creencias y temores tienen en el quehacer como miembros de la institución legislativa y, cómo sus experiencias previas determinan sus patrones de adaptación, aprendizaje, y aporte al trabajo legislativo. Como tratan de evidenciar los trabajos que aquí se presentan, dentro del conjunto de actores institucionalizados relevantes en un sistema político, las élites políticas -como parte de la denominada elite de poder- ejercen importancia sobresaliente en las democracias contemporáneas.

Siguiendo esta línea de investigación, los artículos que forman parte de esta tesis doctoral tienen un denominador común: los políticos y la idea de que los políticos importan. Con este propósito, la investigación se centra en aquellos que ocupan un escaño legislativo, en último término, los tomadores de las decisiones políticas fundamentales como “agentes” al servicio del ciudadano o “principal”. Los legisladores aprueban las leyes, influyen en la política de sus respectivos países y en ellos descansa en última instancia el rendimiento del régimen democrático como hacedores de políticas públicas.

Un segundo elemento de unión de estos cuatro trabajos es el enfoque metodológico estadístico a través del cual se trata de evidenciar el peso de los políticos. En todos ellos se aplica el HJ-Biplot; una técnica de análisis poco utilizada en la Ciencia Política para el estudio de relaciones entre variables. La forma tradicional de abordar el estudio de la relación entre unas variables explicativas y una variable respuesta es utilizar un modelo de regresión múltiple. Sin embargo, pocas veces se contrastan las hipótesis que requiere la correcta aplicación del modelo, probablemente porque en datos de este tipo (variables ordinales o con escalas de Likert) tales hipótesis no suelen ser por lo general, objeto de verificación. Por el contrario, los métodos biplot están libres de hipótesis, capturan 
estructuras de covariación entre las variables y presentan los resultados en planos factoriales donde los ejes son las variables latentes.

El estudio de los políticos en esta tesis se hace desde dos perspectivas diferentes. Por un lado, se abordan las características personales de los parlamentarios latinoamericanos y cómo éstas inciden de forma directa en las características del sistema partidista y de la democracia en sus respectivos países. Por otro, se presta especial atención al papel que desempeña la posición ideológica de los diputados a la hora de configurar diferentes ejes de conflicto y polarización programática en el sistema de partidos.

La elección de las “elites parlamentarias” latinoamericanas como objeto de análisis obedece a mi trayectoria personal y profesional ligada de manera especial al Proyecto de Elites Parlamentarias de América Latina de la Universidad de Salamanca² ${ }^{2}$ en el que, de una forma u otra, llevo trabajando en los últimos casi veinte años.

A pesar de que la pregunta sobre el impacto que tienen los rasgos de los que gobiernan en el desempeño del régimen es antigua -ya la abordó Aristóteles (S. III a.c.) en "La Política”-, resulta complicado ofrecer datos concluyentes sobre qué es ser un buen político o un político de calidad, o cuáles de sus atributos explicarían mejor las variaciones en el funcionamiento del sistema.

Ya desde Weber y Parsons la acción política se concibe intrínsecamente ligada a las percepciones, actitudes y orientaciones políticas de sus protagonistas, a la forma en que construyen su visión de la política y su posición como representantes dentro de la misma. Sin embargo, el desequilibrio de la investigación empírica es manifiesto y la falencia se hace aún más llamativa en el actual contexto de preocupación académica por la evaluación de la calidad de las democracias. Se sabe mucho sobre las instituciones políticas, en cambio se sabe muy poco sobre las personas que se dedican a la política. El tema de la elite política forma parte de ese grupo de cuestiones clásicas de los estudios políticos que no pierden vigencia, ya que preguntas como: ¿quiénes son? ¿qué hacen? ¿ o cómo piensan? estarán siempre en la agenda de investigación debido a los continuos

\footnotetext{
${ }^{2}$ Parliamentary Elites of Latin America (PELA). Esta investigación está dirigida por Manuel Alcántara
} Sáez, Catedrático de Ciencia Política de la Universidad de Salamanca. 
cambios en la estructura de dominación política. Se trata por tanto de un tema de tan amplio espectro que se puede estudiar a través de enfoques que van desde lo normativo (como los relacionados con la representación política), a lo “empírico” (como los que buscan establecer vínculos entre las características de los políticos y sus conductas y actitudes).

Esta tesis doctoral pretende ser un acercamiento empírico al análisis de la política desde la perspectiva de los propios actores. Si bien el estudio de los políticos requiere atender a cinco tipos de cuestiones muy diferentes (Alcántara 2006: XI): 1) su posición en el entramado de la elite de poder; 2) su proceso de formación, socialización y desarrollo de su función de representación; 3) sus valores compartidos y diferenciados; 4) su evaluación desde posiciones ideológicas de diferentes políticas o temas; y 5) su posición con respecto a los partidos políticos de los que forman parte, este trabajo se centra en dos de ellos:

- sus características personales

- y la evaluación que ellos hacen de ejes de antagonismo político desde sus posiciones ideológicas.

Este apartado introductorio a la recopilación de los cuatro artículos que conforman la tesis doctoral pretende poner de relieve la coherencia de las publicaciones presentadas incluyendo cinco sub apartados. En primer lugar se exponen los antecedentes teóricos del objeto de estudio, se presenta la estructura de la tesis, los objetivos, preguntas de investigación e hipótesis del trabajo, así como la metodología, datos y técnicas de análisis utilizadas. Finalmente, se presentan los principales hallazgos en los cuatro trabajos publicados y las futuras líneas de investigación en el abordaje del peso de los políticos en la naturaleza y desempeño de las democracias latinoamericanas.

\section{ANTECEDENTES DEL OBJETO DE ESTUDIO}

La tradición en la Ciencia Política del estudio de las elites no es en absoluto reciente, como pone de manifiesto Alcántara en El oficio del político (2012), ya desde el pensamiento clásico hasta el Renacimiento existía una "preocupación intelectual de la reflexión politológica centrada en los hombres que detentaron el poder o en quienes 
estuvieron en su entorno para aconsejarles” (Alcántara, 2012: 31). Si bien, no siempre la figura del político ha ocupado un lugar prominente en la reflexión de la disciplina.

En la literatura académica sobre elites políticas se pueden encontrar posiciones como las de los llamados elitistas clásicos ${ }^{3}$, quienes estaban más preocupados por demostrar la existencia de una minoría que domina a la mayoría como un hecho privativo de cualquier sociedad -sin prestar mayor atención a los integrantes de esa minoría-. Sus planteamientos dieron pie a una serie de investigaciones que trataban de singularizar a la elite (Dahl, 1961, Mills, 1963, Putnam, 1976). En el trabajo de Mills (1963), por ejemplo, se pone énfasis en señalar que hay distintos tipos de elites de poder (políticas, económicas, militares), personas cuyas posiciones les permiten trascender del medio ordinario de la gente común estando en posición de tomar decisiones que comportan consecuencias importantes.

El texto de referencia para el estudio de la elite política en América Latina es el de Lipset y Solari (1967) donde se abordan los distintos aspectos de la composición y formación de las elites en general y donde se sostiene que para conseguir el desarrollo y modernización de la sociedad es necesario tener una elite competente. Pero casi 50 años después la región latinoamericana se encuentra en una situación muy diferente a la descrita por Lipset y Solari.

Hasta mediados de la década de 1990 el estado de la cuestión referente a América Latina no presentaba sino una llamativa carencia en la producción de materiales y conocimiento sobre la clase política que gobernaba las recientemente (re) instauradas democracias de la región. El impacto del trabajo de Putnam (1973) y su análisis de los factores que determinan las creencias de la clase política de Gran Bretaña e Italia, hace aún más llamativa la inexistencia de estudios homólogos para América Latina, sobresaliendo casi exclusivamente el trabajo de Highley y Gunther (1992). En la última década, pueden encontrarse trabajos que reivindican la importancia de los estudios comparativos de las elites parlamentarias a través de encuesta, como es el caso de Saiegh (2009). Para Europa

\footnotetext{
${ }^{3}$ Bajo el nombre genérico de elitistas clásicos se suele agrupar a Pareto y su teoría de la circulación de las elites; Mosca que se destaca por desarrollar el concepto de clase política y Michels con su Ley de Hierro de la Oligarquía. Además de las obras de los autores mencionados se pueden consultar los estudios sobre los mismos de Rodriguez Zúñiga (1976), Morán (1983) o Albertoni (1988). En ocasiones se incluye a Weber dentro de los elitistas clásicos ya que en sus planteamientos sobre partidos políticos es deudor de Michels.
} 
del Este, cabe destacar en esta línea de investigación el trabajo de Higley, Pakulsli y Wesolowski en 1998, sobre las elites políticas en sociedades postcomunistas y, más recientemente, las contribuciones de Crowther y Matonyte (2007) y Semenova, Edinger y Best (2013). En el caso de las democracias de Europa Occidental, pueden destacarse los trabajos de Best y Cotta (2000) y Cotta y Best (2007). Desde una óptica comparativa más amplia, interregional, pueden citarse otros trabajos como el de Czudnoswki (1983) que pone en relación las elites políticas con el cambio social para los casos de Canadá, Jamaica, Brasil, Kenia, Corea y Turquía, o el de Eldesrveld (1989) en torno a la relación entre la teoría democrática y la investigación empírica sobre las élites políticas en sociedades modernas. Para el caso específico de los Estados Unidos puede mencionarse el trabajo realizado por Etzioni-Halevy en 1993 The elite connection. Esta es una situación muy similar a la existente en la investigación sobre esta problemática en España, ya que no es sino hasta la segunda mitad de dicha década cuando aparecen los relevantes trabajos de Jerez (1997), Botella (1997), Gangas (2000), Delgado (2000), Uriarte (2000), que dan paso a las aportaciones más recientes de Coller y Santana (2009) y Coller, Santana y Jaime (2014).

Aún hoy, los trabajos sobre los rasgos actitudinales y demoscópicos de las elites parlamentarias, y sus procedimientos de medición, continúan en estado incipiente (Diamond, 1999:66) y contrasta enormemente con los avances adquiridos en el conocimiento de estos mismos aspectos en el ámbito de la opinión pública. Preguntas tan fundamentales y teóricamente relevantes para la comprensión del proceso político de cualquier sistema, como la de la correspondencia entre valores, expectativas y preferencias entre ciudadanos y representantes, son en el fondo preguntas de naturaleza empírica (García, Mateos y Rivas, 2014). En este sentido, la producción del Grupo de Investigación de Elites Parlamentarias Latinoamericanas de la Universidad de Salamanca es una de las contribuciones más notorias en este campo para América Latina (Alcántara, 2012; Alcántara y García Montero, 2011; Zechmeister y Corral, 2011; España-Nájera y Martínez Rosón, 2010; Otero y Rodríguez, 2009; Alcántara, 2008).

Las corrientes teóricas que amparan los estudios de las elites políticas podrían articularse en tres grandes grupos (Alcántara y Llamazares, 1997): 1) estructural, y relativo a la vinculación entre el origen socioeconómico de las elites y su acceso a los canales de influencia política; 2) interaccionistas, o estudios que relacionan las orientaciones y 
percepciones de las elites con los propios procesos de interacción que tienen lugar entre ellas y 3) las visiones motivacionistas, que parten de las vocaciones y actitudes que los representantes llevan consigo a la arena política y aquéllas que desarrollan en el curso de su actividad política, de ahí que para comprender la acción política resulte indispensable pasar por el modo en que las propias elites perciben su posición y los instrumentos de que disponen para la consecución de sus fines.

A estas corrientes se sumó la reaparición de la corriente teórica que recupera la preocupación por las instituciones - articulando los niveles micro y macro del análisis, es decir, las elites y los sistemas políticos en los cuales se insertan (Thelen y Steinmo, 1992; Rohrschneider, 1994, Colomer, 2001). La conexión de ambos planos se hace en una doble dirección: por un lado, considerando los impactos que los arreglos institucionales y la experiencia histórica particular que cada país tiene sobre las trayectorias políticas, posicionamientos ideológicos, valores y creencias de los representantes políticos y, por otro, el impacto que este perfil actitudinal, ideológico y de opinión ejerce sobre el proceso de elaboración de políticas públicas, la representación, la dinámica del sistema político y, en definitiva, la naturaleza y la calidad del régimen democrático imperante.

Pero donde más se ha aplicado el perfil político, social y económico de los políticos como variable independiente, ha sido en los estudios sobre carreras políticas (Llanos y Sánchez, 2006; Martínez, 2006). Hibbing (1999) señala que a través del estudio de las carreras políticas se busca determinar, entre otros elementos, qué representantes son mejores y cuáles peores, qué cualidades tienen, así como entender el sistema socio-político del que forma parte la Cámara. Señala también que hay una serie de estudios comparativos que buscan encontrar generalidades a partir de las que se podrían perfilar los políticos de calidad.

Esta sería la línea de investigación del proyecto Elites Parlamentarias Latinoamericanas (PELA), de la que se nutren de manera directa los artículos que forman la presenta tesis doctoral. El estudio de las elites parlamentarias en América Latina llevado a cabo por el grupo de investigación de la Universidad de Salamanca tiene la finalidad de cubrir un vacío empírico, señalado ya en páginas anteriores, en el ámbito de los análisis de elites políticas en América Latina mediante la generación de bases de datos comparables. Si bien la investigación se centra en el estudio de las elites 
parlamentarias latinoamericanas, la contextualización teórica del problema y la evidencia empírica recopilada hasta el momento se insertan dentro de la más amplia preocupación teórico-metodológica por el análisis de los “políticos” como actores fundamentales de cualquier sistema político democrático y su evolución a lo largo del tiempo (García, Mateos, Rivas, 2014). Los cambios acontecidos en la región latinoamericana en la última década han llevado a los investigadores de PELA a focalizar sus intereses en el estudio de la calidad y profesionalización de la política en América Latina, abordando el tema de las carreras políticas, el liderazgo y la calidad de las Cámaras legislativas para, en estos dos últimos años, prestar una mayor atención a la forma en cómo se estructura la representación política en los Parlamentos latinoamericanos. En concreto, analizar cómo se estructura la representación a través de dos componentes: el grado de conexión entre las actitudes y preferencias de los ciudadanos con las actitudes y preferencias de las elites parlamentarias y, en segundo lugar, a través de la actuación de los legisladores durante su labor parlamentaria como reflejo de dichas actitudes y preferencias.

El desarrollo del trabajo de PELA partió de una primera ola de recopilación de datos, dada la escasez de referentes teórico-metodológicos existente, que imponía la necesidad de estudios de caso donde se aplicaron cuestionarios, mediante entrevistas personalizadas, en combinación con una perspectiva comparativa de un número reducido de países, donde el objetivo era conocer las características de los parlamentarios y relaciones causales con un componente más nacional. Esto facilitó la identificación e incorporación de nuevas variables no previstas en el diseño inicial. La generación de ideas y el marco analítico fruto de esta primera fase es lo que permitió la realización de olas sucesivas de entrevistas (actualmente se está realizando una sexta ola de encuestas) a escala regional con un doble objetivo: por un lado que cada uno de los países latinoamericanos represente un estudio de caso y, por otro, que cada país sea una unidad de análisis más dentro del conjunto continental considerado, es decir, la investigación ha pasado a tener una visión tanto regional, como de área y multinivel.

La técnica de recogida de información utilizada en esta investigación ha sido el cuestionario, lo que ha permitido obtener información cuantiosa y sistemática, así como la comparación y descripción metódica de un gran número de casos. Se trata de un cuestionario extenso, con más de ochenta preguntas, en su mayoría cerradas, que facilitan la comparación y la capacidad de generalización para todos los países de América Latina. 
A lo largo de estos veinte años del proyecto, el cuestionario ha sufrido modificaciones, unos cambios que responden por un lado, a la necesidad de garantizar una mayor validez y fiabilidad del cuestionario y, por otro, a los cambios políticos y académicos de interés de los integrantes del proyecto. Si bien, un buen número de preguntas del cuestionario se mantienen constantes a lo largo de estos veinte años con el fin de poder tener una perspectiva temporal de las opiniones de los parlamentarios latinoamericanos sobre determinadas cuestiones políticas, sociales y económicas y conocer qué aspectos permanecen constantes o estables a lo largo del tiempo o cuáles sufren cambios tanto al interior de los países como entre ellos.

Los principales ejes de análisis del cuestionario son: democracia, elecciones y forma de gobierno, partidos políticos, instituciones y fuerzas armadas, papel del Estado y políticas públicas, clientelismo y corrupción, integración y política exterior, trayectoria política y actividad parlamentaria, valores y características socio demográficas.

Como se señaló al inicio de estas páginas, el objeto de estudio de este proyecto son las elites parlamentarias, los miembros de las Cámaras de Representantes ${ }^{4}$, y es a ellos a quienes se les aplica el cuestionario.

El universo de estudio son los/as diputados/as de cada uno de los países recién electos en el momento de realizar la encuesta. La selección de la muestra está basada en criterios proporcionales por partido político respecto a la totalidad de miembros que compone dicha cámara. La selección específica de los entrevistados es aleatoria y en aquellos casos en los que la muestra diseñada no es alcanzada, se aplica un coeficiente de ponderación que le devuelva el peso real que tiene en la cámara con el fin de poder extraer conclusiones sobre la totalidad de la cámara analizada basada en criterios de representatividad por partido político. En total, se han aplicado hasta el momento 7239 entrevistas a diputados latinoamericanos con la distribución por legislatura que aparece en el Cuadro I.

\footnotetext{
${ }^{4}$ En los casos de Poderes Legislativos bicamerales se analiza exclusivamente el Congreso de los Diputados por tener (salvo el caso de Colombia) una mayor representatividad en términos proporcionales y partidistas.
} 
Cuadro I: Número de entrevistas realizadas 1994-2015

\begin{tabular}{lc}
\hline & $\begin{array}{c}\mathbf{N}^{\mathbf{o}} \text { entrevistas } \\
\text { realizadas }\end{array}$ \\
\hline $1^{\text {a }}$ oleada (Legislaturas entre 1993-1997) & 933 \\
2 $^{\mathrm{a}}$ oleada (Legislaturas entre 1997-2002) & 1371 \\
3$^{\mathrm{a}}$ oleada (Legislaturas entre 2002-2006) & 1580 \\
$4^{\mathrm{a}}$ oleada (Legislaturas entre 2006-2010) & 1484 \\
$5^{\text {a }}$ oleada (Legislaturas entre 2010-2014) & 1243 \\
$6^{\text {a }}$ oleada (Legislaturas entre 2014-2018) & 628 \\
TOTAL & $\mathbf{7 2 3 9}$ \\
\hline
\end{tabular}

Nota: en la actualidad, se está realizando trabajo de campo en tres países de la región: Chile.

En ocasiones esa representatividad por partido político de la muestra se ve limitada por el transfuguismo de los propios diputados inmediatamente después de celebrarse las elecciones. Este hecho ha obligado a considerar criterios homogéneos para todos los países tomándose la decisión de que la composición de la Cámara que se considerará para elaborar el diseño muestral será la resultante el día de celebración de las elecciones. Si posteriormente alguno de los representantes cambia de partido y es entrevistado, a efectos de diseño muestral ese legislador es considerado perteneciente al partido por el que inicialmente fue elegido.

Uno de los ejes de análisis sobre cuyo planteamiento metodológico es necesario llamar la atención es el eje izquierda-derecha. Puesto que ha sido una de las vías de mayor difusión y utilización de las bases de datos, a nivel nacional y especialmente a nivel internacional, pero también de debate sobre la validez de este indicador. Desde los inicios de este proyecto aquellos valores y creencias que sirven como base de la ideología que defienden han ocupado parte del interés de sus investigadores. Los productos obtenidos hasta el momento demuestran que uno de los ejes principales en torno a los cuales se articula la competencia partidista es el eje izquierda-derecha y que, a su vez, coincide con los posicionamientos de las elites en otras materias como el aborto y el divorcio, las posturas clericales y anticlericales, o la intervención del Estado (Alcántara, 1991; Ruiz Rodríguez, 2001; Otero, 2004; Ajenjo, 2004; Alcántara, 2006). A estos productos obtenidos en torno a la relevancia del eje izquierda-derecha y su validez para explicar la articulación de la competencia partidista se le suman los dos últimos artículos de esta tesis doctoral. 
Mientras que los dos primeros artículos se encuadran dentro de esta línea de investigación de PELA que analiza el impacto que las características personales de los parlamentarios latinoamericanos, como variable independiente, ejerce en la calidad de la democracia y la dinámica del sistema político de sus respectivos países.

\section{ESTRUCTURA DE LA TESIS}

La tesis está estructurada en cuatro capítulos. En el primer capítulo se busca profundizar en los términos de la relación entre las elites parlamentarias y el sistema político, pero ensayando una lectura distinta y poco habitual, ya que se intenta explicar el vínculo entre los dos conceptos usando la visión de la democracia que, sin caer en el determinismo de lo social o lo económico, plantea que el grado de desigualdad social y económica de una sociedad, afecta a las características de la democracia debido a que éstas, merman las “capacidades” de las personas como ciudadanos.

Uno de los rasgos que más llama la atención de América Latina es la desigualdad social y económica de carácter cuasi estructural de la mayor parte de sus países (World Bank, 2008). Este fenómeno trasciende al funcionamiento del sistema político y repercute, entre otros aspectos, en la calidad de la democracia en la región (O’Donnell, 2004). En este primer capítulo se busca profundizar sobre los potenciales vínculos entre estructura social y política, centrándonos en la relación que puede haber entre los rasgos socio-económicos de la elite política, su proximidad o distancia respecto al resto de la sociedad y la relación de estos elementos con el funcionamiento del sistema político, sobre todo, con el rendimiento del régimen democrático.

En el segundo capítulo, y estrechamente relacionado con el primero, se aborda el tema de la calidad de los políticos dentro del marco de una preocupación general sobre el impacto que tiene en el sistema su desempeño como actores. Mencionar la "mala calidad" de los políticos es uno de los tópicos recurrentes para explicar el estado de las democracias latinoamericanas, visión negativa que aumenta cuando se habla de los representantes electos a las asambleas legislativas. Sin embargo, la superficialidad de tal afirmación queda en evidencia cuando se pide a sus defensores que definan cuáles son los atributos que debe tener un buen político. Los argumentos de los sectores de opinión que se quejan de la calidad de los políticos giran en torno al nivel educativo de los mismos, lo que llama 
aún más la atención si se toma en cuenta que los diputados latinoamericanos con estudios superiores exceden el 90\%. En este trabajo nos preguntamos si existe una relación entre el nivel educativo de los diputados latinoamericanos, en tanto integrantes fundamentales de la elite política, y las características de los sistemas democráticos de sus respectivos países. Al centrarnos en los rasgos de la democracia, se puede evaluar una serie de atributos comparables de los sistemas políticos, en los que necesariamente se refleja el impacto de los políticos en el funcionamiento del sistema. En términos generales, en este capítulo se sostiene que no hay una relación directa entre el grado de educación formal de los diputados y las características de la democracia de los distintos países latinoamericanos debido a que, en condiciones de falta de equidad social y económica, el nivel educativo de las personas es un indicador distorsionado y más bien puede revelar un mayor grado de elitismo de la clase política.

El tercer y cuarto capítulo centra su objeto de estudio en la ideología a fin de determinar el grado en el que la dimensión izquierda-derecha permite capturar características de la vida política y partidaria de cada país latinoamericano. A partir de la ubicación ideológica de los miembros de los partidos políticos es posible conocer qué partidos están más cercanos y cuáles más distantes y hasta qué punto la proximidad entre partidos implica similaridad (Sani y Sartori, 1983). La democratización y consolidación democrática de los países latinoamericanos supuso la vuelta de los partidos a la arena política y con ello un incremento de los estudios de los sistemas de partidos en la región. Frecuentemente, se ha prestado especial atención a tres características fundamentales del sistema de partidos: la fragmentación, la volatilidad política y el número de partidos. Sin embargo, y tal y como señala Coppedge (1997), se ignoran otros aspectos importantes de los sistemas partidistas que constituyen la base de la competición política (la ideología, los intereses políticos, ideales, valores, así como los clivajes o líneas de división). En estos dos últimos capítulos se centra el objeto de estudio en ese tipo de aspectos frecuentemente ignorados por la literatura sobre sistemas de partidos, el posicionamiento ideológico de los partidos políticos y su papel clave como espacio de competencia política en América Latina.

Se utiliza el concepto de clivaje para hacer referencia a las dimensiones de polarización programática que acercan o separan a los partidos políticos latinoamericanos etiquetados como partidos derechistas o izquierdistas, entendiendo la polarización como la distancia 
entre la izquierda y la derecha con relación a preferencias ideológicas respecto a temas concretos de interés político.

En el cuarto capítulo, además, se incluye una discusión teórica sobre la validez de los conceptos izquierda y derecha en América Latina así como los retos de su medición y cómo los espacios de competencia ideológica en los partidos políticos latinoamericanos se mantienen constantes en el período de tiempo analizado.

\section{OBJETIVOS, PREGUNTAS E HIPÓTESIS DEL TRABAJO}

En esta investigación se explora la relación de diversas características de la elite parlamentaria latinoamericana que podrían explicar el desempeño de las democracias en la región (1997-2009). Con este propósito, y desde una novedosa aproximación metodológica, el trabajo parte de un interrogante general sobre los actores clave de la representación en democracia, al que esta tesis trata de dar respuesta utilizando el análisis estadístico multivariante:

OG: ¿Cuál es la incidencia del perfil personal, socioeconómico e ideológico de las elites parlamentarias latinoamericanas en el funcionamiento de la democracia?

Este objetivo general (OG) se desagrega en tres objetivos de investigación específicos $(\mathrm{OE})$ y preguntas $(\mathrm{Q})$ a las que pretende dar respuesta este trabajo:

OE1: Conocer la incidencia de las características personales de los legisladores en el funcionamiento del sistema político.

Q11: ¿Cuáles son las características (no valores y percepciones) de los diputados latinoamericanos que repercuten en el rendimiento de la democracia?

Q12: ¿Qué relación existe entre el nivel educativo de los diputados y el rendimiento del sistema político de un país?

Q13: ¿Anulan los factores estructurales como la pobreza y la desigualdad social de un país los potenciales atributos positivos (nivel educativo) de las elites políticas? 
OE2: Conocer la incidencia del perfil socioeconómico de la elite parlamentaria en el rendimiento del régimen democrático.

Q21: ¿Cómo influye el “nivel de elitismo” de los diputados de un país (desigualdad social) en el funcionamiento de la democracia?

Q22: ¿La distancia económica entre elites parlamentarias y población (desigualdad económica) influye en el acceso a mecanismos formales e informales de poder?

OE3: Conocer la incidencia de la polarización ideológica de la elite parlamentaria en los sistemas de partidos latinoamericanos

Q31: ¿La dimensión izquierda-derecha captura características de la vida política y partidaria de los países latinoamericanos?

Q32: ¿Cuáles son las líneas de división que más polarizan a los partidos de izquierda y derecha en la región?

Q33: ¿Qué familias ideológicas se forman a partir de las dimensiones de polarización programática?

La investigación presentada en esta tesis sustenta las siguientes hipótesis $(\mathrm{H})$ de partida en cada uno de los objetivos específicos de investigación (OE) anteriormente descritos:

OE1: Conocer la incidencia de las características personales de los legisladores en el funcionamiento del sistema político.

$\checkmark$ H1.1 Las características económicas (nivel de ingresos) de los diputados latinoamericanos tienen una repercusión mayor en el funcionamiento del régimen democrático que las características de tipo social y cultural (nivel de estudios y movilidad social).

$\checkmark$ H1.2 En América Latina no se confirma el peso del grado de instrucción educativa como variable que incide positivamente en el desempeño del ejercicio de representación destacado por la literatura (Best y Cotta, 2000; Martínez, 2006). La educación -como atributo en potencia de un político de calidad- es una variable necesaria pero no suficiente para que redunde en el funcionamiento del sistema democrático. 
$\checkmark$ H1.3 En América Latina, a mayor desigualdad social y económica, el elevado nivel de estudios tiende a evidenciar situaciones de privilegio individual (alto nivel de ingresos, poca movilidad social o educativa) por lo que tal atributo potencial no repercute positivamente en el funcionamiento del sistema político.

OE2: Conocer la incidencia del perfil socioeconómico de la elite parlamentaria en el rendimiento del régimen democrático.

$\checkmark$ H2.1 En los casos en los que hay mayor desigualdad económica y los políticos son más “elite” (sus ingresos están más distantes de los que tiene la mayoría de la población) los indicadores que miden diferentes rasgos de la democracia serán peores debido a que su clase política es menos “representativa”.

$\checkmark \quad$ H2.2 En aquellos países de la región en los que la distancia económica entre elite y población es mayor, el acceso a los mecanismos formales e informales del poder son más restrictivos y, por tanto, repercute de manera negativa en el desempeño democrático nacional.

OE3: Conocer la incidencia de la polarización ideológica de la elite parlamentaria en los sistemas de partidos latinoamericanos

$\checkmark$ H3.1 La recuperación del juego democrático en la mayor parte de países de la región y su continuidad en el tiempo ha consolidado antiguos esquemas de confrontación ideológica. La escala izquierda-derecha define hoy en día la polarización en la vida política de los países latinoamericanos.

$\checkmark \quad$ H3.2 Los tradicionales ejes de antagonismo político asociados a la polarización ideológica de los diputados se mantienen en el tiempo en América Latina. Los clivajes de “democracia”, “valores” y “fuerzas armadas” siguen ejerciendo su papel polarizador entre los partidos políticos. 
$\checkmark \quad$ H3.3 La polarización ideológica de la elite parlamentaria hace posible seguir hablando de partidos políticos de izquierda y de derecha y es un claro eje articulador del espacio de competencia partidista de la vida política de la región. A partir de las percepciones de los legisladores latinoamericanos en torno a los distintos ejes programáticos, se encuentran familias ideológicas de derecha como la UDI en Chile, ARENA en El Salvador, el PNH en Honduras y el PRSC en Dominicana y familias ideológicas de izquierda. Dentro de esta última, una izquierda moderada formada por el FA en Uruguay y el PS en Chile y una izquierda revolucionaria formada por el FSLN en Nicaragua, el FMLN en El Salvador y MUPP en Ecuador.

\section{METODOLOGÍA DE INVESTIGACIÓN}

\section{a) Datos utilizados}

Los trabajos recopilados en esta tesis doctoral tienen un claro carácter empírico. En la mayoría de ellos se utilizan las encuestas realizadas a diputados latinoamericanos de 18 países desde 1994 hasta 2009, del proyecto de elites parlamentarias latinoamericanas (PELA) de la Universidad de Salamanca (Manuel Alcántara, dir.). Se asume que los diputados son parte representativa de las elites políticas de cada uno de sus Estados y su estudio se justifica tanto en la posición que ocupan en las instituciones como en el enfoque de toma de decisiones. Son por tanto, en palabras de Mosca (1984), parte de esa minoría que determina la dirección de la cosa pública.

Además de las encuestas de opinión a diputados de la región se han utilizado los siguientes datos agregados de diversas fuentes: 1) datos socio económicos recopilados por instituciones internacionales públicas como el World Bank ${ }^{5}$, UNESCO ${ }^{6}$ y PNUD $^{7}$ y; 2) datos que valoran o miden calidad de la democracia de organizaciones como Freedom House ${ }^{8}$, la Fundación Konrad Adenauer, la consultora Polilat ${ }^{9}$, datos de

\footnotetext{
${ }^{5}$ http://www.worldbank.org/

6 http://www.unesco.org/new/es/education/

7 http://hdr.undp.org/

8 http://www.freedomhouse.org/template.cfm?page=15.

9 Índice de Desarrollo Democrático en América Latina (IDD-Polilat). http://www.iddlat.org/Web\%20IDD-Lat2006/Edicion\%202006.htm
} 
participación democrática de $\operatorname{Vanhanen~}^{10}$, la Fundación Bertelsmann ${ }^{11}$ y los indicadores de “buen gobierno” de Kaufmann y Kray.

1) Datos socioeconómicos: Estos indicadores se utilizan en los dos primeros capítulos con el fin de medir las relaciones entre los rasgos socioeconómicos que definen a las elites parlamentarias y los niveles de desigualdad en los países de la región: el PIB per cápita de cada país, el nivel de desigualdad en los ingresos (concentración de la riqueza en el 10\% y 20\% de la población) y el índice Gini de desigualdad social.

Los datos del PIB per cápita de cada país se han utilizado para contextualizar el dato sobre ingreso de los diputados recogido en los cuestionarios del Proyecto PELA, ya que no es igual ganar 10.000 USD en un país que tenga el PIB per cápita de 3.000 USD que en uno con 9.000 USD. En cuanto a educación se han utilizado los datos de la UNESCO sobre el porcentaje de población que accede a la educación terciaria. Este indicador refleja la disparidad educativa de los países y permite mantener cierta homogeneidad en la estructura de los datos comparados aunque, lamentablemente, no se dispone de dicha información para todos los países.

2) Indicadores de democracia y buen gobierno: Pese a que la democracia es la forma de gobierno extendida en la práctica totalidad de América Latina se pueden encontrar diferencias importantes entre países cuando se aplican indicadores que tratan de medir y analizar lo que se ha dado en llamar “calidad de la democracia”. En esta tesis doctoral se han utilizado siete indicadores distintos, tanto en metodología como en unidad de análisis, que tratan de medir distintos aspectos de la misma. A pesar del debate existente en torno a la utilización de varios índices para medir y caracterizar la democracia, los siete indicadores empleados en este trabajo ofrecen resultados similares, lo que aumenta la fiabilidad de nuestros resultados y refuerza su inclusión en este análisis (Norris, 2006).

Se han utilizado cuatro indicadores que valoran elementos constitutivos de la democracia: el índice de Freedom House (valor medio de los índices de derechos

\footnotetext{
${ }^{10}$ Pippa Norris http://ksghome.harvard.edu

11 Índice de Transformación de Bertelsmann (BTI) http://www.bertelsmann-transformation-index.de
} 
políticos y de libertades civiles), el Î́ndice de Desarrollo Democrático de Polilat, el Índice de participación democrática de Vanhanen medido a partir del grado de competición y participación electoral y, por último, el Índice de Transformación de Bertelsmann teniendo en cuenta únicamente la dimensión política del mismo. A los cuatro anteriores hay que sumar otros tres que buscan valorar aspectos más específicos. Todos ellos forman parte de los indicadores de "buen gobierno" de Kaufmann y Kray y son: estabilidad política, participación ciudadana en la selección de gobiernos y efectividad del gobierno.

\section{b) Técnicas de análisis utilizado}

Como se señala al inicio de este apartado uno de los elementos en común que tienen todos los artículos que forman esta tesis doctoral es la técnica de análisis multivariante aplicada, el HJ-Biplot (Galindo, 1985, 1986), poco utilizada en el ámbito de las Ciencias Sociales, en general, y de la Ciencia Política en particular.

La herramienta de análisis HJ-Biplot ${ }^{12}$ (Galindo, 1985, 1986), extensión de los biplot clásicos de Gabriel (1971) ${ }^{13}$ es una representación gráfica multivariante de marcadores fila (individuos) y columna (variables), elegidos de tal forma que puedan superponerse en el mismo sistema de referencia con máxima calidad de representación.

Una de las ventajas de los métodos Biplot es que están libres de hipótesis y tienen como objetivo capturar las estructuras de covariación entre las variables que intervienen en el estudio y aprovechar esa covariación para poder sustituir las variables observables de partida (generalmente muchas) por variables latentes (generalmente dos o tres) que capturan la mayor parte de la información contenida en los datos. Los métodos Biplot presentan sus resultados sobre planos factoriales donde los ejes son las variables latentes. En los planos factoriales se representan las variables observables y las unidades taxonómicas (individuos).

\footnotetext{
12 Para el análisis HJ-Biplot se ha utilizado el programa estadístico realizado por José Luis Vicente Villardón (2010), Departamento de Estadística de la Universidad de Salamanca.

${ }^{13}$ Los métodos Biplot son técnicas factoriales que permiten reducir la dimensionalidad del problema y facilitar su interpretación. Son una representación gráfica de datos multivariantes. Del mismo modo que un diagrama de dispersión permite representar de manera conjunta dos variables, un Biplot representa de forma simultánea tres o más variables (Gabriel y Odoroff, 1990).
} 
Otra de las ventajas de esta técnica radica en que permite obtener una representación gráfica simultánea sobre la relación entre un conjunto de variables y la posición de grupos de observaciones con perfiles similares en un plano de dimensión reducida, generalmente de dos dimensiones, que serán las de mayor poder explicativo y una calidad de representación óptima. Si el porcentaje de variación explicada es alto, la representación de los datos en el plano se aproximará a los valores originales de la matriz X analizada con un alto grado de fiabilidad ${ }^{14}$. El que la tasa de absorción de inercia sea alta es condición necesaria para la fiabilidad de la interpretación de los casos en el gráfico pero no es condición suficiente, ya que el hecho de que la mayoría de los casos estén bien representados en el subespacio no implica que todos lo estén. Por tanto, es necesario valorar la calidad de representación que se consigue para las filas y las columnas de la matriz de datos (Galindo et al., 1999).

La interpretación de los biplot es sencilla, siguiendo a Galindo (1986), en la representación HJ-Biplot hay que tener en cuenta que:

-Cada individuo (país o partido, en esta tesis) vendrá representado como un punto en un plano factorial mientras que las variables se representan en el plano mediante vectores.

-En una representación $H J$-Biplot, las variables que han presentado mayor variabilidad vendrán representadas por vectores más largos.

-El coseno del ángulo entre dos vectores representa la correlación entre las variables. Esto significa que en un HJ-Biplot, si dos variables están muy relacionadas tendrán un ángulo muy pequeño (próximo a $0^{\circ}$ ). Si el ángulo que forman dos vectores es obtuso las variables presentarán correlaciones negativas mientras que un ángulo recto entre dos vectores indica independencia entre las variables.

-El ángulo que forma cada una de las variables observables (vectores) con la variable latente (ejes factoriales) se entiende en términos de relación e indica la contribución de cada uno de los ejes factoriales de la representación a la variabilidad de las variables. Esta medida se denomina Contribución Relativa del Factor al Elemento (CRFE). Y se interpreta de la misma manera que un coeficiente de determinación en regresión.

\footnotetext{
${ }^{14}$ La variabilidad explicada por los ejes factoriales viene determinada por la tasa de absorción de inercia, que varía entre 0 y 100, de modo que cuanto más se aproximen los valores de los ejes factoriales a 100 más fiable será la representación.
} 
-La proximidad entre los puntos que representan a los individuos (países o partidos en este caso) se interpreta como similitud entre los mismos. Esto significa que si dos individuos aparecen próximos en el gráfico factorial compartirán un perfil similar respecto a las variables utilizadas en el análisis, especialmente si los casos están bien representados. Ese perfil es generado a partir de la posición media de cada uno de los casos en el conjunto de variables incluidas en el análisis.

-La relación entre individuos y variables se realiza en términos de producto escalar es decir, a partir de la proyección perpendicular de los puntos sobre los vectores que representan a las variables. A partir de esta proyección es posible determinar la distribución aproximada que las observaciones toman sobre las variables (Gabriel y Odoroff, 1990).

Como análisis complementarios en esta tesis doctoral se han aplicado un análisis factorial cuyas puntuaciones factoriales medias se han utilizado como variables del análisis $H J$ Biplot, este es el caso del tercer y cuarto capítulo de la tesis y un análisis cluster (con el fin de clasificar los países según su posición en el gráfico biplot) tomando como matriz de partida las coordenadas de los individuos en los factores retenidos en el HJ-Biplot. La ventaja del análisis cluster es que permite establecer grupos homogéneos de forma que los individuos pertenecientes a un mismo grupo son similares, es decir, los valores que toman en cada una de las variables utilizadas en el análisis son análogos. El criterio de agrupación utilizado es el de Ward o método de pérdida de la inercia mínima que une los casos buscando minimizar la varianza dentro de cada grupo (Vicente, Ramírez y Galindo, 1994, 830). Este análisis se ha realizado en el primer y segundo capítulo de la presente tesis. 


\section{CONCLUSIONES}

Los políticos importan. Así lo evidencian los trabajos que dan forma a esta tesis doctoral, demostrando que existe un nexo causal entre los valores y características de la elite parlamentaria y el funcionamiento del sistema político en las democracias latinoamericanas. Bajo esta premisa, se abordaron las dos líneas de investigación que guían los artículos recopilados en esta tesis: la relación entre el perfil de la elite parlamentaria y la democracia (primer y segundo capítulo) y la vigencia del eje izquierda-derecha como elemento explicativo de las diferentes dimensiones de conflicto y polarización en los sistemas de partidos de la región (tercer y cuarto capítulo).

\section{La relación entre perfil de la elite parlamentaria y democracia}

Siguiendo la línea de investigación que aborda el estudio de las características sociales, económicas y culturales de las elites y su correlación con el rendimiento del sistema político, esta tesis doctoral explora cómo algunos de los atributos personales de los parlamentarios latinoamericanos (nivel educativo, nivel de ingresos y movilidad social), tradicionalmente utilizados como indicador de calidad de los políticos, tienen relación directa con el desempeño de las democracias en América Latina. En esta tesis se sostiene que el nivel educativo de los diputados latinoamericanos no es relevante para el buen funcionamiento de la democracia en los países de la región. De hecho, un buen número de países con elites legislativas con elevada formación académica son democracias con un desempeño relativamente deficitario en cuanto a indicadores de calidad.

Mientras que el nivel educativo de los parlamentarios parece no repercutir en una mejor calidad del sistema político del país, este trabajo revela sin embargo que la variable ingresos del diputado sí guarda relación con la situación de la democracia. En aquellos países en los que la clase política posee ingresos más altos, los indicadores de calidad de la democracia son malos y viceversa. No obstante, esta tesis muestra que existen diferencias significativas entre los niveles de ingresos de los diputados latinoamericanos, lo que pondría en cuestionamiento la idea de que la política está destinada a los sectores más ricos de la sociedad. Esto no significa que los ingresos de los diputados que menos ganan sean bajos, sino que la presencia de "oligarquías" en la política varía sustancialmente entre países, algo que influye en el funcionamiento 
de la democracia, especialmente en contextos de desigualdades estructurales como los observados en la región.

Otro aspecto que se confirma en los artículos compilados es la estrecha relación entre las condiciones socioeconómicas, el nivel de pobreza y la situación democrática nacional. A mayor pobreza y menor nivel de desarrollo humano, peor valorada es la democracia. En este sentido, cabe destacar que no siempre la situación de la elite se corresponde con la situación socioeconómica del país, encontrándose que en aquellos países donde la elite política es más “elite” -donde la distancia entre la población y los legisladores es más grande en términos educativos y de renta económica- las democracias presentan indicadores de valoración peores.

Por último, otra de las conclusiones extraídas de esta tesis doctoral es que la trayectoria de las instituciones políticas de los países parece ser determinante a la hora de comprender las características de la elite política. Se observan variadas configuraciones de elites parlamentarias entre los parlamentarios de países con una larga trayectoria democrática del país y aquellos que han tenido experiencias democráticas más erráticas.

\section{La vigencia del continuo izquierda-derecha}

Los trabajos aquí compilados demuestran la validez del continuo izquierda-derecha en los sistemas políticos de América Latina. Las diferentes ubicaciones de los legisladores dan sentido a sus formaciones políticas que con marcadas diferencias ideológicas estructuran los clivajes. Tales clivajes son dimensiones de polarización programática que dan cuenta de la variabilidad del escenario en el que compiten la izquierda y la derecha latinoamericana con las que son plenamente congruentes: el intervencionismo estatal, la democracia, las fuerzas armadas, religión y valores, la imagen de Estados Unidos y, en menor medida, las raíces sociales.

Pero además, el posicionamiento ideológico de los parlamentarios permite encontrar diferencias no solo en los componentes que definen propiamente a la izquierda y a la derecha, sino también en la mayor homogeneidad encontrada en la derecha latinoamericana de acuerdo con las dimensiones de polarización programática analizadas. Esta tesis revela la mayor dispersión de la izquierda con respecto al clivaje 
fuerzas armadas y democracia, lo que introduce marcadas diferencias y vislumbra la existencia de una izquierda moderada y una izquierda de carácter más revolucionario en la región.

El análisis global de las posiciones de los actores políticos respecto a las dimensiones programáticas incluidas en el estudio muestra una superposición de clivajes. En este sentido, las posturas adoptadas por el diputado de un partido político en la dimensión fuerzas armadas deja entrever las posturas que ese mismo diputado adoptará en la dimensión democracia y viceversa. Algo similar ocurre entre la dimensión democracia y raíces sociales.

El período de tiempo analizado en los dos últimos capítulos de esta tesis doctoral (1997-2005) permite vislumbrar -aunque no de manera concluyente dada la limitación del periodo considerado- la continuidad de las dimensiones de polarización programática, además revelar que la dimensión estado/mercado (intervencionismo estatal) ha ido perdiendo peso en el espacio de competencia partidista de los Parlamentos latinoamericanos. Por el contrario, la imagen sobre Estados Unidos aparecer como un nuevo tema de conflicto.

Otra de las conclusiones de esta tesis doctoral es que con el paso del tiempo (desde 1997 a 2005) los partidos políticos latinoamericanos son menos radicales en términos programáticos, adoptando posturas más centristas en todos los temas analizados.

A pesar de que las dimensiones ideológicas permiten seguir hablando de partidos de izquierda y de derecha en los países de América Latina analizados, es necesario tener en cuenta las especificidades propias derivadas de características sui géneris de los sistemas políticos nacionales de los que forman parte. Sin embargo, el estudio de la polarización política en América Latina a partir de la ubicación ideológica de los partidos más extremos de izquierda y de derecha, abre futuras líneas de investigación y lleva a la reflexión sobre las características del espacio de competición con la incorporación del centro ideológico, aspecto no abordado en esta tesis. Es posible que algunos de los partidos de izquierda y de derecha que en este trabajo adoptan posiciones menos extremas encuentren un nicho ideal junto a estas formaciones políticas de centro. 
En términos metodológicos, la investigación contribuye a ponderar el peso de los políticos como variable explicativa de los sistemas políticos y los regímenes democráticos, a través de la técnica de análisis multivariante poco utilizada en la disciplina. Con ello, esta tesis enriquece el marco de técnicas estadísticas y el enfoque cuantitativo más allá de los análisis de regresión, en el estudio de los interrogantes a los que pretende dar respuesta la Ciencia Política contemporánea.

\section{BIBLIOGRAFÍA}

Ajenjo Fresno, Natalia (2004), “Ideological divisions in Central America. A multidimensional methodology”, ponencia presentada en el $X$ Encuentro de Latinoamericanistas Españoles, celebrado en Salamanca (España).

Albertoni, Ettore (1988), “Teoría de las élites y elitismo (apuntes para un análisis histórico y actual)” Sistema: Revista de Ciencias Sociales, núm 83, pp. 43-56.

Alcántara, Manuel (1991), “La relación izquierda-derecha en la política latinoamericana”, Leviatán, núm. 43-44, pp. 73-92.

Alcántara, Manuel e Iván Llamazares (1997), “El análisis de los diputados latinoamericanos en el contexto de los estudios sobre la clase política. Características, objetivos y estrategias de investigación”, América Latina Hoy, n 16, agosto, págs.15-28.

Alcántara, Manuel (ed.) (2006), Políticos y Política en América Latina, Madrid: Siglo XXI.

Alcántara, Manuel (ed.) (2008), Politicians and Politics in Latin America. Boulder: Lynne Rienner.

Alcántara, Manuel y Mercedes García Montero (eds.) (2011), Algo más que presidentes: el papel del poder legislativo en América Latina. Zaragoza: Fundación Manuel Giménez Abad de Estudios Parlamentarios y del Estado Autonómico.

Alcántara, Manuel (2011), El oficio del político. Madrid: Tecnos.

Best, Heinrich y Maurizio Cotta (eds.) (2000), Parliamentary representatives in Europe 1848-2000, Oxford: Oxford University Press. 
Botella, Joan (1997), “Parlamento y carreras políticas”, en M. Ramírez (ed): El Parlamento a debate. Madrid: Trotta.

Coller, Xavier y Andrés Santana (2009), “La homogeneidad social de la elite parlamentaria. Los parlamentarios de los PANE (1980-2005)”, Papers, Revista de Sociología, 92:29-50.

Coller, Xavier, Andrés Santana y Antonio Jaime (2014), “Problemas y soluciones para la construcción de bases de datos de políticos”, Revista Española de Ciencia Política, 34, marzo:169-198.

Colomer, Josep M. (2001), Instituciones políticas. Barcelona: Ariel.

Coppedge, Michel J. (1997), “A Classification of Latin American Political Parties”, Working Paper, núm. 24. Notre Dame: Kellogg Institute.

Cotta Maurizio y Best Heinrich (eds.) (2007), Democratic representation in Europe. Diversity, change and convergence. Oxford: Oxford University Press.

Crowther, William E. e Irmina Matonyte (2007), "Parliamentary Elites as a Democratic Thermometer: Estonia, Lithuania y Moldova compared”, Comunist and Postcomunist Studies 40: 281-299.

Czudnoswski, Mosheon (ed.) (1983), Political Elites and Social Change. Studies of Elite Roles and Attitudes. DeKalb, Ill.: Northern Illinois University Press.

Dahl R. (1961), Who Governs? Democracy and Power in an American City. New Haven: Yale University Press.

Delgado, Irene (2000), “Elites políticas y vida parlamentaria: actividades y motivaciones de los diputados españoles”, en A. Martínez (ed): El Congreso de los diputados en España: funciones y rendimientos. Madrid: Tecnos, págs. 295-342.

Diamond, Larry (1999), Developing Democracy toward consolidation. Baltimore y Londres: The Johns Hopkins University Press.

Diamond, Larry y Leonardo Morlino (2004), “The Quality of Democracy: an overview”, Journal of Democracy, vol.15, nº 4 , pp.20-31.

Diamond, Larry y Leonardo Morlino (comp.) (2005), Assessingthe Quality of Democracy. Baltimore: Johns Hopkins University Press. 
Eldersveld, Samuel (1989), Political Elites in modern societies. Ann Arbor: The University of Michigan Press.

España-Nájera, Anabella y Martínez Rosón, Mar (2010), “What People Need and What Politicians Care About: Political Representation in Central America”. APSA 2010 Annual Meeting Paper.

Etzioni-Halevy, Eva (1993), The Elite connection, Problems and Potential of Western Democracy. Cambridge: Polity Press.

Gabriel, Karl Ruben (1971), “The Biplot graphic display of matrices with application to principal component analysis”, Biometrika, vol. 58, núm. 3, pp. 453-467.

Gabriel, Karl Ruben y Charles L. Odoroff (1990), “Biplot in biomedical research”, Statistics in Medicine, núm. 9, pp. 469-485.

Galindo, María Purificación (1985), Contribuciones a la Representación Simultánea de Datos Multidimensionales, tesis Doctoral, Universidad de Salamanca.

Galindo, María Purificación (1986), “Una alternativa de representación simultánea: HJBiplot”, Questíio, vol. 10, núm. 1, pp. 13-23.

Gangas, Pilar (2000), “Los diputados españoles (1977-1996)”, en A. Martínez (ed): El Congreso de los diputados en España: funciones y rendimientos. Madrid: Tecnos, pp. 271294.

García Díez, Fátima (2005), Procesos contemporáneos de reforma electoral en América Central y Caribe. Salamanca: AECI- Fundación General de la Universidad de Salamanca. García, Fátima, Mateos, Araceli y Rivas, Cristina (2014), "Veinte años de Elites en América Latina (1994-2014)”, Revista de las Cortes Generales, $n^{\circ} 89$ (segundo cuatrimestre de 2013).

Highley J. y Günther, R. (eds.) (1992), Elites and democratic consolidation in Latin America and Southern Europe, Cambridge: Cambridge University Press.

Higley, John, Pakulski, Jan y Wesolowski, Wlodzimierz (eds.) (1998), Postcommunist elites and democracy in Eastern Europe. Houndmills, England: Macmillan.

Linz, Juan J. y Arturo Valenzuela (1994), The failure of Presidential Democracy. 2 vol. Baltimore: The Johns Hopkins University Press. 
Lipset, Seymour y Solari, Aldo (eds.) (1967), Elites in Latin America. New York: Oxford University Press.

Llanos Mariana y Francisco Sánchez (2006), “Council of Elders The Senates and its members in the Southern Cone”, Latin American Research Review. Vol. 41 №1.

Jerez, Miguel (1997), “La élite parlamentaria”, en M. Ramírez (ed): El Parlamento a debate. Madrid: Trotta.

Jones, Mark P. (2005), “The role of parties and party systems in the policymaking process”, paper preparado para el Workshop on State Reform, Public Policies, and Policymaking Process, Inter-American Development Bank, Washington, D.C., February 28-March 2, pp. 1-74.

Mainwaring, Scott y Pérez Liñán, Aníbal (2005), “Latin American Democratization since 1978: Democratic Transitions, Breakdowns, and Erosions”, en Frances Hagopian y Scott Mainwaring (ed.) The Third Wave of Democratization in Latin America. Advances and Setbacks. Cambridge: Cambridge University Press, pp. 14-61.

Martínez Rosón, Mar (2006), “La carrera parlamentaria: ¿la calidad importa?”, en Manuel Alcántara (ed.), Políticos y política en América Latina, Madrid: Siglo XXI.

Mills, Ch. W. (1963). La elite del poder. México. FCE.Molina, 2000

Morán, M. Luz (1983), Origen histórico y gnoseológico de la teoría de las elites, Madrid: Universidad Complutense.

Mosca, G. (1984), La clase política. México D.F: FCE.

Norris, Pippa (2006), "The role of the free press in promoting democratization, good governance, and human development”, ponencia presentada en el encuentro Annual de la Midwest Political Science Association, Chicago, 20-22 de abril.

O’Donnell, Guillermo (2004), “Notas sobre la democracia en América Latina”, en PNUD, La democracia en América Latina: El debate conceptual sobre democracia, Buenos Aires: PNUD.

Olson, David M. (1994), Democratic Legislative Institutions. A comparative view. Armonk, New York: M.E. Sharpe. 
Otero, Patricia (2004), "Partidos y sistemas de partidos en Panamá: un estudio de la estructuración ideológica”. Ponencia presentada en el $X$ Encuentro de Latinoamericanistas Españoles, Salamanca.

Otero Felipe, Patricia y Rodríguez Zepeda, Juan A. (2009). "Partidos y votantes en América Latina: Un estudio de los vínculos ideológicos“, Seminario de Investigación, Instituto de Iberoamérica, Universidad de Salamanca.

Payne J. Mark, Zovatto, Daniel, Carrillo, Fernando y Allamand, Andrés (eds.) 2002, Democracies in Development: Politics and Reform in Latin America, Washington, D.C.: Inter-American Development Bank.

PELA Proyecto Elites Parlamentarias en América Latina (1995-2009), Salamanca: Universidad de Salamanca.

Putnam, Robert (1973), The beliefs of Politicians. Ideology, Conflict and Democracy in Britain and Italy. New Haven: Yale University Press.

Putnam, Robert (1976), The Comparative Study of Political Élites, New Jersey: PrenticeHall.

Rodríguez Zúñiga, L. (1976), Elites y democracia. Valencia: Fernando Torres Editor. Rohrschneider, Robert (1994), "Report from the laboratory: The influence of institutions on political elites' democratic values in Germany". American Political Science Review. Vol. 88 nº 4. Págs. 927-941.

Ruiz Rodríguez, Leticia (2001), "Polarización en el sistema de partidos post-autoritario chileno: cambios y continuidades, 1990-1999”. Santiago de Chile: FLACSO Chile.

Saiegh, Sebastián M. (2008), "Recovering a Basic space from elite surveys: Evidence from Latin America”, en Social Science Research Network. University of California San Diego. Sani, Giacomo y Sartori, Giovanni (1983), ”Polarization, Fragmentation and Competition in Western Democracies”, en Daadler, Hans y Mair, Meter (Eds.), Western European Party Systems: Continuity and Change, London, Sage.

Semenova, Elena, Michael Edinger y Heinrich Best (eds.) (2013), Parliamentary Elites in Central and Eastern Europe. Recruitment and Representation. New York: Routledge. 
Thelen, Kathleen y Sven Steinmo (1992), "Institutionalism in comparative politics", en Sven Steinmo, Kathleen Thelen y Frank Longstreth (eds). Structuring politics: Historical institutionalism in comparative analysis. Nueva York: Cambridge University Press.

Uriarte, Edurne (2000), “La política como profesión y vocación: análisis de las motivaciones y de la carrera política de los diputados españoles”, Revista Española de Ciencia Política, nº3, octubre, pp. 97-124.

Vicente, Santiago, Ramírez, Guillermo y Galindo, María Purificación (1994), “El HJBiplot como base para la búsqueda de clusters en función de la distribución de parados según profesiones en la comunidad de Castilla y León”, comunicación presentada en el IV Congreso de Economía Regional de Castilla y León, Burgos.

Vicente Villardón, J.L. (2010), Multbiplot: A package for Multivariate Analysis using Biplots, Departamento de Estadística. Universidad de Salamanca. (http://biplot.usal.es/ClassicalBiplot/index.html).

World Bank (2008), World Development Indicators 2008, Washington, D.C., The World Bank.

Zechmeister, Elizabeth y Corral, Margarita (2011), "Evaluando la representación por mandato en América Latina a través de las posiciones en la escala izquierda-derecha y de las preferencias económicas”, en Alcántara, Manuel y Mercedes García Montero (ed.). Algo más que Presidentes. El papel del poder legislativo en América Latina. Zaragoza: Fundación Manuel Giménez Abad, pp. 132-154. 


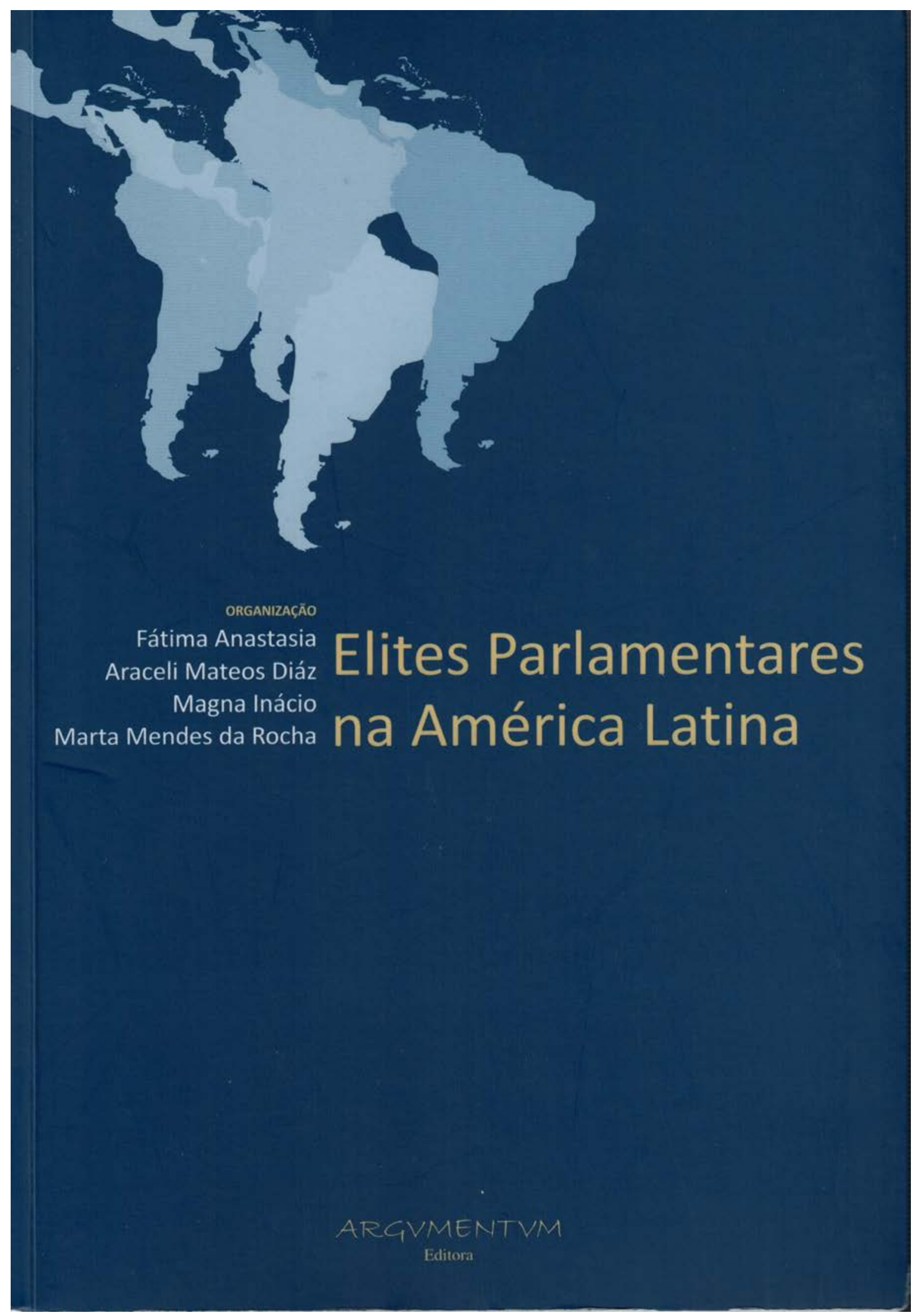




\title{
Patrones socio económicos de la elite legis- lativa y democracia en América Latina
}

\author{
Francisco Sánchez \\ Universidad de Valencia \\ Cristina Rivas \\ Instituto de Iberoamérica, Universidad de Salamanca
}

\section{Introducción}

Uno de los rasgos que más llama la atención de América Latina es la desigualdad social y económica de carácter cuasi estructural de la mayor parte de sus países (World Bank, 2008). Este fenómeno trasciende al funcionamiento del sistema político y repercute, entre otros aspectos, en la calidad de la democracia en la región ( $\mathrm{O}^{\prime}$ Donnell, 2004). Los estudios citados también señalan que las situaciones de desigualdad suelen estar asociadas a entornos polarizados, es decir, escenarios en los que hay grandes diferencias entre los sectores con más y menos recursos. En ese contexto, cabe preguntarse sobre la forma en que diferentes grados de desigualdad y polarización social trascienden al sistema político y sus actores.

Tomando en cuenta estos elementos, en este trabajo se busca profundizar sobre los potenciales vínculos entre estructura social y política, centrándonos en la relación que puede haber entre los rasgos socio-económicos de la elite política, su proximidad o distancia respecto al resto de la sociedad y la relación de estos elementos con el funcionamiento del sistema político, sobre todo, con el rendimiento del régimen democrático. Dentro del vasto grupo de la elite política, nos centraremos en la elite parlamentaria, a la que estudiaremos con el fin de determinar si existen vínculos empíricos entre los elementos señalados.

El artículo está estructurado en distintas secciones: en la primera, se busca determinar el tipo de relación que hay entre los rasgos socio 
económicos de las elites parlamentarias de los países y la estructura de desigualdad de las sociedades latinoamericanas. Para ello, se caracterizan las elites parlamentarias a partir de una serie de variables -que se explicarán en cada una de las secciones- para una vez clasificado nuestro grupo de estudio, hacer un segundo análisis en el que combinaremos los datos con indicadores de acceso a estudios terciarios e indicadores de desigualdad provenientes de organismos internacionales. En la segunda sección, se vinculan las variables arriba señaladas, a partir de las que se definieron las particularidades de las elites, con una serie de indicadores que dan cuenta de las características de la democracia de cada país con el fin de establecer si hay vínculos entre los distintos elementos.

Se trata de un estudio en el que se utilizan datos de diputados de 18 países de América Latina recogidos durante la última década. Se asume que estos diputados son una parte representativa de las elites políticas de cada uno de sus Estados, ${ }^{1}$ justificándose su estudio como grupo por la posición que ocupan en las instituciones y -desde el enfoque de toma de decisiones- debido a que forman parte de esa minoría que, como diría Mosca (1984), determina la dirección de la cosa pública. ${ }^{2}$

Los diputados y senadores son, posiblemente, los integrantes de la elite política sobre la que más se ha trabajado, aparte de su importancia como actores políticos hay otras ventajas asociadas a los rasgos de su ejercicio

\footnotetext{
${ }^{1}$ Para profundizar sobre el papel de los diputados como parte de la elite política y su importancia para la estabilidad de la democracia se puede ver el trabajo de García Díez y Mateos Díaz (2006:10). Uriarte (1997:260) indica que la elite política es el grupo que tiene capacidad de influir en las políticas y actividades del Estado, definición que permite incluir bajo esa categoría a una serie de políticos profesionales que pueden ejercer cargos en los partidos, en el Ejecutivo, en el Legislativo o en los Gobiernos Regionales. Sin embargo, señala también que la mayor parte de las investigaciones sobre elites políticas se centran en los diputados, para explicar las razones retoma a Aberdach, Putnam y Rockman (1981) que señalan que los parlamentarios muestran el lado partidista de la política, son el semillero de los gobiernos y ministerios e influyen en la política de sus respectivos países.

${ }^{2} \mathrm{El}$ enfoque de toma de decisiones (decisión-making approach) para el estudio de elites políticas tiene como trabajo referencial a Who Governs? de Dahl (1961). Pero no es la única manera de aproximarse al estudio de las elites, por ejemplo, Parry (1969) califica al modelo centrado en la capacidad de injerencia de los líderes como "reputacional approach" y pone como ejemplo del mismo al estudio sobre la estructura de poder en las comunidades de Hunter (1953). Una síntesis de los distintos enfoques es planteada por Putnam (1976) que señala que hay al menos tres estrategias para identificar a las elites. Una excelente revisión de los distintos modelos de definición y clasificación de la elite política se pude ver en Uriarte (1997:258 y ss).
} 
como políticos: su concentración espacial y temporal; o la facilidad de establecer pautas de comparación que han contribuido para que se les preste más atención desde la academia. Además de las características sociales, económicas y culturales de los diputados, se han estudiado sus carreras políticas (Hibbing, 1999 y Martínez, 2006) y sus valores y percepciones desde un marco teórico próximo a la cultura política. ${ }^{3}$

En este trabajo utilizaremos datos de 18 países de América Latina, provenientes del Proyecto Elites Latinoamericanas (PELA) del Instituto de Iberoamérica de la Universidad de Salamanca, ${ }^{4}$ que se complementarán con otros datos políticos y socio económicos de organismos internacionales de referencia que se señalarán oportunamente.

Para la clasificación de los países según las características socio económicas de sus elites, los indicadores de desigualdad social y los de democracia se ha utilizado como herramienta de análisis la representación HJ-Biplot (Galindo, 1986), extensión de los biplot clásicos de Gabriel (1971). ${ }^{5}$

\footnotetext{
${ }^{3}$ El texto seminal sobre las elites políticas latinoamericanas es el compilado por Lipset y Solari (1967) en el que se incluyen capítulos temáticos que tratan sobre los distintos aspectos de la composición y formación de las elites en general. A partir de los datos del Proyecto Elites Parlamentarias de la Universidad de Salamanca se han producido una serie de trabajos sobre los diputados Latinoamericanos de entre los que cabe rescatar el libro compilado por Alcántara (2008). Lo Senadores del Cono Sur de América Latina han sido estudiados en Sánchez et al. (2005) o Llanos y Sánchez (2006). También se puede citar una serie de estudios realizados sobre distintos países de América Latina, para el caso de Ecuador se puede consultar Pachano (1991), para la Argentina se pude mirar el trabajo de Mollineli et al. (1999), que sin ser un libro dedicado exclusivamente al Poder Legislativo, aporta cuantiosa información sobre el mismo. Al ser este un trabajo comparativo es menester citar como referencia el libro compilado por Best y Cotta (2000) en el que se recoge e interpreta información proveniente de los diputados de distintos países de Europa entre los años 1848 y 2000. Los estudios de cada país son desarrollados por especialistas sobre cada caso.

${ }^{4}$ El Proyecto Elites Parlamentarias Latinoamericanas tiene como objetivo profundizar en el conocimiento de las actitudes, opiniones y valores de la elite parlamentaria latinoamericana como un factor clave para determinar y evaluar la calidad de la democracia en América Latina. Tiene su origen en el año 1994, bajo la dirección de Manuel Alcántara y ha ido recogiendo a lo largo de las distintas legislaturas las percepciones y actitudes de los parlamentarios latinoamericanos en dieciocho países. Para este trabajo se han utilizado los datos de 4070 cuestionarios, cuya distribución se puede consultar en el Anexo 1 de este trabajo.

${ }^{5}$ Los métodos Biplot son técnicas factoriales que permiten reducir la dimensionalidad del problema y facilitar su interpretación. Son una representación gráfica de datos
} 
La ventaja de la técnica está en que permite obtener una representación gráfica simultánea sobre la relación entre un conjunto de variables y la posición de grupos de observaciones con perfiles similares en un plano de dimensión reducida, generalmente de dos dimensiones, que serán las de mayor poder explicativo. Si el porcentaje de variación explicada es alto, la representación de los datos en el plano se aproximará a los valores originales de la matriz analizada con un alto grado de fiabilidad. ${ }^{6}$

\section{Elites, democracia y desigualdad}

Uno de los temas que ya trató Aristóteles (S. III a.c.) en su libro "La Política", fue el de la existencia de un grupo de personas que se dedican a tomar decisiones de gobierno, a la vez que asoció los rasgos de los que gobiernan con el desempeño del régimen. El asunto de la elite política forma parte de ese grupo de cuestiones clásicas de los estudios políticos que no pierden vigencia, ya que preguntas como: ¿cuáles son las características de los que nos gobiernan?, ¿cómo éstas afectan al funcionamiento del sistema político?, ¿quién posee el poder? o ¿qué atributos permite poseerlos? estarán siempre en la agenda de investigación debido a los continuos cambios en la estructura de dominación política. ${ }^{7}$

Pero tanta centralidad se ha convertido a la vez en una desventaja ya que muchas veces se ha partido del supuesto de que en toda sociedad existe una elite política o que hay una correlación entre las características de las elites y el rendimiento del gobierno sin que esos supuestos

multivariantes. Del mismo modo que un diagrama de dispersión permite representar de manera conjunta dos variables, un Biplot representa de forma simultánea tres o más variables (Gabriel y Odoroff, 1990).

${ }^{6}$ La variabilidad explicada por los ejes factoriales viene determinada por la tasa de absorción de inercia, que varía entre 0 y 100, de modo que cuanto más se aproximen los valores de los ejes factoriales a 100 más fiable será la representación. Una descripción de la forma de interpretación de distintos datos se puede ver el anexo 2 de este trabajo.

${ }^{7}$ Se trata de un tema de tan amplio espectro que se puede estudiar a través de enfoques que van desde lo normativo, como los relacionados con la representación política, a lo "empírico" como los que buscan establecer vínculos entre las características de los políticos y sus conductas y actitudes. Metodológicamente, Quandt (1970) recomienda la comparación entre países y la utilización de datos que puedan ser tratados estadísticamente. 
sean contrastados de forma sistemática buscando establecer el tipo de vínculos posibles. ${ }^{8}$

En la literatura académica sobre elites políticas se puede encontrar posiciones como las de los llamados elitistas clásicos, ${ }^{9}$ para los que la existencia de una minoría que domina a la mayoría es un hecho privativo de cualquier sociedad, argumento que les valió para criticar a la democracia al considerar que esa realidad imposibilita el ideal democrático de igualdad entre los ciudadanos. Una línea argumental parecida encontramos en el trabajo de Mills (1963) que pone énfasis en señalar que hay distintos tipos de elites (políticas, económicas, militares) aunque después las une para indicar que interaccionan para asegurar el control que ejercen. ${ }^{10} \mathrm{El}$ citado autor, se aproxima también a los elitistas clásicos en la crítica que hace a la democracia aunque su enfoque está más orientado a cuestionar

${ }^{8}$ Para una revisión de la literatura sobre elites políticas puede verse los trabajos del Equipo Elites Parlamentarias (2001), Uriarte (1997), Morán (1983) y Quandt (1970). No estamos planteando que no se hayan realizado estudios sistemáticos sobre elites políticas sino que aun quedan muchos aspectos por estudiar, ya que la falta de datos no ha permitido la realización de trabajos sistemáticos. De una forma más clara lo plantea Uriarte (1997:254), al señalar que se han realizado numerosas investigaciones tanto de las elites políticas como de las culturales y económicas y que, en todas ellas, se puede apreciar un consenso generalizado sobre algunas ideas básicas, sobre todo alrededor de la noción de que las sociedades están divididas entre minorías poderosas y grandes masas influidas por esas minorías. Según la misma autora, las perspectivas varían a la hora de analizar las bases de la formación y mantenimiento de esas minorías, sus características, su papel o las consecuencias de su existencia o de sus actos para la democracia, ya que hay diferencias importantes en la identificación de las elites y en los enfoques de la investigación.

${ }^{9}$ Bajo el nombre genérico de elitistas clásicos se suele agrupar a Pareto y su teoría de la circulación de las elites; Mosca que se destaca por desarrollar el concepto de clase política y Michels con su Ley de Hierro de la Oligarquía. Además de las obras de los autores mencionados se pueden consultar los estudios sobre los mismos de Rodriguez Zúñiga (1976), Morán (1983) o Albertoni (1988). En ocasiones se incluye a Weber dentro de los elitistas clásicos ya que en sus planteamientos sobre partidos políticos es deudor de Michels.

${ }^{10}$ Cabe señalar que Mills (1963:260) insististe en la necesidad de distinguir distintos tipos de elites. Señala que a pesar de que actúan de manera conjunta, las distintas elites tienen independencia. Por esa razón, rechaza la idea de clase dirigente porque la noción de clase tiene connotaciones economicistas que pueden llevar a pensar que un grupo de poder "económico" dirige políticamente a la sociedad, no permitiendo, además, diferenciar los espacios de lo político, lo económico o lo militar. El autor ha sido criticado porque la argumentación empírica de su trabajo no es muy "científica" (Albertoni, 1988:52). 
la teoría pluralista de la democracia, al señalar que los vínculos entre las elites deja sin sustento el ideal pluralista de poder repartido.

Con la teoría elitista de la democracia (Shumpeter, 1971) se desarrolló una manera de estudiar y entender el papel de las elites en las democracias modernas, que deja de lado algunas posiciones más clásicas y normativas. La idea de que la democracia consiste en la competencia de elites que buscan el poder a través de las elecciones no sólo llenó un vacío interpretativo sino que también vinculó el rendimiento de la democracia con el desempeño de sus elites.

Otro aporte significativo a la comprensión del papel de las elites en el sistema político es el de la teoría pluralista de la democracia, donde se destaca, por su carácter seminal, el trabajo de Dahl (1961). La visión pesimista del elitismo, por la cual la dinámica interna de la asociación política crea fuerzas extrañas al control popular en todas las instituciones democráticas está, según Butta (1992), en gran parte injustificado porque el solo control de una asociación por parte de una minoría no es contradictorio con el control a los líderes ejercitado a través de procesos electorales. El autor insiste en que se mantienen los tres elementos fundamentales de la democracia pluralista: control popular, elites y pluralidad de centros de poder y de la elite misma.

Desde la cultura política, Inglehart y Welzel (2006:221) critican el protagonismo dado a las elites en los proceso democráticos y señalan que el determinismo democrático centrado en las elites implica que el surgimiento y la supervivencia de las instituciones políticas dependan del comportamiento de las elites, particularmente de sus elecciones institucionales: sí los líderes políticos son concebidos y se conciben como los fundadores de la democracia, cumplirían también la función, después de su instauración inicial, de mantenerla o destruirla. Esta afirmación supone que los que ejercen el poder son independientes de los valores y creencias de la población que gobiernan. Desde esta perspectiva el comportamiento de las elites no depende de las influencias de las masas. Irónicamente, esto supone que las preferencias de las masas no son en realidad importantes para la democracia, cuando el quid de la democracia es que sí lo son.

A la par que se discutía sobre la función de las elites en los gobiernos democráticos se abría también una nueva agenda de investigación que buscaba señalar en qué se diferencian del resto de la población los integrantes del grupo minoritario que toma unilateralmente las decisiones de importancia nacional. Las investigaciones se preguntaron por las características sociales, económicas y culturales de las elites y, sobre todo, 
en determinar si existe algún tipo de correlación entre los rasgos de las elites y el rendimiento del sistema político (Lasswell, 1961).

Rokkan realizó un planteamiento que ha servido de base para investigaciones posteriores que se han desarrollado en este sentido. Observando los patrones de comportamiento político, él sostiene que los cambios en la composición de las elites reflejan el proceso de movilización social y política, de integración social y de establecimiento de reglas de acceso a posiciones y recursos en la sociedad. ${ }^{11}$

Los argumentos anteriores ligan la cuestión de las elites a la representación política. Así, por ejemplo, la línea argumental desarrollada por Best y Cotta (2000) sostiene que los cambios en la composición de las elites reflejan variaciones en los niveles de inclusión política de la población que se produce en los procesos de democratización. Sostienen que existe una interdependencia entre cambio social y la transformación de la representación parlamentaria. La representación es entendida como una "bisagra" entre sociedad y política donde los conflictos sociales y las estructuras de autoridad son trasladados a la acción política, pero al mismo tiempo los actores políticos guían, estructuran e interpretan las demandas de la sociedad.

En este sentido, la representación política también se entendería de una manera próxima a la planteada por Sartori (2005) cuando explica el concepto "representación sociológica". Como señala Linz (1998:249), la mayor parte de estudios se han centrado en la representatividad de las elites en términos de características tales como clase, sexo, origen regional o étnico y movilidad social, reflejando una preocupación por la igualdad de oportunidades.

En este trabajo, se busca profundizar en los términos de la relación entre elites y democracia, pero ensayando una lectura distinta y poco ha-

\footnotetext{
${ }^{11}$ El esfuerzo más significativo dentro de esta línea de trabajo es el compilado por Best y Cotta (2000:6), que resumen los objetivos de su trabajo de la siguiente manera: Our view is that the empirical study of parliamentary elites can add a new dimension to these analyses by documenting how and to what extent the representatives, that is, those actors which are at the same time the main products and producers of the democratization processes and of the democratic institutions, have changed in parallel with the other dimensions of that great transformation. (...) the parallel sequences of developments concerning: (a) the rules of admission to the political arena (suffrage rights and the other political rights); (b) the extent and patterns of political mobilization of the citizenship (turnout); (c) the main agents of political mobilization (parties); (d) institutional arrangements (parliamentarization of governments, and so on); (e) characteristics of political elites.
} 
bitual, ya que se intenta explicar el vínculo entre los dos conceptos usando la visión de la democracia que, sin caer en el determinismo de lo social o lo económico, plantea que el grado de desigualdad social y económica de una sociedad, afecta a las características de la democracia debido a que éstas, merman las "capacidades" de las personas como ciudadanos. ${ }^{12}$

La teoría de las "capacidades" (Sen, 2006) apela a la necesidad de que los ciudadanos cuenten con unos mínimos de bienestar social y económico para poder relacionarse de forma activa con el sistema político y aspirar al ideal de igualdad que ofrece la democracia. La novedad de este enfoque está en que ofrece alternativas analíticas para explicar los problemas de consolidación de la democracia una vez que las variables institucionales han sido largamente exploradas.

Los trabajos elaborados desde esa perspectiva analítica suelen centrarse en los efectos de la desigualdad en las "capacidades" políticas de los sectores más pobres, pero no prestan mucha atención a los sectores que se benefician de la situación de desigualdad. En este trabajo queremos profundizar en el segundo campo buscando vínculos entre la situación de desigualdad que vive un país, los rasgos de sus elites parlamentarias y las características de la democracia. Invirtiendo el argumento, se podría decir que la carencia de recursos que se refleja en las limitadas "capacidades" políticas, se transforma, en el caso de las elites, en un exceso de recurso que se verá reflejado en abundantes "capacidades" políticas. ${ }^{13}$

\footnotetext{
12 Dentro de esta línea se puede consultar el texto de O’Donnell (2004:43 y ss) y demás artículos compilados en PNUD (2004), que al ser pensados para explicar la situación de América Latina, resultan de interés especial para este trabajo. También se pueden consultar los trabajos de Tulchin y Brown (2003) o Sen (2006).

${ }^{13}$ Luego de revisar distintos estudios sobre elites políticas, Uriarte (1997:270) señala que: parece claro que algunas características favorecen notablemente la llegada a las elites políticas. Es así que haber nacido en ciudades, pertenecer a la clase media o media alta, haber cursado estudios universitarios, preferentemente en instituciones de elite, y ser hombre, son todos ellos rasgos que aumentan las posibilidades de poder alcanzar posiciones de elite política. Ahora bien, también es cierto que los rasgos señalados favorecen el ascenso, no solo de la elite política sino del conjunto de todas las elites y que no todos los que poseen esas características llegan a posiciones de elite. Aquí también cabe recordar la recomendación de Mills (1963:263) cuando se pregunta: ¿es qué entonces el origen elevado y la carrera de los hombres eminentes, no significa nada respecto a la distribución del poder?. De ningún modo. Sólo nos recuerdan que debemos cuidarnos de toda deducción simple y directa acerca del carácter político y la política en relación con el origen y la carrera, pero que tampoco debemos desdeñarlos en nuestro intento de comprensión de la política.
} 
A partir de esa explicación, usamos aquí una hipótesis de trabajo muy simple: en los casos en los que hay mayor desigualdad y los políticos son más "elite" (es decir, sus ingresos y educación propia y de sus padres está más distante de la que tiene la mayoría de la población) los indicadores que miden diferentes rasgos de la democracia serán peores debido a que su clase política es menos "representativa" y porque su ascenso, gobierno y permanencia reflejan por si mismas una mayor fortaleza de la estructura de desigualdades, a la par que muestran deficiencias en los mecanismos de inclusión y liberalización del régimen político.

No estamos planteando que la representación política en democracia deba funcionar necesariamente como un espejo de la sociedad, sino más bien, nuestro argumento se sostiene en que la mayor distancia entre elite y sociedad es una evidencia de las dificultades de acceso que pueden tener algunos sectores a los procesos de toma de decisiones y para que sus demandas sean atendidas.

Debido a los pocos antecedentes teóricos que traten el impacto de la desigualdad socio económica con las características de las elites políticas aquí se usará el desarrollo conceptual de los autores que exploraron en ese campo con el fin de analizar el vínculo entre las características socio económicas de las elites parlamentarias y los cambios o permanencias en el régimen político. Además del texto de Best y Cotta (2000), Putnam (1976), en su trabajo seminal sobre elites políticas, usó indicadores socio económicos, de clase y sobre antecedentes familiares para estudiar a las elites de países europeos y concluir que disminuían los sectores aristocráticos y aumentaban las clases medias, lo que refleja claramente el proceso de disminución de los grados de desigualdad que significó el proceso de democratización.

\section{Desigualdad y elite política}

El objetivo de esta sección es explorar el tipo de relación que hay entre los rasgos socio económicos de las elites parlamentarias y la estructura de desigualdad de sus respectivos países. Comenzaremos caracterizando socio económicamente a las elites parlamentarias para, una vez clasificado el grupo de estudio, realizar un segundo análisis en el que se combinan los rasgos de los parlamentarios con indicadores de desigualdad provenientes de organismos internacionales y datos de acceso a estudios terciarios. A partir de ese análisis, se podrán señalar los patrones de relación, o no, 
que se den entre el nivel de desigualdad de un país y las características de su elite política.

Para medir el estatus socio económico de los diputados de los distintos países, se han empleado tres variables elaboradas a partir de información contenida en la base de datos del Proyecto Elites Parlamentarias Latinoamericanas: nivel de ingresos declarados por los diputados, nivel educativo de los parlamentarios y nivel educativo de sus padres.

Cabe señalar que el indicador de ingresos no es el salario que perciben los diputados por su actividad parlamentaria, se trata de los ingresos globales que ellos dicen tener; además, se han utilizado los datos del PIB per cápita de cada país para "contextualizar" el dato sobre ingreso recogido en los cuestionarios del proyecto de elites, ya que no resulta igual ganar 10.000 USD en un país que tenga el PIB per cápita de 3.000 USD que en uno con 9.000 USD. A través de ese cálculo se obtuvo una variable con una escala que varía entre $-2,5$ y $+2,5$, donde valores negativos indican que los ingresos de los parlamentarios están por debajo del PIB per cápita del país mientras que valores positivos indicarán que los ingresos de los parlamentarios son superiores al PIB per cápita del país.

La variable educación es categórica y fue recogida a partir de cinco opciones de respuesta: sin estudios, primarios, secundarios, universitarios y de postgrado. Como se ha señalado, además de los datos relativos al nivel de estudios del propio legislador, se incluyó información relativa a los estudios de los padres, con el fin de contar con un indicador que muestre indicios de movilidad social y del contexto socio económico del legislador. La mayor parte de los trabajos comparados sobre desigualdad social en América Latina utilizan variables educativas para determinar la movilidad social de un individuo. ${ }^{14}$ Los antecedentes familiares son importantes para explicar la movilidad en términos de educación y constituyen uno de los principales factores que determinan la movilidad social en las sociedades meritocráticas (IPES, 2008:121). La familia y el entorno social de un individuo son uno de los principales agentes de socialización política en el período de juventud de una persona y son determinantes en el acceso a oportunidades y resultados futuros. ${ }^{15}$

\footnotetext{
${ }^{14}$ Sobre movilidad social y educación se pueden consultar, entre otros, a Ferranti, Perry, Ferreira y Walton (2003); Andersen (2001); Behrman, Gaviria y Székely (2001) y Dahan y Gaviria (1999).

${ }^{15}$ Ver entre otros Lipset, Lazarsfeld, Barton y Linz (1954) y Almond y Verba (1963). Estos últimos afirman que la temprana socialización del individuo en la familia ejerce una influencia importante sobre sus posteriores actitudes y participación política.
} 
En general, las elites mantienen su posición a lo largo del tiempo a través de una serie de mecanismos como puede ser el ámbito de las relaciones sociales. Así, por ejemplo, se da un alto porcentaje de matrimonios entre personas con nivel educativo similar (Ferranti, Perry, Ferreira, y Walton, 2003:8). En este sentido, las elites parlamentarias latinoamericanas de la última década no son una excepción, la correlación entre los distintos niveles de estudio del padre y de la madre de los diputados de los dieciocho países analizados es muy alto (Tabla 1). Los países con las correlaciones más elevadas son Venezuela, Bolivia, Brasil, Panamá y Guatemala. Por su parte, en países como Paraguay, Uruguay y Perú la relación entre el nivel de estudios del padre y el de la madre es menos fuerte.

Tabla 1: Correlación entre nivel de estudios del padre, de la madre y del diputado por países.

\begin{tabular}{|c|c|c|c|}
\hline País & $\begin{array}{c}\text { Correlación estudios } \\
\text { padre-estudios madre }\end{array}$ & $\begin{array}{l}\text { Correlación estudios } \\
\text { padre-estudios hijos }\end{array}$ & $\begin{array}{l}\text { Correlación estudios } \\
\text { madre-estudios hijos }\end{array}$ \\
\hline - Argentina (ARG) &, $669 * *$ &, $304 * *$ &, $176^{* *}$ \\
\hline - Bolivia (BOL) &, $775^{* *}$ &, $434 * *$ &, $446^{* *}$ \\
\hline - Brasil (BRA) &, $756^{* *}$ & ,153 &, $202^{*}$ \\
\hline - Chile (CHL) &, $613 * *$ &, $149 *$ &, $180 * *$ \\
\hline - Colombia (COL) &, $729 * *$ &, $175^{* *}$ &, $156^{* *}$ \\
\hline - Costa Rica (CRI) &, $656^{* *}$ &, $267 * *$ &, $262 * *$ \\
\hline - Salvador (SLV) &, $654 * *$ &, $420 * *$ &, $365^{* *}$ \\
\hline - Ecuador (ECU) &, $705 * *$ &, $145^{*}$ &, $138 *$ \\
\hline - Guatemala (GTM) &, $745^{* *}$ &, $324 * *$ &, $262 * *$ \\
\hline - Honduras (HND) &, $700 * *$ &, $387 * *$ &, $309 * *$ \\
\hline - México (MEX) &, $691 * *$ &, $242 * *$ &, $238 * *$ \\
\hline - Nicaragua (NIC) &, $638 * *$ &, $210 * *$ &, $157 *$ \\
\hline - Panamá (PAN) &, $751^{* *}$ &, $370^{* *}$ &, $359 * *$ \\
\hline - Paraguay (PRY) &, $515 * *$ & ,138 &, $305^{* *}$ \\
\hline - Perú (PE) &, $598 * *$ &, $246^{* *}$ & ,138 \\
\hline - R. Dominicana (DOM) &, $670 * *$ &, $178 * *$ &, $195 * *$ \\
\hline - Uruguay (URY) &, $559 * *$ &, $272 * *$ &, $242 * *$ \\
\hline - Venezuela (VEN) &, $800 * *$ & ,171 & , 120 \\
\hline
\end{tabular}

** La correlación es significativa al nivel 0,01

* La correlación es significativa al nivel 0,05

Fuente: Elaboración propia con Datos PELA (1998-2007). 
Los resultados de algunas investigaciones llevadas a cabo entre la población latinoamericana ponen de manifiesto la estrecha relación existente entre el nivel de estudios de los padres y el de los hijos. Los vástagos de padres con niveles más altos, tanto en educación como en ingresos, reciben una mayor educación (IPES, 2008, 121). Hecho que también parece corroborarse en el caso de las elites parlamentarias latinoamericanas. En la práctica totalidad de países analizados, se observa una estrecha relación entre nivel de estudios de los padres y el nivel de estudios de los hijos (Tabla 1) sobre todo en Bolivia, El Salvador, Honduras y Panamá, mientras que en países como Venezuela no existe relación alguna entre el nivel de estudios alcanzado por los padres y el nivel de estudios logrado por los hijos. Algo similar sucede en Brasil o Paraguay, si bien, resulta llamativo que en estos países el nivel de estudios de los diputados está más relacionado con el nivel de estudios conseguido por la madre que por el padre.

La relación entre el nivel de ingresos de los diputados y el nivel de estudios alcanzado, es relativamente débil para algo más de la mitad de los países analizados. Tan sólo existe correlación en El Salvador, Honduras, Nicaragua, Perú, República Dominicana y Uruguay, siendo especialmente fuerte en estos últimos cuatro países. En cambio, en diez de los dieciocho países estudiados la relación es más acentuada entre el nivel de estudios alcanzado por los padres y los ingresos de los diputados (Tabla 2).

Tabla 2: Correlación entre nivel de estudios del padre, de la madre y del diputado con el nivel de ingresos de los parlamentarios por países.

\begin{tabular}{|l|c|c|c|}
\hline \multicolumn{1}{|c|}{ País } & $\begin{array}{c}\text { Correlación estudios } \\
\text { padre-nivel de ingresos }\end{array}$ & $\begin{array}{c}\text { Correlación estudios } \\
\text { madre-nivel de ingresos }\end{array}$ & $\begin{array}{c}\text { Correlación estudios } \\
\text { hijos-nivel de ingresos }\end{array}$ \\
\hline - Argentina (ARG) &, $140^{*}$ &, 018 &,- 056 \\
\hline - Bolivia (BOL) &, $145^{*}$ &, $155^{*}$ &,- 029 \\
\hline - Brasil (BRA) &,- 008 &, 052 &, 054 \\
\hline - Chile (CHL) &, 043 &,- 020 &,- 011 \\
\hline - Colombia (COL) &, 105 &, 049 &, 071 \\
\hline - Costa Rica (CRI) &, 057 &, 056 &, 138 \\
\hline - Salvador (SLV) &, $259 * *$ &, $230^{* *}$ &,- 030 \\
\hline - Ecuador (ECU) &, 131 &, $214^{* *}$ &,- 007 \\
\hline - Guatemala (GTM) &, 119 &, $148^{*}$ & \\
\hline
\end{tabular}


FRANCISCO SÁNCHEZ | CRISTINA RIVAS

\begin{tabular}{|l|c|c|c|}
\hline - Honduras (HND) &, $182^{* *}$ &, $193^{* *}$ &, $150^{*}$ \\
\hline - México (MEX) &, $100^{*}$ &, $128^{* *}$ &, 013 \\
\hline - Nicaragua (NIC) &, $227^{* *}$ &, $306^{* *}$ &, $240^{* *}$ \\
\hline - Panamá (PAN) &, $181^{*}$ &, $257^{* *}$ &, 049 \\
\hline - Paraguay (PRY) &, 110 &, 043 &,$- 256^{* *}$ \\
\hline - Perú (PE) &, 018 &, 018 &, $209 * *$ \\
\hline - R. Dominicana (DOM) &, $200 * *$ &, $244 * *$ &, $203 *$ \\
\hline - Uruguay (URY) &, 092 &, $169 *$ &, 047 \\
\hline - Venezuela (VEN) &, 085 &,- 017 & \\
\hline
\end{tabular}

** La correlación es significativa al nivel 0,01

* La correlación es significativa al nivel 0,05

Fuente: Elaboración propia con Datos PELA (1998-2007).

A pesar de los diferentes niveles de correlación que se han ido dando al agrupar de distinta forma las variables, es indudable que existe cierto vínculo entre ellas, relación que trataremos de establecer mediante una representación HJ-Biplot del grado de educación y nivel de ingresos de los diputados y el nivel de educación de su familia. Gracias a esa herramienta, se lleva a cabo la clasificación de los países según los factores socio económicos antes anotados.

En la figura 1 se puede ver que el eje 1, definido por las variables relativas a educación, es dominante al explicar el $48 \%$ de la varianza total de la matriz de datos. El segundo eje de análisis, recoge el 39\% de la variabilidad total, y viene explicado por el indicador ingresos de los diputados. Por tanto, el primer plano factorial, el formado por los ejes 1 y 2 , con una tasa de inercia del $87 \%$ garantiza la fiabilidad de la representación de los datos. 
Figura 1: Representación gráfica de los países de acuerdo a las características socio económicas de los diputados a partir del análisis HJ-Biplot

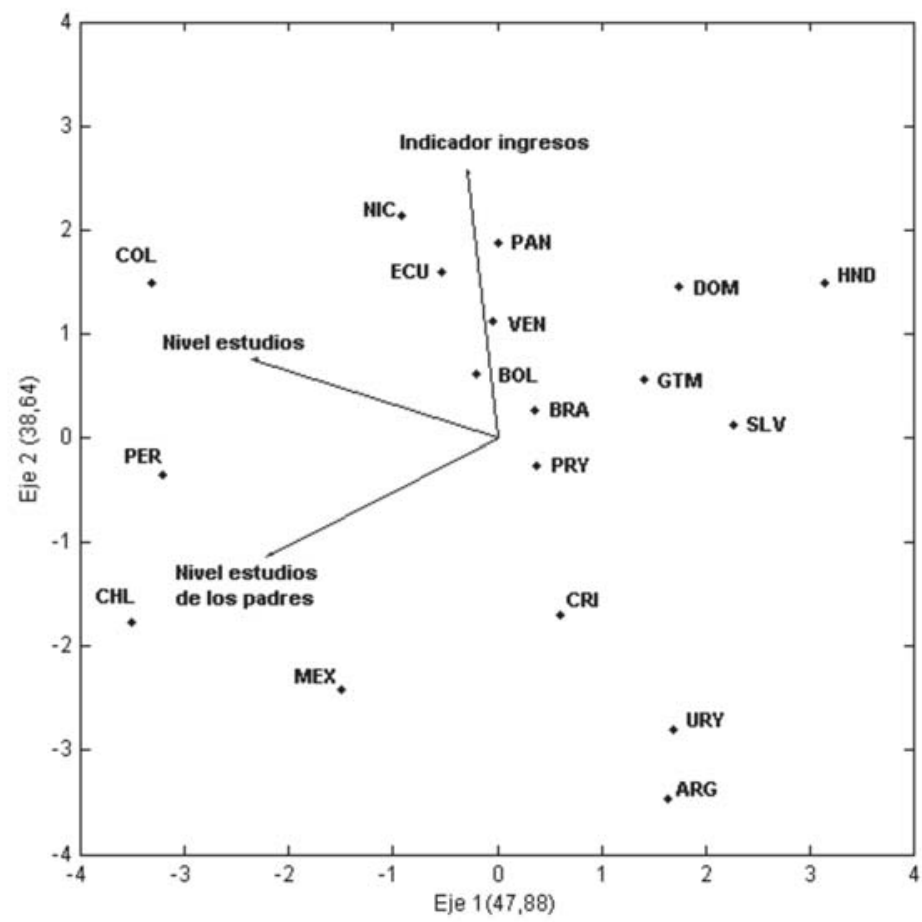

Fuente: Datos PELA (1998-2007) y World Bank (1998-2006). World Development Indicators database: http://www.worldbank.org/data/onlinedatabases/onlinedatabases.html

En la Tabla 3 se presentan las contribuciones desglosadas por ejes factoriales. ${ }^{16}$ A partir de esos valores se puede señalar que las tres variables incluidas en el análisis contribuyen de manera significativa a la identificación de los grupos de países, si bien, es el indicador de ingresos el que mayor importancia explicativa tiene en la posición y clasificación de los países, con una contribución de 902 en el eje 2.

${ }^{16}$ La Contribución Relativa del Factor al Elemento (CRFE) representa la parte de variabilidad de un elemento explicada por el factor, y se interpreta de la misma manera que un coeficiente de determinación en regresión. De forma, que si un elemento (caso o variable) recibe una alta contribución de un factor y baja de los demás, ese elemento será una característica casi exclusiva de ese factor, y será precisamente el elemento más importante a la hora de interpretar un eje. Esta medida toma valores entre 0 y 1000. 
FRANCISCO SÁNCHEZ | CRISTINA RIVAS

Tabla 3: Contribuciones relativas del factor al elemento de la Figura 1.

\begin{tabular}{|l|c|c|c|}
\hline \multicolumn{1}{|c|}{ Variables } & Eje 1 & Eje 2 & Eje 3 \\
\hline Estudios del diputado & 758 & 79 & 164 \\
\hline Estudios de los padres & 667 & 178 & 154 \\
\hline Indicador ingresos del diputado & 11 & 902 & 86 \\
\hline
\end{tabular}

Fuente: Elaboración propia a partir de los Resultados HJ-Biplot.

La Figura 1 muestra también cómo los países quedan claramente divididos por las tres variables socio económicas que tratan de medir el "nivel de elitismo" de los diputados latinoamericanos. Partiendo de la base de que la práctica totalidad de los parlamentarios tiene formación superior, ya que el $90 \%$ de ellos cuenta con estudios de nivel terciario, el primer plano factorial separa, por un lado, a aquellos países en los que los diputados tienen los niveles de estudio más elevados de toda América Latina y proceden de familias donde el nivel educativo de los padres es relativamente alto respecto al del resto de la región (situados en la parte izquierda del gráfico) frente a los que tienen unos menores niveles de estudio y con padres cuya educación ha sido menor (situados en la parte derecha del gráfico).

Por otro lado, los ejes factoriales también permiten diferenciar entre aquellos países latinoamericanos donde los diputados tienen unos ingresos por encima del PIB per cápita del país (posicionados en la parte superior) de aquellos con unos ingresos por debajo del PIB nacional (parte inferior del gráfico).

Proyectando cada uno de los países de forma perpendicular sobre los vectores que representan a las variables se observan tres grandes grupos: un primer grupo situado en la parte izquierda del gráfico, un segundo grupo situado en la parte inferior y un tercer grupo -el más numeroso- ubicado en el cuadrante superior derecho del gráfico.

Todos aquellos países posicionados cerca de la punta de la flecha que representa el nivel de estudios del diputado y el nivel de estudios de los padres serán aquellos que posean elites parlamentarias más formadas en materia educativa, es decir, los que tienen un alto porcentaje de diputados con estudios de postgrado completados mientras que, los situados en los extremos opuestos de estos vectores, serán los que tengan niveles educativos inferiores siempre teniendo en cuenta que, como hemos dicho antes, el nivel de estudios alcanzado por la mayoría de los parlamentarios latinoamericanos son terciarios.

Lo mismo sucede con el indicador de ingresos, los países situados cerca de la punta de la flecha que representa a esta variable, tendrán unos 
ingresos por encima del PIB per cápita del país mientras que los situados en el otro extremo tendrán unos ingresos por debajo del PIB nacional.

Para complementar la información ofrecida por el gráfico, en la tabla 4 , se presentan los valores medios de los países en cada una de las variables. Se ha incluido además un índice que pretende dar un indicio de la movilidad social de los diputados a través de la comparación entre el nivel de estudios del diputado con el de sus padres. A partir de los datos, se puede afirmar que los países en los que existe una mayor "movilidad educativa" de las elites parlamentarias son: República Dominicana, Venezuela, Nicaragua y Colombia, con distancias por encima de 1,60. Por el contrario, los países con niveles de movilidad educativa más bajos se dan en Chile, Argentina, Uruguay, México y, en menor medida, en Perú, con valores por debajo de 1,25 .

Tabla 4: Clasificación de la elite parlamentaria Latinoamericana según sus características socio económicas

\begin{tabular}{|l|c|c|c|c|}
\hline \multicolumn{1}{|c|}{ Países } & $\begin{array}{c}\text { Nivel de estudios } \\
\text { diputado (A) }\end{array}$ & $\begin{array}{c}\text { Nivel de estudios } \\
\text { de los padres (B) }\end{array}$ & $\begin{array}{c}\text { Indicador ingresos } \\
\text { del diputado }\end{array}$ & $\begin{array}{c}\text { "Movilidad } \\
\text { educativa" (A-B) }\end{array}$ \\
\hline - Argentina (ARG) & 3,97 & 2,81 & $-2,50$ & 1,16 \\
\hline - Bolivia (BOL) & 4,14 & 2,87 & 0,00 & 1,27 \\
\hline - Brasil (BRA) & 4,19 & 2,71 & $-0,60$ & 1,48 \\
\hline - Chile (CHL) & 4,32 & 3,32 & $-1,00$ & 1,00 \\
\hline - Colombia (COL) & 4,56 & 2,92 & 0,00 & 1,64 \\
\hline - Costa Rica (CRI) & 4,19 & 2,70 & $-1,90$ & 1,49 \\
\hline - Salvador (SLV) & 4,02 & 2,56 & $-0,70$ & 1,46 \\
\hline - Ecuador (ECU) & 4,20 & 2,84 & 0,50 & 1,36 \\
\hline - Guatemala (GTM) & 4,09 & 2,63 & $-0,40$ & 1,46 \\
\hline - Honduras (HND) & 3,85 & 2,58 & 0,50 & 1,27 \\
\hline - México (MEX) & 4,24 & 3,05 & $-1,80$ & 1,19 \\
\hline - Nicaragua (NIC) & 4,37 & 2,69 & 0,30 & 1,68 \\
\hline - Panamá (PAN) & 4,17 & 2,77 & 0,60 & 1,40 \\
\hline - Paraguay (PRY) & 4,13 & 2,79 & $-0,70$ & 1,34 \\
\hline - Perú (PE) & 4,39 & 3,15 & $-0,50$ & 1,24 \\
\hline -R. Dominicana (DOM) & 4,20 & 2,41 & $-0,40$ & 1,79 \\
\hline - Uruguay (URY) & 3,97 & 2,79 & $-2,10$ & 1,18 \\
\hline - Venezuela (VEN) & 4,31 & 2,62 & $-0,40$ & 1,69 \\
\hline
\end{tabular}

Fuente: Elaboración propia con Datos de PELA (1998-2007) y World Bank (1998-2006). World Development Indicators database: http://www.worldbank.org/data/onlinedatabases/onlinedatabases.html 
Como señalamos en la parte en que explicamos las herramientas metodológicas empleadas en este trabajo, complementaremos los resultados del HJ-Biplot con un análisis de conglomerados jerárquico a partir de las coordenadas obtenidas en el biplot para, de este modo, identificar y corroborar la clasificación realizada de manera visual a partir del posicionamiento de los puntos en el gráfico.

La figura 2 muestra cinco clusters claramente diferenciados, ${ }^{17}$ el primero formado por Ecuador, Panamá y Bolivia, el segundo por Argentina, Uruguay, Costa Rica y México, el tercero por Brasil, Paraguay, Salvador, Guatemala, República Dominicana, Nicaragua y Venezuela, el cuarto por Chile, Perú y Colombia y el quinto por Honduras.

Figura 2: Dendograma de agrupación de los países según variables socioeconómicas

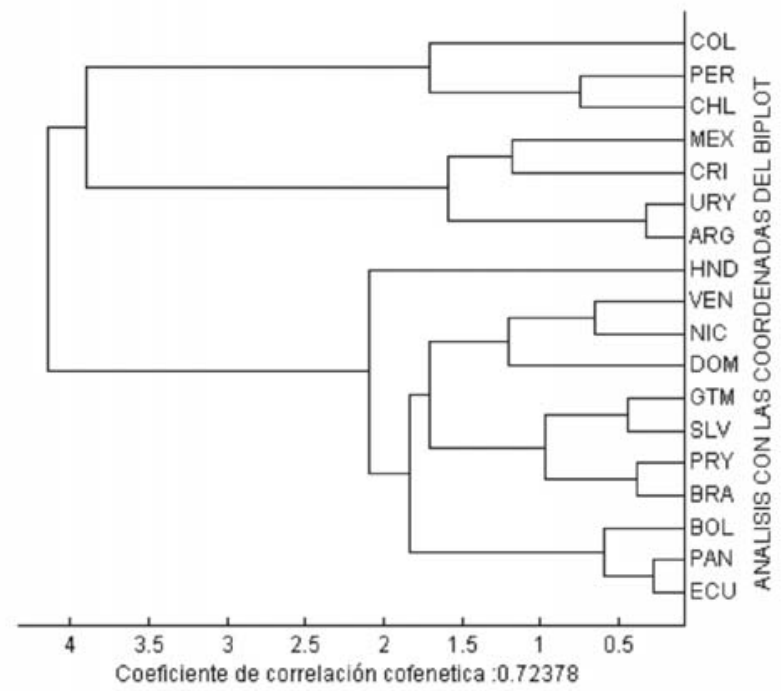

Fuente: Elaboración propia a partir de las coordenadas del HJ-Biplot

\begin{abstract}
${ }^{17}$ Se ha utilizado como medida del grado de buena clasificación el coeficiente de correlación cofenética (Rohlf y Sokal, 1981) que varía entre 0 y 1 . Si el valor está próximo a 0 existe una distorsión entre las distancias iniciales y las resultantes del análisis de conglomerados jerárquico. Si el valor está próximo a 1 , indica que hay una buena estructura jerárquica entre los casos analizados. En este estudio, el coeficiente de correlación cofenética es de 0,72 , lo que nos permite hablar de una clasificación de los casos aceptable.
\end{abstract}


Una de las ventajas de aplicar el método cluster a partir de las coordenadas del biplot es que posibilita determinar qué variables son las responsables de la formación de los distintos clusters (Vicente, Ramírez y Galindo, 1994:830). La tabla 5 presenta las configuraciones que los clusters tienen en los planos factoriales destacando qué variables son las que mayor incidencia tienen en la formación de los grupos. Es así que el primer cluster, el integrado por Ecuador, Panamá y Bolivia se forma exclusivamente por el nivel de ingresos elevado que tienen las elites parlamentarias de estos países, siendo los diputados panameños los de mayores ingresos de toda América Latina, seguidos de los ecuatorianos.

El segundo cluster también tiene como principal variable de agrupación el indicador de ingresos pero, en este caso, en contraposición con lo acontecido en el cluster anterior, los diputados argentinos, costarricenses, mexicanos y uruguayos se caracterizan por tener los ingresos más bajos de toda América Latina.

El cluster más numeroso es el tercero y está constituido por Brasil, Paraguay, Salvador, Guatemala, Nicaragua, Venezuela y República Dominicana quedando determinado, principalmente, por el nivel educativo tanto de los diputados como de sus padres. Los parlamentarios de estos siete países se caracterizan por ser universitarios y procedentes de familias donde el máximo nivel de estudios alcanzado por los padres es el secundario, uno de los más bajos si se tiene en cuenta la formación académica de los padres de los parlamentarios del resto de los clusters. La elite nicaragüense, además, se caracteriza por tener unos ingresos por encima del PIB per cápita del país, lo que la sitúa entre los países más elitistas de América Latina, muy próxima a la de los países del cluster 1, como se pone de manifiesto en la figura 2 . 
FRANCISCO SÁNCHEZ | CRISTINA RIVAS

Tabla 5: Países que forman los clusters y características socio económicas

\begin{tabular}{|c|c|c|c|c|}
\hline \multirow{3}{*}{ Clusters } & \multirow{3}{*}{ Países } & \multirow{3}{*}{ Ejes } & \multicolumn{2}{|l|}{ Variables socioeconómicas } \\
\hline & & & \multicolumn{2}{|l|}{ Planos } \\
\hline & & & $1-2$ & $1-3$ \\
\hline \multirow{3}{*}{1} & Bolivia & 3,2 & \multirow{3}{*}{ Indicador ingresos (913) } & \\
\hline & Ecuador & 2,3 & & \\
\hline & Panamá & 2,3 & & \\
\hline \multirow{4}{*}{2} & Argentina & 2,1 & \multirow{4}{*}{ Indicador ingresos (913) } & \\
\hline & Costa Rica & 2,3 & & \\
\hline & México & 21 & & \\
\hline & Uruouav & 21 & & \\
\hline \multirow{7}{*}{3} & Brasil & 3,1 & Estudios diputado & \\
\hline & Guatemala & 1,2 & (837) & \\
\hline & Nicaragua & 2,1 & Estudios padres & \\
\hline & Paraguay & 1,2 & $(845)$ & \\
\hline & Salvador & 1 & Indicador de ingresos & \\
\hline & R. Dominicana & 1,3 & (913) & \\
\hline & Venezuela & 3,2 & & \\
\hline \multirow{4}{*}{4} & Chile & 1,2 & Estudios diputado & \\
\hline & Colombia & 1,2 & $(837)$ & \\
\hline & Perú & 1 & Estudios padres & \\
\hline & & & $(845)$ & \\
\hline \multirow{4}{*}{5} & \multirow{4}{*}{ Honduras } & \multirow{4}{*}{1,3} & Estudios diputado & \\
\hline & & & $(837)$ & \\
\hline & & & Estudios padres & \\
\hline & & & $(845)$ & \\
\hline
\end{tabular}

Fuente: Elaboración propia con resultados del HJ-Biplot y análisis de conglomerados.

El cuarto cluster lo forman Chile, Colombia y Perú siendo el nivel educativo, tanto de los diputados como de sus padres, lo que determina su configuración y lo discrimina del resto de grupos. Los parlamentarios de estos países se caracterizan por su alta formación educativa, con un elevado porcentaje de ellos con estudios de postgrado completos, principalmente en Colombia y Perú, además proceden de familias donde sus 
progenitores destacan por tener, en buena medida, estudios universitarios, principalmente de grado medio.

El último cluster por analizar es el formado por Honduras que tiene como variables dominantes las relativas a educación. A diferencia del cluster anterior, lo que caracteriza a los diputados hondureños es su menor formación educativa, la más baja de toda la región. Algo que también está en consonancia con la educación recibida por los padres, que al igual que ellos tienen un nivel de estudios relativamente bajo. Las medias obtenidas para cada uno de los clusters en las tres variables socio económicas se recogen en la Tabla 6 .

Tabla 6: Medias de los clusters en las variables socio económicas

\begin{tabular}{|c|c|c|c|c|}
\hline Clusters & $\begin{array}{c}\text { Nivel de estudios } \\
\text { diputado }(A)\end{array}$ & $\begin{array}{c}\text { Nivel de estudios } \\
\text { de los padres }(B)\end{array}$ & $\begin{array}{c}\text { Indicador ingresos } \\
\text { del diputado }\end{array}$ & $\begin{array}{c}\text { "Movilidad } \\
\text { educativa" }(A-B)\end{array}$ \\
\hline - Cluster 1 & 4,17 & 2,83 & 0,37 & 1,34 \\
\hline - Cluster 2 & 4,09 & 2,84 & $-2,08$ & 1,25 \\
\hline - Cluster 3 & 4,19 & 2,63 & $-0,41$ & 1,56 \\
\hline - Cluster 4 & 4,42 & 3,13 & $-0,50$ & 1,29 \\
\hline - Cluster 5 & 3,85 & 2,58 & 0,50 & 1,27 \\
\hline
\end{tabular}

*Las medias obtenidas para cada uno de los grupos en las variables de análisis presentan diferencias significativas al 95\% de confianza.

Fuente: Elaboración propia a partir de los resultados del análisis de conglomerados.

Antes de pasar a otro punto queremos resaltar la heterogeneidad en la configuración socioeconómica de las elites parlamentarias latinoamericanas. Cabe subrayar dos tendencias que se muestran claramente en el estudio, por un lado, hay significativas diferencias entre los niveles de ingresos de los diputados, lo que pondría en cuestionamiento la visión, bastante generalizada y aun por ser estudiada, de que la política en América Latina está destinada solo a los sectores más ricos. No queremos decir con esto que los ingresos de los diputados sean bajos, sino que la presencia de "oligarquías" en la política varía sustancialmente entre países, variación, que es de esperar, tendrá algún impacto, positivo o negativo, en el funcionamiento de la democracia y sobre todo, al tomar en cuenta las desigualdades estructurales de los países.

Un aspecto que podría estar asociado a la mayor o menor presencia de personas pudientes en los legislativos es la rentabilidad del negocio de la política, es posible que en los países donde los diputados tengan más 
ingresos, el participar en política presente muchos más atractivos que el solo hecho de quedarse en el mundo de la empresa privada. Además, está aun por estudiarse el papel de los partidos y otros mecanismos de acceso al sistema político como medios para generar oportunidades y equilibrar las posibilidades de los sectores económicamente dispares en los países de la región.

Por otro lado, es notable el elevado nivel de estudios de los diputados latinoamericanos, lo que lleva a plantear que se trata de elites que, en teoría, tienen una buena educación formal y que, además, provienen de hogares en los que, tomando en cuenta el nivel educativo de sus padres, el contexto socio cultural es relativamente "ilustrado". Las evidencias que se han encontrado abren una serie de interrogantes, sobre todo en relación a la calidad de los políticos o, dicho de otra manera, cuál es la formación adecuada para un político. Debate que cobra mucho más sentido en América Latina donde siguen quedando fuertes rezagos de la ideología de la ilustración y el progreso que fue tan popular en América Latina a finales del siglo XIX y principios del XX, ${ }^{18}$ llegando al extremo de cuestionar a presidentes como Morales o Lula por carecer de formación universitaria o proponer, por parte de sectores trasnochados, que se exija como requisito para ser candidato el estar en posesión de un título universitario.

Una vez caracterizada la elite parlamentaria latinoamericana, buscaremos relaciones entre los rasgos socio económicos de las mismas y una serie de indicadores de desigualdad en América Latina. También se incluirá en el análisis un indicador que refleje la disparidad educativa de los países y así mantener cierta homogeneidad en la estructura de los datos que venimos comparando aunque, lamentablemente, no se dispone de dicha información para todos los países. Los indicadores de desigualdad social utilizados han sido cuatro: nivel de desigualdad en los ingresos (concentración de la riqueza en el $10 \%$ y $20 \%$ de la población), índice Gini de desigualdad social y el PIB per cápita de los países. En cuanto a educación, se han utilizado los datos de la UNESCO sobre el porcentaje de población que accede a la educación terciaria, si bien, dicha información no esta disponible para los casos de Ecuador y República Dominicana, por lo que ambos países quedarán fuera de nuestro análisis conjunto aunque se tendrá en cuenta su posición en base al resto de variables del análisis.

\footnotetext{
${ }^{18}$ Basta recordar el "gobierno de científicos" que pretendió Madero para México, o la proclama de "Civilización o Barbarie" que sirvió al argentino Rozas para ampliar la frontera, eufemismo usado para llamar a la aniquilación de la población nativa, o el "Orden y Progreso" que aun ilustra la bandera brasileña.
} 
La representación biplot (figura 3) pone de manifiesto una clara división entre los distintos países latinoamericanos en función de las características socio económicas de sus elites parlamentarias y los indicadores de desigualdad de los países. El eje dominante, eje 1, explica el 45\% de la varianza total y está definido claramente por las variables económicas y de desigualdad social siendo las más relevantes en el análisis, los índices que miden el nivel de desigualdad en los ingresos (Tabla 7).

El segundo, tercero y cuarto eje factorial están explicados por las variables relativas a educación, el nivel de estudios de los padres en el eje 2 (con un $21 \%$ de varianza explicada), el nivel de estudios de los diputados en el eje 3 ( $16 \%$ de varianza) y el acceso de la población a estudios terciarios en el eje 4 ( $10 \%$ de variabilidad explicada). Por tanto, el plano factorial formado por los cuatro primeros ejes, con una tasa de inercia del 91\% garantiza la fiabilidad de los datos. Se ha decidido retener estos cuatro ejes porque tanto el eje 3 como el 4 son importantes para interpretar la formación académica de la elite así como el acceso a educación terciaria de la población. ${ }^{19}$

Tabla 7: Contribuciones relativas del factor al elemento para los diputados e indicadores socio económicos

\begin{tabular}{|l|c|c|c|c|}
\hline \multicolumn{1}{|c|}{ Variables } & Eje 1 & Eje 2 & Eje 3 & Eje 4 \\
\hline Estudios del diputado & 0 & 386 & 501 & 19 \\
\hline Estudios de los padres & 86 & 749 & 6 & 0 \\
\hline Indicador ingresos del diputado & 597 & 0 & 211 & 80 \\
\hline $10 \%$ & 736 & 35 & 92 & 52 \\
\hline $20 \%$ & 777 & 71 & 127 & 0 \\
\hline Gini & 477 & 209 & 87 & 126 \\
\hline PIB per cápita & 616 & 97 & 166 & 52 \\
\hline Estudios terciarios & 292 & 158 & 51 & 457 \\
\hline
\end{tabular}

Fuente: Elaboración propia a partir de los resultados HJ-Biplot.

El primer plano factorial (figura 3) permite diferenciar a países con altos índices de desigualdad socio económica y con elites parlamentarias que perciben unos ingresos por encima del PIB per cápita del país, todos ellos situados en la parte derecha, de países como Argentina, Uruguay o Costa Rica que tienen menor desigualdad social, y por consiguiente con

${ }^{19}$ Por cuestión de espacio, no se incluirán en este trabajo los gráficos de la representación biplot correspondientes a los planos factoriales formados por los ejes 1-3 y 1-4. 
una elite política menos elitista en términos económicos (situados a la izquierda del gráfico).

También los gráficos biplot, permiten hablar de dos grandes grupos según el nivel educativo de los diputados y el de sus familiares más cercanos. Así, todos aquellos países situados en la parte inferior del gráfico se caracterizan por tener un alto "nivel de elitismo" educativo, algo que también se traduce en un mayor acceso de la población a estudios terciarios. Mientras que los situados en la parte superior se caracterizan por tener una elite parlamentaria con menor formación académica, que procede de un entorno familiar con un nivel de estudio relativamente bajo y, que además, presentan las peores tasas de acceso a educación terciaria, como por ejemplo Honduras, Salvador o Guatemala.

Figura 3: Representación gráfica de los países, nivel de elitismo de los diputados latinoamericanos e indicadores socio económicos y educativos a partir del análisis HJ-Biplot

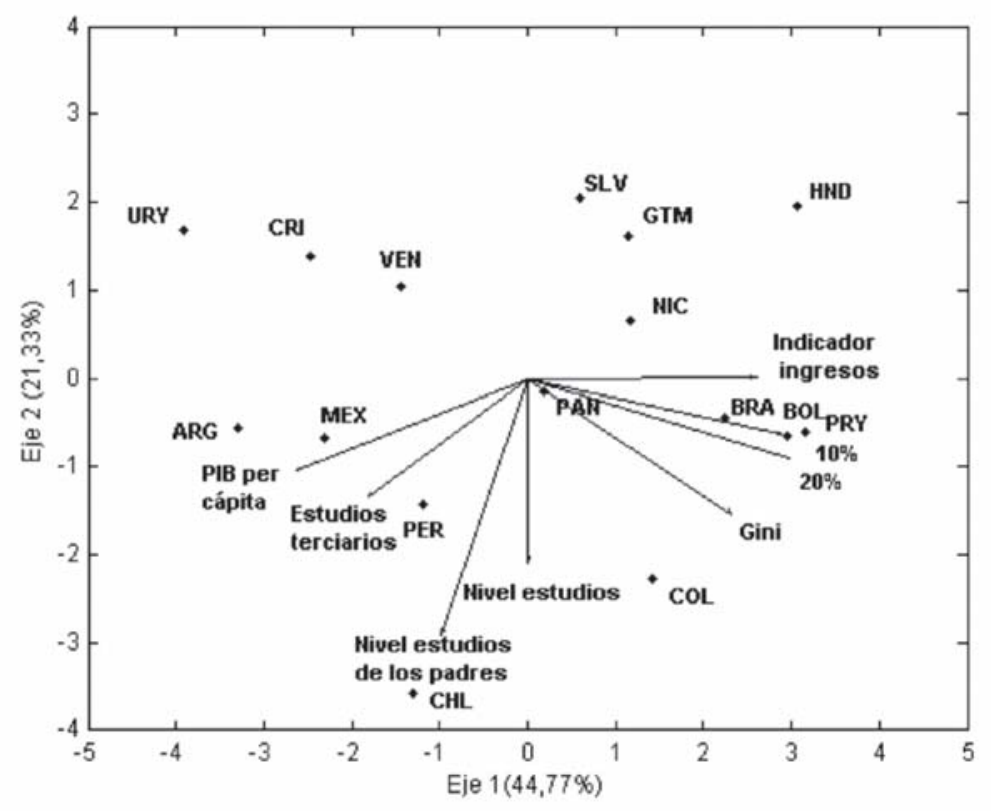

Fuente: Datos PELA (1998-2007) y World Bank (1998-2006). World Development Indicators database: http://www.worldbank.org/data/onlinedatabases/onlinedatabases.html; UNESCO (1999-2005), Datos del Informe de Desarrollo Humano (2003-2006) del PNUD. 
Las correlaciones entre las características de las elites parlamentarias y los indicadores de desigualdad socio económica y educación se presentan en la tabla 8. Las correlaciones más fuertes se dan entre las variables que miden el nivel de desigualdad en los ingresos. También parece existir una relación, aunque en este caso menos fuerte entre el nivel educativo de los padres de los diputados y las tasas de población con acceso a educación terciaria. De manera que a mayor acceso de la población a estudios universitarios mayor porcentaje de padres con educación superior.

Tabla 8: Correlaciones entre características de las elites e indicadores de desigualdad social y educación

\begin{tabular}{|c|c|c|c|c|c|c|c|}
\hline & 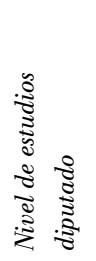 & 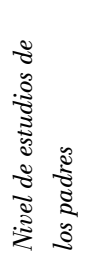 & 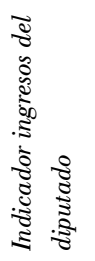 & $\stackrel{8}{9}$ & จิ & : & 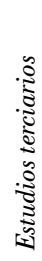 \\
\hline \multicolumn{8}{|l|}{$\begin{array}{l}\text { Nivel de estudios } \\
\text { diputado }\end{array}$} \\
\hline $\begin{array}{l}\text { Nivel de estudios } \\
\text { padres }\end{array}$ &, $539 *$ & & & & & & \\
\hline $\begin{array}{l}\text { Indicador ingresos } \\
\text { del diputado }\end{array}$ &, 245 &,- 166 & & & & & \\
\hline $10 \%$ &,- 173 & 019 &, 383 & & & & \\
\hline $20 \%$ &,- 187 & 011 &, 342 &, $946^{* *}$ & & & \\
\hline Gini &,- 074 & ,098 & ,169 &, $618 * *$ &, $807 * *$ & & \\
\hline Estudios terciarios & ,088 &, $482^{*}$ &,- 380 &, 025 &, 023 & ,043 & \\
\hline
\end{tabular}

* La correlación es significativa al nivel 0,05 (bilateral).

** La correlación es significativa al nivel 0,01 (bilateral).

Fuente: Datos PELA (1998-2007), World Bank: World Development Indicators database, http://www.worldbank.org/data/onlinedatabases/onlinedatabases.html, UNESCO (1999-2005), Datos del Informe de Desarrollo Humano (2003-2006) del PNUD. 
En la Tabla 9 se puede ver la composición de los distintos grupos a partir de las coordenadas de los países en los cuatro ejes factoriales retenidos en el análisis HJ-Biplot. El método cluster formó un primer grupo que podríamos definir de "clase media" integrado por Argentina, Costa Rica, México y Uruguay que se caracteriza por tener un PIB per cápita alto y un nivel de desigualdad en los ingresos relativamente bajo si se compara con el resto de países de América Latina. En estos países el $10 \%$ más rico recibe entre el 20 y el $35 \%$ del ingreso total. A esto hay que sumar el hecho de que los ingresos de sus elites parlamentarias están por debajo del PIB per cápita nacional. El nivel de estudios de los diputados que forman este grupo también contribuye a su formación ya que, a pesar de tener en su gran mayoría estudios universitarios, hay un grupo significativo de diputados con estudios universitarios medios, sobre todo en Uruguay y Argentina.

Bolivia, Brasil, Honduras y Paraguay han sido agrupados en función de sus datos de desigualdad económica siendo estos países los que presentan los mayores niveles de desigualdad de toda América Latina. Cabe resaltar que Brasil, que forma parte de este grupo, es a la vez el país latinoamericano con el PIB más grande, lo que podaría haber pesado mucho para su integración en otro grupo pero debido a los elevados niveles de desigualad del países comparte grupo con países con economías pequeñas. A la desigualad económica se suma el hecho de que son países con las tasas más bajas de acceso a educación terciaria, aquí sobresale nuevamente Brasil donde tan sólo un $13 \%$ de la población tiene acceso a la educación terciaria algo que, en parte, podría explicarse por el elevado número de habitantes. Parece ser, que los altos niveles de desigualdad se reflejan en la mala calidad del sistema educativo, hasta el punto de afectar a las propias elites, las que teóricamente tendrían más posibilidades de acceso a las instituciones educativas, algo que como se ha podido comprobar en este trabajo no se cumple en estos países.

Lo interesante del grupo formado por Colombia y Chile es que el factor que más peso tiene como criterio de agrupación es el nivel de estudios de los padres de la elite parlamentaria cuyo rasgo característico es su elevada formación académica, la más alta de toda la región. Pero también contribuye en su formación el hecho de que estos dos países cuenten con un nivel medio de desigualdad en los ingresos y un elevado índice gini de desigualdad social.

Panamá, Perú y Venezuela son países que comparten el alto porcentaje de personas con acceso a estudios terciarios, entre el 33 y $43 \%$ de 
la población, lo que, como era de esperarse, se refleja en que el nivel de estudios de los diputados y de sus familias, sea también relativamente alto, aunque por debajo del alcanzado por los pertenecientes al cluster 3 .

En el último grupo, formado por Guatemala, Nicaragua y El Salvador, tienen gran importancia las variables educativas ya que, el nivel de estudios de los diputados en estos países así como el de sus familiares es de los más bajos de la región. Esto puede encontrar su explicación en el hecho de que el acceso a la educación terciaria en estos países es muy bajo y las propias elites parlamentarias no escapan a esta situación.

Por último, y aunque Ecuador y República Dominicana han quedado fuera de nuestro análisis debido a la falta de información sobre el porcentaje de población con acceso a educación terciaria en el país, se ha tratado de ver, a partir de los distintos indicadores de desigualdad social utilizados así como de las características de sus elites parlamentarias, el cluster con el que mayor afinidad o proximidad podría tener. $Y$ en este caso, teniendo en cuanta únicamente los datos de desigualdad y las características socio económicas de sus diputados podríamos decir, que ambos países estarían muy próximos al cluster 4, formado por Panamá, Perú y Venezuela, caracterizados por el nivel de estudios relativamente alto de sus diputados, su elevado nivel de ingresos, sobre todo en Panamá y Ecuador y con unos indicadores medios de desigualdad social.

Tabla 9: Países que forman los clusters y características socio económicas

\begin{tabular}{|c|c|c|c|c|c|}
\hline \multirow{3}{*}{ Clusters } & \multirow{3}{*}{ Países } & \multirow{3}{*}{ Ejes } & \multicolumn{3}{|c|}{ Variables socioeconómicas } \\
\hline & & & \multicolumn{3}{|l|}{ Planos } \\
\hline & & & $1-2$ & $1-3$ & $1-4$ \\
\hline \multirow{4}{*}{1} & Argentina & 1,3 & $20 \%(848)$ & Indicador Ingresos & \\
\hline & Costa Rica & 1,2 & $10 \%(771)$ & (808) & \\
\hline & México & 1,2 & Gini (686) & PIB (782) & \\
\hline & Uruguay & 1,2 & & Estudios diputado (501) & \\
\hline \multirow{4}{*}{2} & Bolivia & 1,4 & $20 \%(848)$ & Indicador Ingresos & Estudios terciarios \\
\hline & Brasil & 1,4 & $10 \%(771)$ & (808) & (749) \\
\hline & Honduras & 1,2 & Gini (686) & PIB (782) & \\
\hline & Paraguay & 1,3 & & & \\
\hline \multirow{2}{*}{3} & Chile & 2,1 & Estudios padres & & \\
\hline & Colombia & 2,1 & (835) & & \\
\hline
\end{tabular}


FRANCISCO SÁNCHEZ | CRISTINA RIVAS

\begin{tabular}{|c|l|c|c|c|c|}
\hline 4 & Panamá & 4 & Estudios padres & Estudios diputado & Estudios terciarios \\
& Perú & 3,2 & $(749)$ & $(501)$ & $(457)$ \\
Venezuela & 3,1 & & & \\
\hline 5 & Guatemala & 2,1 & Estudios padres & Estudios diputado & \\
& Nicaragua & 3,1 & $(835)$ & $(501)$ & \\
Salvador & 2 & & & \\
\hline
\end{tabular}

Fuente: Elaboración propia con resultados del HJ-Biplot y análisis de conglomerados.

En la tabla 10 se presentan las medias de los clusters en las variables utilizadas para la clasificación de los países. Los cinco clusters obtenidos presentan diferencias significativas entre ellos en cinco de las ocho variables incluidas en el análisis: el indicador de ingresos del diputado, los dos indicadores del nivel de desigualdad de los ingresos (10\% y $20 \%)$, el índice de desigualdad social Gini y el PIB per cápita del país, en el resto de variables estas diferencias no son relevantes.

Tabla 10: Medias de los clusters en las variables de desigualdad social y características socioeconómicas de los diputados latinoamericanos (16 países)

\begin{tabular}{|c|c|c|c|c|c|c|c|c|}
\cline { 2 - 9 } \multicolumn{1}{c|}{} & \multicolumn{4}{c|}{ Grado de elitismo } & \multicolumn{4}{c|}{ Nivel de desigualdad social } \\
\hline Clusters & $\begin{array}{c}\text { Nivel de } \\
\text { estudios } \\
\text { diputado }\end{array}$ & $\begin{array}{c}\text { Nivel de } \\
\text { estudios de } \\
\text { los padres }\end{array}$ & $\begin{array}{c}\text { Indicador } \\
\text { ingresos del } \\
\text { diputado* }\end{array}$ & $10 \% *$ & $20 \% *$ & Gini* & $\begin{array}{c}\text { PIB per } \\
\text { cápita* }\end{array}$ & $\begin{array}{c}\text { población } \\
\text { con acceso } \\
\text { a estudios } \\
\text { terciarios }\end{array}$ \\
\hline - Cluster 1 & 4,09 & 2,84 & $-2,08$ & 27,30 & 14,01 & 49,06 & 9679,25 & 33,18 \\
\hline - Cluster 2 & 4,08 & 2,74 & $-0,20$ & 75,85 & 26,89 & 56,48 & 4326,75 & 20,75 \\
\hline - Cluster 3 & 4,44 & 3,12 & $-0,50$ & 47,58 & 20,90 & 57,58 & 8002,50 & 33,65 \\
\hline - Cluster 4 & 4,29 & 2,85 & $-0,10$ & 35,28 & 16,20 & 49,88 & 5727,33 & 37,90 \\
\hline - Cluster 5 & 4,16 & 2,63 & $-0,27$ & 42,43 & 18,50 & 52,92 & 3980,67 & 15,67 \\
\hline
\end{tabular}

*Las medias obtenidas para cada uno de los grupos en las variables de análisis presentan diferencias significativas al 95\% de confianza.

Fuente: Elaboración propia con los resultados del análisis de conglomerados. 
Una vez que se han señalado las distintas dinámicas de relación entre las variables, queremos subrayar una serie de elementos que pueden servir de pauta para continuar con la exploración de los datos y posteriores análisis. En primer lugar, y con los matices oportunamente indicados, queremos señalar que existe una relación muy débil entre el nivel de ingresos de los diputados y el nivel de estudios alcanzado, resultando más significativa la relación entre los ingresos del diputado y el nivel de estudios de los padres, lo que hace presuponer que hay factores de bienestar heredado.

Por otro lado, al analizar la variable niveles educativos, cabe indicar que parece haber un factor estructural que influye, más allá de la situación socio económica del diputado y su familia de origen, siendo el caso extremo Honduras, pero ese factor estructural se nota también en países donde mejoraron los servicios educativos, como Venezuela, que ha invertido e invierte parte de su riqueza petrolera en educación o el caso de República Dominicana y Nicaragua donde los regímenes instalados, una vez superados sus regímenes sultanísticos, prestaron mayor atención a la educación que los precedentes.

Los ingresos siguen teniendo un peso importante aunque no es la variable determinante como medio de acceso a la elite política. Buscar que "otras" características comparten los grupos de países que se formaron de acuerdo a la variable ingresos, puede dar alguna pista para posteriores análisis, así por ejemplo, resulta claro el mayor impacto de los ingresos de los diputados en los países más pequeños.

Por último, no se pude afirmar que haya una relación directa entre los mayores niveles de desigualdad de los países y la existencia de una elite política con mejores ingresos y elevados niveles de estudios, a la vez que provenientes de familias de buena posición social. Si bien hay países donde eso sucede, la heterogeneidad de casos obliga a que se mire cada país por separado haciendo difícil la comparación global para toda la región. 


\section{Elites políticas y características de la democracia}

La forma en la que se concretan los principios, valores y normas de la democracia varían de acuerdo a las características de los distintos sistemas políticos. Estas diferencias se dejan ver no solo en las formas institucionales que va tomando, sino que también, en distintos aspectos cualitativos. Pese a que la democracia es la forma de gobierno extendida en la práctica totalidad de América Latina se pueden encontrar diferencias importantes entre los distintos países cuando se aplican indicadores que tratan de medir y analizar lo que se ha dado en llamar "calidad de la democracia".

A pesar de que se trata de un concepto abstracto que ha propiciado un gran debate en torno a la operacionalización del concepto (Díaz y Mateos, 2006:11), hay modelos como el de Diamond y Morlino (2004:22) que plantean que la calidad de la democracia puede evaluarse desde dos perspectivas: una desde el punto de vista de los ciudadanos y otra más objetiva, a partir del rendimiento institucional, evaluándose el cumplimiento de una serie de dimensiones tales como imperio de la ley, participación, competición y accountability, todas ellas de carácter procedimental, la libertad y la igualdad política, de carácter sustantivo y la dimensión responsiveness que enlazaría las dimensiones procedimentales con las sustantivas.

A pesar de que el planteamiento anterior no pone de relieve el papel de los actores políticos, su estudio es fundamental para valorar la calidad de la democracia ya que son ellos los que accionan la maquinaria institucional del sistema político. No hay que olvidar que las instituciones tienen un papel relativamente autónomo dentro del proceso político pero no de supremacía ni de subordinación. Estas instituciones determinan los costes de transacción o impactan en la forma en la que actúan las personas u organizaciones, ya que éstas toman en cuenta las oportunidades e incentivos que las instituciones les brindan para desarrollar sus estrategias de adaptación o resistencia, con las que buscarán maximizar sus beneficios y reducir sus pérdidas llegando, incluso, a la modificación de las mismas.

Partiendo de las inquietudes señaladas en el párrafo anterior, en esta parte del trabajo exploraremos los datos buscando relaciones entre las características socio económicas de las elites parlamentarias de los países latinoamericanos y el desempeño de la democracia de cada uno de los países. Nos preguntamos si el "nivel de elitismo" de los diputados de un país repercute en el rendimiento de la democracia del mismo.

En lo que tiene que ver con las características de los diputados seguiremos utilizando los mismos datos con los que hemos venido trabajan- 
do hasta ahora, mientras que, para evaluar la democracia en los países latinoamericanos hemos utilizado siete indicadores distintos, tanto en metodología como en unidad de análisis, que tratan de medir distintos aspectos de la misma. La aplicación de distintos indicadores que tratan de medir democracia y buen gobierno nos permite montar una especie de "sistema de contraste" para ver si los resultados obtenidos son coherentes y se mantienen, independientemente de las variables que se utilicen para valorar la democracia y buen gobierno. ${ }^{20}$

Se han utilizado cuatro indicadores que valoran elementos constitutivos de la democracia: el índice de Freedom House, FH, (valor medio de los índices de derechos políticos y de libertades civiles) estandarizado a una escala de 100 puntos, donde valores próximos a 100 indican países "libres" y valores próximos a 1 países "no libres". El Índice de Desarrollo Democrático de Polilat (IDD) medido en una escala de 1 a 10, donde el 1 significa menor desarrollo democrático y el 10 mayor desarrollo democrático, el Î́ndice de participación democrática de Vanhanen (Van) medido a partir del grado de competición y participación electoral, estandarizado a una escala de 100 puntos, donde valores próximos a 100 indican una mayor participación democrática mientras que valores cercanos a 1 indican una mínima participación democrática y, por último, el Índice de Transformación de Bertelsmann (BTI) medido en una escala de 1 a 5 , donde 1 significa bajos niveles de democracia y el 5 altos niveles de democracia. El BTI cuenta con dos dimensiones, una política y otra económica; pero en este trabajo tan sólo se ha considerado la dimensión política para evitar efectos de colinealidad con los indicadores económicos que se usa en el trabajo.

A los cuatro anteriores hay que sumar otros tres que buscan valorar aspectos más específicos, estos forman parte de los indicadores de "buen gobierno" de Kaufmann y Kray y son: estabilidad política (stable), participación ciudadana en la selección de gobiernos (voice and accountability) y efectividad del gobierno (effectiveness). Los tres están medidos en una escala que varía entre $-2,5$ y $+2,5$, donde valores próximos a $-2,5$ indican "mal gobierno", escasa participación ciudadana y la incapacidad de un

${ }^{20}$ A pesar del debate existente entorno a la utilización de distintos índices para medir y caracterizar la democracia, los siete indicadores empleados en este trabajo ofrecen resultados similares, lo que aumenta la fiabilidad de nuestros resultados y refuerza su inclusión en este análisis (Norris, 2006). Sobre las ventajas y desventajas en el empleo de los principales índices de democracia se puede consultar Landman, Todd (2003). 
gobierno para formular e implementar políticas públicas mientras que, valores próximos a $+2,5$, indicarían todo lo contrario.

Para conocer si las características socio económicas de los diputados influyen en el rendimiento de la democracia del país, se ha recurrido nuevamente a una representación HJ-Biplot (figura 4). Los tres primeros ejes de la representación biplot absorben un $86 \%$ de la variabilidad total, lo que nos lleva a centrar la interpretación en la información relacionada con estos tres primeros factores y dejar de lado a los otros siete restantes que aportan información residual.

La primera dimensión extraída (representada en el eje horizontal, eje 1) explica el $63 \%$ de la varianza de la matriz de datos y está definida, básicamente, por los indicadores de democracia y buen gobierno. El segundo eje de análisis aporta una menor información, absorbe el $17 \%$ de la variabilidad total. Las variables con mayor calidad de representación en esta dimensión son las relacionadas con el nivel educativo, tanto de los diputados como de sus padres. El tercer eje factorial, tan sólo explica el $7 \%$ de la información, y es el indicador de ingresos, el que mayor calidad de representación tiene en este eje.

El posicionamiento de las diez variables en el primer plano factorial (ejes 1-2 de la figura 4) permite diferenciar, por ejemplo, a países como Chile, Costa Rica y Uruguay, situados en la parte izquierda del gráfico, con los mejores indicadores de democracia en América Latina y con una elite parlamentaria cuyos ingresos están por debajo de la media del PIB per cápita nacional, de países como Venezuela, Guatemala, Ecuador, Paraguay, Nicaragua, Perú y Colombia con los peores indicadores de democracia de toda América Latina y diputados con ingresos similares o superiores al PIB per cápita del país, situados en la parte derecha del gráfico.

Por otra parte, el eje 2 divide a los países según el nivel educativo de sus elites parlamentarias y de su entorno familiar. Países como Colombia, Perú y Chile, con las elites académicamente más formadas de la región se sitúan en la parte superior del gráfico mientras que los países con diputados que tienen un menor nivel de estudios y proceden de un entorno familiar con escasa formación académica se sitúan en la parte inferior, un ejemplo claro de ello es el de Honduras, El Salvador o República Dominicana, este último se ve arrastrado a esta posición no tanto por el nivel educativo de sus elites si no por el de sus padres, el más bajo de toda América Latina. 
Figura 4: Representación gráfica de los países, características socio económicas de los diputados e indicadores sobre democracia a partir del análisis HJ-Biplot

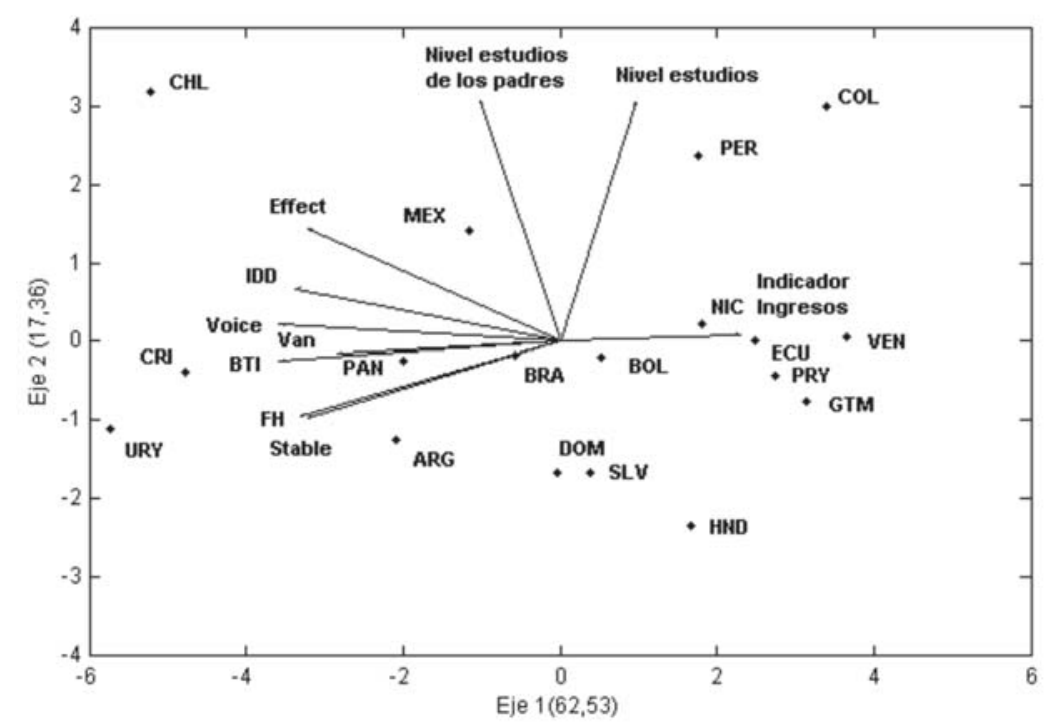

Fuente: Datos PELA (1998-2007), World Bank: World Development Indicators database, http://www. worldbank.org/data/onlinedatabases/onlinedatabases.html, Konrad Adenauer y Polilat. http://www.iddlat.org/, Norris, Pippa: http://ksghome.harvard.edu/ pnorris/Data/Data.htm y http://www.bertelsmanntransformation-index.de/16.0.html?\&L=1.

En la tabla 11 se muestran los valores de las correlaciones entre las variables utilizadas en esta parte del estudio. Como era de esperarse, las correlaciones entre distintos indicadores relativos a la democracia son muy altas, lo avala la coherencia de los estudios sobre la calidad de la democracia y constata de forma contundente las diferencias existentes entre los países de la región. Las relaciones más fuertes se dan, por un lado, entre el Índice de Transformación de Bertelsmann (BTI) y el Índice de participación ciudadana (voice) y el de estabilidad política (stable) y, por otro, entre el Índice de desarrollo democrático (IDD), el Índice de participación ciudadana (voice) y el Índice de gobierno efectivo (effect).

También existe correlación, aunque menor, en el caso de los ingresos y los indicadores sobre el rendimiento de la democracia, si bien esa correlación es negativa. Es decir, que a mayores ingresos de los diputados de un país, y por tanto mayor "nivel de elitismo" económico, la democracia muestra peores indicadores. Esta correlación aporta evidencia para sos- 
tener uno de los aportes iniciales del trabajo, en el sentido de que cuanto mayor sea la distancia económica entre elites y población, el acceso a los mecanismos formales e informales del poder puede resultar más restrictivo y, por tanto, repercutir en las características de la democracia. En cambio, el nivel de estudios del diputado y el de sus padres presenta correlaciones muy bajas con el resto de variables del análisis, sus vectores son casi perpendiculares lo que hace pensar que la mayor o menor formación académica de las elites no repercute de forma relevante para tener una "mejor democracia" (figura 4).

Tabla 11: Correlaciones entre variables socio económicas e indicadores de democracia y buen gobierno

\begin{tabular}{|c|c|c|c|c|c|c|c|c|c|c|}
\hline & 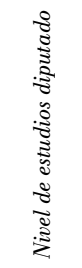 & 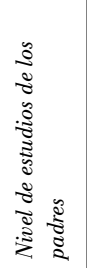 & 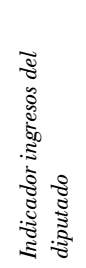 & 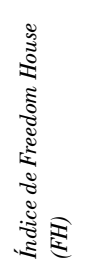 & 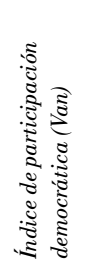 & 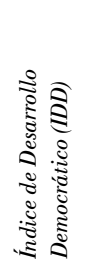 & 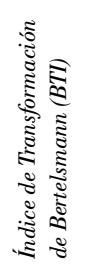 & 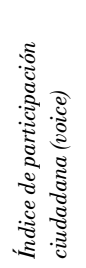 & 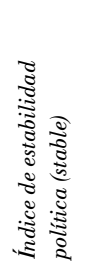 & 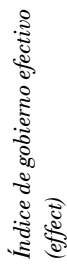 \\
\hline \multicolumn{11}{|l|}{ Nivel de estudios diputado } \\
\hline Nivel de estudios de los padres &, 434 & & & & & & & & & \\
\hline Indicador ingresos del diputado &, 240 &,- 199 & & & & & & & & \\
\hline Índice de Freedom House (FH) & $-4,34$ &, 070 &,$- 493^{*}$ & & & & & & & \\
\hline $\begin{array}{l}\text { Índice de participación } \\
\text { democrática (Van) }\end{array}$ &,- 160 & , 130 &,- 412 &, $720 * *$ & & & & & & \\
\hline $\begin{array}{l}\text { Índice de Desarrollo } \\
\text { Democrático (IDD) }\end{array}$ &,- 096 &, 362 &,$- 485^{*}$ &, $718 * *$ &, $605 * *$ & & & & & \\
\hline $\begin{array}{l}\text { Índice de Transformación de } \\
\text { Bertelsmann (BTI) }\end{array}$ &,- 291 & ,195 &,$- 584^{*}$ &, $856^{* *}$ &, $710 * *$ &, $893 * *$ & & & & \\
\hline $\begin{array}{l}\text { Índice de participación } \\
\text { ciudadana (voice) }\end{array}$ &,- 154 &, 272 &,$- 538^{*}$ &, $830^{* *}$ &, $742 * *$ &, $914 * *$ &, $977 * *$ & & & \\
\hline $\begin{array}{l}\text { Índice de estabilidad política } \\
\text { (stable) }\end{array}$ & $-4,11$ &, 008 &,$- 473^{*}$ &, $837 * *$ &, $627 * *$ &, $819 * *$ &, $925^{* *}$ &, $900 * *$ & & \\
\hline $\begin{array}{l}\text { Índice de gobierno efectivo } \\
\text { (effect) }\end{array}$ &, 059 &, $548 *$ &,$- 527 *$ &, $628 * *$ &, $632 * *$ &, $918 * *$ &, $817 * *$ &, $863^{* *}$ &, $673 * *$ & \\
\hline
\end{tabular}

Fuente: Datos PELA (1998-2007), World Bank: World Development Indicators database, http://www. worldbank.org/data/onlinedatabases/onlinedatabases.html, Konrad Adenauer y Polilat. http://www.iddlat.org/, Norris, Pippa: http://ksghome.harvard.edu/ pnorris/Data/Data.htm y http://www.bertelsmanntransformation-index.de/16.0.html?\&L=1. 
Un análisis detallado de las contribuciones recogidas en la Tabla 12 pone de manifiesto que las diez variables incluidas en el análisis contribuyen de manera significativa a la construcción de una tipología de países según las características socio económicas de las elites parlamentarias y su relación con el grado de democracia de sus respectivos países, siendo el Indicador de Transformación de Bertelsmann (BTI), el Indice de participación ciudadana (voice and accountability), el Índice de Desarrollo Democrático (IDD) y el Índice de estabilidad democrática (stable), las variables que más contribuyen a la formación de los distintos grupos de países, con Contribuciones Relativas del Factor al Elemento comprendidas entre 954 y 819 . Es decir, son las variables con mayor variabilidad en el análisis y que más discriminan a los distintos grupos de países.

Tabla 12: Contribuciones Relativas del Factor al Elemento para el características socio económicas de los diputados e indicadores de democracia

\begin{tabular}{|l|c|c|c|}
\hline Variables & Eje 1 & Eje 2 & Eje 3 \\
\hline Estudios del diputado & 69 & 697 & 53 \\
\hline Estudios de los padres & 76 & 702 & 40 \\
\hline Indicador ingresos del diputado & 395 & 1 & 526 \\
\hline Índice Freedom House (FH) & 772 & 70 & 39 \\
\hline Índice de participación democrática (Van) & 599 & 2 & 14 \\
\hline Índice de participación ciudadana (Voice) & 952 & 3 & 17 \\
\hline Índice de estabilidad democrática (Stable) & 819 & 68 & 0 \\
\hline Índice de Gobierno efectivo (Effect) & 768 & 156 & 9 \\
\hline Índice de desarrollo democrático (IDD) & 849 & 34 & 5 \\
\hline Índice de transformación de Bertelsmann (BTI) & 954 & 5 & 5 \\
\hline
\end{tabular}

Fuente: Elaboración propia a partir de los resultados HJ-Biplot.

Para complementar los resultados arrojados por el HJ-Biplot, se ha realizado un análisis de conglomerados jerárquico tomando como varia- 
bles las coordenadas de los países en los tres ejes factoriales retenidos. ${ }^{21}$ La clasificación de los países de acuerdo a este método se presenta en la figura 4, en la que se observan cinco grupos bien diferenciados. El primero formado por Argentina y México, el segundo por Bolivia, Brasil, Honduras, Panamá, República Dominicana y El Salvador, el tercero por Chile, Costa Rica y Uruguay, el cuarto por Colombia y Perú y el último, por Ecuador, Guatemala, Nicaragua, Paraguay y Venezuela. ${ }^{22}$

Figura 5: Dendograma de agrupación de los países según variables socio económicas e indicadores de democracia y buen gobierno

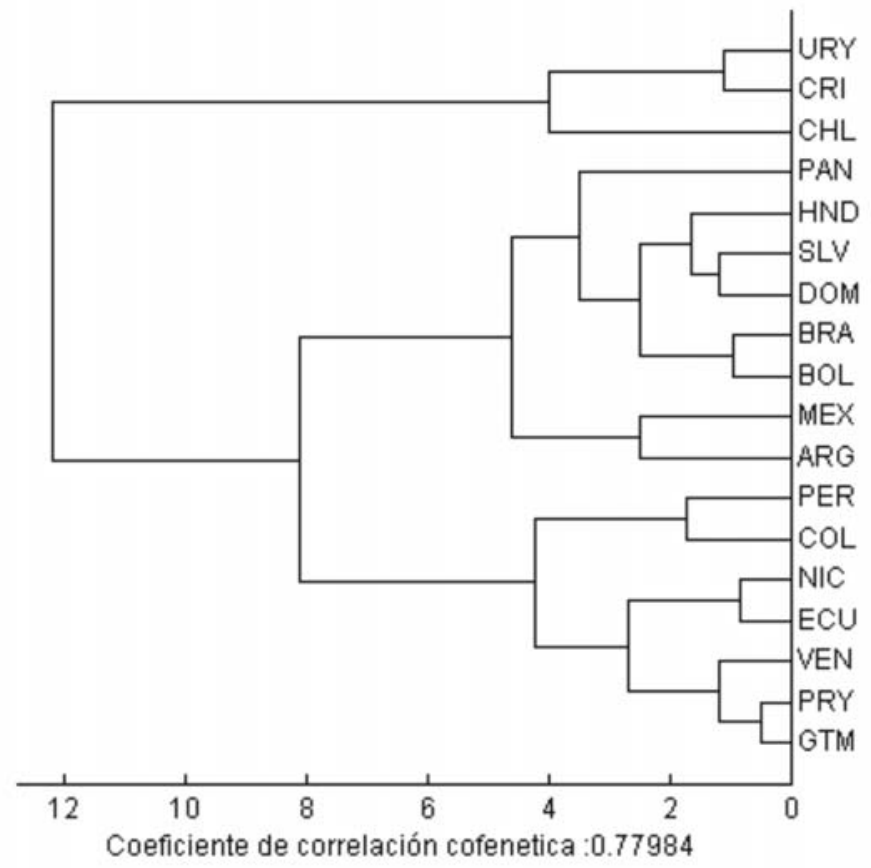

Fuente: elaboración propia a partir de las Coordenadas del HJ-Biplot

${ }^{21}$ El método utilizado para la agrupación de países es el método ward o de pérdida de inercia mínima (Vicente, Ramírez y Galindo, 1994:829).

${ }^{22}$ El Coeficiente de correlación cofenética obtenido en el análisis es de 0,78 , por lo que se puede considerar aceptable la clasificación obtenida del análisis de conglomerados jerárquico. 
El análisis de las Contribuciones Relativas del Factor al Elemento de las variables que mayor incidencia tienen en la formación de los clusters (Tabla 13) nos ha servido para formar los distintos grupos de países. El cluster formado por Argentina y México se constituye, sobretodo, por el nivel de ingresos de sus diputados que está muy por debajo del PIB per cápita de sus respectivos países. Además, este grupo se caracteriza por tener unos niveles democráticos aceptables en esta última década, aunque sus indicadores de buen gobierno son relativamente malos, especialmente, en lo que a estabilidad política se refiere.

El cluster compuesto por Bolivia, Brasil, Honduras, Panamá, República Dominicana y El Salvador se caracteriza por el nivel de estudios alcanzado por sus diputados así como por el de sus familiares más directos. A pesar de que, como ya se ha señalado con anterioridad en este trabajo, la gran mayoría de los diputados latinoamericanos de la última década cuenta con estudios universitarios, en estos países existe un mayor número de legisladores con estudios universitarios incompletos, especialmente en Honduras y El Salvador. También se trata de un grupo donde la movilidad educativa es relativamente alta, sobre todo en República Dominicana, Brasil y El Salvador. Otra de las variables importantes, y también determinante en la formación de este cluster, es el nivel de ingresos que tienen los diputados de estos países. Se puede decir que se trata del grupo más elitista en términos económicos en la medida en que sus ingresos son iguales o están por encima del PIB per cápita nacional en la mitad de los países que lo integran. Los casos más claros de elitismo los encontramos en Panamá y Honduras. Una excepción a esto se encuentra en Brasil y El Salvador, donde sus parlamentarios tienen unos ingresos ligeramente por debajo del PIB del país. Estas tres variables tienen un peso relativamente alto en la configuración de este grupo lo que hace que Panamá, con unos indicadores de democracia altos, se encuentre ubicada en este grupo. 
FRANCISCO SÁNCHEZ | CRISTINA RIVAS

Tabla 13: Países que forman los clusters según características socioeconómicas y de la democracia

\begin{tabular}{|c|c|c|c|c|}
\hline \multirow{3}{*}{ Clusters } & \multirow{3}{*}{ Países } & \multirow{3}{*}{ Ejes } & \multicolumn{2}{|l|}{ Variables socioeconómicas } \\
\hline & & & \multicolumn{2}{|l|}{ Planos } \\
\hline & & & $1-2$ & $1-3$ \\
\hline 1 & $\begin{array}{l}\text { Argentina } \\
\text { México }\end{array}$ & 1,3 & $\begin{array}{l}\text { BTI (954) } \\
\text { Voice (952) } \\
\text { Effect (924) } \\
\text { IDD (849) } \\
\text { Stable (819) } \\
\text { FH (772) }\end{array}$ & Indicador ingresos (925) \\
\hline 2 & $\begin{array}{l}\text { Bolivia } \\
\text { Brasil } \\
\text { Honduras } \\
\text { Panamá } \\
\text { R. } \\
\text { Dominicana } \\
\text { Salvador }\end{array}$ & $\begin{array}{c}3 \\
3 \\
2,1 \\
3,1 \\
2,3 \\
2\end{array}$ & $\begin{array}{l}\text { Estudios diputado (697) Estudios } \\
\text { padres (702) }\end{array}$ & Indicador ingresos (925) \\
\hline 3 & $\begin{array}{l}\text { Chile } \\
\text { Costa Rica } \\
\text { Uruguay }\end{array}$ & $\begin{array}{c}1,2 \\
1 \\
1\end{array}$ & $\begin{array}{l}\text { BTI (954) } \\
\text { Voice (952) } \\
\text { Effect (924) } \\
\text { IDD (849) } \\
\text { Stable (819) } \\
\text { FH (772) } \\
\text { Estudios diputado (697) } \\
\text { Estudios padres (702) }\end{array}$ & \\
\hline 4 & $\begin{array}{l}\text { Colombia } \\
\text { Perú }\end{array}$ & $\begin{array}{l}2,1 \\
2,1\end{array}$ & $\begin{array}{l}\text { Estudios diputado (770) } \\
\text { Estudios padres (778) }\end{array}$ & \\
\hline 5 & $\begin{array}{l}\text { Ecuador } \\
\text { Guatemala } \\
\text { Nicaragua } \\
\text { Paraguay } \\
\text { Venezuela }\end{array}$ & $\begin{array}{c}1 \\
1 \\
1,3 \\
1,3 \\
1\end{array}$ & $\begin{array}{l}\text { BTI (954) } \\
\text { Voice (952) } \\
\text { IDD (849) } \\
\text { Stable (819) } \\
\text { FH (772) } \\
\text { Effect (768) }\end{array}$ & Indicador ingresos (925) \\
\hline
\end{tabular}

Fuente: Elaboración propia con resultados del HJ-Biplot y análisis de conglomerados. 
Es interesante señalar que en el tercer cluster, el constituido por Chile, Costa Rica y Uruguay, las variables socio económicas pasan a un segundo plano y se determina de manera casi exclusiva por los indicadores de democracia. Los tres países que forman este grupo se caracterizan por tener, con diferencia, los mejores indicadores de democracia y buen gobierno de toda América Latina. El nivel de estudios tanto del diputado como de su familia es lo que distancia dentro de este grupo a Chile de Costa Rica y Uruguay. No debemos olvidar que los parlamentarios chilenos son unos de los que tienen mayor formación universitaria de la región, al igual que sus padres.

Aunque resulte un poco contradictorio, el cuarto grupo es el formado por Colombia y Perú. Lo que determina claramente su formación es el alto nivel educativo de sus diputados, con un elevado porcentaje de ellos con estudios de postgrado. También proceden de familias en las que la formación académica de los padres es relativamente alta respecto al resto de países de América Latina. Los malos indicadores sobre calidad de democracia y buen gobierno registrados por estos dos países es lo que los separa de Chile, muy próximo a ellos en materia educativa.

Los datos anteriores plantean la pregunta de cuál es el rol de calidad educativa de las elites en el rendimiento del sistema político, la respuesta posiblemente esté en los contenidos de la educación recibida o en aspectos mucho más subjetivos relacionados con la cultura política.

El último cluster está formado por Ecuador, Guatemala, Nicaragua, Paraguay y Venezuela. Este grupo se ha formado a partir de los malos indicadores sobre democracia y buen gobierno que les asemeja. Y se parece al formado por Perú y Colombia cuyas democracias también cuentan con malos indicadores de calidad y buen gobierno a lo largo del período de estudio. Otro rasgo importante de los países agrupados en este cluster es que sus diputados cuentan con unos ingresos relativamente altos respecto a los que obtienen los parlamentarios del resto de países latinoamericanos, estando muy próximos en materia económica a los países pertenecientes al cluster 2, como Honduras y Panamá, donde el criterio primordial para agrupar los países fue su alto nivel de ingresos.

Las medias obtenidas para cada uno de los clusters en las diez variables de análisis se recogen en la Tabla 14. De todas ellas, ocho presentan diferencias de medias significativas al 95\% de confianza, lo que nos permite concluir que los clusters obtenidos difieren entre ellos en las variables de calidad de democracia y "nivel de elitismo" económico. En cambio, no es posible hablar de diferencias relevantes en el caso del nivel de estudios de los diputados y en el de sus padres. 
Tabla 14: Medias de los clusters en las variables socioeconómicas y democracia

\begin{tabular}{|c|c|c|c|c|c|c|c|c|c|c|}
\hline \multirow[b]{2}{*}{ Cluster } & \multicolumn{3}{|c|}{ Grado de elitismo } & \multicolumn{7}{|c|}{ Indicadores de democracia } \\
\hline & 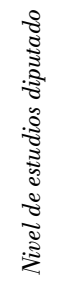 & 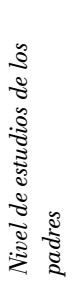 & 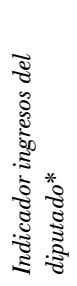 & 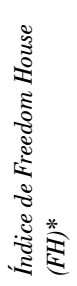 & 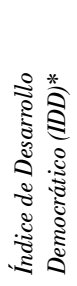 & 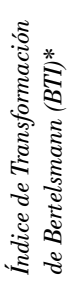 & 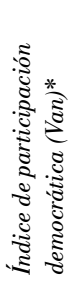 & 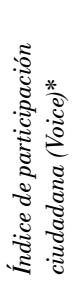 & 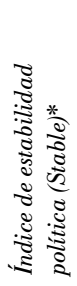 & 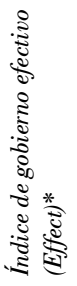 \\
\hline - Cluster 1 & 4,11 & 2,93 & $-2,15$ & 85,68 & 5,33 & 3,71 & 43,58 & 0,19 & $-0,23$ & 0,03 \\
\hline - Cluster 2 & 4,10 & 2,65 & $-0,10$ & 80,92 & 4,71 & 3,64 & 36,50 & 0,11 & $-0,17$ & $-0,30$ \\
\hline - Cluster 3 & 4,16 & 2,94 & $-1,67$ & 92,82 & 9,15 & 4,86 & 47,71 & 0,98 & 0,75 & 0,70 \\
\hline - Cluster 4 & 4,48 & 3,04 & $-0,25$ & 64,26 & 3,82 & 3,04 & 23,07 & $-0,23$ & $-1,39$ & $-0,25$ \\
\hline - Cluster 5 & 4,22 & 2,71 & $-0,14$ & 65,69 & 2,99 & 3,04 & 22,82 & $-0,26$ & $-0,75$ & $-0,78$ \\
\hline
\end{tabular}

Fuente: Elaboración propia con los resultados del análisis de conglomerados.

* Las medias obtenidas para cada uno de los grupos en las variables de análisis presentan diferencias significativas al 95\% de confianza.

Recapitulando los resultados de esta sección, se puede concluir que existe un fuerte vínculo entre el "elitismo" económico de las elites parlamentarias y los poco satisfactorios indicadores de la democracia y buen gobierno de los países latinoamericanos. Mientras que el "elitismo" académico, es decir, altos niveles educacionales de sus diputados, no se traducen necesariamente en mejores indicadores de democracia, esto es evidente en los casos de Colombia y Perú, aunque también hay países como Chile que servirían para argumentar lo contrario, pero en este caso nos interesa señalar que no se cumple la expectativa. No existen casos de países con malos niveles de educación y altos niveles de democracia.

Los ejemplos más claros de que la mayor desigualdad económica entre elites parlamentarias y población se traduce en malos gobiernos y democracias débiles son Venezuela, Ecuador, Paraguay, Nicaragua y Guatemala. De manera contrafáctica, cabe señalar que en los países en que las desigualdades económicas entre elites y población son menores como Chile, Costa Rica y Uruguay los datos que presentan sus democracias a lo largo del período de estudio son mejores. 


\section{A manera de conclusiones}

El análisis precedente ha mostrado las distintas dinámicas de relación entre las variables estudiadas, la exploración realizada muestra, sobre todo, la heterogeneidad entre los casos y una serie de claras tendencias de vínculo. El trabajo partió del presupuesto de que en los casos en los que hay mayor desigualdad y los políticos son más "elite" (es decir, sus ingresos y educación propia y de sus padres está más distante de la que tiene la mayoría de la población) la "calidad de la democracia" será menor debido a que su clase política es menos "representativa" y porque su asenso, gobierno y permanencia reflejan por si mismas una mayor fortaleza de la estructura de desigualdades, a la par que muestran deficiencias en los mecanismos de inclusión y liberalización del régimen político. Presupuesto que se confirma en términos generales, sobre todo, en los casos ubicados en los extremos, con la salvedad, de que los países con mayor desigualdad no son necesariamente los que tienen diputados con mayor nivel de estudios, auque sí lo son respecto a la población que en esos países tiene acceso a estudios terciarios.

Es más clara la relación entre un mayor nivel de "elitismo" económico de la clase política con las características de la democracia que la que existe entre los niveles de desigualdad económica y las características socio económicas de los diputados, algo que debe ser contrastado de manera individual en cada país, ya que es difícil la comparación global para toda la región debido al tamaño de las economías y población del país.

Existen significativas diferencias entre países a la hora de medir los niveles de ingresos de los diputados pero siempre dentro de un rango que va entre ingresos medios e ingresos altos. También es notable el elevado nivel de estudios de los diputados latinoamericanos que además, provienen de hogares con un buen contexto socio cultural, si se toma en cuenta el nivel educativo de sus padres.

El estudio abre una serie de interrogantes sobre la relación entre la calidad de los políticos y la calidad de la democracia. A pesar de la dificultad de establecer cuáles son los criterios para decir que un político es de calidad, no cabe duda de que el nivel de estudios del político puede servir como indicador, el mismo que como ya hemos visto, no tiene correlación con los mejores o perores indicadores de la democracia de los países. También resulta interesante señalar que en varios países, el nivel de estudios tampoco ayuda a mejorar el nivel de ingresos de las personas o sirve como un mecanismo efectivo de movilidad social. 
Por último, señalar algunos temas en los que podría ahondarse a partir de lo visto en este trabajo por investigaciones futuras. Así por ejemplo, parece ser que la trayectoria de las instituciones políticas de los países parece ser determinante para comprender las características de la elite política. Los países con una trayectoria de democrática más larga muestran una configuración de elites distintas a los países con experiencias democráticas más erráticas. En este sentido, cabría prestar mayor atención al papel de los partidos políticos y de los otros mecanismos de acceso al sistema político ya que son los medios por excelencia para generar oportunidades y equilibrar las posibilidades de los sectores económicamente dispares.

\section{Bibliografía}

ABERBACH, J.; PUTNAM, R.; y ROCKMAN, B. Bureaucrats and Politicians in Western Democracies. Cambridge: Harvard University Press, 1981.

ALBERTONI, E. "Teoría de las elites y elitismo (Apuntes para el análisis histórico y actual). Sistema: Revista de Ciencias Sociales, nº 83, 1988, pp. 43-56.

ALCÁNTARA, M. "La democracia en América Latina: calidad y rendimiento", Sistema, 203-204, Madrid, 2008, pp. 125-147.

ALCÁNTARA, M. Politicians and Politics in Latin America. Boulder: Lynne Rienner, 2007.

ALMOND, G. y VERBA, S. The Civic Culture. Princeton: Princeton University Press, 1963.

ANDERSEN, L. "Social mobility in Latin American: Links with adolescent schooling". Working Paper, R-433, Washington D.C.: Banco Interamericano de Desarrollo, 2001, pp.1-45.

BEHRMAN, J., GAVIRIA, A. y SZÉKELY, M. "Intergeneracional mobility in Latin America". Working Paper, \#452, Washington D.C.: Banco Interamericano de Desarrollo, 2001, pp.1-38.

BEST, H. y COTTA, M. (eds.). Parliamentary representatives in Europe 1848-2000. Oxford: Oxford University Press, 2000.

BUTTA, G. "Il problema della classe politica nel pensamiento politico Americano. In: ALVAREZ DE MORALES, A. y GARCÍA, C. (comp.) Las clases dirigentes. Madrid: Editoriales de Derecho Reunidas, 1992, pp. 101-107. 
DAHAN, M. y GAVIRIA, A. "Sibling correlations and social mobility in Latin America", Working Paper, \#395, Washington D.C.: Banco Interamericano de Desarrollo, 1999, pp.1-29.

DAHL. R. Who Governs? Democracy and Power in an American City. New Haven: Yale University Press, 1961.

DIAMOND, L. y MORLINO, L. "The Quality of Democracy. An Overview", Journal of Democracy. Vol. 15, n.. 4, 2004, pp. 20-31.

DÍAZ, D., GIANNINI, P., LUNA, J.P. y NÚÑEZ, R. "El secreto de mi éxito. Seis Caminos para llegar y permanecer en Valparaíso", Revista de Ciencia Política, Volumen 26, $\mathrm{n}^{\circ}$ 1, 2006, pp.169-190.

EQUIPO DE INVESTIGACIÓN DE ELITES PARLAMENTARIAS. "Elites parlamentarias en América Latina. Continuidad y cambio en la década de 1990", Revista Española de Ciencias Políticas n5, 2001, pp. 173-197.

FERRANTI, D., PERRY, G., FERREIRA, F. y WALTON, M. Desigualdad en América Latina y el Caribe: ¿ruptura con la historia?. Resumen Ejecutivo. Estudio del Banco Mundial sobre América Latina y el Caribe, 2003, pp. 1-24.

GABRIEL, K.R. "The Biplot graphic display of matrices with application to principal component analysis", Biometrika, 58, 3, 1971, pp. 453467.

GABRIEL, K.R. y ODOROFF, C.L. "Biplot in biomedical research", Statistics in Medicine, 9, 1990, pp.469-485.

GALINDO, M. P. "Una alternativa de representación simultánea: HJ-Biplot". Questíio, 10 (1), 1986, pp. 13-23.

GARCÍA, F. y MATEOS, A. El Proyecto elites parlamentarias latinoamericanas: continuidades y cambios (1994-2005). En Alcántara, M. (ed.). Políticos y política en América Latina. Madrid: Siglo XXI, 2006, pp. 3-25.

HIBBING, J. "Legislative Careers: Why and How We Should Study Them?", Legislative Studies Quarterly, Vol.24, No.2, 1999, pp.149-171.

HUNTER, F. Community Power Structure: A Study of Decision Makers. Chapel Hill: University of North Carolina Press, 1953.

INGLEHART, R. y WELZEL, C. Modernización, cambio cultural y democracia: la secuencia del desarrollo humano. Madrid: CIS, 2006.

LANDMAN, T. "Map-Making and Analysis of the Main International Initiatives on Developing Indicators on Democracy and Good Governance", Eurostat (Statistical Office of the Commission of the European Communities), University of Essex, 2003. 
LINZ, J. Problemas de la democracia hoy. En Del Águila, R.; Vallespín,F. et al. La democracia en sus textos. Madrid: Alianza, 1998.

LIPSET, S. A., LAZARSFELD, P., BARTON, A. y LINZ, J. The psychology of voting: an analisys of political behavior. En GARDEN, L., ed.. Handbook of Social Psychology. II, Cambridge: Addison Wesley Publishing, 1954. pp. 1124-1177.

LIPSET, S.M. y SOLARI, A. Elites y desarrollo en América Latina. Buenos Aires: Paidós, 1967.

LLANOS, M. y SÁNCHEZ, F. "Councils of Elders? The Senates and its members in the Southern Con", Latin American Research Review, vol. 41, n.1, 2006, pp. 133-153.

MARTÍNEZ, M. La carrera parlamentaria: ¿̨la calidad importa?. En Alcántara, M. (ed.). Políticos y política en América Latina. Madrid: Siglo XXI, 2006, pp. 175-215.

MILLS, Ch. W. La elite del poder. México: FCE, 1963.

MOLLINELI, et al. Congreso, Presidencia y Justicia en Argentina. Buenos Aires: Temas Grupo Editorial, 1999.

MORÁN; M.L. Origen histórico y gnoseológico de la teoría de las elites. Madrid: Universidad Complutense, 1983.

MOSCA, G. La clase política. México D.F: FCE, 1984.

NORRIS, P. "The role of the free press in promoting democratisation, good governance, and human development". Paper for the Midwest Political Science Association annual meeting, 20-22 Abril, Chicago, 2006.

O'DONNELL, G. Notas sobre la democracia en América Latina. En PNUD. La democracia en América Latina: El debate conceptual sobre democracia. Buenos Aires: PNUD, 2004, pp. 11- 87.

PACHANO, S. Los diputados: una élite política. Quito: Corporación Editora Nacional, 1991.

PARRY, G. Políticas elites. London: George Alles and Unwin, 1969.

PELA, (1998-2007), ALCÁNTARA, M. (Dir.), Universidad de Salamanca.

PNUD. La democracia en América Latina: El debate conceptual sobre democracia. Buenos Aires: PNUD, 2004.

PUTNAM, R. The Comparalive Study of Polilical Élites. New Jersey, 1976.

QUANDT, WILLIAM. “The comparative study of political elites". Comparative Politics Series. Number: 01-004. Sage, 1970.

RODRIGUEZ ZÚÑIGA, L. Elites y democracia. Valencia: FernandoTorres Editor, 1976. 
PATRONES SOCIO ECONÓMICOS DE LA ELITE LEGISLATIVA Y DEMOCRACIA EN AMÉRICA LATINA

ROHLF, F.J. y SOKAL, R.R. "Comparing numerical taxonomic studies", Systematic Zool, 30, 1981, pp. 459-490.

SÁNCHEZ, F.; LLANOS, M.; y NOLTE, D. Bicameralismo, Senados y senadores en el Cono Sur Latinoamericano. Barcelona: Parlament de Catalunya - ICPS, 2005.

SARTORI, G. Elementos de teoría política. Madrid: Alianza Editorial, 2005.

SEN, A. El valor de la democracia. Barcelona: El Viejo topo, 2006.

SHUMPETER, JOSEPH. Capitalismo, socialismo y democracia. Madrid: Aguilar, 1971.

TULCHIN, J. y BROWN, A. Democratic Governance and Social Inequality. Boulder: Lynne Rienner, 2003.

URIARTE, Edurne. "El análisis de las elites políticas", Revista de Estudios Políticos, no 97, 1997, pp. 249-275.

VICENTE, S., RAMÍREZ, G. y GALINDO, P. "El HJ-Biplot como base para la búsqueda de clusters en función de la distribución de parados según profesiones en la comunidad de Castilla y León", comunicación presentada en el IV Congreso de Economía Regional de Castilla y León, Burgos, 1994, pp. 822-835.

WORLD BANK. World Development Indicators 2008. Washington, DC: The World Bank, 2008. 
FRANCISCO SÁNCHEZ | CRISTINA RIVAS

\section{Anexo 1}

\begin{tabular}{|c|c|c|}
\hline & $N^{o}$ entrevistas & \% sobre el congreso \\
\hline - Argentina & 233 & \\
\hline$(97-01)$ & 128 & 49,8 \\
\hline$(03-07)$ & 105 & 40,8 \\
\hline - Bolivia & 276 & \\
\hline$(97-02)$ & 98 & 75,4 \\
\hline$(02-06)$ & 80 & 61,5 \\
\hline$(06-10)$ & 98 & 75,4 \\
\hline - Brasil & 134 & \\
\hline$(03-07)$ & 134 & 26,0 \\
\hline - Chile & 267 & \\
\hline$(97-01)$ & 89 & 74,2 \\
\hline$(01-05)$ & 88 & 73,0 \\
\hline$(06-10)$ & 90 & 75,0 \\
\hline - Colombia & 290 & \\
\hline$(98-02)$ & 88 & 54,7 \\
\hline$(02-06)$ & 95 & 57,0 \\
\hline$(06-10)$ & 107 & 64,5 \\
\hline - Costa Rica & 157 & \\
\hline$(98-02)$ & 49 & 85,9 \\
\hline$(02-06)$ & 57 & 90,0 \\
\hline$(06-10)$ & 107 & 100,0 \\
\hline - El Salvador & 274 & \\
\hline$(97-00)$ & 58 & 69,0 \\
\hline$(00-03)$ & 64 & 76,2 \\
\hline$(03-06)$ & 80 & 95,0 \\
\hline$(06-09)$ & 72 & 85,0 \\
\hline - Ecuador & 210 & \\
\hline$(98-02)$ & 112 & 92,6 \\
\hline$(02-06)$ & 98 & 98,0 \\
\hline - Guatemala & 263 & \\
\hline$(95-99)$ & 63 & 78,8 \\
\hline$(00-04)$ & 79 & 70,0 \\
\hline$(04-08)$ & 121 & 77,0 \\
\hline
\end{tabular}


PATRONES SOCIO ECONÓMICOS DE LA ELITE LEGISLATIVA Y DEMOCRACIA EN AMÉRICA LATINA

\begin{tabular}{|c|c|c|}
\hline & $N^{o}$ entrevistas & \% sobre el congreso \\
\hline - Honduras & 264 & \\
\hline$(97-01)$ & 71 & 55,5 \\
\hline$(01-05)$ & 102 & 76,7 \\
\hline$(06-10)$ & 91 & 71,1 \\
\hline - México & 502 & \\
\hline$(97-00)$ & 126 & 25,2 \\
\hline$(00-03)$ & 124 & 24,0 \\
\hline$(03-06)$ & 124 & 24,8 \\
\hline$(06-09)$ & 128 & 25,6 \\
\hline - Nicaragua & 199 & \\
\hline$(97-01)$ & 70 & 75,3 \\
\hline$(01-06)$ & 60 & 65,2 \\
\hline$(07-11)$ & 69 & 75,0 \\
\hline - Panamá & 132 & \\
\hline$(99-04)$ & 64 & 90,0 \\
\hline (04-09) & 68 & 78,2 \\
\hline - Paraguay & 121 & \\
\hline$(98-03)$ & 65 & 81,2 \\
\hline$(03-08)$ & 56 & 70,0 \\
\hline - Perú & 179 & \\
\hline$(01-06)$ & 83 & 69,2 \\
\hline$(06-11)$ & 96 & 80,0 \\
\hline - R. Dominicana & 315 & \\
\hline$(98-02)$ & 103 & 69,1 \\
\hline$(02-06)$ & 118 & 78,7 \\
\hline$(06-10)$ & 94 & 52,8 \\
\hline - Uruguay & 154 & \\
\hline$(00-05)$ & 68 & 68,7 \\
\hline$(05-10)$ & 86 & 86,9 \\
\hline - Venezuela & 100 & \\
\hline$(00-05)$ & 100 & 60,6 \\
\hline TOTAL & 4070 & \\
\hline
\end{tabular}


FRANCISCO SÁNCHEZ | CRISTINA RIVAS

Anexo 2

\section{Sistema de interpretación de las técnicas de análisis}

La interpretación de los biplot es sencilla: las variables se representan mediante vectores y las observaciones mediante puntos. La relación entre las propias variables y las que se dan entre éstas y los ejes factoriales extraídos, viene determinada por la longitud y ángulo de los vectores, que se interpreta en términos de variabilidad y covariabilidad, respectivamente. Así, cuanto mayor sea la longitud de un vector mayor variabilidad tendrá esa variable en el análisis y más varianza explicará en uno de los ejes factoriales extraídos. Por su parte, si el ángulo entre dos vectores es pequeño (próximo a $0^{\circ}$ ), esas dos variables estarán correlacionadas positivamente; mientras que si el ángulo que forman es de $180^{\circ}$ las variables presentarán correlaciones negativas. Un ángulo recto entre dos vectores indica baja correlación entre las variables.

Para interpretar la posición de los casos, se considera que la proximidad entre los puntos significa similitud. Los casos próximos en el plano compartirán un perfil similar respecto a las variables utilizadas en el análisis. Ese perfil es generado a partir de la posición media de cada uno de los casos en el conjunto de variables incluidas en el análisis.

Y, finalmente, la relación entre casos y variables se analiza a partir de la proyección perpendicular de los puntos sobre los vectores. A partir de esta proyección es posible determinar la distribución aproximada que las observaciones toman sobre las variables (Gabriel y Odoroff, 1990).

A pesar de que los biplot son una técnica útil de visualización que permite analizar la relación entre las propias variables, entre los casos y entre éstos y las variables, no pueden utilizarse para hacer inferencias estadísticas (Díaz, Giannini, Luna, Núñez, 2006; 179). Por ello, para completar el análisis y para que la interpretación de la clasificación de países según su posición en el gráfico biplot sea objetiva, se ha realizado un análisis cluster tomando como variables de clasificación las coordenadas obtenidas en el HJ-Biplot. La ventaja del análisis cluster está en que permite establecer grupos homogéneos de forma que los países pertenecientes a un mismo grupo son similares, es decir, los valores que toman en cada una de las variables utilizadas en el análisis son análogos. El método utilizado para el análisis cluster es el de Ward o método de pérdida de la inercia mínima que une los casos buscando minimizar la varianza dentro de cada grupo (Vicente, Ramírez y Galindo, 1994, 830). 


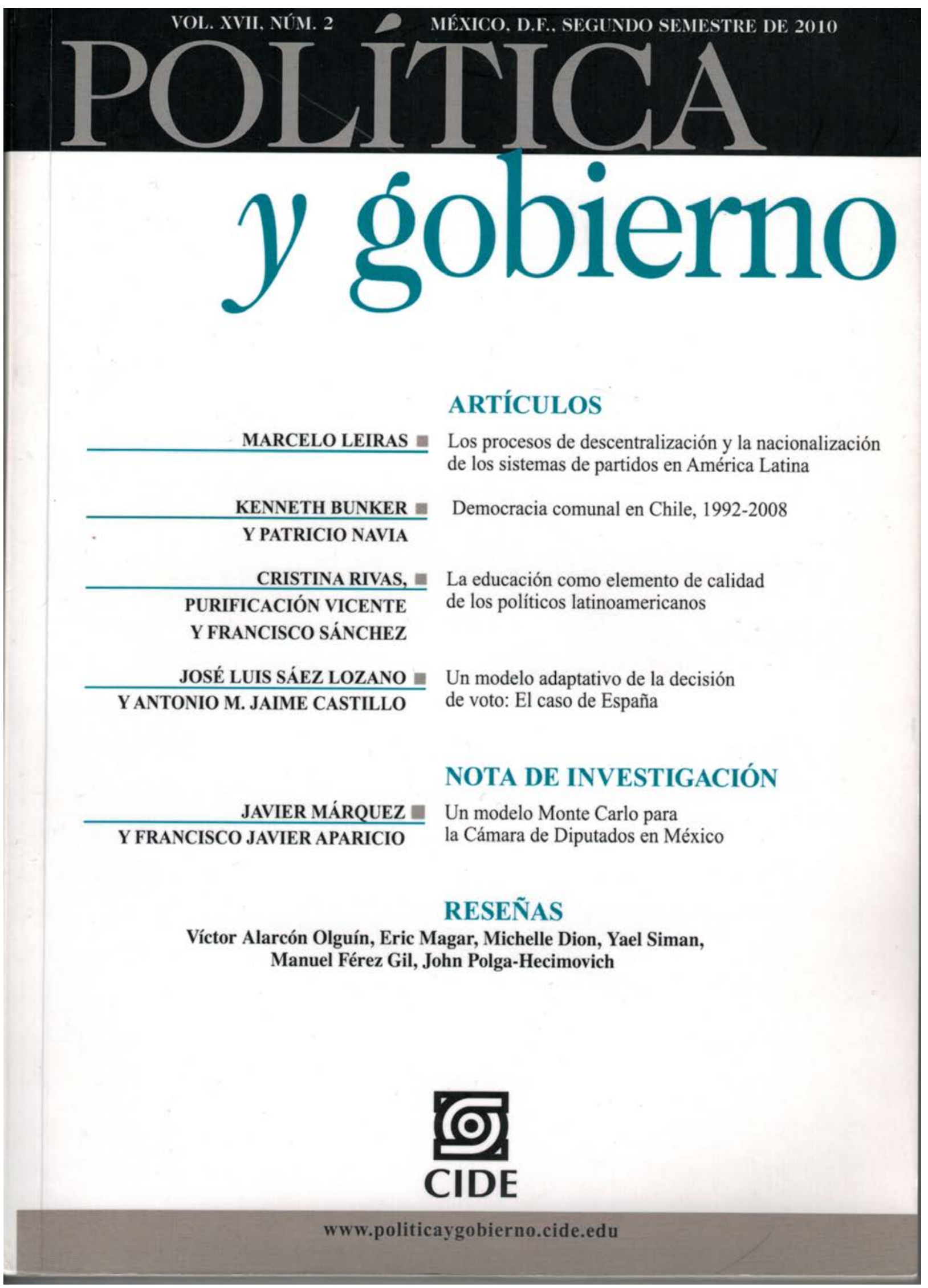




\title{
La educación como elemento de calidad de los políticos latinoamericanos
}

\author{
Cristina Rivas, Purificación Vicente y Francisco Sánchez*
}

Resumen: A partir del supuesto de que el nivel educativo es un indicador de la calidad de la élite política, en este trabajo planteamos la hipótesis de que el grado educativo alcanzado por los legisladores de algunos países latinoamericanos no redunda positivamente en las características de la democracia de sus respectivos países, debido a que, en condiciones de falta de equidad social y económica, como ocurre en los casos de los países que estudiamos, un elevado nivel de estudios puede evidenciar más bien situaciones de privilegio individual o de grupo y, por lo tanto, no repercutir positivamente en las condiciones generales del sistema social y político.

Palabras clave: élite parlamentaria, educación, calidad de los políticos, democracia, desigualdad social.

\section{Education as an Element of Quality of Latin American Politicians}

Abstract: In this work we assume the level of education as an indicator of political elite's quality. Our hypothesis is that legislators' education level in some of the Latin American countries has not a positive impact on the characteristics of democracy. Instead, under social and economic inequalities, a high level of education shows individual or collective privileges and, therefore, it does not have an effect on the general condition of social and political system.

Keywords: parliamentary elite, education, the quality of politicians, democracy, social inequality.

*Cristina Rivas es investigadora del Instituto de Iberoamérica, Universidad de Salamanca, Hospedería Fonseca, calle Fonseca, 2, 37002, Salamanca. Tel. (+34) 923294636 . Correo electrónico: crisrivas@usal.es.Purificación Vicente es profesora de estadística en la Facultad de Ciencias Sociales de la Universidad de Salamanca, C/ Alfonso X El Sabio s/n, Campus Miguel de Unamuno, Facultad de Medicina, 37007, Salamanca. Tel. 923294400 ext. 1852. Correo electrónico: purivg@usal.es. Francisco Sánchez es profesor de ciencia política de la Universidad de Valencia, Edificio Departamental Occidental, Campus dels Tarongers, Avda. dels Tarongers, s/n, 46071, Valencia. Tel. (+34) 963828867 . Correo electrónico: fransalo@uv.es.

Artículo recibido en noviembre de 2008 y aceptado para su publicación en febrero de 2010.

VOLUMEN XVII · NÚMERO 2 - II SEMESTRE DE 2010 • PP. 279-319

Política y gobierno 279 


\section{Introducción}

Мencionar la mala calidad de los políticos es uno de los tópicos recurrentes para explicar el estado de las democracias latinoamericanas, visión negativa que aumenta cuando se habla de los representantes electos a las asambleas legislativas. Sin embargo, la superficialidad de tal afirmación queda en evidencia cuando se pide a sus defensores definir cuáles son los atributos que debe tener un buen político. Los argumentos de los sectores de opinión que se quejan de la calidad de los políticos giran en torno al nivel educativo de los mismos, lo que llama aún más la atención si se toma en cuenta que los diputados latinoamericanos con estudios superiores exceden 90 por ciento. Cabe recordar que los sectores más conservadores de sus respectivos países pusieron en entredicho la capacidad para ejercer la presidencia de Lula da Silva y Evo Morales debido a su falta de estudios universitarios. Por el contrario, al hablar del ecuatoriano Rafael Correa suele mencionarse que obtuvo un doctorado en Estados Unidos, como si eso fuese garantía potencial de una buena gestión. Estas posiciones reflejan prejuicios elitistas y una visión de la política como un espacio destinado sólo para ilustrados.

A pesar de que la pregunta sobre la influencia que tienen los rasgos de los gobernantes en el desempeño del régimen es antigua — ya la abordó Aristóteles (s. III a.C.) en La Política - resulta complicado ofrecer datos concluyentes sobre qué es un buen político o un político de calidad, o cuáles de sus atributos explicarían mejor las variaciones en el funcionamiento del sistema. En este trabajo nos adentramos en el tema de la calidad de los políticos dentro del marco de una preocupación general sobre la repercusión que tiene en el sistema su desempeño como actores; nos preguntamos si existe una relación entre el nivel educativo de los diputados latinoamericanos, en tanto integrantes fundamentales de la élite política, y las características de los sistemas democráticos de sus respectivos países; al centrarnos en los rasgos de la democracia, podemos evaluar una serie de atributos comparables de los sistemas políticos, en los que necesariamente se refleja el impacto de los políticos en el funcionamiento del sistema. En términos generales, sostenemos que no hay una relación directa entre el grado de educación formal de los diputados y las características de la democracia de los distintos países latinoamericanos debido a que, en condiciones de inequidad social y económica, el nivel educativo de las personas es un indicador distorsionado y más bien puede revelar un mayor grado de elitismo de la clase política. 
Dentro del vasto grupo de la élite política, nos centraremos en la élite parlamentaria, pues asumimos que es una parte representativa de todas ellas en cada uno de sus Estados. ${ }^{1}$ La posición privilegiada que tienen en el sistema político, los convierte en actores fundamentales en el funcionamiento del régimen, ya que de ellos depende, en gran medida, la operación cotidiana del sistema, la generación de normas que construyan la democracia o el control de las autoridades para que no puedan operar fuera de los parámetros democráticos. Es de esperarse que existan relaciones entre los rasgos y valores de los diputados y las características de la democracia de sus respectivos países.

Para contrastar la hipótesis que se explicará detalladamente más adelante, se lleva a cabo una representación HJ-Biplot (Galindo, 1985, 1986) que permite reflejar simultáneamente variables y países en un espacio de dimensión reducida, de forma que no sólo se puede conocer la configuración de los países, sino las variables responsables de esa configuración. Un segundo objetivo de este trabajo es realizar una clasificación de los países en función del nivel de estudios, ingresos y estudios de los padres de los diputados; las características de la democracia y los indicadores de la situación social del país. Para eso se ha realizado un análisis cluster tomando como matriz de partida las coordenadas de los individuos en los factores retenidos en el HJ-Biplot (Vicente, 1992).

La información utilizada procede de los datos individuales obtenidos de las encuestas realizadas a diputados de los parlamentos de 17 países latinoamericanos, entre los años 2005 y 2009, ${ }^{2}$ y en el Proyecto Élites Latinoamericanas (PELA) de la Universidad de Salamanca. ${ }^{3}$ Estos datos serán com-

${ }^{1}$ Para profundizar sobre el papel de los diputados como parte de la élite política y su importancia para la estabilidad de la democracia puede verse el trabajo de García y Mateos (2006, p. 10) o el de Uriarte (1997, p. 260), quien indica que la élite política es el grupo que tiene capacidad de influir en las políticas y actividades del Estado, definición que permite incluir en esa categoría a un grupo de políticos profesionales que pueden ejercer cargos en los partidos, en el Ejecutivo, en el Legislativo o en los gobiernos locales. Sin embargo, señala también que la mayor parte de las investigaciones sobre élites políticas se centran en los diputados y, para explicar las razones, retoma a Aberdach, Putnam y Rockman (1981), que sostienen que los parlamentarios muestran el lado partidista de la política, son el semillero de los gobiernos y ministerios, e influyen en la política de sus respectivos países.

${ }^{2}$ Se deja fuera del estudio a Venezuela por falta de información. Para el caso de Brasil y Panamá los datos disponibles corresponden al periodo legislativo anterior, 2002-2006 en Brasil y 20032008 en Panamá.

${ }^{3}$ El Proyecto Élites Parlamentarias Latinoamericanas tiene su origen en 1994, bajo la dirección de Manuel Alcántara de la Universidad de Salamanca, y ha ido recogiendo a lo largo de las distintas legislaturas las percepciones y actitudes de los parlamentarios latinoamericanos en 18 países.

VOLUMEN XVII · NÚMERO 2 • II SEMESTRE DE 2010

Política y gobierno 281 
plementados con indicadores que valoran diversos aspectos de la democracia y con otras cifras elaboradas por organismos internacionales, que muestran la desigualdad socioeconómica. ${ }^{4}$

El artículo comienza con dos secciones en las que se retoman los principales debates en torno a las características y atributos de los políticos, en primer lugar, y sobre los criterios para valorar las democracias en segundo lugar; para explicar a continuación nuestro modelo de análisis. Antes de la parte empírica —en la que se detallará y expondrá el comportamiento de las variables - se presentarán las técnicas estadísticas usadas y se aportarán pistas sobre la forma de interpretar los resultados.

\section{¿Cómo se ha valorado la calidad de los políticos?}

Es posible que las tendencias de análisis dentro de la ciencia política que más atención han prestado a los políticos / clase política / élite política ${ }^{5}$ sean la teoría de las élites y los estudios sobre carreras políticas - aspectos sobre los que volveremos más adelante-, pero sigue siendo muy difícil determinar cuáles son las características (no los valores ni percepciones) de los políticos que repercuten de forma positiva en el fortalecimiento y la consolidación de los sistemas democráticos. Para Stone et al. (2004), influye un conjunto de habilidades personales y de recursos estratégicos, mientras que para Martínez (2006, p. 179) la calidad de los políticos puede entenderse como un conjunto concreto de características presentes (o ausentes) en los dirigentes (en este caso legisladores) y no como las características que diferencian a los candidatos que lograron la elección de aquellos que no fueron electos. Dicha distinción pretende desmarcarse de la literatura que establece como únicos criterios de calidad los que pueda tener un buen candidato,

${ }^{4}$ Debido a la variedad de datos y a la complejidad de las metodologías utilizadas, la naturaleza de los datos usados para valorar las democracias y la desigualdad socioeconómica se detallarán más adelante, en la sección correspondiente del artículo.

${ }^{5}$ Usamos los términos arriba señalados de forma indistinta para referirnos al grupo de gobernantes, es decir, a aquellos que participan de forma activa o pasiva en la administración del poder político entendido como espacio en el que se toman decisiones con carácter obligatorio. Si bien, desde los elitistas clásicos, hubo un debate sobre la diferencia entre élite y clase política, al que posteriormente se sumaron autores como Mills (1963), en los últimos años ha perdido intensidad por el uso generalizado de la expresión clase política y la menor influencia del marco teórico marxista en las ciencias sociales. 
pues no necesariamente un buen candidato será un buen político electo. Esta definición habla de características (sociales, económicas, políticas, educativas y profesionales) pero sin señalarlas a priori pues, como muestra el trabajo, esas particularidades presentes o ausentes dependen y operan en función de los contextos. Estaría en la línea de lo planteado por Mosca (1984, p. 115), quien sostuvo que el acceso a la clase política estaba favorecido por distintas cualidades ligadas al contexto histórico.

Después de revisar distintos estudios sobre élites políticas, Uriarte (1997, p. 270) señala que parece claro que algunas características favorecen notablemente la posibilidad de formar parte de la élite política. Así, haber nacido en ciudades, pertenecer a la clase media o media-alta, haber cursado estudios universitarios — preferentemente en instituciones de élite- y ser hombre aumenta las posibilidades de alcanzar posiciones en la élite política. Ahora bien, es cierto que la conjunción de los rasgos señalados favorece el acceso no sólo a la élite política, sino al conjunto de todas las élites, pero poseer esas especificaciones tampoco garantiza acceder a la élite, ya que hay otros elementos que intervienen.

Más allá de que las conceptualizaciones sobre lo que sería un buen legislador — un buen político- pongan el énfasis en atributos abstractos como la honestidad, la competencia, la eficiencia, la experiencia o la profesionalización, ${ }^{6}$ se entiende la necesidad de ponderar valores más bien subjetivos porque las solas características sociales o la trayectoria personal del político no son garantía de un mejor o peor desempeño, razón por la que hay que hacer esfuerzos para encontrar esos otros factores. Compartimos con Martínez (2006) la observación de que casi todos los estudios realizados al respecto utilizan una batería de datos socioeconómicos y demográficos muy parecidos, entre los que siempre está el nivel educativo de los políticos, que es el mejor indicador de un potencial incremento de sus capacidades y destrezas en el desempeño de las funciones que les son propias.

La complejidad de las investigaciones sobre la influencia de los políticos en las peculiaridades del propio sistema no está en establecer relaciones entre las variables, sino en la búsqueda de relaciones causales, sobre todo cuando se trata de demostrar que la variable independiente son las caracte-

${ }^{6} \mathrm{Al}$ respecto pueden consultarse los siguientes trabajos: Padró y Snyder (2004); Burns et al. (2004); Reiser (2003); Dal Bó, Dal Bó y Di Tella (2002); Moncrief et al. (2001); Uriarte (2000); Brady et al. (1999); Norris (1997); Epstein et. al. (1997); Katz y Sala (1996), y Mondak (1995).

VOLUMEN XVII · NÚMERO 2 • II SEMESTRE DE 2010

Política y gobierno 283 
rísticas de los políticos ${ }^{7}$ (Alcántara et al., 2006; Alcántara y Rivas, 2007; Blondel Müller-Rommel, 2009; Hoffman-Lange, 2009). Abundando en lo anterior, hay trabajos como el de Inglehart y Welzel (2006, p. 275) que señalan que el aumento de los valores democráticos opera como una fuerza social que consolida la integridad de la élite; u otros, la mayoría, en los que se enfatizan los valores y aptitudes de las élites como variable independiente, más no sus características socioeconómicas ni sus destrezas políticas. ${ }^{8} \mathrm{Un}$ grupo diferente de trabajos es el que forman aquellos en los que se explica el surgimiento de los sistemas democráticos gracias a una serie de pactos y acuerdos entre los grupos de élite, estudios criticados por transmitir una visión determinista del papel de las élites en el surgimiento y mantenimiento del sistema democrático. ${ }^{9}$

A pesar de que la mayoría de la literatura sobre los políticos asume que el grado de instrucción educativa de los mismos es una variable fundamental para valorarlos, no profundiza sobre el tema y se queda en enunciados de tipo general, señalando que uno de los atributos que debe tenerse en cuenta es su nivel educativo. Este tipo de argumentos suele ir acompañado de la afirmación de que los políticos de calidad conllevan el mejor funcionamiento de los sistemas políticos y, por ende, del tipo de régimen. Lo que subyace es el argumento de que los políticos mejor formados están capacitados para generar mejores políticas públicas, lo que llevaría a un mejor

${ }^{7} \mathrm{El}$ texto seminal sobre las élites políticas latinoamericanas es el compilado por Lipset y Solari (1967), en el que se incluyen capítulos temáticos que tratan sobre los distintos aspectos de la composición y formación de las élites en general. No estamos planteando que no se hayan realizado estudios sistemáticos sobre élites políticas, sino que aún quedan muchos aspectos pendientes por considerar, ya que la falta de datos ha dificultado la elaboración de este tipo de trabajos. De una forma más clara lo plantea Uriarte (1997, p. 254), al señalar que se han llevado a cabo numerosas investigaciones tanto de las élites políticas como de las culturales y económicas, y que en todas ellas se puede apreciar un consenso generalizado sobre algunas ideas básicas, sobre todo alrededor de la noción de que las sociedades están divididas entre minorías poderosas y grandes masas influidas por esas minorías. Sin embargo, según la misma autora, las perspectivas varían a la hora de analizar las bases de la formación y mantenimiento de esas minorías, sus características, su papel o las consecuencias de su existencia o de sus actos para la democracia, ya que hay diferencias importantes en la identificación de las élites y en los enfoques de la investigación.

${ }^{8}$ Sobre el tema trata el texto compilado por Alcántara (2006), cuya base de datos fundamenta las encuestas de élites que aquí se usan o el artículo de Stevens, Bishin y Barr (2006) sobre las preferencias autoritarias de las élites latinoamericanas.

${ }^{9}$ Algunas de estas visiones son las que tiene Bunce (20007, p. 709) o las que se desarrollaron para explicar las transiciones, como se puede comprobar en las aportaciones del libro de Highley y Günther (1992). 
funcionamiento del sistema y mayor satisfacción de los ciudadanos. Como ya se dijo, éstos suelen ser supuestos habituales en los estudios sobre la calidad de los políticos, pero muy pocas veces se ha demostrado si existe relación entre alguna de las características que con frecuencia se asocian con el buen político y el funcionamiento efectivo de un sistema político.

Aunque elaborada a partir de datos de opinión de la población, la teoría del "desarrollo humano" de Inglehart y Welzel (2006) señala que hay una relación directa entre el acceso a la educación y el desarrollo de valores de autoexpresión que necesariamente se reflejan en mayores niveles de democratización; entre las investigaciones sobre las características de las élites que han servido para demostrar la relación entre ellas y los cambios en los sistemas políticos destaca la compilación de Best y Cotta (2000). En ese trabajo se desarrolla la clásica línea argumental de Stein Rokkan para señalar que el estudio empírico de las características de las élites parlamentarias agrega una nueva dimensión a los análisis de cómo y en qué medida los representantes, es decir, aquellos actores que son al mismo tiempo los principales productos y los productores de los procesos de democratización y de las instituciones democráticas, han cambiado en paralelo con las otras dimensiones de esa gran transformación. Una de las variables más importantes de la investigación compilada por Best y Cotta (2000) es el nivel académico de los legisladores, ya que, en el contexto de su trabajo, sirve para mostrar cambios en el acceso a la educación, la movilidad social, el acceso a recursos materiales o simbólicos, y la profesionalización de sectores medios; aspectos que sirven de base para la creación de una nueva clase política profesional, que se desarrolla a la par del proceso de democratización.

El análisis de las características, las destrezas y los rasgos de los políticos ha sido abordado sobre todo en la literatura sobre élites políticas. ${ }^{10} \mathrm{Si}$ bien los llamados elitistas clásicos ${ }^{11}$ estaban más preocupados por demostrar la

\footnotetext{
${ }^{10}$ Se trata de un tema de tan amplio espectro que se puede estudiar a través de enfoques que van desde lo normativo, como los relacionados con la representación política, hasta lo empírico, como los que buscan establecer vínculos entre las características de los políticos y sus conductas y actitudes. Metodológicamente, Quandt (1970) recomienda la comparación entre países y la utilización de datos que puedan tratarse estadísticamente.

${ }^{11}$ Bajo el nombre genérico de "elitistas clásicos" suele agruparse a Pareto y su teoría de la circulación de las élites; a Mosca, que se destaca por desarrollar el concepto de clase política, y a Michels, con su Ley de Hierro de la Oligarquía. Además de las obras de los autores mencionados se pueden consultar los estudios sobre los mismos de Rodríguez Zúñiga (1976), Morán (1983) o Albertoni (1988). En ocasiones se incluye a Weber dentro de los elitistas clásicos, ya que en sus planteamientos sobre partidos políticos es deudor de Michels.
} 
existencia de una minoría que domina a la mayoría como un hecho privativo de cualquier sociedad — sin prestar mayor atención a los integrantes de esa minoría - sus planteamientos dieron origen a una serie de investigaciones que trataban de singularizar a la élite (Dahl, 1961; Mills, 1963; Putnam, 1976). Las investigaciones se preguntaron por las características sociales, económicas y culturales de las élites y, sobre todo, intentaron determinar si existía algún tipo de correlación entre los rasgos de las mismas y el rendimiento del sistema político (Lasswell, 1961). Como señala Linz (1998, p. 249), la mayoría de los estudios se han centrado en la representatividad de las élites en términos de particularidades tales como clase, sexo, origen regional o étnico y movilidad social, lo que refleja una preocupación por la igualdad de oportunidades.

La economía política (public economics) también ha prestado atención al personal político. Para Besley (2005) la clave de la calidad de los políticos está en su selección, razón por la que analiza los incentivos que se dan en ese proceso. En una línea parecida, se han incluido como atributos de calidad elementos como la transparencia (Mattozzi y Merlo, 2007) o el ser competente y honesto (Caselli y Morelli, 2004), pero sus aportes tienen la limitación, para esta investigación, de que se trata de modelos teóricos de búsqueda de equilibrios y no examinan o indagan la trayectoria de una o varias élites políticas específicas.

Donde más se ha aplicado el perfil político, social y económico de los políticos como variable independiente ha sido en los estudios sobre carreras políticas. ${ }^{12}$ Hibbing (1999) señala que a través del estudio de las carreras políticas se busca determinar, entre otros elementos, qué representantes son mejores y cuáles peores, qué cualidades tienen, así como entender el sistema sociopolítico del que forma parte la Cámara. Señala también que hay una serie de estudios comparativos que buscan encontrar generalidades a partir de las que se podrían perfilar los políticos de calidad.

Como puede verse, el estudio de los políticos (clase política, élite política) es un campo que sigue ofreciendo una serie de interrogantes. Por lo general, se ha recurrido a describirlos para luego tratar de sacar generalizaciones que liguen los "tipos ideales" con la manera en la que funciona el sistema político (Blondel y Müller-Rommel, 2009), pero en este trabajo

\footnotetext{
${ }^{12}$ Para un análisis de las carreras de los senadores del Cono Sur, véase el trabajo de Llanos y Sánchez (2006), mientras que para el estudio de los legisladores latinoamericanos se puede consultar a Martínez (2006).
} 
queremos dar un paso adelante y avanzar en la comprensión de la manera en que operan de forma diferenciada atributos que teóricamente potencian la calidad de los políticos - en este caso, el nivel de estudios- No cuestionamos el hecho de que los estudios puedan ayudar (que no es lo mismo que garantizar) a que los políticos desempeñen de mejor manera sus tareas, ya que se trata de un proceso de adquisición de conocimientos y destrezas. Lo que aquí se sostiene es más bien que la educación, como buen atributo en potencia de un político de calidad, tiene que ser contextualizado, ya que el desarrollo de su capacidad dependerá del escenario sociopolítico en el que se encuentre el sujeto y de su trayectoria personal.

Rodríguez (2005, p. 342) explica de forma clara la influencia de la posición social sobre la pertenencia a la élite política. A partir de los trabajos de Putnam (1976) y Aberbach et al. (1981), señala que hay dos grandes modelos de acceso a los puestos privilegiados del poder político: la plutocracia y la meritocracia, modalidades que pueden funcionar de forma separada, alternativa o simultánea. En un modelo basado en la combinación de credenciales educativas y origen social, formar parte de la élite requiere un alto grado de formación académica. El acceso a la universidad se encuentra afectado por el origen social de los individuos, dándose un proceso de selección social indirecta. Los sujetos con un importante capital educativo no llegan por igual a la élite política debido a que entre individuos con igual nivel de estudios persiste un sesgo social a favor de los que pertenecen a los estratos sociales más elevados. En resumen: el nivel educativo y el origen social afectan conjuntamente el ingreso a la élite.

No hay que olvidar que la educación no es sólo un mecanismo de movilidad social (Neelsen, 1975) y ascenso meritocrático ${ }^{13}$ que contribuye a democratizar a la sociedad, sino que también puede convertirse en un medio de movilidad política (Best y Cotta, 2000). En contextos como los aquí estudiados, en los que hay situaciones de desigualdad social y económica estructurales, las dificultades para el acceso a la educación o las diferencias de calidad que existen dentro del sistema educativo hacen que los estudios no funcionen necesariamente como un sistema de movilidad. Por el contrario, en estas circunstancias el individuo se enfrenta a estructuras sólidas de exclusión que no lo valorarán necesariamente en función de sus méritos,

\footnotetext{
${ }^{13}$ Los estudios sobre élites políticas siempre coinciden en que la meritocracia puede entenderse como un signo de desarrollo de la clase política en las sociedades modernas (Rodríguez, 2005, p. 344).
}

VOLUMEN XVII · NÚMERO 2 • II SEMESTRE DE 2010

Política y gobierno 287 
sino más bien con base en una serie de imaginarios sociales predeterminados. Es más, los estudios pueden ser un indicador de la exclusión social y política que padece gran parte de la población, lo que en principio no sería benéfico para el funcionamiento del sistema político.

\section{¿Cómo valorar las características de la democracia?}

Los desiguales niveles de consolidación democrática ${ }^{14}$ en los países de América Latina han despertado un creciente interés por el estudio de las características de la democracia en la región, siendo la conclusión casi generalizada que ésta muestra una serie de falencias (Altman y Pérez Liñán, 2002; Diamond y Morlino, 2004; Hagopian y Mainwaring, 2005; Morlino, 2009). Cabe recordar que la democracia está basada en principios de ciudadanía universal, lo cual implica que los individuos no sólo reclaman igualdad política que los haga soberanos, principalmente a partir del voto, sino también condiciones para alcanzar igualdad social y económica, algo lejos de lograr en América Latina y que dificulta la aceptación e interiorización de las rutinas democráticas (Alcántara, 2008).

La forma en la que se concretan los principios, valores y normas de los regímenes democráticos varía de acuerdo con las características de los distintos sistemas políticos, pero es posible definir una serie de aspectos que pueden dar cuenta de su funcionamiento. No cabe duda de que una buena democracia es una democracia de calidad, entendiendo como tal aquel ordenamiento institucional estable que, mediante instituciones y mecanismos que funcionen correctamente, garantice las condiciones de posibilidad para el ejercicio de la libertad y el logro de mayores cuotas de igualdad efectiva entre los ciudadanos. Es un régimen muy legitimado, estable, que satisface a los ciudadanos (calidad por resultados) (Morlino, 2009, p. 186).

A pesar de que se ha propiciado un gran debate en torno a la operacionalización del concepto de calidad de la democracia (García y Mateos, 2006, p. 11), hay varias propuestas analíticas, siendo, a nuestro juicio, la más completa, la planteada por Diamond y Morlino (2004, p. 22) y Morlino (2009, p. 187)

${ }^{14}$ La consolidación — según Di Palma (1988)— se refiere a la creación de un consenso básico sobre las reglas del juego democrático y la disminución o desaparición del riesgo de una interrupción de la competencia democrática. Solamente después de ese punto se puede decir que han echado raíces las funciones y rutinas institucionales, lo que incluye la socialización de las personas que actúan en el marco de las instituciones democráticas. 
que señala que deben tomarse en cuenta dos perspectivas: una, la de los ciudadanos (a partir del grado de satisfacción de éstos con los resultados) y otra, más objetiva, a partir del rendimiento institucional, a fin de evaluar el nivel de cumplimiento de ocho dimensiones: cinco de carácter procedimental: imperio de la ley, participación, competición y responsabilidad vertical (exigida por los ciudadanos) y horizontal (exigida por instituciones del poder público); otras dos de carácter sustantivo: las libertades civiles y políticas, y la igualdad política, y por último, la dimensión responsiveness (reciprocidad / respuesta a la voluntad popular), que enlazaría a las dimensiones procedimentales con las sustantivas.

Además de las categorizaciones centradas en la idea de la calidad de la democracia, hay otras que ponen el foco de atención en el gobierno (entendido en un sentido muy amplio), es decir, en el modo en que se ejerce la autoridad en un país. Kaufmann, Kraay y Zoido (2002, pp. 4-5) sistematizan su propuesta para caracterizar a la democracia a partir de seis dimensiones: voice and accountability, referido a los procesos por los cuales los gobiernos y autoridades son elegidos y reemplazados; estabilidad política; efectividad del gobierno; regulatory quality, regulación de las políticas de mercado, control de los precios, etc.; rule of law, respeto a las norma vigentes y, por último, el control de la corrupción. ${ }^{15}$

A pesar de que los conceptos anteriores no ponen de relieve el papel de los actores políticos, su estudio es fundamental para valorar la calidad de la democracia, pues son ellos los que accionan la maquinaria institucional del sistema político. ${ }^{16}$ No hay que olvidar que las instituciones tienen un papel relativamente autónomo dentro del proceso político aunque no de supremacía ni de subordinación. Determinan los costos de transacción o repercuten en la forma en la que actúan las personas u organizaciones, ya que éstas toman en cuenta las oportunidades e incentivos que las instituciones les brindan para desarrollar sus estrategias de adaptación o resistencia. Así buscarán maximizar sus beneficios y reducir sus pérdidas, llegando incluso a la modificación de las mismas.

${ }^{15}$ Hemos mantenido los originales en inglés porque su uso y comprensión están generalizados y porque no hay una convención lo suficientemente amplia sobre las palabras en español que mejor servirían para esos conceptos politológicos.

${ }^{16}$ A pesar del énfasis que pone en los elementos estructurales y procedimentales, el mismo Morlino (2009) insiste en la necesidad de estudiar la relación entre la calidad de la élite política y la calidad de la democracia, pero no profundiza en el argumento ni desarrolla una metodología de análisis, como sí lo hace con otros factores. 
Desde la óptica de la cultura política, Inglehart y Welzel (2006, p. 221) critican el protagonismo dado a las élites en los procesos democráticos y señalan que el determinismo democrático centrado en ellas implica que el surgimiento y la supervivencia de las instituciones políticas dependan del comportamiento de las élites, en particular de sus elecciones institucionales: si los líderes políticos son concebidos y se conciben como los fundadores de la democracia cumplirían también la función, después de su instauración inicial, de mantenerla o destruirla. Esta afirmación supone que los que ejercen el poder son independientes de los valores y creencias de la población que gobiernan. Según esta perspectiva el comportamiento de las élites no depende de las influencias de las masas. Irónicamente, esto supone que las preferencias de las masas no son en realidad importantes para la democracia, cuando el quid de la democracia es, precisamente, que sí lo son.

En este ensayo se hace una lectura poco habitual de la relación entre élites y democracia, ya que se intenta explicar el vínculo entre los dos conceptos a partir del contexto social y económico, sin caer en visiones reduccionistas o deterministas. Como ya se ha señalado, se plantea que la falta de equidad social y económica tiene consecuencias sobre los procesos de formación, reclutamientos y ejercicio de la élite política y la calidad de la democracia en un país (O’Donnell, 1997 y 2004; PNud, 2004; Tulchin y Brown, 2003).

Las grandes desigualdades socioeconómicas que caracterizan a los países latinoamericanos junto al fenómeno de la "captura estatal" por parte de la élite de estos países han sido utilizadas como posibles explicaciones de este efecto negativo que puede producirse en la relación entre crecimiento económico y gobierno democrático efectivo (Kaufmann y Kraay, 2002, p. 2).

$\mathrm{El}$ argumento que vincula la democracia y las condiciones de desigualdad o de pobreza señala que los "pobres" tienen mermadas sus "capacidades" como ciudadanos (Sen, 2006). En el fondo se apela a la necesidad de que los ciudadanos, para relacionarse de forma activa con el sistema político y aspirar al ideal de igualdad que ofrece la democracia, cuenten con niveles mínimos de bienestar social y económico. Cuanto más igualitaria y abundante sea la distribución de bienes como la educación o el acceso a la información, mayor será la probabilidad de que los ciudadanos tomen decisiones políticas informadas que respondan a sus intereses, algo que contribuirá, en buena medida, a mejorar la calidad de la democracia (Levine y Molina, 2007, pp. 24-25).

Los trabajos elaborados con esa perspectiva analítica suelen centrarse en los efectos de la desigualdad en las capacidades políticas de los sectores más 
pobres, pero no prestan mucha atención a los sectores que se benefician de la situación de desigualdad. Invirtiendo el argumento, se podría decir que la carencia de recursos que se refleja en las limitadas capacidades políticas, se transforma, en el caso de las élites, en un exceso de recursos que se verá reflejado en abundantes capacidades políticas. El razonamiento que está detrás de esta presunción es que las grandes desigualdades producen una especie de juego de suma cero, donde las carencias de los sectores más bajos se convierten en ganancias de los sectores más favorecidos.

Las élites políticas de los países formarían un grupo más diferenciado de la mayoría, con acceso a ventajas sociales y económicas no disfrutadas por el resto de la población (Milanovic y Muñoz, 2008, p. 27). En este artículo se trata de profundizar en este campo buscando vínculos entre una estructura caracterizada por la falta de equidad social y económica, las características de la democracia y la calidad potencial de las élites políticas medidas a través de su nivel educativo.

\section{Nuestra propuesta de estudio}

Partimos del supuesto de que el nivel educativo es un indicador de la calidad de la élite política y planteamos como hipótesis que el grado educativo alcanzado por los legisladores de algunos países latinoamericanos no redunda positivamente en las características de la democracia de sus respectivos países, debido a que, en condiciones de falta de equidad social y económica, como ocurre en los casos de los países que se estudian, un elevado nivel de estudios puede evidenciar más bien situaciones de privilegio individual o de grupo reflejadas en un alto nivel de ingresos y poca movilidad social o educativa y, por lo tanto, no repercutir positivamente en las condiciones generales del sistema social y político.

Para contrastar nuestro argumento, relacionaremos los datos sobre el nivel educativo de los diputados con indicadores sobre las características de las democracias de los respectivos países. Una vez establecida la relación entre las dos variables, se introducen como elementos de control, en cada uno de los países, el índice de desarrollo humano y el índice de pobreza humana (como indicadores de desigualdad). Por otro lado, para valorar la situación de privilegio de los diputados, analizaremos sus ingresos económicos declarados, es decir, cuánto dicen ganar en caso de que tengan otros ingresos además del sueldo como diputados y, por último, informa- 
ción sobre el nivel educativo del padre y de la madre de los mismos, esto último para tratar de determinar si ha habido mayor o menor movilidad educativa (¿social?).

Se recurre habitualmente al supuesto de que en toda sociedad existe una correlación entre las características de las élites y el rendimiento del gobierno, pero son pocos los estudios que han contrastado esos supuestos de forma sistemática. La clase política desempeña un papel importante como pilar explicativo de la calidad de la democracia, sin embargo, hasta la fecha son más bien escasos los trabajos dedicados a analizar cuestiones como la influencia en los sistemas políticos de la calidad de los dirigentes ${ }^{17}$ su nivel de elitismo o la diferenciación social, étnica o económica de la élite con respecto a la mayoría de la sociedad.

Aquí uno de los objetivos es explorar el efecto de anulación o reconversión de los potenciales atributos positivos de las élites - en este caso nivel educativo- que tienen los factores socioeconómicos estructurales, como la pobreza, el nivel de ingresos o la movilidad social. En resumen, se pretende demostrar que tener políticos bien formados no es muy relevante; también es necesario comprometerse a cambiar las condiciones estructurales en los ámbitos político, social y económico, para así mejorar de la democracia.

Son pocos los autores que han tratado de estudiar la repercusión de la desigualdad socioeconómica en la manera en que operan las características de las élites políticas. Además de los trabajos de Best y Cotta (2000), que coinciden en señalar que los cambios en la composición de las élites reflejan variaciones en los niveles de inclusión política de la población, Putnam (1976) también utilizó indicadores socioeconómicos, de clase y antecedentes familiares para estudiar a las élites y concluir que se reducían los sectores aristocráticos y aumentaban las clases medias, lo que reflejaba claramente el proceso de disminución de los grados de desigualdad que implicó el proceso de democratización.

Como ya se ha señalado, se usará la variable educación como un indicador que nos aproxime de forma suficiente a las características de la élite. En este caso, la variable educación es categórica y ha sido recogida a partir de seis opciones de respuesta: sin estudios, primarios, secundarios, universitarios de grado medio, universitarios superiores y de posgrado. Es de esperarse que mientras más elevados sean los estudios de los legisladores, éstos

${ }^{17}$ Un análisis sobre la calidad de los políticos a partir de su carrera política (experiencia en el partido, experiencia pública y nivel educativo) puede verse en Martínez (2006, pp. 175-211). 
resulten de mejor calidad y por lo tanto ejerzan una influencia positiva en el sistema democrático, la misma que tiene que reflejarse en las características de la democracia.

Además de los datos relativos al nivel de estudios del propio legislador, se incluyó información relativa a los estudios de los padres, con el fin de contar con un indicador que mostrase indicios de movilidad social y del contexto socioeconómico del legislador. La mayor parte de los trabajos comparados sobre desigualdad social en América Latina utilizan variables educativas para determinar la movilidad social de un individuo. ${ }^{18}$ Los antecedentes familiares son importantes para explicar la movilidad en términos de educación y constituyen uno de los principales factores que determinan la movilidad social en las sociedades meritocráticas (IPES, 2008, p. 121). La familia y el entorno social de un individuo son dos de los principales agentes de socialización política en el periodo de juventud de una persona y son determinantes en el acceso a oportunidades y resultados futuros. ${ }^{19}$

Para medir el estatus socioeconómico de los diputados de los distintos países se ha utilizado el nivel de ingresos declarado (a partir de los datos del Proyecto Élites Parlamentarias Latinoamericanas) respecto al PIB per cápita del país. Se han utilizado los datos del PIB per cápita para contextualizar el dato sobre ingreso recogido en los cuestionarios del proyecto de élites, ya que no resulta igual ganar 10000 usD en un país que tenga un PIB per cápita de 3000 usD que en uno de 9000 usD. $^{20}$

${ }^{18}$ Sobre movilidad social y educación en América Latina se pueden consultar, entre otros, a Ferranti, Perry, Ferreira y Walton (2003); Andersen (2001); Behrman, Gavira y Székely (2001), y Dahan y Gaviria (1999).

${ }^{19}$ Véase entre otros Lipset, Lazarsfelfd, Barton y Linz (1954), y Almond y Verba (1963). Estos últimos afirman que la temprana socialización del individuo en la familia ejerce una influencia importante sobre sus posteriores actitudes y participación política.

${ }^{20}$ La pregunta sobre los ingresos formulada a los diputados fue la siguiente: ¿Podría indicarme dentro de cuál de estas categorías se incluirían sus actuales ingresos mensuales? De 1000 a 4000 usD; de 4001 a 7000 usD; de 7001 a 10000 usD y más de 10000 usD. Se refiere al total de los ingresos de un parlamentario, no sólo a los percibidos por su cargo político; por lo tanto, dentro de este total estarían incluidas, por ejemplo, las dietas parlamentarias de las que, en cierto modo, no puede decirse que sean ingresos individuales. Pero es el único modo que tenemos, en este caso, de medir el nivel económico de un parlamentario. Para poder comparar el conjunto de países de la región se opta por contextualizar el ingreso de acuerdo con el PIB per cápita del país. Así, el PIB per cápita se clasificó en función de las categorías de ingresos recogidas en el cuestionario del PELA. El cálculo del indicador es sencillo, se restan los ingresos de cada uno de los diputados del PIB del país y se calcula el promedio de ese valor. A partir de ese cálculo se obtuvo una variable con una escala entre $-2.5 \mathrm{y}+2.5$, donde valores negativos indican que los ingresos de los parla-

VOLUMEN XVII · NÚMERO 2 • II SEMESTRE DE 2010

Política y gobierno 293 
El segundo grupo de datos empleados son los destinados a valorar la democracia de cada uno de los países incluidos en el estudio. Hemos utilizado tres, realizados con metodologías diferentes, con el fin de cubrir la mayor cantidad de aspectos, a saber: el Índice Freedom House (FH), el Índice de Desarrollo Democrático en América Latina (IDD-Polilat) y el Índice de Transformación de Bertelsmann (BTI) que, con metodologías diferentes, pero con aproximaciones teóricas parecidas, tratan de medir los distintos grados de desarrollo de las democracias. ${ }^{21}$ El índice Freedom House evalúa los derechos políticos y libertades civiles de las personas en 193 países del mundo: está construido sobre una escala de 1 a 7 , los valores próximos a 1 indican países libres y los valores próximos a 7 países no libres. ${ }^{22}$ Por su parte, el Índice de Desarrollo Democrático, IDD, está diseñado para medir el desarrollo democrático en América Latina y considera 31 indicadores agrupados en cuatro dimensiones: la legalidad del régimen democrático, el respeto de los derechos políticos y las libertades civiles, la calidad institucional y el grado de eficiencia política, y el ejercicio de poder efectivo para gobernar. ${ }^{23}$ Está construido sobre una escala de 1 a 10, donde valores próximos a 1 indican bajo desarrollo democrático mientras que valores próximos a 10 apuntan alto desarrollo democrático. A diferencia del FH, se combinan no sólo indicadores procedentes de percepciones subjetivas, sino también in-

mentarios están por debajo del PIB per cápita del país mientras que valores positivos indican que los ingresos de los parlamentarios son superiores al PIB per cápita del país.

${ }^{21}$ El empleo de distintos indicadores que tratan de medir la democracia nos permite montar una especie de "sistema de contraste" para ver si los resultados obtenidos son coherentes y se mantienen, independientemente de las variables y metodologías que se utilicen para medir el nivel de calidad de democracia. Además, cada uno de ellos aporta algún elemento nuevo en la medición. A pesar del debate existente en torno a la utilización de distintos índices para medir y caracterizar la democracia, los indicadores empleados en este trabajo ofrecen resultados similares, lo que aumenta la confiabilidad de nuestros resultados y refuerza su inclusión en este análisis (Norris, 2006). Sobre las ventajas y desventajas del empleo de los principales índices de democracia puede consultarse Landman (2003).

${ }^{22}$ En este trabajo el índice FH ha sido recalculado. En primer lugar se cambió la dirección de la escala de manera que valores próximos a 7 fuesen países libres y valores próximos a 1 países no libres (para una mejor interpretación de los resultados posteriores). Después se calculó el valor promedio a partir de los valores obtenidos tanto en el índice de libertades civiles como en el de libertades políticas y se estandarizó a una escala de 100 puntos, donde valores próximos a 0 indican países no libres y valores próximos a 100 países libres. http://www.freedomhouse.org/template. cfm?page $=15$.

${ }^{23}$ Para más información, consúltese: http://www.idd-lat.org/Web\%20IDD-Lat2006/Edicion\%202006.htm. 
dicadores empíricamente cuantificables. El último índice utilizado es el Índice de Transformación de Bertelsmann, ${ }^{24}$ BTI, medido en una escala de 1 a 10, donde 1 significa bajos niveles de democracia y 10 altos niveles de democracia. El BTI cuenta con dos dimensiones, una política y otra económica, en este trabajo tan sólo se ha considerado la dimensión política. En vista de que los índices no incluyen la trayectoria histórica, la durabilidad y la estabilidad de largo plazo, se ha incluido la variable "número de años en democracia desde 1948". Los datos provienen de la clasificación realizada por Mainwaring (1998).

\section{Metodología para el análisis de los datos}

Para comprobar la hipótesis de partida planteada en este trabajo, es decir, la relación entre elitismo de los parlamentarios y características de la democracia, utilizamos como herramienta de análisis la representación HJ-Biplot (Galindo, 1985, 1986), extensión de los Biplot clásicos de Gabriel (1971). ${ }^{25}$ El HJ-Biplot propuesto por Galindo $(1985,1986)$ es una representación gráfica multivariante de marcadores fila (países) y columna (nivel de estudios de los diputados y de sus padres, ingresos, indicadores de democracia e indicadores de desigualdad social), elegidos de tal forma que puedan superponerse en el mismo sistema de referencia con máxima calidad de representación.

La forma tradicional de abordar el estudio de la relación entre unas variables explicativas y una variable respuesta es utilizar un modelo de regresión múltiple; sin embargo, pocas veces se contrastan las hipótesis que requiere la correcta aplicación del modelo, probablemente porque en datos de este tipo (variables ordinales o con escalas Likert) esas hipótesis por lo general no se verifican. Estas hipótesis suponen que la relación entre las variables explicativas y la respuesta es lineal, que las variables se ajustan a un modelo normal y que son homoscedásticas (igualdad de varianzas) y que las variables explicativas son independientes. Cuando existe relación entre las variables explicativas se produce el fenómeno de la colinealidad y los

${ }^{24}$ Véase la explicación de la metodología en: http://www.bertelsmann-transformationindex.de.

${ }^{25}$ Los métodos Biplot son técnicas factoriales que permiten reducir la dimensionalidad del problema y facilitan su interpretación. Son una representación gráfica de datos multivariantes. Del mismo modo que un diagrama de dispersión permite representar de manera conjunta dos variables, un Biplot representa de forma simultánea tres o más variables (Gabriel y Odoroff, 1990).

VOLUMEN XVII · NÚMERO 2 • II SEMESTRE DE 2010

Política y gobierno

295 
coeficientes de regresión pueden no ser interpretables. Por el contrario, los métodos Biplot están libres de hipótesis y tienen como objetivo capturar las estructuras de covariación entre las variables que intervienen en el estudio y aprovechar esa covariación para sustituir las variables observables de partida (generalmente muchas) por variables latentes (generalmente dos o tres) que capturan la mayor parte de la información contenida en los datos. Los métodos Biplot presentan sus resultados sobre planos factoriales donde los ejes son las variables latentes. En los planos factoriales se representan las variables observables (nivel educativo de los legisladores, indicadores sobre calidad de la democracia y desigualdad social) y las unidades taxonómicas (países).

Una de las ventajas de esta técnica radica en que permite obtener una representación gráfica simultánea sobre la relación entre un conjunto de variables y la posición de grupos de observaciones con perfiles similares en un plano de dimensión reducida, generalmente de dos dimensiones, que serán las de mayor poder explicativo y una calidad de representación óptima. Si el porcentaje de variación explicada es alto, la representación de los datos en el plano se aproximará a los valores originales de la matriz $\mathrm{X}$ analizada con un alto grado de confiabilidad. ${ }^{26}$ El que la tasa de absorción de inercia sea alta es condición necesaria para la confiabilidad de la interpretación de los casos en el gráfico Biplot pero no es condición suficiente, ya que el hecho de que la mayoría de los casos estén bien representados en el subespacio no implica que todos lo estén. Por lo tanto, es necesario valorar la calidad de representación que se consigue para las filas y las columnas de la matriz de datos (Galindo et al., 1999).

La interpretación de los Biplot es sencilla, siguiendo a Galindo (1986), en la representación HJ-Biplot hay que tener en cuenta que:

- Cada país estará representado como un punto en un plano factorial en el que los estudios, ingresos, indicadores de democracia y de desigualdad social desempeñan el papel de variables explicativas. Por su parte, las variables se representan en el plano mediante vectores.

- En una representación HJ-Biplot, las variables que han presentado mayor variabilidad, en los distintos países de estudio, estarán representa-

\footnotetext{
${ }^{26}$ La variabilidad explicada por los ejes factoriales está determinada por la tasa de absorción de inercia, que varía entre 0 y 100, de modo que cuanto más se aproximen los valores de los ejes factoriales a 100 más confiable será la representación.
} 
das por vectores más largos (por ejemplo en la gráfica 3, el Índice de pobreza y el Índice de Desarrollo Humano (IDH) han sido las variables que mayor variabilidad han tenido en el análisis y más varianza explicarán en uno de los ejes factoriales).

- El coseno del ángulo entre dos vectores representa la correlación entre las variables. Esto significa que en un $\mathrm{HJ}$-Biplot, si dos variables están muy relacionadas tendrán un ángulo muy pequeño (próximo a $0^{\circ}$ ). Por ejemplo, en la gráfica 1, los años de democracia de un país están muy relacionados con el Índice de Desarrollo Democrático (IDD) de ese país. Si el ángulo que forman dos vectores es obtuso las variables presentarán correlaciones negativas (un ejemplo de esto se puede encontrar en la gráfica 3 con la variable ingresos del diputado y el IDH, lo que indicaría que a mayores ingresos del diputado en un determinado país menor es el IDH que presenta dicho país). Un ángulo recto entre dos vectores indica independencia entre las variables, esto se ve claramente en la gráfica 1, con la variable nivel educativo de los diputados y los indicadores de democracia.

- El ángulo que forma cada una de las variables observables (vectores) con la variable latente (ejes factoriales) se entiende en términos de relación e indica la contribución de cada uno de los ejes factoriales de la representación a la variabilidad de las variables. Esta medida se denomina contribución relativa del factor al elemento (CRFE) y se interpreta de la misma manera que un coeficiente de determinación en regresión.

- La proximidad entre los puntos que representan a los países se interpreta como similitud entre los mismos. Esto significa que si dos países aparecen próximos en el gráfico factorial compartirán un perfil similar respecto a las variables utilizadas en el análisis, especialmente si los países están bien representados. Ese perfil se genera a partir de la posición media de cada uno de los casos en el conjunto de variables incluidas en el análisis.

- La relación entre países y variables se realiza en términos de producto escalar, es decir, a partir de la proyección perpendicular de los puntos países sobre los vectores que representan a las variables. A partir de esta proyección es posible determinar la distribución aproximada que las observaciones toman sobre las variables (Gabriel y Odoroff, 1990).

- Si en un país, una variable (Índice de Desarrollo Democrático) toma un valor preponderante ese país estará representado por un punto próximo al extremo del vector que representa a esa variable. Por ejemplo, en la gráfica 1, los países situados en la parte derecha del gráfico (Chile, Costa Rica y Uruguay) son los que presentan mejores indicadores de democracia. 
Para completar el análisis y para la realización de la clasificación de países según su posición en el gráfico Biplot se ha realizado, siguiendo a Vicente (1992), un análisis cluster tomando como matriz de partida las coordenadas de los individuos en los factores retenidos en el HJ-Biplot. La ventaja del análisis cluster es que permite establecer grupos homogéneos de forma que los países pertenecientes a un mismo grupo son similares, es decir, los valores que toman en cada una de las variables utilizadas en el análisis son análogos. El criterio de agrupación utilizado es el de Ward o método de pérdida de la inercia mínima que une los casos buscando minimizar la varianza dentro de cada grupo (Vicente, Ramírez y Galindo, 1994, p. 830).

\section{Educación de los diputados y características de la democracia}

Pese a que la democracia es la forma de gobierno extendida en prácticamente toda América Latina, se pueden encontrar diferencias importantes entre los distintos países cuando se aplican indicadores que tratan de medir y analizar sus características. Uno de los objetivos de este trabajo es demostrar que en la región latinoamericana aspectos de la calidad de los políticos, en este caso medida a partir de su nivel educativo, no están relacionados con la valoración positiva o negativa que se pueda hacer desde distintas metodologías del funcionamiento de la democracia existente en cada país. En resumen, una mayor preparación académica de los parlamentarios no es relevante para el mejor rendimiento de la democracia.

Para ello se ha recurrido a una representación HJ-Biplot (gráfica 1), ${ }^{27}$ que pone de manifiesto que no existe relación entre las características de la democracia en el país y el nivel educativo de los diputados latinoamericanos, si bien contribuye a explicar el posicionamiento de los países en la

\footnotetext{
${ }^{27}$ Antes de interpretar las gráficas Biplot habría que tener en cuenta una serie de aspectos importantes del análisis. Por un lado la bondad de ajuste de la representación Biplot en el subespacio de máxima inercia (es decir, conocer cuál es la cantidad de información retenida en el análisis), y por otro, la parte de variabilidad de cada una de las variables explicadas por el factor y la calidad de representación de los países en las gráficas. Dado que la variabilidad total de los datos no puede ser recogida en una sola gráfica, puesto que no se trata de un fenómeno bidimensional, se han retenido los tres primeros ejes factoriales del HJ-Biplot. La tasa de inercia en el primer plano factorial (es decir, la cantidad de información retenida), formada por el eje 1 y 2 , alcanza 90.9 por ciento, consiguiéndose en el espacio, formado por los tres primeros ejes, 96.2 por ciento de la variabilidad total en los datos, lo que garantiza la confiabilidad de la interpretación con una pérdida de información pequeña (9\%).
} 
CUADRO 1. Contribuciones relativas del factor al elemento para el nivel educativo de los diputados latinoamericanos y características de la democracia

\begin{tabular}{lrrc}
\hline Variables & Eje 1 & Eje 2 & Eje 3 \\
\hline Nivel de estudios & 0 & 986 & 10 \\
Índice Freedom House (FH) & 915 & 1 & 42 \\
Índice de Desarrollo Democrático (IDD) & 881 & 9 & 10 \\
Índice de Transformación Bertelsmann (BTI) & 904 & 45 & 10 \\
Años de democracia (Durabilidad) & 773 & 33 & 192 \\
\hline
\end{tabular}

Fuente: Elaboración propia a partir de los resultados HJ-Biplot.

gráfica y ayuda a remarcar las diferencias existentes entre los políticos de unos países y otros. El vector que representa la formación académica y los vectores relativos a la democracia en el país forman un ángulo recto, lo que indica independencia entre las variables.

Por otro lado, la gráfica 1 muestra, como era de esperar, la alta correlación entre los indicadores que valoran las características de la democracia y los gobiernos (los ángulos que forman los vectores que representan a estas variables son próximos a $0^{\circ}$ ), lo avala la coherencia de los estudios sobre la calidad de la democracia ${ }^{28}$ y comprueba de forma contundente las diferencias existentes entre los países de la región, a la vez que reafirma nuestra estrategia de estudio consistente en usar una serie de indicadores con el fin de cubrir un mayor número de aspectos valorados.

En los cuadros 1 y 2 se presentan las contribuciones relativas del factor al elemento (CRFE) tanto para el nivel de estudio de los parlamentarios como para los indicadores de democracia y los países, desglosados por ejes factoriales. Estas contribuciones indican la parte de dispersión de un elemento explicada por un factor, de modo que si un elemento recibe una alta contribución de un factor y baja de los demás, indica que ese elemento es una característica casi exclusiva de ese factor, y serán esos elementos los más importantes a la hora de interpretar dicho eje..$^{29}$ Las variables mejor representadas en el eje 1 serán las que más discriminen a los países en el primer plano factorial (eje 1-2).

\footnotetext{
${ }^{28}$ Véanse Alcántara (2008), y Levine y Molina (2007), entre otros.

${ }^{29}$ La CRFE toma valores entre 0 y 1000.
} 
Las cinco variables incluidas en el análisis contribuyen de manera significativa a la identificación de los distintos grupos de países, si bien el Índice Freedom House y el Índice de Transformación de Bertelsmann son los que mayor importancia explicativa tienen en la posición de los países, con una contribución de 915 y 904, respectivamente en el eje 1 (cuadro 1). Por su parte, el nivel educativo resulta ser la única característica propia del eje 2, es decir, recibe una fuerte contribución del eje 2 y baja de los demás.

A partir de los datos que muestra el cuadro 2, se puede decir que son característicos del eje 1, es decir, se diferencian del resto por su posicionamiento en las variables relativas a democracia: Costa Rica (966), Chile (914), Guatemala (835) y Uruguay (798), principalmente, unos países por valores altos en estas variables y otros, como es el caso de Guatemala, por sus bajos valores en los indicadores de democracia. Mientras que Brasil, Colombia, Paraguay y República Dominicana tienen las contribuciones más altas del eje 2, de manera que se diferenciarán del resto de los países por la formación académica de sus parlamentarios.

El posicionamiento de las cinco variables en el primer plano factorial (gráfica 1) permite diferenciar a países como Chile, Costa Rica y Uruguay, situados en la parte derecha del gráfico, con los mejores índices de calidad de la democracia de toda América Latina, de Guatemala, Paraguay, Nicaragua, Ecuador, Colombia y Bolivia con los peores indicadores de democracia de la región, todos ellos situados en la parte izquierda de la gráfica. ${ }^{30}$

Por otra parte, el eje 2 divide a los países según el nivel de elitismo educativo de sus parlamentarios. Países como Colombia, Nicaragua, Ecuador, Chile y República Dominicana, con las élites académicamente más formadas de la región, se sitúan en la parte superior del gráfico. No en vano, 61 por ciento de los actuales diputados colombianos tiene estudios de posgrado (una situación de privilegio si tenemos en cuenta que 24 por ciento de la población colombiana tiene acceso a educación terciaria), al igual que 47

${ }^{30}$ La ubicación de los países en la gráfica se obtiene de la proyección perpendicular de cada uno de ellos sobre los vectores que representan a las variables. Todos los países localizados cerca de la punta de la flecha que representa las variables relativas a democracia serán aquellos con mejores puntuaciones en esas variables y con un mayor grado de institucionalización democrática, mientras que los situados en los extremos opuestos de estos vectores serán los que tengan peores indicadores de democracia. Lo mismo sucede con el nivel de estudios alcanzado, los países situados cerca de la punta de la flecha que representa a esta variable tendrán la formación académica más elevada mientras que los situados en el otro extremo tendrán un nivel de estudios inferior. 
CUADRO 2. Contribuciones relativas del factor al elemento para nivel de estudios de los diputados y características de la democracia

\begin{tabular}{lrrr}
\hline Países & Eje 1 & Eje 2 & Eje 3 \\
\hline Argentina (ARG) & 473 & 360 & 99 \\
Bolivia (BOL) & 565 & 198 & 221 \\
Brasil (BR) & 4 & 829 & 1 \\
Chile (CH) & 914 & 69 & 2 \\
Colombia (CO) & 370 & 534 & 59 \\
Costa Rica (CR) & 966 & 28 & 5 \\
Ecuador (ECU) & 558 & 372 & 68 \\
El Salvador (SAL) & 498 & 429 & 11 \\
Guatemala (GU) & 835 & 2 & 114 \\
Honduras (HON) & 503 & 408 & 6 \\
México (ME) & 81 & 76 & 625 \\
Nicaragua (NI) & 614 & 291 & 33 \\
Panamá (PAN) & 196 & 17 & 642 \\
Paraguay (PAR) & 406 & 559 & 1 \\
Perú (PE) & 635 & 237 & 13 \\
República Dominicana (RDOM) & 0 & 573 & 22 \\
Uruguay (URU) & 798 & 185 & 13 \\
\hline Fin & 514 & \\
\hline
\end{tabular}

Fuente: Elaboración propia a partir de los resultados HJ-Biplot.

por ciento de los chilenos y 44 por ciento de los peruanos. Mientras que los países con diputados que tienen una menor formación académica ${ }^{31}$ se sitúan en la parte inferior, un ejemplo claro de ello es el de Paraguay, Uruguay, Brasil u Honduras, donde tan sólo uno de cada seis parlamentarios tiene estudios de posgrado.

${ }^{31}$ Partimos del hecho de que 89 por ciento de los actuales parlamentarios latinoamericanos tienen estudios universitarios, ya sean de grado medio o superior. Por lo tanto, cuando hablamos de países con élites con menor nivel formativo nos estamos refiriendo, por ejemplo, a tener un menor número de parlamentarios con estudios de posgrado o un mayor número de ellos con estudios universitarios medios. 
GRÁFICA 1. Representación de los países, nivel de estudios de los diputados latinoamericanos y características de la democracia a partir del análisis HJ-Biplot

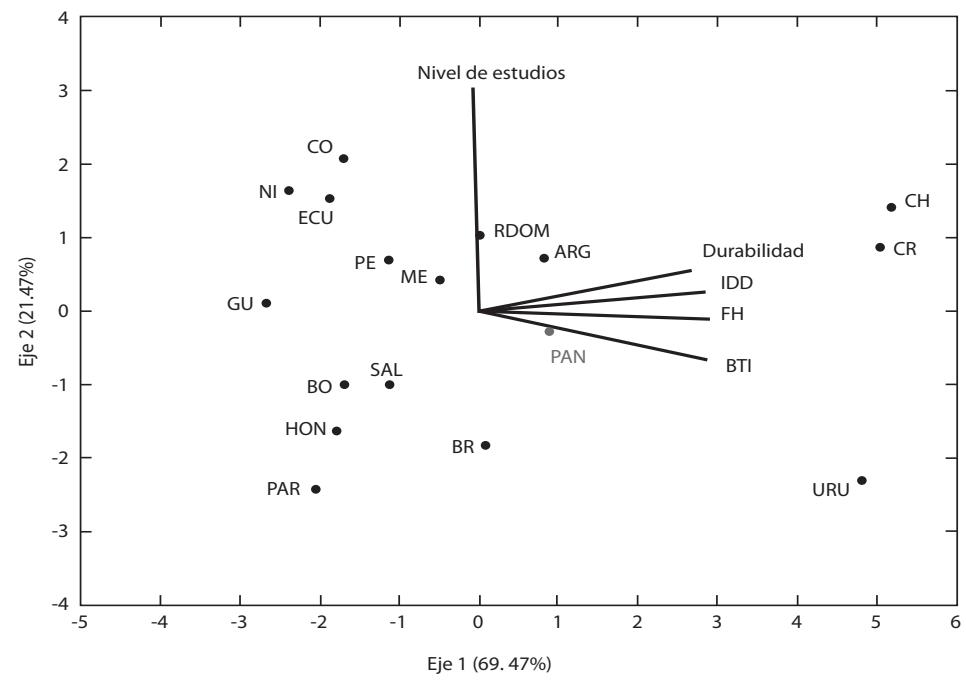

Fuente: Datos PELA (2005-2009), World Bank: Konrad Adenauer y Polilat. http://www.idd-lat.org/Edicion\%202006.htm, http://www.freedomhouse.org, http://www.bertelsmann-transformation-index.de/ y Mainwaring (1998).

Una vez corroborada, en parte, nuestra hipótesis de partida - los ejemplos más claros serían Colombia, Nicaragua, Ecuador o Uruguay-clasificaremos a los países latinoamericanos a partir del nivel de estudios de su clase política y las características de la democracia. Para ello, se usará un análisis de conglomerados jerárquico, tomando como variables las coordenadas de los países en los tres ejes factoriales retenidos en el HJ-Biplot. ${ }^{32}$ Como se mencionó en el apartado de metodología, una de las ventajas de aplicar el método cluster a partir de las coordenadas del Biplot es que hace posible determinar qué variables son las responsables de la formación de los distintos clusters.

${ }^{32}$ El método utilizado para la agrupación de países es el método Ward o de pérdida de inercia mínima (Vicente, Ramírez y Galindo, 1994, p. 829). 
GRÁFICA 2. Dendograma de agrupación de los países según nivel educativo de los diputados latinoamericanos y características de la democracia

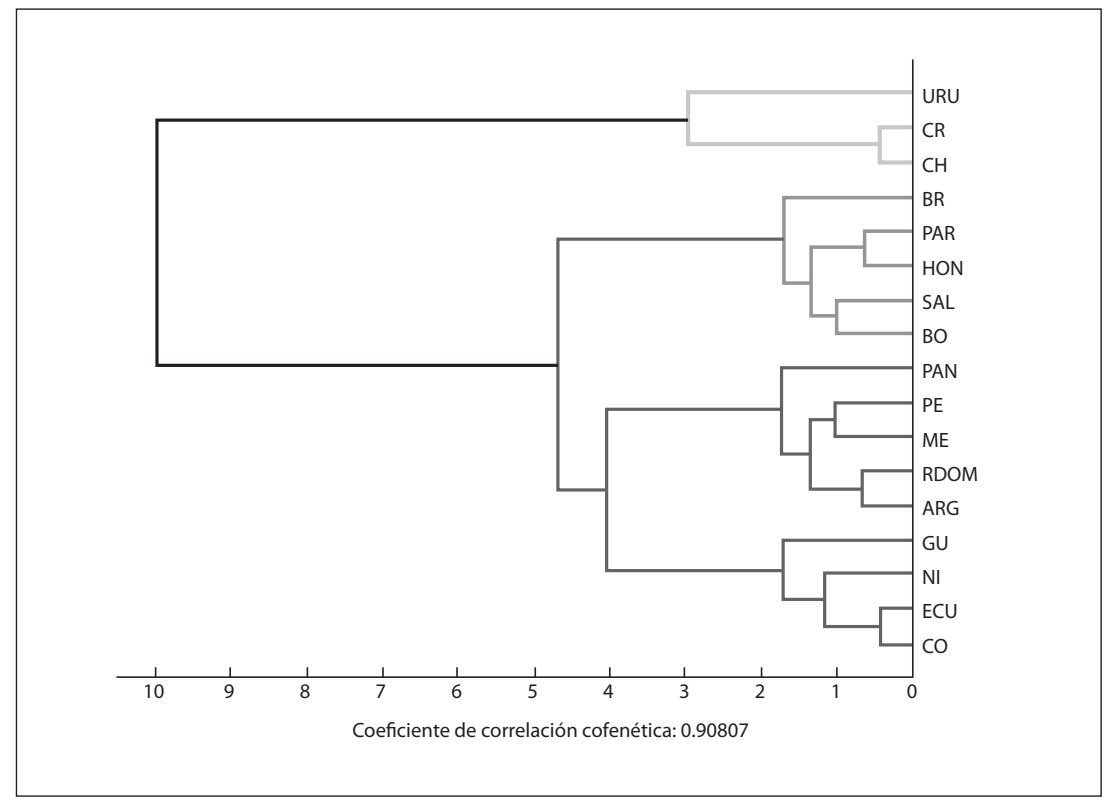

Fuente: Elaboración propia a partir de las coordenadas del HJ-Biplot.

La clasificación de los países de acuerdo con este método se presenta en la gráfica 2, en la que se observan tres grupos bien diferenciados. ${ }^{33} \mathrm{El}$ primero formado por Chile, Costa Rica y Uruguay, el segundo por Paraguay, Honduras, El Salvador, Bolivia y Brasil y, el último, el más numeroso, por Ecuador, Colombia, Nicaragua, Guatemala, Argentina, República Dominicana, México, Perú y Panamá. Para determinar las diferentes configuraciones de los clusters en los planos factoriales del HJ-Biplot, se han analizado detenidamente las CRFE de aquellas variables con mayor incidencia en la formación de los clusters (Vicente et al., 1994, p. 830).

${ }^{33}$ Se ha utilizado como medida de buena clasificación el coeficiente de correlación cofenética (Rohlf y Sokal, 1981) que varía entre 0 y 1 . Si el valor está próximo a 0 existe una distorsión entre las distancias iniciales y las resultantes del análisis de conglomerados jerárquico, mientras que si el valor está próximo a 1 indica que hay una buena estructura jerárquica entre los casos analizados. En este estudio, el coeficiente de correlación cofenética es de 0.91 , lo que nos permite hablar de una buena clasificación de los casos. 
CUADro 3. Clusters de clasificación según nivel educativo de los diputados y características de la democracia

\begin{tabular}{|c|c|c|c|c|}
\hline \multirow[t]{3}{*}{ Clusters } & \multirow[t]{3}{*}{ Países } & \multirow[t]{3}{*}{ Ejes } & \multicolumn{2}{|c|}{ Variables } \\
\hline & & & \multicolumn{2}{|c|}{ Planos } \\
\hline & & & $1-2$ & $1-3$ \\
\hline \multirow{4}{*}{1} & Costa Rica & 1 & FH (916) & \\
\hline & Uruguay & 1,2 & IDD (890) & \\
\hline & Chile & 1 & ВтІ (949) & \\
\hline & & & Durabilidad (806) & \\
\hline \multirow{5}{*}{2} & Brasil & 2 & Nivel de estudios (986) & Durabilidad (965) \\
\hline & Paraguay & 2,1 & $\mathrm{FH}(916)$ & \\
\hline & Honduras & 1,2 & IDD (890) & \\
\hline & El Salvador & 1,2 & BTI (949) & \\
\hline & Bolivia & 1,3 & & \\
\hline \multirow{9}{*}{3} & Panamá & 3,1 & $\mathrm{FH}(916)$ & Durabilidad (965) \\
\hline & Perú & 1,2 & IDD (890) & \\
\hline & México & 3 & ВтІ (949) & \\
\hline & $\begin{array}{l}\text { República } \\
\text { Dominicana }\end{array}$ & 2 & Nivel de estudios (986) & \\
\hline & Argentina & 1,2 & & \\
\hline & Guatemala & 1,3 & & \\
\hline & Nicaragua & 1,2 & & \\
\hline & Ecuador & 1,2 & & \\
\hline & Colombia & 2,1 & & \\
\hline
\end{tabular}

Fuente: Elaboración propia con resultados del HJ-Biplot y análisis de conglomerados.

El primer cluster, constituido por Costa Rica, Uruguay y Chile, se determina de manera casi exclusiva por los atributos de sus democracias y un alto grado de institucionalización. Son países que tienen, con diferencias, los mejores indicadores en este campo de toda América Latina. Sin embargo, el nivel educativo es lo que distancia dentro de este grupo a Chile y Costa 
Rica (situados en la parte superior de la gráfica 1) de Uruguay (posicionado en la parte inferior de la misma gráfica). El caso de Uruguay merece mención aparte, ya que muestra que el nivel educativo de los diputados - comparativamente bajo- no es ningún impedimento para tener una de las democracias de más calidad de la región.

El segundo cluster, compuesto por Brasil, Paraguay, Honduras, El Salvador y Bolivia, se forma principalmente debido a que sus diputados se caracterizan por tener un nivel de estudios inferior al del resto de sus pares latinoamericanos (cuadro 3). A pesar de que, como ya se ha señalado en este trabajo, la mayoría de los diputados latinoamericanos cuenta con estudios universitarios, en estos países existe un mayor número de legisladores con estudios universitarios medios o incompletos, los valores más bajos en esta variable los encontramos en Paraguay, Brasil y Honduras (gráfica 1). Aunque en la configuración de este cluster las variables relativas a calidad de la democracia han tenido una incidencia menor, lo cierto es que podemos decir que todos estos países tienen unos indicadores de calidad de la democracia regulares, si bien mejores que los presentados por los países del cluster 3 .

Por último, el tercer cluster está formado por Ecuador, Colombia, Nicaragua, Guatemala, Argentina, República Dominicana, México, Perú y Panamá. Este grupo se caracteriza por tener unos bajos indicadores en la valoración de sus democracias y un nivel de estudios muy alto (situados en el cuadrante superior izquierdo de la gráfica 1), con la excepción de Panamá y Guatemala, con élites menos formadas académicamente.

\section{Educación, características de la democracia y desigualdad social}

Que la educación de la clase política no es un factor que incida de forma clara en el rendimiento de la democracia en un país parece que es un hecho demostrado en este trabajo. Ahora bien, queda aún por contrastar nuestro planteamiento inicial de que una élite parlamentaria más preparada académicamente, en América Latina, puede ser un posible indicador del grado de elitismo de la clase política, en países con un alto grado de desigualdad social, y donde el porcentaje medio de población con acceso a estudios terciarios en toda la región es de 28 por ciento.

¿Pero influyen o están relacionados los ingresos de los diputados y el nivel de estudios de los padres (vistos como un elemento de mayor o menor movilidad social) con las características de la democracia en el país? Para 
CUADRO 4. Contribuciones relativas del factor al elemento para el nivel educativo de los diputados latinoamericanos, características de la democracia e indicadores de desigualdad y movilidad social

\begin{tabular}{lccc}
\hline Variables & Eje 1 & Eje 2 & Eje 3 \\
\hline Nivel de estudios & 28 & 547 & 7 \\
Índice Freedom House (FH) & 774 & 108 & 42 \\
Índice de Desarrollo Democrático (IDD) & 808 & 16 & 101 \\
Índice de Transformación Bertelsmann (BTI) & 714 & 196 & 29 \\
Años de democracia (Durabilidad) & 695 & 21 & 2 \\
Ingresos & 546 & 0 & 382 \\
Índice de Desarrollo Humano (IDH) & 862 & 12 & 17 \\
Índice de pobreza humana (I. Pobreza) & 826 & 0 & 42 \\
Nivel de estudios del padre & 77 & 835 & 21 \\
Nivel de estudios de la madre & 245 & 643 & 34 \\
\hline
\end{tabular}

Fuente: Elaboración propia a partir de los resultados HJ-Biplot.

ello se ha recurrido nuevamente a una representación HJ-Biplot (gráfica 3) con las siguientes variables: nivel de estudios del diputado, nivel de estudios de los padres, indicador de ingresos del diputado, indicadores de democracia (FH, BTI e IDD), años de la democracia, Índice de Desarrollo Humano e índice de pobreza en el país.

El primer eje factorial del análisis Biplot recoge la mayor parte de la información y absorbe 55.8 por ciento de la variabilidad total de los datos; es decir, las variables mejor representadas en el eje 1 serán las que más discriminen a los países en el primer plano factorial (eje 1-2). Las variables con mayor calidad de representación en esta dimensión son las relacionadas con la democracia y los indicadores de desigualdad social (cuadro 4). El segundo y tercer eje aportan una menor información ( 23.8 y 6.8 por ciento, respectivamente), aunque ofrecen resultados interesantes para alguna de las variables del estudio, así como para algunos de los países objeto de análisis. El segundo eje está definido, básicamente, por el nivel educativo, tanto de los diputados como de sus padres. La bondad de ajuste global en el espacio formado por los tres primeros ejes $(1,2$ y 3$)$ alcanza 86.3 por ciento, lo que 
garantiza la interpretación de los datos y justifica la decisión final de explicar sólo los tres primeros ejes en el análisis. ${ }^{34}$

El cuadro 4 pone de manifiesto que las diez variables incluidas en el análisis contribuyen de manera significativa a la identificación de los distintos grupos de países, si bien el Índice de Desarrollo Humano, el Índice de pobreza y el Î́ndice de Desarrollo Democrático son los que mayor importancia explicativa tienen en la posición de los países, con una contribución de 862,826 y 808 , respectivamente en el eje 1 . Por su parte, el nivel educativo, tanto de los diputados como de sus padres, resulta ser la única característica propia del eje 2 (es decir, recibe una fuerte contribución del eje 2 y baja de los demás). La calidad de representación en las gráficas Biplot para prácticamente la totalidad de los países es buena o aceptable, de modo que es posible extraer conclusiones confiables respecto a las proyecciones de los países sobre las variables utilizadas (cuadro 5).

La gráfica 3 pone de manifiesto dos aspectos importantes: uno, la clara división entre los distintos países latinoamericanos en función, por un lado, de las características de la democracia, desarrollo humano, pobreza y elitismo económico de los actuales parlamentarios latinoamericanos y, por otro, del nivel educativo (considerando tanto los estudios de los diputados como los de sus padres). Un análisis más detallado de la clasificación de países a partir de su posicionamiento en la gráfica la veremos más adelante (gráfica 4).

Se mantiene, a pesar de la inclusión en el análisis de variables contextuales, la fuerte correlación entre los distintos indicadores de democracia, así como de los años del régimen democrático, con ángulos entre los vectores que los representan próximos a cero. $\mathrm{Al}$ igual que la relación existente entre IDH y pobreza con indicadores de democracia. A mayor desarrollo humano y menores niveles de pobreza en un país, mejores son los indicadores sobre su democracia.

Los resultados del HJ-Biplot también muestran que el nivel educativo de los diputados no es relevante para obtener mejores indicadores de democracia y que, con la introducción en el análisis de otras variables relativas a su situación económica o a su familia de origen, pierde poder explicativo (cuadro 4). Sin embargo, algo que empíricamente no ha sido demostrado es si existe relación entre los ingresos de los parlamentarios y la situación de la

\footnotetext{
${ }^{34}$ Por cuestión de espacio y dado que la dimensión 3 del análisis Biplot no aporta información determinante que no pueda ser explicada por el primer plano factorial, no se presenta en este trabajo la gráfica formada por los ejes 1-3.
} 
CUADRO 5. Contribuciones relativas del factor al elemento para el nivel educativo de los diputados latinoamericanos, características de la democracia e indicadores de desigualdad y movilidad social

\begin{tabular}{|c|c|c|c|}
\hline Países & Eje 1 & Eje 2 & Eje 3 \\
\hline Argentina (ARG) & 564 & 105 & 279 \\
\hline Bolivia (BOL) & 553 & 11 & 90 \\
\hline Brasil (BR) & 4 & 697 & 52 \\
\hline Chile $(\mathrm{CH})$ & 772 & 111 & 106 \\
\hline Colombia (co) & 16 & 704 & 128 \\
\hline Costa Rica (CR) & 694 & 182 & 4 \\
\hline Ecuador (ECU) & 19 & 780 & 136 \\
\hline El Salvador (SAL) & 692 & 258 & 13 \\
\hline Guatemala (cu) & 822 & 8 & 8 \\
\hline Honduras (HON) & 712 & 52 & 159 \\
\hline México (ME) & 168 & 442 & 5 \\
\hline Nicaragua (NI) & 662 & 111 & 7 \\
\hline Panamá (PAN) & 74 & 32 & 309 \\
\hline Paraguay (PAR) & 487 & 350 & 7 \\
\hline Perú (PE) & 32 & 765 & 73 \\
\hline República Dominicana (RDOM) & 94 & 301 & 3 \\
\hline Uruguay (URU) & 628 & 325 & 0 \\
\hline
\end{tabular}

Fuente: Elaboración propia a partir de los resultados HJ-Biplot.

democracia en la región. Pues bien, al observar en la gráfica 3 el ángulo que forman cualesquiera de los vectores que representan los indicadores de democracia y el vector de los ingresos se puede concluir que efectivamente existe una relación entre ambos indicadores, aunque se trata de una correlación negativa (al ángulo que forman ambos vectores es obtuso). Lo que se traduce en que a valores altos en el indicador de ingresos de los diputados de un país, valores bajos en las variables de democracia. Lo que conduce a 
GRÁFICA 3. Representación de los países, para el nivel educativo de los diputados latinoamericanos, características de la democracia e indicadores de desigualdad y movilidad social

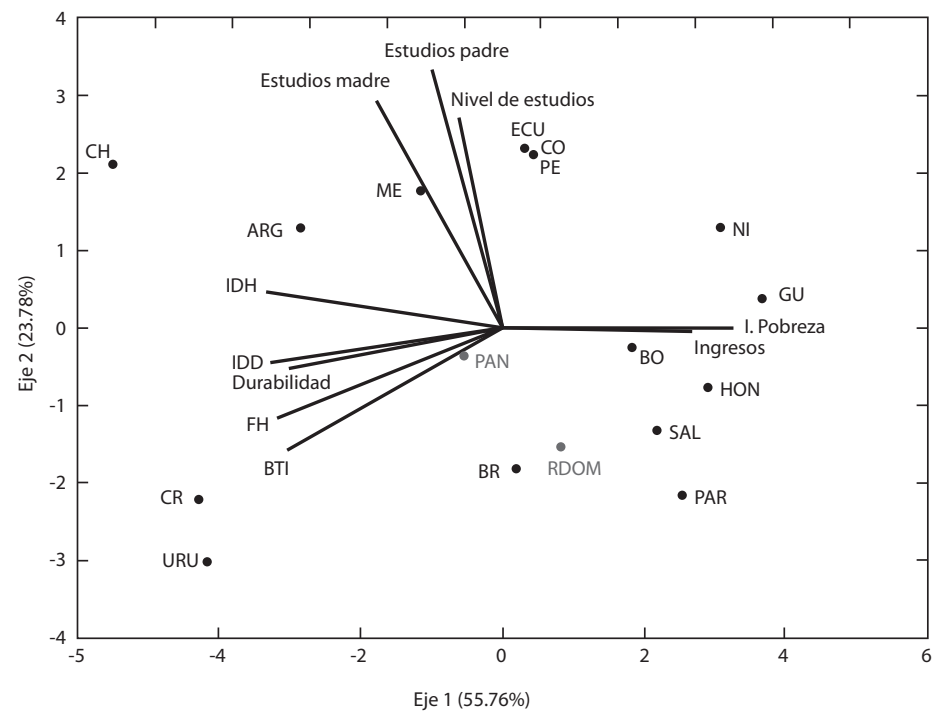

Fuente: Datos Pela (2005-2009), World Bank: Konrad Adenauer y Polilat. http://www.idd-lat.org/Edicion\%202006.htm, http://www.freedomhouse.org, http://www.bertelsmann-transformation-index.de/, Mainwaring (1998) y http://www.hdr.undp.org/es/informes/mundial/.

pensar que cuanto mayor sea la distancia económica entre élites y población, el acceso a los mecanismos formales e informales del poder puede resultar más restrictivo y, por lo tanto, repercutir en la situación de la democracia.

Los ejemplos más claros de que la desigualdad económica entre la clase política y la población se traduce en bajos niveles de calidad de la democracia se encuentran en Guatemala, Ecuador, Bolivia, Nicaragua, Honduras y Paraguay. De manera contraria, en los países con menor desigualdad económica entre parlamentarios y población, Uruguay, Costa Rica y Chile, los datos de la democracia son los mejores de América Latina. De igual modo, a partir de la gráfica 3 se puede señalar que existe una estrecha relación entre nivel de estudios de los padres y nivel de estudios de los hijos, sin embargo, no existe relación alguna entre el nivel de ingresos de los diputa- 
dos y los estudios alcanzados, lo que hace presuponer que hay factores de bienestar heredados.

Para completar los resultados obtenidos en el análisis HJ-Biplot, se ha realizado un análisis de conglomerados jerárquico tomando como variables las coordenadas de los países en los tres ejes factoriales retenidos. ${ }^{35}$ La clasificación de los países de acuerdo con este método se presenta en la gráfica 4, en la que se observan tres grupos bien diferenciados. El primer cluster, constituido por Costa Rica, Uruguay y Chile, se determina de manera casi exclusiva por los indicadores de calidad de la democracia, nivel de desarrollo humano y nivel de pobreza en el país (cuadro 6). Los tres países que forman este grupo se caracterizan por tener, con diferencia, los mejores indicadores de democracia de toda América Latina, los índices de pobreza más bajos de la región y un índice de desarrollo humano también elevado. El nivel educativo, tanto del diputado como de sus padres, es lo que distancia dentro de este grupo a Chile y Costa Rica de Uruguay. No debemos olvidar que los parlamentarios chilenos son unos de los que tienen mayor formación universitaria de la región, al igual que sus padres. Por el contrario, Uruguay cuenta con el menor número de diputados con estudios de posgrado de la región. Aunque en menor medida, la menor desigualdad económica en estos países entre ciudadanos y élite también ha contribuido notablemente a la configuración de este cluster.

El segundo cluster está formado por Panamá, República Dominicana, Brasil, Nicaragua, Guatemala, Honduras, Paraguay, El Salvador y Bolivia (cuadro 6). Dentro de este grupo podemos hablar de dos subgrupos de países, uno que se caracteriza básicamente por tener bajos indicadores de democracia, bajos índices de desarrollo humano y una elevada pobreza: Nicaragua, Guatemala, Honduras, Paraguay, El Salvador y Bolivia. Y otro caracterizado por tener un elitismo educativo medio y procedencia de familias con una formación académica baja, como es el caso de Panamá, Brasil y República Dominicana — este último adopta esta posición no tanto por el nivel educativo de los diputados como por el de sus padres, uno de los más bajos de toda América Latina, aunque sus indicadores de democracia son medios. El siguiente plano donde encontramos información sobre este clus-

\footnotetext{
${ }^{35}$ El método utilizado para la agrupación de países es el método Ward o de pérdida de inercia mínima (Vicente, Ramírez y Galindo, 1994, p. 829). El coeficiente de correlación cofenética obtenido es de 0.82 , por lo que se puede considerar buena la clasificación obtenida del análisis de conglomerados jerárquico.
} 
GRÁFICA 4. Dendograma de agrupación de los países según nivel educativo de los diputados latinoamericanos, características de la democracia e indicadores de desigualdad y movilidad social

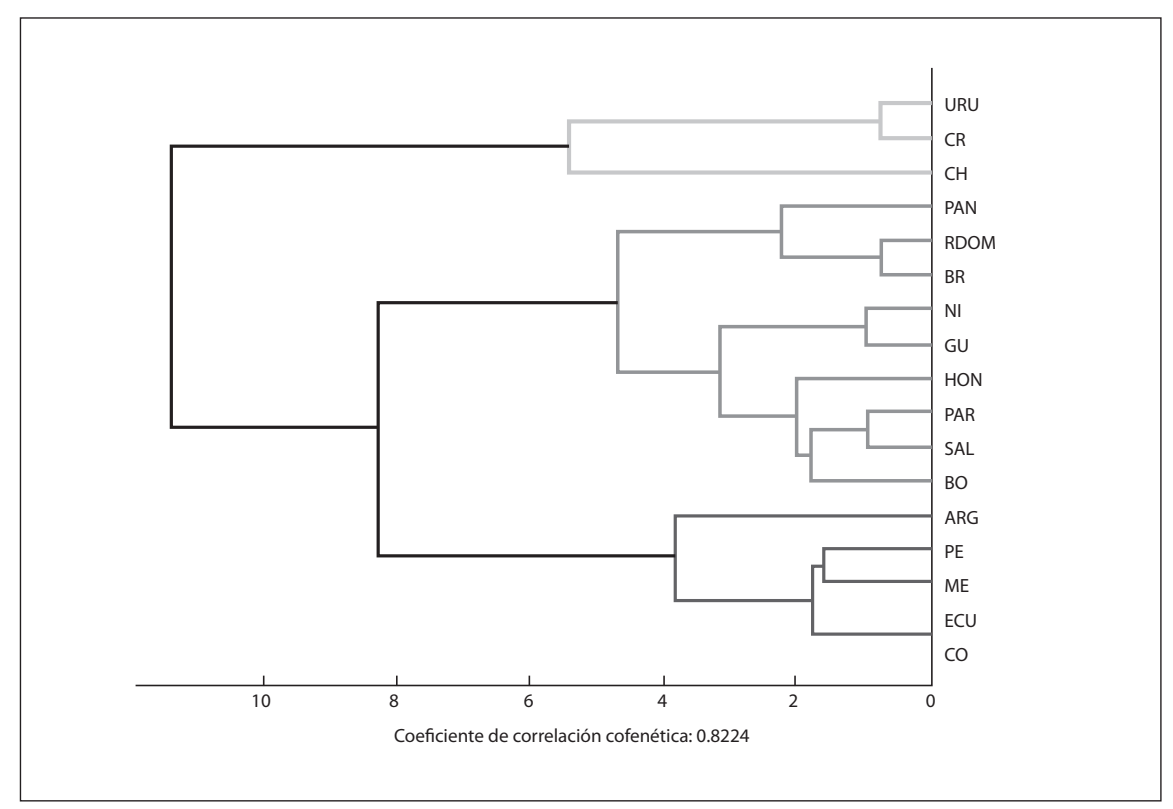

Fuente: Elaboración propia a partir de las coordenadas del HJ-Biplot.

ter es en el plano 1-3, donde la variable ingresos tiene una relevancia especial, ya que los sueldos de los parlamentarios de estos nueve países son elevados, sobre todo en Guatemala, Honduras o Nicaragua, que presentan los valores más altos en esta variable.

Por último, el grupo formado por Argentina, Perú, México, Ecuador y Colombia (cuadro 6) se determina principalmente por el elevado nivel educativo de sus diputados así como su procedencia familiar, se trata de diputados con padres que cuentan con una de las formaciones académicas más elevadas de la región. El nivel de ingresos de los diputados de estos países también tiene una relevancia especial en la formación de este grupo. En la gráfica 3 se aprecia como el elitismo económico de los parlamentarios de Ecuador, Colombia y Perú es relativamente alto, si bien no es el caso de Argentina o México, donde la distancia económica entre diputados y ciudadanos es menor, próxima a la de los países del primer cluster. 
CUADRO 6. Clusters de clasificación según nivel educativo de los diputados latinoamericanos, características de la democracia e indicadores de desigualdad y movilidad social

\begin{tabular}{|c|c|c|c|c|}
\hline \multirow[t]{3}{*}{ Clusters } & \multirow[t]{3}{*}{ Países } & \multirow[t]{3}{*}{ Ejes } & \multicolumn{2}{|c|}{ Variables } \\
\hline & & & \multicolumn{2}{|c|}{ Planos } \\
\hline & & & $1-2$ & $1-3$ \\
\hline \multirow{3}{*}{1} & Costa Rica & 1,2 & $\mathrm{FH}(882)$ & Ingresos (928) \\
\hline & Uruguay & 1,2 & IDD (824) & IDH (874) \\
\hline & Chile & 1,2 & ВТІ (910) & \\
\hline \multirow{9}{*}{2} & Panamá & 3,1 & Durabilidad (716) & \\
\hline & $\begin{array}{l}\text { República } \\
\text { Dominicana }\end{array}$ & 2,1 & $\begin{array}{l}\text { Estudios del padre } \\
(912)\end{array}$ & \\
\hline & Brasil & 2,0 & $\begin{array}{l}\text { Estudios de la } \\
\text { madre (888) }\end{array}$ & \\
\hline & Nicaragua & 1,2 & Í. Pobreza (826) & \\
\hline & Guatemala & 1,0 & & \\
\hline & Honduras & 1,3 & & \\
\hline & Paraguay & 1,2 & & \\
\hline & El Salvador & 1,2 & & \\
\hline & Bolivia & 1,0 & & \\
\hline \multirow{5}{*}{3} & Argentina & 1,3 & & \\
\hline & Perú & 2,0 & & \\
\hline & México & 2,1 & & \\
\hline & Ecuador & 2,3 & & \\
\hline & Colombia & 2,3 & & \\
\hline
\end{tabular}

Fuente: Elaboración propia con resultados del HJ-Biplot y análisis de conglomerados. 


\section{Conclusiones}

A partir de los datos analizados en este trabajo se confirma la hipótesis planteada y que el nivel educativo de los diputados no es relevante para el buen funcionamiento de la democracia en los países latinoamericanos. Más bien, llama la atención el hecho de que un grupo significativo de países con élites legislativas bastante educadas tengan unas democracias de calidad relativa. Se observa también que el nivel de estudios puede reflejar situaciones de privilegio social o económico de los diputados.

Cabe señalar que es notablemente elevado el nivel de estudios de los diputados latinoamericanos en promedio, lo que nos lleva a plantear que se trata de élites que, en teoría, tienen una buena educación formal y que, para buena parte de los países considerados, además, provienen de hogares con un contexto sociocultural relativamente alto, a juzgar por el nivel educativo de los padres.

Otro de los hallazgos del trabajo es la estrecha relación entre los ingresos económicos de los diputados y la situación de la democracia de sus respectivos países. En aquellos países con una clase política con más ingresos, los indicadores que valoran la democracia son malos y viceversa. Sin embargo, es necesario señalar que hay significativas diferencias entre los niveles de ingresos de los diputados latinoamericanos, lo que pondría en cuestionamiento la visión, bastante generalizada y aún por ser estudiada, de que la política en América Latina está destinada sólo a los sectores con mayores recursos. No queremos decir con esto que los ingresos de los diputados sean bajos, sino que la presencia de oligarquías en la política varía sustancialmente entre países, variación que tiene algún impacto en el funcionamiento de la democracia y, sobre todo, si tomamos en cuenta las desigualdades estructurales de los países.

También se confirma, una vez más, lo que ha sostenido la literatura: que existe una estrecha relación entre las condiciones socioeconómicas, en este caso medidas a través del IDH y el índice de pobreza, y la situación democrática de los países. Se observa claramente que los países con menor desarrollo humano y con mayores índices de pobreza son a la vez los que tienen democracias peor valoradas. Pero, y aquí otro elemento planteado por la hipótesis, la situación de las élites en esos países no siempre se corresponde, y de manera considerable, con la de la población, ya que cuentan, en promedio, con ingresos elevados y una buena educación. 
Por último, nos gustaría señalar que la trayectoria de las instituciones políticas de los países parece ser determinante para comprender las características de la élite política. Los países con una trayectoria democrática más larga muestran una configuración de élites distinta a la de los países con experiencias democráticas más erráticas. En este sentido, cabe prestar mayor atención al papel de los partidos políticos y de los otros mecanismos de acceso al sistema político, ya que éstos son los medios por excelencia para generar oportunidades y equilibrar las posibilidades de los sectores económicamente dispares. $\mathbf{P}_{\mathbf{g}}$

\section{Referencias bibliográficas}

Aberbach, Joel, Robert Putnam y Bert Rockman (1981), Bureaucrats and Politicians in Western Democracies, Cambridge, Harvard University Press. Albertoni, Ettore (1988), "Teoría de las élites y elitismo (apuntes para un análisis histórico y actual)”, Sistema: Revista de Ciencias Sociales, 83, pp. 43-56.

Alcántara, Manuel (ed.) (2006), Políticos y política en América Latina, Madrid, Siglo XXI.

(2008), "La democracia en América Latina: Calidad y rendimiento", Sistema, 203-204, pp. 125-147.

Alcántara, Manuel y Cristina Rivas (2007), "Las dimensiones de la polarización partidista en América Latina”, Política y Gobierno, XIV(2), pp. 349-390.

Almond, Gabriel y Sidney Verba (1963), The Civic Culture, Princeton, Princeton University Press.

Altman, David y Aníbal Pérez Liñán (2002), "Assessing the Quality of Democracy: Freedom, Competitiveness and Participation in Eighteen Latin American Countries", Democratiæation, 9(2), pp.85-100.

Andersen, L. (2001), "Social Mobility in Latin America: Links with Adolescent Schooling”, documento de trabajo R-433, Washington D.C., Banco Interamericano de Desarrollo, pp. 1-45.

Behrman, Jere, Alejandro Gaviria y Miguel Székely (2001), Intergenerational Mobility in Latin America", documento de trabajo 452, Washington D.C., Banco Interamericano de Desarrollo, pp. 1-38.

Besley, Timothy (2005), "Political Selection", The Journal of Economic Perspectives, 19(3), pp. 43-60. 
Best, Heinrich y Maurizio Cotta (eds.) (2000), Parliamentary Representatives in Europe 1848-2000, Oxford, Oxford University Press.

Brady, David, Kara Buckley y Douglas Rivers (1999), "The Roots of Careerism in the U.S. House of Representatives", Legislative Studies Quarterly, 24(4), pp. 489-510.

Blondel, Jean y Ferdinand Müller-Rommel (2009), "Political Elites", en Russell J. Dalton y Hans-Dieter Klingemann, The Oxford Handbook of Political Behavior, Oxford, oup, pp. 818-833.

Bunce, Valerie (2000), "Comparative Democratization: Big and Bounded Generalizations”, Comparative Political Studies, 33, pp. 703-734.

Burns, Nancy, Laura Evans, Gerald Gamm y Corrine Mcconnaughy (2004), "Pockets of Expertise: Careers and Professionalism in 20th-Century State Legislatures", ponencia presentada ante la American Political Science Association, Chicago.

Caselli, Francesco y Massimo Morelli (2004), "Bad Politicians”, Journal of Public Economics, Elsevier, 88(3-4), pp. 759-782.

Dal Bó, Ernesto, Pedro Dal Bó y Rafael Di Tella (2002), “"Plata o Plomo': Bribe and Punishment in a Theory of Political Influence”, documento de trabajo 28, Brown University, Department of Economics.

Dahan, Momi y Alejandro Gaviria (1999), "Sibling Correlations and Social Mobility in Latin America", documento de trabajo 395, Washington D.C., Banco Interamericano de Desarrollo, pp. 1-29.

Dahl, Robert (1961), Who Governs? Democracy and Power in an American City, New Haven, Yale University Press.

Diamond, Larry y Leonardo Morlino (2004), "The Quality of Democracy: An Overview", Journal of Democracy, 15(4), pp. 20-31.

Di Palma, Giuseppe (1988), "La consolidación democrática: Una visión minimalista”, Revista Española de Investigaciones Sociológicas, 42, pp. 67-92.

Epstein, David et al. (1997), "A Comparative Approach to Legislative Organization: Careerism and Seniority in the United States and Japan", American Journal of Political Science, 41, pp. 965-998.

Equipo de Investigación de Élites Parlamentarias (2001), "Élites parlamentarias en América Latina: Continuidad y cambio en la década de 1990", Revista Española de Ciencias Políticas, 5, pp. 173-197.

Ferranti, David de et al. (2003), Desigualdad en América Latina y el Caribe: ¿Ruptura con la historia?, resumen ejecutivo, estudio del Banco Mundial sobre América Latina y el Caribe, pp. 1-24.

Gabriel, Karl Ruben (1971), "The Biplot Graphic Display of Matrices with 
Application to Principal Component Analysis”, Biometrika, 58(3), pp. 453-467.

Gabriel, Karl Ruben y Charles L. Odoroff (1990), "Biplot in Biomedical Research”, Statistics in Medicine, 9, pp. 469-485.

Galindo, María Purificación (1985), "Contribuciones a la representación simultánea de datos multidimensionales", tesis doctoral, Universidad de Salamanca.

(1986), "Una alternativa de representación simultánea: HJ-Biplot", Questiio, Quaderns d'Estadistica 10(1), pp. 13-23.

Galindo, María Purificación et al. (1999), "El análisis HJ-Biplot como herramienta de estudio en un ecosistema acuático", Statistics and Environment, pp. 85-94.

García, Fátima y Araceli Mateos (2006), "El Proyecto Élites Parlamentarias Latinoamericanas: Continuidades y cambios (1994-2005)”, en Manuel Alcántara (ed.), Políticos y política en América Latina, Madrid, Siglo XXI.

Hagopian, Frances y Scott Mainwaring (eds.) (2005), The Third Wave of Democratization in Latin America: Advances and Setbacks, Cambridge, Cambridge University Press.

Hibbing, John (1999), "Legislative Careers: Why and How We Should Study Them?" Legislative Studies Quarterly, 24(2), pp. 149-171.

Highley John y Richard Günther (eds.) (1992), Elites and Democratic Consolidation in Latin America and Southern Europe, Cambridge, Cambridge University Press.

Hoffman-Lange, Ursula (2009), "Methods of Elite Research", en Russell J. Dalton y Hans-Dieter Klingemann, The Oxford Handbook of Political Behavior, Oxford, oup, pp. 910-928.

Inglehart, Ronald y Christian Welzel (2006), Modernización, cambio cultural y democracia: La secuencia del desarrollo humano, Madrid, CIS.

IPES (2008), ¿Los de afuera? Patrones cambiantes de exclusión en América Latina y el Caribe, Banco Interamericano de Desarrollo.

Katz, Jonathan y Brian Sala (1996), "Careerism, Committee Assignments, and the Electoral Connection", American Political Science Review, 90(1), pp. 21-33.

Kaufmann, Daniel y Aart Kraay (2002), "Growth without Governance", documento de trabajo 2928, Policy Research.

Kaufmann, Daniel, Aart Kraay y Pablo Zoido-Lobatón (2002), "Governance Matters II: Updated Indicators for 2000-2001”, documento de trabajo 2772, Policy Research. 
Landman, Todd (2003), "Map-Making and Analysis of the Main International Initiatives on Developing Indicators on Democracy and Good Governance", Eurostat (Statistical Office of the Commission of the European Communities), University of Essex.

Lasswell, D. Harold (1961), Politics: Who Gets What, When, How, Meridian Book.

Levine, Daniel y José Enrique Molina (2007), "La calidad de la democracia en América Latina: Una visión comparada”, América Latina Hoy, 45, pp. $17-46$.

Linz, Juan José (1998), "Problemas de la democracia hoy", Del Águila, R. et al., La democracia en sus textos, Madrid, Alianza.

Lipset, Seymour et al. (1954), "The Psychology of Voting: An Analysis of Political Behaviour", en Gardner Lindzey (ed.), Handbook of Social Psychology II, Cambridge, Addison Wesley Publishing, Inc.

Llanos Mariana y Francisco Sánchez (2006), "Council of Elders: The Senates and its members in the Southern Cone", Latin American Research Review, 41(1), pp. 133-152,

Mainwaring, Scott (1999), "La durabilidad de la democracia en América Latina, 1940-1998”, Política y Gobierno, (VI)2, México, segundo semestre.

Martínez Rosón, Mar (2006), "La carrera parlamentaria: ¿La calidad importa?”, en Manuel Alcántara (ed.), Políticos y política en América Latina, Madrid, Siglo XXI.

Mattozzi, Andrea y Antonio Merlo (2007), "The Transparency of Politics and the Quality of Politicians", American Economic Review, 97(2), pp. 311-315.

Milanovic, Branko y Rafael Muñoz de Bustillo (2008), "La desigualdad de la distribución de la renta en América Latina: Situación, evolución y factores explicativos", América Latina Hoy, 48, pp. 15-42.

Mills, Charles W. (1963), La élite del poder, México, FCE.

Moncrief, Gary, Peverille Squire y Malcom E. Jewell (2001), Who Runs for the Legislature?, Nueva Jersey, Prentice Hall.

Mondak, Jeffery J. (1995), "Competence, Integrity, and the Electoral Success of Congressional Incumbents", Journal of Politics, 57(4), pp. 1043-1069.

Morán, M. Luz (1983), Origen histórico y gnoseológico de la teoría de las élites, Madrid, Universidad Complutense.

Morlino, Leonardo (2009), Democracias y democratizaciones, Madrid, CIS. Mosca, G. (1984), La clase política, México, FCE . 
Neelsen, John P. (1975), "Education and Social Mobility", Comparative Education Review, 19(1), pp. 129-143.

Norris, Pippa (ed.) (1997), Passages to Power: Legislative Recruitment in Advanced Democracies, Cambridge, Cambridge University Press.

(2006), "The Role of the Free Press in Promoting Democratization, Good Governance, and Human Development", ponencia presentada en el encuentro anual de la Midwest Political Science Association, Chicago, 20-22 de abril.

O’Donnell, Guillermo (1997), Contrapuntos, Buenos Aires, Paidós. (2004), "Notas sobre la democracia en América Latina", en PNUD, La democracia en América Latina: El debate conceptual sobre democracia, Buenos Aires, PNUD.

Padró I. Miquel, Gerard y James M. Snyder (2004), "Legislative Effectiveness and Legislative Life", MIT Department of Economics documento de trabajo 04-28.

PELA (1998-2008), Proyecto dirigido por Manuel Alcántara, Universidad de Salamanca.

PNUD (2004), La democracia en América Latina: El debate conceptual sobre democracia, Buenos Aires, PNUD.

Putnam, Robert (1976), The Comparative Study of Political Elites, Nueva Jersey, Prentice-Hall.

Quandt, William (1970), "The Comparative Study of Political Elites", Comparative Politics Series, 01-004.

Reiser, Marion (2003), "From Political Amateurs to Professional Politicians? An Analysis of Councillors in four German Cities", ponencia presentada ante la American Political Science Association, Filadelfia.

Rodríguez Teruel, Juan (2005), "Los ministros de la España democrática: Perfil, trayectorias y carrera ministerial de los miembros del gobierno de Suárez a Zapatero (1976-2005)”, tesis doctoral, Universidad Autónoma de Barcelona.

Rodríguez Zúñiga, L. (1976), Élites y democracia, Valencia, Fernando Torres Editor.

Rohlf, James y Robert Sokal (1981), “Comparing Numerical Taxonomic Studies”, Systematic Zool, 30, pp. 459-490.

Sen, Amartya (2006), Elvalor de la democracia, Barcelona, El Viejo Topo.

Stevens, Daniel, Benjamin Bishin y Robert Barr (2006), "Authoritarian Attitudes, Democracy and Policy Preferences among Latin American Elites", American Journal of Political Science, 50(3), pp. 606-620. 
Stone, Walter, Maisel Sandy y Cherie D. Maestas (2004), "Quality Counts: Extending the Strategic Politician Model of Incumbent Deterrence", American Journal of Political Science, 48(3), pp. 479-495.

Tulchin, Joseph y Amelia Brown (2003), Democratic Governance and Social Inequality, Boulder, Lynne Rienner.

Uriarte, Edurne (1997), "El análisis de las élites políticas", Revista de Estudios Políticos, 97, pp. 249-275. (2000), "La política como vocación y profesión: Análisis de las motivaciones y de la carrera política de los diputados españoles", Revista Española de Ciencia Política, 3, pp. 97-124.

Vicente, Santiago (1992), "Las técnicas de representación de datos multidimensionales en el estudio del índice de producción industrial en la CEE", tesis doctoral, Universidad de Salamanca.

Vicente, Santiago, Guillermo Ramírez y María Purificación Galindo (1994), "El HJ-Biplot como base para la búsqueda de clusters en función de la distribución de parados según profesiones en la comunidad de Castilla y León”, comunicación presentada en el IV Congreso de Economía Regional de Castilla y León, Burgos.

World Bank (2008), World Development Indicators 2008, Washington, D. C., The World Bank. 


\section{Politicians AND Politics}

in Latin America

edited by

Manuel Alcántara Sáez 
Rivas Pérez, Cristina. 2008. “The dimensions of Polarization in Parliaments”. En Manuel Alcántara Sáez (ed.). Politicians and Politics in Latin America. United of States of America: Lynne Rienner Publishers, Inc., pp.139-160.

\section{Resumen en castellano:}

\section{“Las dimensiones de la polarización en los Parlamentos”}

\section{Objetivos de la investigación}

Este capítulo tiene como objetivo una primera aproximación empírica a la identificación de clivajes que contribuyen a la polarización y división de los partidos políticos en América Latina. Se parte del hecho de que existe una marcada diferencia en el posicionamiento ideológico de los partidos políticos objeto de estudio (partidos ubicados a la izquierda o a la derecha del continuo ideológico) y mediante distintas técnicas estadísticas se pretenden corroborar las diferencias existentes entre la izquierda y la derecha latinoamericana en base a los clivajes previamente identificados, así como conocer cuáles son las principales dimensiones programáticas de polarización en los actuales Parlamentos latinoamericanos, todo ello desde una perspectiva transnacional. En definitiva, se pretende determinar si los temas que tradicionalmente separaban a la izquierda y a la derecha siguen teniendo vigor en la actualidad o si por el contrario se ha producido una transformación en la polarización política de la región.

\section{Metodología y datos utilizados}

En términos metodológicos, el trabajo se estructura en torno a un análisis factorial, frecuentemente utilizado en este tipo de estudios con el fin de identificar estructuras latentes que permitan establecer cuáles son los principales ámbitos de diferenciación de la derecha y la izquierda en América Latina (a partir de las opiniones de sus representantes) y una representación biplot de medias de los factores resultantes y los partidos políticos seleccionados, todo ello desde una perspectiva transnacional. La construcción de factores transnacionales permite obtener parámetros comparables a partir de los cuáles es posible conocer la importancia relativa de las líneas de polarización ideológica-programática. 
El HJ-Biplot es un análisis multivariante poco utilizado en el ámbito de las ciencias sociales y, más concretamente, en el campo de la ciencia política. El propósito de esta técnica es representar gráficamente y de manera simultánea, los partidos y las dimensiones programáticas obtenidas en el análisis factorial, de este modo, además de conocer cuáles son las principales líneas de variabilidad entre las distintas fuerzas políticas y qué aspectos permiten distinguir claramente entre partidos de izquierda y de derecha en la región, es posible la construcción de familias partidistas sobre la base de estas dimensiones.

El HJ-Biplot, aunque no reproduce los elementos de la matriz de datos original, tiene la ventaja de que se trata de una representación simultánea en sentido estricto, de manera que los marcadores para los partidos políticos (individuos) y para las dimensiones programáticas (variables) son elegidos de forma que ambos puedan superponerse en el mismo sistema de referencia lográndose una máxima calidad de representación tanto para los partidos políticos como para las variables que definen los clivajes de la polarización.

Los datos utilizados para llevar a cabo el estudio de las dimensiones de la polarización parlamentaria proceden de las opiniones de los diputados latinoamericanos del “Proyecto Elites Parlamentarias Latinoamericanas" (PELA) de la Universidad de Salamanca (Manuel Alcántara dir.) durante el período 1999-2005.

\section{Resultados alcanzados}

Los cinco clivajes o dimensiones programáticas establecidos en este estudio (resultado de un análisis factorial exploratorio con rotación varimax utilizando las respuestas dadas por las elites parlamentarias de los actuales Congresos latinoamericanos a toda una serie de preguntas que miden sus preferencias económicas, políticas, religiosas y sociales) son: “Intervencionismo estatal”, “Fuerzas armadas”, “religión y valores”, “raíces sociales” y “democracia”.

Cada una de esas líneas de división tiene una dinámica propia aunque puede producirse una superposición de las mismas, es decir, que partidos políticos situados en el extremo de una dimensión sean los mismos que están en el extremo de las otras dimensiones.

Los resultados obtenidos en el análisis HJ-Biplot ponen de relieve que la izquierda y la derecha latinoamericana quedan claramente separadas por las dimensiones de 
polarización programática obtenidas. Distinguiendo claramente entre los partidos políticos de derecha y los partidos políticos de izquierda. Dentro de la izquierda aparecen dos grupos claramente diferenciados: por un lado, una izquierda más revolucionaria y, por otro, una izquierda más moderada.

De las cinco dimensiones de polarización obtenidas tan sólo la denominada "raíces sociales” es la que tiene un menor poder discriminatorio, en términos ideológicos, entre las fuerzas políticas de izquierda y de derecha en América Latina, aunque como se pone de manifiesto en el capítulo permite también distinguir entre partidos de izquierda y de derecha.

En la tabla 1 se presentan a modo de resumen las familias partidistas formadas a partir de cada una de las dimensiones de polarización.

La capacidad estructuradora del clivaje religioso entre partidos de izquierda y de derecha ha quedado patente (ver tabla 1), pese a que el conflicto religioso como dimensión programática de polarización partidista vaya disminuyendo. Los resultados obtenidos ponen de manifiesto el proceso de secularización que están experimentando las sociedades latinoamericanas, aunque menor al que se podía esperar, puesto que partidos situados más a la izquierda en el continuo ideológico mantienen posturas más moderadas respecto al clivaje religioso, como es el caso de la ID, MVR y FMLN que partidos de ideología similar en Europa Occidental.

La clasificación de los partidos en la dimensión "Intervención estatal” muestra que los partidos indiscutiblemente estatistas son principalmente de izquierdas.

El clivaje “democracia” está conformado por variables que tienen que ver con la cultura política de la clase parlamentaria: el apoyo al régimen democrático, a los partidos políticos y a las elecciones. La clasificación de los partidos políticos latinoamericanos en esta dimensión deja vislumbrar una clara fractura dentro de la izquierda en la región. Por un lado, una izquierda democrática moderada y por otro, una izquierda autoritariarevolucionaria (MAS-B, FMLN, PSP, MUPP-NP y MVR).

La clasificación de los partidos en base a la dimensión "raíces sociales” revela una estrecha relación existente entre este clivaje y el relativo a la democracia. Parece evidente, que aquellos partidos cuyos integrantes cuentan con antecedentes familiares de alto nivel educativo son también aquellos que aceptan de manera inequívoca la democracia como mejor forma de gobierno y, viceversa, las fuerzas políticas definidas 
como autoritarias son las que cuentan entre sus filas con diputados que proceden de familias con un menor nivel educativo. Por tanto, es factible considerar la presencia de una superposición de estas dos dimensiones de polarización programática.

Tabla 1: Familias partidistas según su posicionamiento en las dimensiones de polarización programática

\begin{tabular}{|c|c|c|}
\hline Dimensiones de & Ejes & Partidos políticos \\
\hline \multirow[b]{2}{*}{ Religión y valores } & Religiosos/conservadores & $\begin{array}{l}\text { UDI, ARENA, COPEI, } \\
\text { PAP, PSP, PSN, PLC, PA, } \\
\text { PC, PS-P }\end{array}$ \\
\hline & Seculares/progresistas & $\begin{array}{l}\text { PPD, PS-C, PRE, ARI, } \\
\text { EP/FA, ID, MUPP-NP, } \\
\text { MVR, PUD, FMLN, } \\
\text { PRIAN, FSLN, MAS-B }\end{array}$ \\
\hline \multirow{2}{*}{ Intervención estatal } & $\begin{array}{l}\text { A favor intervención } \\
\text { estatal }\end{array}$ & $\begin{array}{l}\text { EP/FA, PPD, PS-C, PRE, } \\
\text { ARI, MAS-B, PUD, } \\
\text { MUPP-NP, FMLN, } \\
\text { PRIAN, MVR, ID, FSLN }\end{array}$ \\
\hline & No intervención estatal & $\begin{array}{l}\text { UDI, ARENA, COPEI, } \\
\text { PC, PSP, PSN, PLC, PA, } \\
\text { PAP }\end{array}$ \\
\hline \multirow{2}{*}{ Democracia } & Democracia & $\begin{array}{l}\text { PPD, PS-C, PAP, PRE, } \\
\text { EP/FA, ARI, ID, PSN, } \\
\text { PLC, COPEI, PA }\end{array}$ \\
\hline & Autoritarismo & $\begin{array}{l}\text { PC, PSP, PUD, MAS-B, } \\
\text { FMLN, PRIAN, MVR, } \\
\text { MUPP-NP }\end{array}$ \\
\hline \multirow{2}{*}{ Raíces sociales } & Alto nivel educativo & $\begin{array}{l}\text { PPD, PS-C, PAP, PRE, } \\
\text { EP/FA, ARI, ID, PSN, } \\
\text { PLC, COPEI, UDI, PA, } \\
\text { ARENA, PC }\end{array}$ \\
\hline & Bajo nivel educativo & $\begin{array}{l}\text { PSP, PUD, MAS-B, } \\
\text { FMLN, PRIAN, MVR, } \\
\text { MUPP-NP, FSLN }\end{array}$ \\
\hline \multirow{2}{*}{ Fuerzas Armadas } & Pro-militar & $\begin{array}{l}\text { ARENA, PCN, FSLN, } \\
\text { MVR, PC, PA, UDI, PLC, } \\
\text { FMLN, PSN }\end{array}$ \\
\hline & Anti-militar & $\begin{array}{l}\text { MAS-B, COPEI, PAP, } \\
\text { PUD, PSC, ID, EP/FA, } \\
\text { MUPP-NP }\end{array}$ \\
\hline
\end{tabular}

Fuente: Elaboración propia a partir datos PELA (1999-2005). 
Por último, la dimensión "Fuerzas Armadas" que ofrece una clasificación de los partidos muy similar a la obtenida en la dimensión de “democracia”. En este sentido existe una superposición de los clivajes y se observa cómo los partidos posicionados en el polo "pro-militar” son los mismos que los posicionados en el polo "autoritarismo”, y viceversa, los “anti-militar” coinciden, en su gran mayoría, con los “democráticos”. Pero para comprender bien este clivaje debe tenerse en cuenta el carácter militar de algunos partidos políticos así como la distinta suerte que corrieron durante los años de autoritarismo y presencia de los regímenes militares.

\section{Conclusiones}

A lo largo de este capítulo se ha intentado demostrar la validez en la actualidad de las líneas de división partidistas en América Latina, entendidas como dimensiones de polarización programática, que dan cuenta de la variabilidad del escenario en el que compiten la izquierda y la derecha latinoamericana.

En términos metodológicos, este trabajo se proponía constatar la utilidad de construir y analizar dimensiones de polarización programática comunes a todos los sistemas de partidos latinoamericanos, de manera que fuera posible comparar las estructuras de competencia partidista entre la izquierda y la derecha desde una perspectiva transnacional.

De los resultados obtenidos se puede concluir que la mayor polarización entre partidos se produce en dos dimensiones tradicionales, la religiosa y la intervención estatal y dos, producto de la experiencia autoritaria, la de Fuerzas Armadas y democracia. Uno de los clivajes de partida que parece estar quedando obsoleto y que, no permite discriminar de manera contundente a las fuerzas políticas de izquierda y de derecha es el nivel de estudios de los padres.

Junto a estas cuestiones puede concluirse que las cinco dimensiones de polarización programática a las que se ha hecho referencia en este capítulo son congruentes con la dimensión ideológica. Parece clara la distinción entre fuerzas políticas de derecha e izquierda en torno a estas dimensiones si bien, como se ha visto a lo largo de este capítulo, estas dimensiones no sólo separan a la derecha de la izquierda sino que además muestran la existencia de dos subgrupos dentro de la izquierda (el moderado y el 
revolucionario). Mientras que la derecha latinoamericana se muestra más homogénea en relación a las cinco dimensiones programáticas analizadas.

De esta forma, y a modo de conclusión, se puede decir que el continuo izquierdaderecha es útil, desde un punto de vista analítico, para sintetizar las dimensiones de competencia partidista en los Parlamentos latinoamericanos. 


\title{
6 \\ The Dimensions of Polarization in Parliaments
}

\author{
Cristina Rivas Pérez
}

OVER THE LAST FOUR DECADES, A LARGE NUMBER OF STUDIES HAVE been conducted on the dimensions of party competition in European democracies. This type of analysis has made it possible to assess the persistence and change of social and political cleavages. ${ }^{1}$

Democratization and democratic consolidation in Latin America have given rise to a growing number of studies on party systems in the region. Most often these studies have focused on three basic characteristics of the party system: fragmentation, electoral volatility, and the effective number of parties. By contrast, there have been few studies on other topics critical to party competition, such as ideology, orientations and values, and cleavages, or political divides. ${ }^{2}$

There have even been debates on the appropriateness of the concept of cleavages in the analyses of the region's politics. However, if cleavages are understood as relatively stable patterns of polarization, by virtue of which certain groups endorse specific policies or parties, ${ }^{3}$ then their applicability to Latin American politics is entirely justified.

"Cleavage" in this chapter refers to the dimensions of programmatic polarization that separate-or bring together-Latin American political parties labeled as either rightist or leftist, whereas "polarization" is understood as the distance between left and right regarding ideological preferences on issues of political interest.

This chapter examines which cleavages condition the divisions and polarizations of political parties in Latin America. It also assesses whether the topics that traditionally have distinguished "left" and "right" are still important in Latin American politics. This chapter aims also at establishing what social, economic, religious, and political divides constitute the leftright dimension in Latin America. ${ }^{4}$ This empirical analysis is based on the assumption that the left-right dimension simplifies the political world and 
reflects a number of underlying dimensions. ${ }^{5}$ With this purpose in mind, this chapter analyzes parties located in extreme positions in the left-right dimension, according to the PELA data (see Table 6.12 in the chapter appendix). ${ }^{6}$ The selection of these cases facilitates the identification of those elements that affect ideological and programmatic polarization.

The first part of this chapter evaluates the usefulness of the left-right dimension in classifying and distinguishing political parties in Latin America. The second part explores the main dimensions of variability among parties, as well as the aspects that allow us to distinguish between left and right parties. Finally, based on the analysis of the main dimensions of programmatic polarization, this chapter examines party families in Latin America.

Methodologically, the chapter uses factor analysis and a biplot representation of the resulting average factors and of the selected political parties. Constructing factors for the whole region allows us to compare the dimensions of ideological and programmatic polarization across nations. This analysis is structured around five factors: state intervention in public policies, religion and moral values, social background, democracy, and the armed forces.

This study hopes to make a substantive contribution to the study of left and right parties in Latin American parliaments, which in the future should be complemented by studies that include center parties. Such works will allow us to test whether the findings of this chapter hold when the whole spectrum of ideological positions is taken into consideration.

\section{Left and Right Parties in Latin American Parliaments}

The vocabulary of "right" and "left" is standard in many countries. The use of the left-right dimension allows citizens to place parties, programs, and decisions in a coherent and clearly understandable framework. ${ }^{7}$

It has been frequently pointed out that the left-right dimension lacks analytical value in the study of Latin American party systems. ${ }^{8}$ However, it must be taken into account that definitions of "left" and "right" can vary regionally, cross-nationally, and across time. ${ }^{9}$

For these reasons, a comparative analysis of the left-right dimension must not focus on fixed ideological criteria, but on spatial considerations. Differences in regional and national historical trajectories, rooted in specific social and political experiences, ${ }^{10}$ limit the general applicability of understandings of the left-right dimension.

Some studies refer to two basic components in the definition of the leftright dimension: a symbolic component and a substantive one; the latter is connected to specific ideological preferences regarding political, religious, economic, and social issues. ${ }^{11}$ This chapter focuses on the presence of these programmatic dimensions in Latin American parliaments and, more specifi- 
cally, aims at identifying the programmatic positions of political parties. This analysis will allow us to label political parties and to establish the main party families in Latin America. ${ }^{12}$. It is based on the legislators' individual responses regarding their ideological self-placements and the ideological placements of their respective parties. ${ }^{13}$

Almost all Latin American legislators (98 percent) were able to place themselves in the left-right dimension. This fact endorses the use of this dimension as a criterion for the classification of parties. Table 6.1 shows the classification of thirty Latin American parties in the left-right dimension, with fourteen parties leaning to the right and sixteen parties to the left. ${ }^{14}$

There are few doubts about the placement of parties in the left-right dimension. Perhaps the most debatable case is that of the Panamanian PA, which, in spite of being defined by its members as rightist, could also be considered as a center party. Overall, the classification in Table 6.1 provides a picture which is very similar to those of other studies. ${ }^{15}$

\section{潭 The Main Dimensions of \\ Polarization in Latin American Parliaments}

The left-right dimension has been traditionally linked to class-based economic conflicts, but other issues also contribute to party competition (religious and moral values, authoritarianism-democracy, neoliberalism-statism, nationalism-regionalism, etc.).

Table 6.1 Classification of Latin American Parties by Ideology

\begin{tabular}{|c|c|c|c|}
\hline \multicolumn{2}{|c|}{ Parties on the Right } & \multicolumn{2}{|c|}{ Parties on the Left } \\
\hline & & Argentina & ARI \\
\hline & & Bolivia & MAS \\
\hline Chile & UDI & Chile & PPD, PS \\
\hline Colombia & PC & & \\
\hline Dominican Republic & PRSC & & \\
\hline Ecuador & PSC, PRIAN & Ecuador & PRE, ID, MUPP-NP, PSP \\
\hline El Salvador & ARENA, PCN & El Salvador & FMLN \\
\hline Guatemala & GANA, PSN & & \\
\hline \multirow[t]{2}{*}{ Honduras } & $\mathrm{PNH}$ & Honduras & PUD \\
\hline & & Mexico & PRD \\
\hline \multirow{4}{*}{$\begin{array}{l}\text { Nicaragua } \\
\text { Panama }\end{array}$} & PLC & Nicaragua & FSLN \\
\hline & PA, PS & & \\
\hline & & Peru & PAP \\
\hline & & Uruguay & $\mathrm{EP} / \mathrm{FA}$ \\
\hline Venezuela & COPEI & Venezuela & MAS, MVR \\
\hline
\end{tabular}

Source: Based on PELA 1999-2005.

Note: Only parties with at least five legislators were included in the analysis. 
The five dimensions, or cleavages, considered in this study result from the application of an exploratory factor analysis with varimax rotation on twenty PELA variables. ${ }^{16}$ These variables are shown in Table 6.2. ${ }^{17}$

The goal of this principal components analysis is to identify the latent structures that will allow us to differentiate between right and left in Latin America on the basis of the opinions and preferences of their legislators. Table 6.3 shows the main results of this factor analysis (complete results are presented in Table 6.13 of the chapter appendix). Five factors explain 53.7 percent of the total variance. The first factor, connected to state intervention (the first eight variables in Table 6.2), accounts for 15.6 percent of the variance. The second factor, related to the evaluation of the military, accounts for 11.3 percent of the variance. The third factor is linked to religiosity and moral values; it accounts for 10.9 percent of variation. The fourth factor has to do with legislators' social backgrounds, and accounts for 8.9 percent of the total variance. Finally, the fifth factor connects to attitudes toward democracy and democratic institutions, and accounts for 6.8 percent of variance. Once the five dimensions of polarization have been established, it is necessary to determine which dimensions give rise to higher levels of interparty polarization, as well as how party families are placed on these dimensions.

Table 6.2 Variables in the Analysis

Variables

State intervention to subsidize housing

State intervention to provide jobs

State intervention to provide citizens with health care

State intervention to guarantee a free and universal university education

State intervention to provide unemployment benefits

State intervention to provide unemployment insurance

State intervention to protect the environment

State intervention to cover basic citizen needs

Strength of religious conviction and observance of religious practices

Attitude toward divorce

Attitude toward abortion

Trust in the Catholic Church

Evaluation of the role played by the military nowadays

Trust in the armed forces

Relations between the armed forces and the government threaten democratic stability

Relations with the armed forces are a problem for democratic consolidation

Education of the respondent's father

Education of the respondent's mother

Democracy is preferable to an authoritarian regime

Role of political parties

Elections as a mechanism of political representation

Source: Based on PELA 1999-2005. 
Table 6.3 Analysis of Rotated Factors

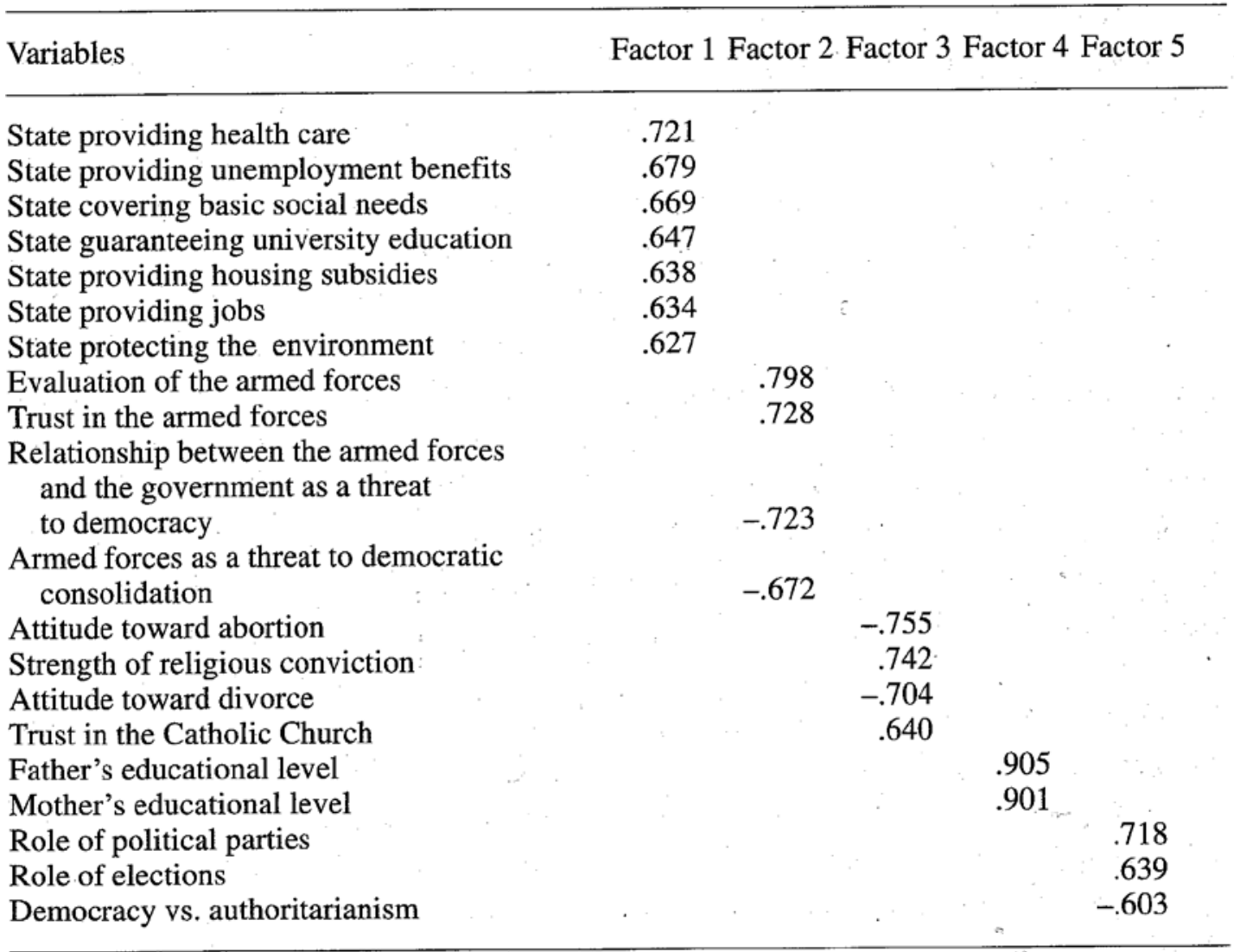

Source: Data of factor analysis from PELA 1999-2005.

This factor analysis has been complemented by an HJ-Biplot analysis, an extension of Gabriel's biplot techniques. ${ }^{18}$ It is sometimes useful to graphically represent data stemming from multivariate analysis. This HJBiplot presents the average scores for each party based on factor analysis. ${ }^{19}$ These graphical representations are useful because they not only show the configuration of individuals and parties, but also show which variables account for such configurations.

Although HJ-Biplot does not reproduce the elements of the original matrix, it has the advantage of presenting markers for political parties and for programmatic dimensions within one graphic representation. ${ }^{20}$ There are many possible biplots for a specific group of data: this chapter provides the representation that gives us the most interesting insights for the interpretation of these data. Parties are placed perpendicularly on the vectors representing the dimensions extracted from factor analysis, which allows us to identify those variables that help differentiate groups of parties.

In order to assess how well this biplot representation fits, it is necessary to first consider the inertia (variability) absorption rate. A high variability absorption rate is a necessary condition for considering reliable our inter- 
pretation of the position of political parties and of programmatic dimensions. However, it is not a sufficient condition. ${ }^{21}$

Table 6.4 presents the proportion of variability absorbed by the first three-factor axes. ${ }^{22}$ As this table shows, the first axis captures most of the information and absorbs 35.57 percent of the total variability. That is, the dimension or dimensions best represented in axis 1 are the cleavages that most strongly polarize left and right parties in the first factor. The second axis also provides us with important information, but less so than the first one ( 23.54 percent). The variability rate in the first factor plane, formed by axes 1 and 2 , reaches 59.12 percent. The space formed by axes 1,2 , and 3 accounts for 78.58 percent of the variability. In the following pages, attention is focused on the first factor plane. Secondary attention is paid to the third axis, which, with an inertia absorption rate of 19.48 percent, clarifies the positions of some parties and the character of some of the programmatic dimensions considered here.

Factor axes identify those programmatic dimensions that determine differences among political parties. The measure for the relationship between the biplot axes of representation and each of the observed variables is labeled "the relative contribution of the factor to the element." 23 This contribution allows us to establish what dimensions of programmatic division are most closely connected to each axis and, consequently, which variables account for the placement of parties in each of the factor axes. This scale ranges from 0 to 1,000 . The closer the value is to 1,000 , the higher the variability of this dimension in the study. ${ }^{24}$

Not all the variables included in the analysis are well represented in the first factor plane (axes 1 and 2). Table 6.5 shows that there are two dimensions that are characteristic of axis 1 ; namely, those that get a strong contribution from axis 1 and a low contribution from the other axes: state intervention, and religion and values. The democracy dimension attains the highest contribution from axis 2 , whereas the third axis is determined by the armed forces dimension (with a value of 889 over 1,000 ). The social background factor shows less power to discriminate among political parties. 25

A more detailed analysis would require consideration of why the contri-

Table 6.4 Proportion of Cumulative Variability Absorbed

\begin{tabular}{lll} 
& Variability Absorbed & Accumulated Variability Absorbed \\
\hline Axis 1 & 35.57 & 35.57 \\
Axis 2 & 23.54 & 59.12 \\
Axis 3 & 19.48 & 78.58 \\
\hline
\end{tabular}

Source: HJ-Biplot analysis with data from PELA 1999-2005. 
Table 6.5 Relative Contributions of the Factors to the Programmatic Dimensions

\begin{tabular}{lccc}
\hline Programmatic Dimensions & Axis 1 & Axis 2 & Axis 3 \\
\hline State intervention & $\mathbf{5 8 8}$ & 125 & 56 \\
Armed forces & 52 & 52 & $\mathbf{8 8 9}$ \\
Religion and values & $\mathbf{5 4 0}$ & 205 & 11 \\
Social background & 396 & 276 & 0 \\
Democracy & 203 & 519 & 17 \\
\hline
\end{tabular}

Source: HJ-Biplot analysis with data from PELA 1999-2005.

Note: Data in bold numbers reveal a high or very high contribution of some of the axes.

bution of the social background dimension is so low. A possible interpretation lies in the similarity of legislators' positions on this dimension. Another possible interpretation is that this dimension is better represented in factor planes different from those we consider here. In that case, it would be necessary to examine the planes formed by the axes 1 and 4,2 and 4 , or 3 and 4 .

As for the political parties, the quality of their representation can be interpreted as the amount of information on a party captured by the axes. The addition of relative contributions of each factor to the element provides us with information on the quality of representation in the reduced dimensional space. The closer to 1,000 the value of a political party in the factor axes, the higher the quality of representation in the factor plane. Based on these considerations, it must be pointed out that the PNH, PRD, PRSC, and MAS in Venezuela are not well represented in the reduced dimensional space and, therefore, we cannot draw reliable conclusions about them. It is also necessary to be cautious regarding the Guatemalan GANA, since the contributions they get from these axes are low. The representation of the remaining political parties is good or acceptable in some of the factor planes analyzed (see Table 6.6). It is also important to take into account the relative contribution of each factor axis to each party in order to interpret the discriminating power of factor axes. The parties that get a strong contribution from axis 1 and a low contribution from the rest of the axes are mainly the PSN (867), PLC (779), UDI (641), and MUPPNP (682). This indicates that the positions of these parties in the state intervention, and religion and values dimensions are different from those of other parties. The PPD, the Chilean PS, the PSP, PRE, and PAP are the political forces with the highest contributions from axis 2 (986, 911, 900, 874 , and 808 , respectively). That is, they can be differentiated from the remaining parties principally in their democratic orientations. The highest contributions of axis 3 are for the PCN (663) and ARENA (501). In these cases, parties are mainly differentiated by their positions in the armed forces dimension. 
Table 6.6 Relative Contributions of the Factors to Political Parties

\begin{tabular}{lrrr}
\hline Political Parties & Axis 1 & Axis 2 & Axis 3 \\
\hline ARI & 330 & 605 & 0 \\
MAS-B & 472 & 134 & 374 \\
UDI & 641 & 187 & 6 \\
PPD & 16 & $\mathbf{9 8 6}$ & 4 \\
PS-C & 3 & $\mathbf{9 1 1}$ & 48 \\
PC & 269 & 178 & 357 \\
PSC & 113 & 1 & 322 \\
PRE & 87 & $\mathbf{8 7 4}$ & 0 \\
ID & 410 & 233 & 232 \\
MUPP-NP & 682 & 65 & 6 \\
PRIAN & 219 & 196 & 16 \\
PSP & 1 & $\mathbf{9 0 0}$ & 16 \\
GANA & 49 & 0 & 209 \\
PSN & $\mathbf{8 6 7}$ & 1 & 21 \\
PNH & 83 & 12 & 141 \\
PUD & 417 & 374 & 110 \\
PRD & 183 & 106 & 16 \\
PLC & 779 & 0 & 42 \\
FSLN & 237 & 12 & 439 \\
PA & 466 & 9 & 71 \\
PS-P & 311 & 4 & 7 \\
PAP & 7 & $\mathbf{8 0 8}$ & 79 \\
PRSC & 9 & 2 & 89 \\
ARENA & 358 & 132 & 501 \\
FMLN & 536 & 99 & 40 \\
PCN & 218 & 502 & 663 \\
EP/FA & 486 & 168 & 6 \\
MVR & 255 & 37 & 498 \\
MAS-V & 404 & & 648 \\
COPEI & & & \\
\hline
\end{tabular}

Source: HJ-Biplot with data from PELA 1999-2005.

Note: Data in bold numbers reveal a high or very high contribution of some of the axes.

Inspection of Figure 6.1 shows that, with a few exceptions, the Latin American left and right are clearly different in the dimensions of programmatic polarization extracted from factor analysis. Right parties are located to the left of the first factor plane and left parties are placed to the right of that plane. There are two types of left parties: a more revolutionary left, placed in the upper right quadrant, and a more moderate left, placed in the lower right quadrant.

Since the ideological dimension is well represented in Figure 6.1, the following pages focus on establishing the main programmatic dimensions of variability among Latin American parties. For this purpose, it is necessary to take into consideration the length and angle of the vectors that represent the cleavages, as well as the perpendicular projection of the points, the 
Figure 6.1 Representation of the Polarization Dimensions, HJ-Biplot Axes 1 and 2

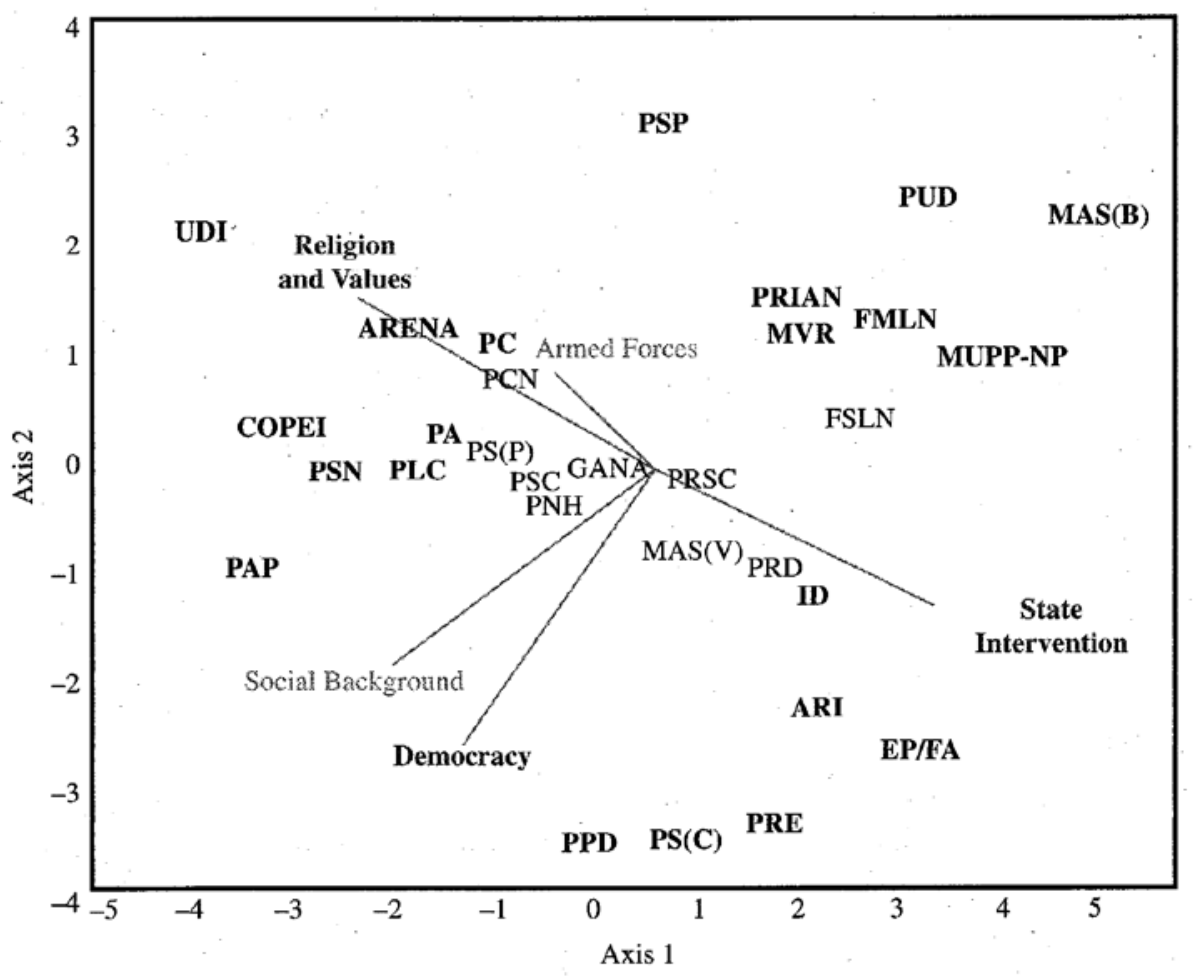

Source: Created by the author based on PELA 1999-2005.

political parties, over the vectors that represent programmatic dimensions or cleavages. Thus, the longer the vector, the higher the variability the vector of this cleavage has in the analysis; and the smaller the angle formed by the vector and factor axis is, the higher its importance in the study will be. The perpendicular projection of parties onto the vectors allows us to establish what dimensions are the most useful for distinguishing among subsets of political parties.

Figures 6.1 and 6.2 show that four programmatic dimensions polarize the thirty cases under study: religion and values, and state intervention, which characterize axis 1; democracy, which characterizes axis 2; and armed forces, which characterizes axis $3 .{ }^{26}$ The first factor plane (see Figure 6.1) distinguishes parties with a strong religious component; these parties are placed on the left side of the graph of parties espousing secularist views. It also distinguishes parties favorable to more state intervention (placed on the right side) from those adopting neoliberal economic views (placed in the upper left of the quadrant).

The dimension related to democratic attitudes also allows us to distin- 
Figure 6.2 Representation of the Polarization Dimensions, HJ-Biplot Axes 1 and 3

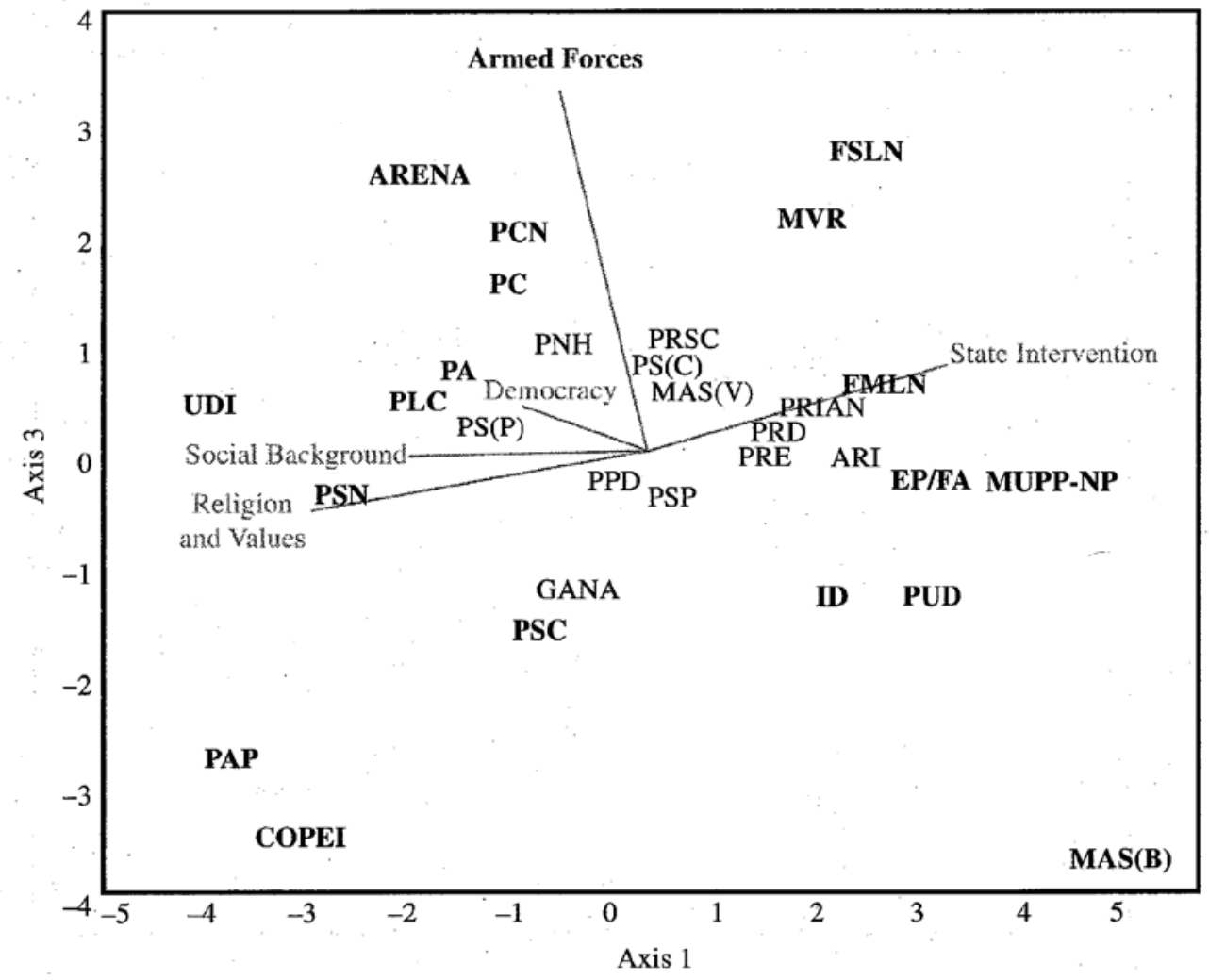

Source: Created by the author based on PELA 1999-2005.

guish among political parties. This cleavage separates parties fully endorsing democratic institutions (in the lower half of Figure 6.1) from those harboring doubts about democratic institutions (in the upper half). ${ }^{27}$ In spite of its lower quality, the social background dimension allows us to distinguish those political parties in which a majority of its members are from families with a high cultural and educational level (in the lower half) from those whose families have a lower educational level (in the upper right-hand quadrant).

The second factor plane, formed by axes 1 and 3 , is the one that best captures party polarization in the armed forces dimension. Figure 6.2 shows that the vector representing the armed forces cleavage distinguishes between parties that positively evaluate the current role of the military (upper side of the figure) and those parties holding negative views of the military (lower side of the figure). ${ }^{28}$

Based on the previous analysis, particularly on the results of the HJBiplot representation, a classification of party families is proposed in the next section. This classification will take into consideration the distance between political forces: the higher the distances, the stronger the differ- 
ences between political parties will be. This is also true the other way around: the shorter the distances, the greater the similarities among parties will be.

\section{Classification of Parties in the Religion and Values Dimension}

The importance of the religious cleavage in the political attitudes and behavior of citizens in both Europe and Latin America can hardly be disputed, particularly in those cases in which Christian-democratic parties have been present.

The Catholic Church has played a very important role in Latin American history and society. ${ }^{29}$ In the political arena, the importance of the Church is felt, for instance, in the formation of conservative political forces or in the processes of democratic transition. Even if religion has lost some of its political importance, it continues to affect differences between left and right parties, as was previously shown. Its importance does not strictly relate to religious faith, but is connected to moral issues that have been particularly divisive in Latin America, such as abortion and divorce.

Four variables are connected to this cleavage: strength of religious conviction (which takes into account religious feelings, beliefs, and practice); attitudes toward abortion; attitudes toward divorce; and trust in the Catholic Church. The conservative pole would be characterized by its strong religious conviction, its opposition to abortion and divorce, and its trust in the Catholic Church. By contrast, the progressive and liberal pole would be characterized by its weaker religious conviction, its endorsement of the right to abortion and divorce, and its mistrust of the Catholic Church.

UDI, ARENA, COPEI, PSN, and PC are the most conservative and religious parties, followed by PLC, PCN, and PA. The Ecuadorian left parties PSP and PAP also hold predominantly religious values. At the opposite pole are the progressive liberal parties, such as PPD; the Chilean PS, PRE, EP/FA, ARI; the Bolivian MAS, PUD, and MUPP-NP; as well as ID, MVR, FMLN, FSLN, and the right party PRIAN (see Table 6.7).

Table 6.7 Classification of Political Parties in the Religion and Values Dimension

Political Parties

Religious/Conservative Secularist/Progressive
UDI, ARENA, COPEI, PAP, PSP, PSN, PLC, PA, PC, PS-P

PPD, PS-C, PRE, ARI, EP/FA, ID, MUPP-NP, MVR, PUD, FMLN, PRIAN, FSLN, MAS-B

Source: Based on the results of HJ-Biplot.

Note: Parties for which the quality of representation is low are not included. 
There is a small group of parties with an intermediate position in this cleavage. They adopt moderate positions either in the conservative area (like the Panamanian PS, PSC, and PCN) or on the progressive side, like the Venezuelan MAS and the Mexican PRD. We must, however, be careful regarding the positions of these parties, since the quality of their representation in Figure 6.1 is low and, therefore, not reliable.

Overall, these data reveal that, in spite of the process of secularization, the religious cleavage continues to structure Latin American party systems, although in an attenuated manner.

\section{Classification of Parties in the State Intervention Dimension}

The structural economic transformations consisting of neoliberal and promarket policies have become another object of competition for Latin American parties. The different positions held by political parties regarding the state's role in the economy have made this cleavage central to the region's politics since the 1980 s. This is so despite widespread consensus on the implementation of promarket and orthodox fiscal policies. ${ }^{30}$ Neoliberal and promarket policies have been traditionally linked to right parties, whereas statist positions have been espoused by left parties.

The variables constituting the state-market dimension concern such issues as health care, housing, university education, jobs, unemployment benefits, the environment, and the basic needs of the population. As previously shown, social variables (e.g., health care, unemployment benefits, and providing for basic needs) make the strongest contribution to this dimension.

The clearly statist parties are the left-oriented EP/FA, PPD, the Chilean PS, PRE, ARI, PUD, the Bolivian MAS, MUPP-NP, FMLN, MVR, and ID; and also the right party PRIAN, which has shown positions different from those of other right parties in all dimensions of programmatic polarization. ${ }^{31}$ Right parties are neoliberal. This is the case of UDI, COPEI, ARENA, and the Guatemalan, Colombian, Panamanian, and Nicaraguan right, Again, PAP and PSP are closer to right, neoliberal than to left, statist positions (see Table 6.8).

Table 6.8 Classification of Political Parties in the State Intervention Dimension

Political Parties

In favor of state intervention

EP/FA, PPD, PS-C, PRE, ARI, MAS-B, PUD, MUPP-NP, FMLN, PRIAN, MVR, ID, FSLN

Against state intervention UDI, ARENA, COPEI, PC, PSP, PSN, PLC, PA, PAP

Source: Based on HJ-Biplot analysis.

Note: Parties for which the quality of representation is low are not included. 
A group of right parties adopt moderate neoliberal positions; they are the PCN, the Panamanian PS, PNH, and PSC. A group of moderate statist parties also exists-the Venezuelan MAS and the Mexican PRD. However, the low quality of representation for this group of parties prevents us from drawing definitive conclusions on their positions in this dimension.

\section{Classification of Parties in the Democracy Dimension}

The authoritarian experiences of many Latin American countries in the 1970s and 1980s left their imprint on party systems, as well, and gave rise to an authoritarianism-democracy cleavage. Democratic transition processes, however, gave rise to widespread positive evaluations of democracy. 32

The variables included in the democracy cleavage relate to the political culture of the parliamentary elite. More specifically, they consist of support for democracy and for two key institutions of the democratic regime: political parties and elections. Legislators are most likely to support the democratic regime, but there may be significant differences on views of elections and political parties. When interpreting these data, it must be kept in mind that in some Latin American countries electoral processes were not competitive, and that some political parties had authoritarian connections and inclinations. ${ }^{33}$

Figure 6.1 allows us to classify political parties by two main poles, one "democratic," which includes parties unconditionally endorsing democracy, political parties, and elections, and one "authoritarian," which includes parties expressing doubts about democracy as the best possible regime, as well as doubts about political parties and elections.

The group of democratic parties is mainly formed by the left parties PPD and PS in Chile, the PAP in Peru, PRE and ID in Ecuador, EP/FA in Uruguay, and ARI in Argentina; and by the right parties COPEI, PSN, and PLC (see Table 6.9). The "authoritarian" pole includes the Colombian PC, PSP, PUD, FMLN, the Bolivian MAS and PRIAN, as well as MUPP-NP, MVR, FSLN, and, to a lesser extent, ARENA. A third group of parties is at

Table 6.9 Classification of Political Parties in the Democracy Dimension

Political Parties

Democracy

PPD, PS-C, PAP, PRE, EP/FA, ARI, ID, PSN, PLC, COPEI, PA

Authoritarianism PC, PSP, PUD, MAS-B, FMLN, PRIAN, MVR, MUPP-NP

Source: Based on HJ-Biplot analysis.

Note: Parties for which the quality of representation is low are not included. 
the center of this dimension. It includes UDI, PA, PSC, and PNH. Overall, this dimension divides the Latin American left into two main groups: a moderate, democratic left and a revolutionary-authoritarian left. It also reveals that the specific position of the Peruvian PAP-close to the right parties both in the religion and moral values and in the state intervention dimensions-is different from that of other conservative parties, due to its evaluations of democracy.

\section{Classification of Parties in the Social Background Dimension}

The process of political socialization and its influence on the behavior of politicians have been addressed often in the study of political elites. Most of the literature underlines the importance of two elements in political socialization processes: the time and the agents of socialization. Different authors pay special attention to family as one of the main agents in this process. ${ }^{34}$ Closely connected with time and agents is the social context of political socialization (the family's socioeconomic status and educational level). Family and social contexts exert specific influences on political views and party identifications. 35

The goal here is to establish whether the social context of legislators and, in particular, the educational levels of their fathers allow us to distinguish among political parties. Even if this is not one of the dimensions showing strong variability (see Figure 6.1), it also shows significant differences between left and right parties.

Table 6.10 demonstrates that, whereas right parties are characterized by high educational levels, left political groups (with the exception of the Chilean and Uruguayan ones) are characterized by lower educational levels.

This classification overlaps with our previous classification in the democracy dimension. Parties whose members come from more highly educated families are more supportive of democracy, whereas those with members from lower educational levels are more critical of democratic institutions. Therefore, it can be pointed out that there is an overlap between these two dimensions of polarization.

Table 6.10 Classification of Political Parties in the Social Background Dimension

Political Parties

\begin{tabular}{ll}
\hline High educational level & PPD, PS-C, PAP, PRE, EP/FA, ARI, ID, PSN, \\
Low educational level & PLC, COPEI, UDI, PA, ARENA, PC \\
& PSP, PUD, MAS-B, FMLN, PRIAN, MVR, MUPP-NP, FSLN
\end{tabular}

Source: Based on HJ-Biplot analysis.

Note: Parties with a low quality of representation are not included. 


\section{Classification of Parties in the Armed Forces Dimension}

This dimension is directly connected to the role played by the military in recent authoritarian regimes; it is also related to the quite different experiences of political parties during episodes of authoritarianism. Three variables constitute this dimension: evaluation of the role played nowadays by the military, trust in the armed forces, and view of whether the relationships between the military and the national government pose any risk to democratic consolidation.

Table 6.11 shows that the promilitary pole includes ARENA, PCN, FSLN, MVR, and the Colombian PC. The PA, UDI, and PLC also display promilitary orientations. The FMLN also holds positive views of the military. Within the antimilitary pole, there is one subgroup of parties holding strongly antimilitary views, such as the Bolivian MAS, COPEI, PAP, and PUD, and perhaps also PSC and ID in Ecuador; and a second subgroup that displays a more moderately negative evaluation of the military, which is formed by EP/FA and MUPP-NP.

The classification of left and right parties in this dimension is very similar to the one observed in the democracy dimension. Therefore, these two cleavages overlap: the promilitary parties are the same as those positioned in the authoritarian pole, and vice versa. This shows that issues related to the authoritarian past and the role of the military are connected to democratic evaluations, and that these two dimensions continue to divide Latin American political parties.

\section{Conclusion}

This chapter has tried to show the analytical usefulness of the cleavage approach to the study of left-right politics in Latin American legislatures. It also has sought to demonstrate that left-right divisions have a multidimensional character.

Instead of adopting a conception of cleavages centered around social conflicts, along the lines of Seymour Martin Lipset and Stein Rokkan (1967), this chapter has followed a more flexible approach, focusing on the

Table 6.11 Classification of Political Parties in the Armed Forces Dimension

Political Parties

\begin{tabular}{ll}
\hline Promilitary & ARENA, PCN, FSLN, MVR, PC, PA, UDI, PLC, FMLN \\
Antimilitary & MAS-B, COPEI, PAP, PUD, PSC, ID, PSN, EP/FA, MUPP-NP
\end{tabular}

Source: Based on HJ-Biplot analysis.

Note: Parties for which the quality of representation is low are not included. 
different dimensions of programmatic polarization. ${ }^{36}$ This approach allows us to assess which cleavages give rise to stronger divisions among parties.

In methodological terms, this analysis has attempted to establish dimensions of polarization that may be useful to the comparative study of Latin American party systems and to represent, simultaneously, the position of parties in all the dimensions of polarization.

Our analysis has shown that five dimensions structure party competition in Latin America and that polarization is larger in four dimensions: religion and moral values, state intervention, democracy, and armed forces. By contrast, divisions connected to social background play a much lesser role.

This analysis has pointed out an overlap between the armed forces and democracy dimensions; these divisions are often more connected to national experiences than to left-right ideological differences. There is also significant overlap between the social background and democracy dimensions.

The five dimensions analyzed in this chapter are congruent with divisions in the left-right ideological dimension; they clearly separate left and right parties. However, this analysis also shows two subgroups within the Latin American left, one more moderate and another more radical. By contrast, the positions of the Latin American right are much more homogeneous in these five dimensions.

Overall, the position of parties in the left-right dimension provides us with a useful map of the orientations of parties on economic, political, and socioeconomic issues. Therefore, the left-right dimension simplifies and synthesizes crucial information about policy preferences in Latin American legislatures.

Finally, it is necessary to conduct more in-depth analyses of political parties (including centrist parties) and party systems to complement the results of this research. Inclusion of centrist parties will provide us with a more encompassing and accurate picture of the dimensions of polarization in Latin American party systems. 
Appendix

Table 6.12 Party Placement and Individual Self-Placement in the Left-Right Dimension (scale from 1 to 10 )

\begin{tabular}{|c|c|c|c|c|c|}
\hline Country & $\begin{array}{l}\text { Political } \\
\text { Party }\end{array}$ & $\begin{array}{c}\text { Average } \\
\text { Ideological } \\
\text { Self- } \\
\text { Placement }\end{array}$ & $\begin{array}{l}\text { Average } \\
\text { Party } \\
\text { Placement }\end{array}$ & $\stackrel{\mathrm{N}}{\mathrm{N}}$ & $\begin{array}{c}\mathrm{N} \\
\text { (Sample) }\end{array}$ \\
\hline Argentina & ARI & 3.50 & 4.17 & 12 & 6 \\
\hline Bolivia & MAS & 1.57 & 2.14 & 27 & 14 \\
\hline \multirow[t]{3}{*}{ Chile } & UDI & 7.00 & 7.08 & 36 & 24 \\
\hline & PPD & 3.77 & 3.85 & 21 & 13 \\
\hline & PS & 2.56 & 2.56 & 12 & 9 \\
\hline Colombia & $\mathrm{PC}$ & 6.81 & 7.63 & 48 . & 27 \\
\hline Dominican Republic & PRSC & 6.72 & 7.97 & 36 & 29 \\
\hline \multirow{6}{*}{ Ecuador } & PSC & 6.83 & 8.08 & 24 & 23 \\
\hline & PRE & 3.92 & 4.21 & 14 & 14 \\
\hline & ID & 3.60 & 3.47 & 15 & 15 \\
\hline & MUPP-NP & 3.00 & 3.22 & 11 & 9 \\
\hline & PRIAN & 5.60 & 7.10 & 10 & 10 \\
\hline & PSP & 3.67 & 4.00 & 6 & 6 \\
\hline \multirow[t]{3}{*}{ El Salvador } & ARENA & 8.04 & 8.42 & 27 & 26 \\
\hline & FMLN & 1.76 & 1.72 & 31 & 29 \\
\hline & PCN & 6.93 & 7.27 & 16 & 15 \\
\hline \multirow[t]{2}{*}{ Guatemala } & GANA & 6.58 & 7.35 & 34 & 25 \\
\hline & PSN & 7.17 & 7.17 & 7 & 6 \\
\hline \multirow{2}{*}{ Honduras } & $\mathrm{PN}$ & 7.15 & 7.70 & 61 & 47 \\
\hline & PUD & 2.60 & 3.00 & 5 & 5 \\
\hline Mexico & PRD & 2.82 & 3.14 & 95 & 22 \\
\hline \multirow[t]{2}{*}{ Nicaragua } & PLC & 7.00 & 7.11 & 48 & 27 \\
\hline & FSLN & 1.83 & 1.69 & 38 & 29 \\
\hline \multirow{2}{*}{ Panama } & PA & 7.29 & 7.05 & 16 & 14 \\
\hline & PS & 7.17 & 9.00 & 8 & 6 \\
\hline Peru & PAP & 3.91 & 3.81 & 28 & 22 \\
\hline Uruguay & EP/FA & 2.60 & 3.03 & 40 & 30 \\
\hline \multirow[t]{3}{*}{ Venezuela } & COPEI & 5.83 & 7.00 & 7 & 6 \\
\hline & MVR & 3.68 & 4.13 & 77 & 47 \\
\hline & MAS & 3.83 & 3.83 & 21 & 12 \\
\hline
\end{tabular}

Source: Data based on PELA 1999-2005.

Note: Only parties with at least five legislators are included in the analysis. 


\section{6}

Table 6.13 Results of Factor Analysis (total variance explained)

\begin{tabular}{|c|c|c|c|c|c|c|c|c|c|}
\hline \multirow[b]{2}{*}{ Component } & \multicolumn{3}{|c|}{$\begin{array}{c}\text { Initial } \\
\text { Eigenvalues }\end{array}$} & \multicolumn{3}{|c|}{$\begin{array}{l}\text { Extraction Sums of } \\
\text { Squared Loadings }\end{array}$} & \multicolumn{3}{|c|}{$\begin{array}{c}\text { Rotation Sums } \\
\text { of Squared Loadings }\end{array}$} \\
\hline & Total & $\begin{array}{c}\% \text { of } \\
\text { Variance }\end{array}$ & $\begin{array}{c}\text { Cumulative } \\
\%\end{array}$ & Total & $\begin{array}{c}\% \text { of } \\
\text { Variance }\end{array}$ & $\begin{array}{c}\text { Cumulạtive } \\
\%\end{array}$ & Total & $\begin{array}{c}\% \text { of } \\
\text { Variance }\end{array}$ & $\underset{\%}{\text { Cumulative }}$ \\
\hline 1 & 3.472 & 17.359 & 17.359 & 3.472 & 17.359 & 17.359 & 3.123 & 15.613 & 15.613 \\
\hline 2 & 2.506 & 12.530 & 29.890 & 2.506 & 12.530 & 29.890 & 2.265 & 11.325 & 26.938 \\
\hline 3 & 1.799 & 8.996 & 38.886 & 1.799 & 8.996 & 38.886 & 2.199 & 10.997 & 37.934 \\
\hline 4 & 1.659 & 8.293 & 47.179 & 1.659 & 8.293 & 47.179 & 1.792 & 8.962 & 46.897 \\
\hline 5 & 1.311 & 6.557 & 53.736 & 1.311 & 6.557 & 53.736 & 1.368 & 6.840 & 53.736 \\
\hline 6 & .907 & 4.533 & 58.269 & & & & & & \\
\hline 7 & .893 & 4.466 & 62.734 & & & & & & \\
\hline 8 & .844 & 4.220 & 66.955 & & & & & & \\
\hline 9 & .787 & 3.935 & 70.889 & & & & & & \\
\hline 10 & .739 & 3.693 & 74.583 & & & & & & \\
\hline 11 & .700 & 3.499 & 78.082 & & & & & & \\
\hline 12 & .668 & 3.340 & 81.422 & & & & & & \\
\hline 13 & 609 & 3.046 & 84.468 & & & & & & \\
\hline 14 & .564 & 2.820 & 87.288 & & & & & & \\
\hline 15 & .539 & 2.695 & 89.984 & & & & & & \\
\hline 16 & .492 & 2.461 & 92.444 & & & & & & \\
\hline 17 & .460 & 2.298 & 94.743 & & & & & & \\
\hline 18 & .428 & 2.139 & 96.882 & & & & & & \\
\hline 19 & .350 & 1.752 & 98.633 & & & & & & \\
\hline 20 & .273 & 1.367 & 100.000 & & & & $\therefore$ & & \\
\hline
\end{tabular}

Source: Based on PELA 1999-2005.

Note: Extraction method used is principal component analysis. 
Table 6.14 Questions Used

\begin{tabular}{|c|c|}
\hline Cleavage & Question \\
\hline Religion and values & $\begin{array}{l}\text { With reference to your religious feelings and beliefs, where would } \\
\text { you place yourself on a scale from } 1 \text { to } 10 \text {, with "1" corresponding to } \\
\text { the lowest level of religious conviction and the observance of reli- } \\
\text { gious practices and " } 10 \text { " corresponding to the highest level? } \\
\text { - Degree of support for divorce and abortion: "1," totally opposed; " } 2 \text {," } \\
\text { only in some circumstances; and " } 3 \text {," completely in favor. } \\
\text { - To what degree do you trust in the actions of the Catholic Church in } \\
\text { public life in your country? Very much, a lot, not much, not at all. }\end{array}$ \\
\hline Armed forces & $\begin{array}{l}\text { - On this card, there are a series of squares to be filled in that go from } \\
\text { " } 1 \text {," very negative, to " } 10 \text {," very positive. On this scale, where would } \\
\text { you place the role of the armed forces at the present moment? } \\
\text { - To what degree do you believe the relationship between the armed } \\
\text { forces and the government to be a threat to democracy: very high, } \\
\text { high, low, not at all? } \\
\text { - To what degree do you trust in the actions of the armed forces in pub- } \\
\text { lic life in your country: very much, a lot, not much, not at all? } \\
\text { - Could you tell me how important the relationship with the armed } \\
\text { forces is to the consolidation of democracy in your country: very } \\
\text { important, important, not very important, or not at all important? }\end{array}$ \\
\hline Dem & $\begin{array}{l}\text { With which of the following statements do you most agree? } \\
\text { "Democracy is preferable to any other form of government"; or, "In } \\
\text { the context of economic crisis or political instability, an authoritarian } \\
\text { government may be preferable to a democratic one." } \\
\text { - There are people who say that without parties there cannot be democ- } \\
\text { racy. How would you rate your agreement with this statement: very } \\
\text { much in agreement, in agreement, somewhat in agreement, not at all } \\
\text { in agreement? }\end{array}$ \\
\hline State i & $\begin{array}{l}\text { I would like to get your opinion on a series of functions traditionally } \\
\text { assigned to the state. In general, tell me to what degree - very high, } \\
\text { high, low or not at all-you believe the state should intervene in the } \\
\text { following areas: subsidizing housing for citizens; creating employ- } \\
\text { ment; providing public health coverage; guaranteeing universal and } \\
\text { free university education; providing unemployment insurance; pro- } \\
\text { tecting the environment; covering basic needs of the population. }\end{array}$ \\
\hline Social background & $\begin{array}{l}\text { What level of schooling did your father officially complete: none, } \\
\text { primary school, high school or similar, junior college degree or simi- } \\
\text { lar, BA, or graduate degree? } \\
\text { - What level of schooling did your mother officially complete: none, } \\
\text { primary school, high school or similar, junior college degree or } \\
\text { similar, BA, or graduate degree? }\end{array}$ \\
\hline
\end{tabular}

Source: Based on PELA 1999-2005. 


\section{Notes}

1. Lipset and Rokkan (1967), and Inglehart (1984).

2. Coppedge (1997).

3. Inglehart (1984).

4. The relative importance of cleavages varies over time, and there is always a critical cleavage that predominates over others and that structures party competition.

5. See, for instance, Sartori (1999).

6. These data are based on the individual perceptions and evaluations of legislators.

7. Sani and Montero (1986:155).

8. On the utility of the left-right dimension in Latin America, see Alcántara (1991:88). This author argues that four factors make the use of this distinction less common in Latin America. The first one relates to the legacies of populist regimes; the second one lies in the quite recent character of many Latin American parties. The third factor pertains to the legacies of authoritarian regimes and to the divide between democracy and authoritarianism. Finally, the fourth factor has to do with the emergence of new issues, which might also weaken the importance of left-right differences in Latin America.

9. Coppedge (1997:6)

10. Crespo (1997:116).

11. Luna and Zechmeister (2003:6).

12. Alcántara (2004:134). Some authors point out that in order to speak of parties in which ideology plays a role, it is only necessary that they adopt clear positions on a number of issues (Coppedge, 1997).

13. Legislators placed themselves and their respective parties on a scale ranging from 1 to 10 , in which "1" means "left" and "10" means "right." Parties are considered to be left oriented when their average value is less than or equal to 4 in the party placement and self-placement variables, and to be right oriented when their average value in both variables is equal to or higher than 7. Table 6.12 in the appendix shows averages in the self-placement and party placement dimensions. Party positions are very similar in both variables, except for the cases of the Colombian PC, the Ecuadorian PSC and PRIAN, the Guatemalan GANA, the Dominican PRSC, and the Venezuelan COPEI.

14. In the Uruguayan case, the data for this analysis correspond to the 2000-2005 legislative period. Parties with less than five members in parliament were excluded from the analysis.

15. Thus, this classification coincides to a large extent with the typology elaborated by Alcántara (2004c:157). However, whereas Alcántara considers five ideological locations (left, center-left, center, center-right, and right), this chapter only distinguishes three basic placements (left, center, and right).

16. The results of this analysis meet the requirements of factor analysis. The value for the Kaiser Meyer Olkin measure of sample adequacy equals 0.736 . The five factors reported here explain 53.74 percent of the variance. The number of cases considered in the analysis was 502 .

17. Questions for these variables are reported in Table 6.14 in this chapter's appendix.

18. Galindo (1986) and Galindo and Cuadras (1986).

19. These evaluations might not coincide exactly with the strategic positions adopted in parliament by political parties. This analysis assumes, however, that there is a strong association between the average positions of parliamentarians and those 
of their respective political parties. Due to the proportionality and representativeness of the samples, differences in the number of legislators are assumed not to affect the results of this analysis.

20. It must be kept in mind that in the HJ-Biplot representation, programmatic dimensions are presented through vectors, and political parties as points with their corresponding labels. Those dots close to the point of the arrow above the gravity center have a higher magnitude and correspond to positive values, whereas those projected below the gravity center have negative values. The more distant the points are from the center of gravity, the higher the variability of these parties in the study. Closeness between dots reveals similarity between parties. Finally, the longer the vector, the higher the contribution of that element (dimension) to total variability.

21. Galindo, Fernández, Ávila, del Río, and Fernández (1999).

22. Factor axes refer to the axes of biplot representation. These axes are new variables, consisting of linear combinations of the original variables, that allow us to represent more than two variables in one dispersion figure, often in two-dimensional space. Their meaning is given by the variables they consist of. Factor axes are not related to the factors extracted by factor analysis.

23. The relative contribution of a factor to the element represents the amount of variability of each of the variables explained by that factor, and must be interpreted in the same way as the determination coefficient in a linear regression. That is, it indicates the contribution of each of the factor axes to the biplot representation of the dimensions of ideological polarization.

24. Since the axes are independent, the contribution of each of them to each variable is also independent. Therefore, it is possible to calculate the contribution of a factor plane by adding the contributions of the axes that form it. For instance, the contribution of the plane to the state intervention dimension will be the result of adding the contributions of axes 1,2 , and 3 to this dimension; that is, 588, 125, and 56 , respectively. Consequently, the contribution of the first plane to the state intervention dimension will be 769 (out of 1,000).

25 . When one variable, in this case the social background dimension, gets a similar contribution from more than one axis (396 in axis 1 and 276 in axis 2), this indicates its low variability in the study and, therefore, its low discriminating power.

26. A dimension characterizes an axis when it must be interpreted with regard to that axis.

27. Differences in this dimension do not necessarily reveal the presence of antidemocratic values but the existence of different views regarding the role of key democratic institutions, such as elections and political parties.

28. Due to its low quality, the graphic representation of the factor planes formed by axes 2 and 3 is not shown in this chapter, nor would it add anything of interest to the information presented in Figures 6.1 and 6.2.

29. Correa and Viera-Gallo (1986:58).

30. Luna and Zechmeister (2003).

31. The PRIAN is considered to be a right party. However, the average ideological self-placement of its legislators is 5.60 . The fact that this biplot analysis is based on legislators' perceptions may account for the distinctive position of this party.

32. Martínez Rodriguez (1997).

33. Crespo (1997:131).

34. See, among others, Lipset, Lazarsfeld, Barton, and Linz (1954) and Almond and Verba (1965). Almond and Verba indicate that early socialization exerts an important influence on the political attitudes and participation patterns of individuals. 
160 Party Politics ANd IDEOLogy

35. See, for instance, Soule $(1969: 446)$ for a study on the state legislators of Michigan, and Kornberg and Thomas (1965:768-771) for a study on legislators in the United States and Canada.

36. See Inglehart (1984). 


\section{Bibliography}

Adelantado, José, ed. (2000). Transformaciones del estado de Bienestar. Barcelona: Icaria.

Agosto, Gabriela, and Francisco Cueto (2001). "República Dominicana." In M. Alcántara and F. Freidenberg, eds., Partidos políticos de América Latina: Centroamérica, México y República Dominicana, pp. 615-698. Salamanca: Ediciones Universidad de Salamanca.

Ajenjo, Natalia (1999). "La cultura política de las elites como condición para la democracia: Los casos de Chile y México." Paper delivered at the VI encuentro de Latinoamericanistas en España, Cáceres, Spain.

Alcántara, Manuel (1991). "La relación izquierda-derecha en la política latinoamericana." Leviatán 43-44, pp. 73-93.

(1994). "Análisis comparado del papel de los partidos políticos en los procesos de transición política." In Silvia Dutrenit and Leonardo Valdés, eds., El fin de siglo y los partidos políticos en América Latina. Mexico City: Instituto Mora.

(1995a). "La elite parlamentaria latinoamericana y el continuo izquierdaderecha." In W. Hofmeister and J. Thesing, eds., La transformación de los sistemas políticos en América Latina, pp. 385-410. Buenos Aires: CIEDLA.

- (1995b). "El estudio de las elites parlamentarias en América Latina." Inguruak: Revista Vasca de Sociología y Ciencia Política, no. 13, pp. 25-37.

(1997). "Democracia y valores democráticos en la clase política latinoamericana." In Helena González and Heidulf Schmidt, eds., Democracia para una nueva sociedad (Modelo para armar). Caracas: Nueva Sociedad.

(1999). Sistemas políticos de América Latina. Madrid: Tecnos.

(2000a). "De la perception par les elites parlamentaires latino-américaines du rôle des États-Unis dans la région." In Isabelle Vagnoux, ed., Les États-Unis et les élites latino-américaines, pp. 141-154. Aix-en-Provence: Publications de l'Université de Provence.

(2000b). South American Legislatures: Thinking About Economic Integration and Defense Policy. Washington, D.C.: CSIS.

(2002)."Experimentos de democracia interna: Las primarias de partidos en América Latina.” Working Paper no. 293. Hellen Kellogg Institute for International Studies, University of Notre Dame, Notre Dame, Indiana. - (2003). Sistemas políticos de América Latina. 3rd ed. Madrid: Tecnos.

- (2004). "Quality of Democracy or Quality of Politics?" In Guillermo O'Donnell, Jorge Vargas Cullell, and Osvaldo M. Iazzetta, eds., The Quality of Democracy: Theory and Applications, pp. 234-238. Notre Dame, Ind.: University of Notre Dame Press. 
(2004a). ¿Instituciones o máquinas ideológicas? Origen, programa y organización de los partidos latinoamericanos. Barcelona: ICPS.

- (2004b). "Partidos en América Latina: Precisiones conceptuales, estado actual y retos futuros." Documentos CIDOB, no. 3. Barcelona: Fundación CIDOB.

Alcántara, Manuel, and Flavia Freidenberg (1997). "Elites parlamentarias e integración subregional en América Latina." America Latina Hoy, no. 17, pp. 11-17.

— Ediciones Universidad de Salamanca.

Alcántara, Manuel, and Iván Llamazares (1997). "El análisis de los diputados latinoamericanos en el contexto de los estudios sobre la clase política: Características, objetivos y estrategias de investigación." América Latina Hoy, no. 16 (August): pp. 15-28.

Alcántara, Manuel, and Juan Pablo Luna (2004). "Ideología y competencia partidista en dos post-transiciones: Chile y Uruguay en perspectiva comparada." Revista de Ciencia Política 24, no. 1, pp. 128-168.

Alcántara, Manuel, Mercedes García Montero, and Francisco Sánchez (2005). Funciones, procedimientos y escenarios: Un análisis del poder legislativo en América Latina. Salamanca: Ediciones de la Universidad de Salamanca.

Alcántara, Manuel, and Marisa Ramos (2000). "Los diputados latinoamericanos y las opciones de la inserción internacional: El caso de la Comunidad Iberoamericana." In Francisco Rojas Arevena, ed., Las Cumbres Iberoamericanas: Una mirada global. Santiago and Caracas: FLACSO and Nueva Sociedad.

Alfaro Salas, Sergio (2001). "Costa Rica." In Manuel Alcántara and Flavia Freidenberg, eds., Partidos políticos de América Latina: Centroamérica, México y República Dominicana, pp. 33-134. Salamanca: Ediciones de la Universidad de Salamanca.

Almond, Gabriel, and Sydney Verba (1965). The Civic Culture, Political Attitudes and Democracy in Five Nations: An Analytic Study. Boston: Little, Brown.

Altman, David, and Aníbal Pérez-Liñán (1999). "Más allá de la poliarquía: Una aproximación a la calidad de las democracias." Revista Uruguaya de Ciencia Politica, no. 11, pp. 83-105.

(2002). "Assessing the Quality of Democracy: Freedom, Competitiveness, and Participation in Eighteen Latin American Countries." Democratization 9, no. 2, pp. 85-100.

Ames, Barry (1992). "Electoral Strategy Under Open-List Proportional Representation." American Journal of Political Science 2, no. 39, pp. 406-433. - (2000). "Disciplina partidaria en la legislatura brasileña." Política y Gobierno 7, no. 1, pp. 15-61.

Amorin Neto, Octavio, and Fabiano G. M. Santos (1997). "The Executive Connection: Explaining the Puzzles of Party Cohesion in Brazil." Paper delivered at the LASA Congress, Guadalajara, Mexico.

Anderson, Lee (1968). "Organizational Theory and the Study of State and Local Parties." In William J. Crotty, ed., Approaches to the Study of Party Organization. Boston: Allyn and Bacon.

Angell, Alan (2003). "Party Change in Chile in Comparative Perspective." Revista de Ciencia Política 28, no. 2, pp. 88-108.

APSA. Committee on Political Parties (1950). "Towards a More Responsible TwoParty System." American Political Science Review (September).

Arnold, Charles (2003). "Candidate Quality and Candidate Emergence: An 
Exploratory Study Utilizing a New Method for Measuring Quality." Paper delivered at the meeting of the American Political Science Association, Philadelphia, Pennsylvania.

Aron, Raymond (1989). Estudios sociológicos. Madrid: Espasa Calpe.

Barnes, Samuel (1977). Representation in Italy: Institutionalized Tradition and Electoral Choice. Chicago: University of Chicago Press.

Bartolini, Stefano (1998). "Partidos y sistemas de partidos.” In Gianfranco Pasquino, Stefano Bartolini, Maurizio Cotta, Leonardo Morlino, Angelo Panebianco, eds., Manual de Ciencia Política, pp. 217-264. Madrid: Alianza Universidad.

Beck, Ulrich (1994). La sociedad del riesgo. Barcelona: Paidos. (1998). ¿Qué es la globalización? Falacias del globalismo, respuestas a la globalización. Barcelona: Paidos.

Beer, Carolina (2004). Electoral Competition and Institutional Change in Mexico. Notre Dame, Ind.: University of Notre Dame Press.

Beltrán, Virgilio Rafael (1970). El papel político y social de las fuerzas armadas en América Latina. Caracas: Monte Ávila Editores.

Blondel, Jean (1978). Political Parties: A Genuine Case for Discontent? London: Oxford University Press.

Bobbio, Norberto (1995). Derecha e Izquierda: Razones y significados para una distinción política. Madrid: Taurus.

Botella, Joan (1997). "Parlamento y carreras políticas." In M. Ramírez, ed., El parlamento a debate. Madrid: Trotta.

Bowler, S., David M. Farrel, and Richard Katz (1999). Party Discipline and Parliamentary Government. Columbus: Ohio State University Press.

Brady, David, Kara Buckley, and Douglas Rivers (1999). "The Roots of Careerism in the U.S. House of Representatives." Legislative Studies Quarterly 24, no. 4, pp. 489-510.

Brutonel, Michael, Richard Gunther, and John Higley (1992). "Introduction: Elite Transformations and Democratic Regimes." In Elites and Democratic Consolidation in Latin America and Southern Europe. Cambridge: Cambridge University Press.

Burns, Nancy, Laura Evans, Gerald Gamm, and Corrine McConnaughy (2004). "Pockets of Expertise: Careers and Professionalism in Twentieth-Century State Legislatures." Paper delivered at the meeting of the American Political Science Association, Chicago, Illinois.

Calvert, Peter (2004). "Executive Leadership and Legislative Assemblies: Latin America." The Journal of Legislative Studies 10, nos. 2-3, pp. 218-229.

Carey, John. (1998). Term Limits and Legislative Representation. New York: Cambridge University Press.

(1999). "Partidos, coaliciones y el Congreso chileno en los años noventa." Política y Gobierno, no. 2, pp. 365-405.

(2000). "Party Unity in Legislative Voting." Paper delivered at the meeting of the American Political Science Association, Washington, D.C.

(2001). "Party and Coalition Unity in Legislative Voting." Paper delivered at the meeting of the American Polítical Science Association, Washington, D.C.

(2002). "Getting Their Way, or Getting in the Way? Presidents and Party Unity in Legislative Voting." Paper delivered at the Comparative Politics Workshop, University of Chicago, Chicago, Illinois.

Caselli, Francesco, and Massimo Morelli (2004). "Bad Politicians." Journal of 
Public Economics 88, nos. 3-4, pp. 759-782. Available at http://ideas.repec. org/p/cpr/ceprdp/2402.html\#author.

Castañeda, Jorge G. (1995). La utopía desarmada: Intrigas, dilemas y promesas de la izquierda en América Latina. México: Editorial Joaquín Mortiz, Grupo Planeta.

Castells, Manuel (1998). La era de la información. Vol. 2. Madrid: Alianza.

Cavarozzi, Marcelo (1991). "Más allá de las transiciones a la democracia en América Latina." Revista de Estudios Políticos, no. 74, pp. 85-112.

(2002). Autoritarismo y democracia. Buenos Aires: Eudeba.

Cavarozzi, Marcelo, and Juan Abal Medina, eds. (2002). El asedio a la política: Los partidos latinoamericanos en la era neoliberal. Buenos Aires: Politeia.

CEPAL (2003). Panorama Social de América Latina 2002-2003 (August).

Cheibub, José Antonio, and Adam Przeworski (1999). "Democracy, Elections and Accountability for Economic Outcomes." In Adam Przeworski, Susan Stokes, and Bernard Manin, eds., Democracy, Accountability, and Representation. New York: Cambridge University Press.

Chin, Michelle L., and Michelle M. Taylor-Robinson (2005). "The Rules Matter: An Experimental Study of the Effects of Electoral Systems on Shifts in Voters' Attention." Electoral Studies 24, no. 3, pp. 465-483.

Close, David, ed. (1995). Legislatures and the New Democracies in Latin America. Boulder, Colo.: Lynne Rienner Publishers.

Cohen, Joshua (1989). "Deliberation and Democratic Legitimacy." In A. Hamlin and B. Pettit, eds., The Good Polity. Oxford: Oxford University Press.

Collier, David, and Steven Levistky (1997). "Democracy with Adjectives: Conceptual Innovation in Comparative Research." World Politics 49, no. 3, pp. $430-451$.

Colomer, Josep M. (2001). Instituciones políticas. Barcelona: Ariel.

Colomer, Josep M., and Luis E. Escatel (2005). "La dimensión izquierda-derecha en América Latina." Desarrollo Económico 44, no. 177, pp. 123-136.

Combellas, Ricardo (1985). COPEI: Ideología y liderazgo. Caracas: Editorial Ariel.

Conaghan, Catherine (1995). "Políticos versus partidos: Discordia y desunión en el sistema de partidos ecuatoriano." In Scott Mainwaring and Timothy Scully, eds., La construcción de las instituciones democráticas, pp. 355-447. Santiago: CIEPLAN.

Converse, Philip, and Roy Pierce (1986). Political Representation in France. Cambridge: Harvard University Press.

Coppedge, Michael (1997). "A Classification of Latin American Political Parties." Working Paper no. 24. Kellogg Institute, Notre Dame University, Notre Dame, Indiana.

- (1998). "The Dynamic Diversity of Latin American Party Systems." Party Politics 4, no. 4, pp. 547-568.

Corral, Margarita (2004). "El focus y el estilo de representación parlamentaria en América Central: Un análisis de las percepciones y actitudes de los diputados." Paper delivered at the X encuentro de Latinoamericanistas Españoles, Salamanca, Spain.

Correa, Enrique, and José A. Viera-Gallo (1986). Iglesia y dictadura. Chile: Chile y América.

Cotta, Maurizio, and Heinrich Best (2000). Parliamentary Representatives in Europe 1848-2000: Legislative Recruitment and Careers in Eleven European Countries. Oxford: Oxford University Press.

Crespo, Ismael (1997). "La cultura política de la clase parlamentaria centroamericana." Revista Mexicana de Sociología 59, no. 1, pp. 115-139. 
(1998). "Clase política, diseños institucionales y gobernabilidad en Centroamérica." In J. Botella and J. M. Sanahuja, eds., Centroamérica después de la crisis. Barcelona: ICPS.

Crewe, Ivor (1985). Electoral Change in Western Democracies: Patterns and Sources of Electoral Volatility. New York: St. Martin's Press.

Crisp, Brian F., and Scott W. Desposato (2004). "Constituency Building in Multimember Districts: Collusion or Conflict?” Journal of Politics 66, no. 1, pp. 136-156.

Crisp, Brian F., Maria C. Escobar-Lemmon, Bradford S. Jones, Mark. P. Jones, and Michelle M. Taylor-Robinson (2004). "Vote-Seeking Incentives and Legislative Representation in Six Presidential Democracies.” Journal of Politics 66, no. 3, pp. 823-846.

Cutright, Philips (1963). "National Political Development: Its Measurement and Social Correlates.” In Nelson W. Polsby, Robert A. Dentler, and Paul A. Smith, eds., Politics and Social Life, pp. 569-582. Boston: Houghton Mifflin.

Czudnoswski, Mosheon, ed. (1983). Political Elites and Social Change: Studies of Elite Roles and Attitudes. DeKalb: Northern Illinois University Press.

Dahl, Robert A. (1971). Polyarchy: Participation and Opposition. New Haven, Conn.: Yale University Press.

Dal Bó, Ernesto, Pedro Dal Bó, and Rafael Di Tella (2002). "Plata o Plomo": Bribe and Punishment in a Theory of Political Influence." Working Paper no. 28. Department of Economics, Brown. University, Providence, Rhode Island. Available at http://www.econ.brown.edu/2002/wp2002-28.pdf.

Dalton, Russell (1985). "Political Parties and Political Representation: Party Supporters and Party Elites in Nine Nations." Comparative Political Studies 18, no. 3, pp. 267-299.

de Swaan, Abram (1973). Coalition Theories and Cabinet Formation. Amsterdam: Elsevier.

Del Campo, Esther, and Elena Martínez Barahona (2000). "La derecha en Chile." Paper delivered at the LASA Congress, Miami, Florida.

Del Campo, Esther, and Marisa Ramos (1997). "La paradoja partidista: Institucionalización y representación en los partidos políticos latinoamericanos." America Latina Hoy, no. 16, pp. 29-39.

Delgado, Irene (2000). "Elites políticas y vida parlamentaria: Actividades y motivaciones de los diputados españoles." In A. Martínez, ed., El Congreso de los diputados en España: Funciones y rendimientos, pp. 295-342. Madrid: Tecnos.

Delgado Gómez-Escalonilla, Lorenzo (1988). Diplomacia franquista y política cultural hacia Iberoamérica, 1939-1953. Madrid: Centro de Estudios Históricos.

Di Tella, Torcuato S. (1993). Historia de los partidos políticos en América Latina. Buenos Aires: Siglo XX, Fondo de Cultura Económico.

Diamond, Larry (1992). "Economic Development and Democracy Reconsidered." In Gary Marks and Larry Diamond, eds., Reexamining Democracy: Essays in Honor of Seymour Martin Lipset. Newbury Park, Calif.: Sage. (1999). Developing Democracy Toward Consolidation. Baltimore and London: Johns Hopkins University Press.

Diamond, Larry, Jonathan Hartlyn, Juan J. Linz, and Seymour Martin Lipset (1999). Democracy in Developing Countries: Latin America. 2nd ed. Boulder and London: Lynne Rienner Publishers.

Diamond, Larry, and Leonardo Morlino (2004). "The Quality of Democracy: An Overview." Journal of Democracy 15, no. 4, pp. 20-31.

Diaz, Borja, and Sebastián Linares (2005). "Fortalecimiento de la independencia 
judicial en centroamérica: Un balance tras veinte años de reformas." América Latina Hoy, no. 39, pp. 47-96.

Dix, Robert H. (1989). "Cleavage Structures and Party Systems in Latin America." Comparative Politics 22, no. 1, pp. 23-37.

Domínguez, Jorge (1998). "Free Politics and Free Markets in Latin America." Journal of Democracy 9 , no. 4, pp. 10-84.

Downs, Anthony (1957). An Economic Theory of Democracy. New York: Harper.

Duverger, Maurice (1951). Los partidos políticos. Mexico DF: Fondo de Cultura Económico.

Eckstein, Susan, and Timothy Wickham-Crowley (2003). Struggles for Social Rights in Latin America: Race, Gender, Labor and Subsistence. New York and London: Routledge.

Eldersveld, Samuel (1989). Political Elites in Modern Societies. Ann Arbor: University of Michigan Press.

Epstein, David, David Brady, Sadafumi Kawato, and Sharyn O'Halloran (1997). “A Comparative Approach to Legislative Organization: Careerism and Seniority in the United States and Japan." American Journal of Political Science 41, pp. 965-998.

Esaiasson, Peter, and Knut Heidar (2000). Beyond Westminster and Congress: The Nordic Experience: Columbus: Ohio State University Press.

Esaiasson, Peter, and Soren Holmberg (1996). Representation from Above: Members of Parliament and Representative Democracy in Sweden. Aldershot: Dartmouth Publishing.

Escobar-Lemmon, María, and Erika Moreno (forthcoming 2007). "Mejor solo que mal acompañado: Political Entrepreneurs in Colombia." In S. Morgenstern and P. M. Siavelis, eds., Pathway to Power: Political Recruitment and Candidate Selection in Latin America. University Park: Pennsylvania State University.

Etzioni-Halevy, Eva (1993). The Elite Connection: Problems and Potential of Western Democracy. Cambridge, Eng.: Polity Press.

Eulau, Heinz, John Wahlke, William Buchanan, and Leroy Ferguson (1959). "The Role of Representative: Some Empirical Observations on the Theory of Edmund Burke." American Political Science Review, no. 53, pp. 742-756.

Farah, Barbara (1980). "Political Representation in West Germany: The Institution and Maintenance of Mass-Elite Linkages." Doctoral dissertation, Department of Political Science, University of Michigan, Ann Arbor, Michigan.

Figuereido, Argelina, and Fernando Limongi (1995). "Partidos políticos na Câmara dos Deputados: 1989-1994." Dados 38, no. 3.

Fiorina, Morris P. (1994). "Divided Government in the American States: A Byproduct of Legislative Professionalism?" American Political Science Review 88, no. 2, pp. 304-316.

- (1999). "Further Evidence of the Partisan Consequences of Legislative Professionalism." American Journal of Political Science 43, no. 3, pp. 974-977.

Foweraker, Joe (1998). "Institutional Designs, Party Systems, and Governability: Differentiating the Presidential Regimes of Latin America." British Journal of Political Science, no. 28, pp. 651-676.

Fowler, Linda L. (1993). Candidates, Congress, and the American Democracy. Ann Arbor: University of Michigan Press.

Freidenberg, Flavia (1999). "Actitudes a la democracia de las elites parlamentarias en Argentina, Ecuador, Perú y Uruguay." Master's thesis, Instituto Interuniversitario de Estudios de Iberoamérica y Portugal, Universidad de Salamanca, Salamanca, Spain. 
(2000). "Posiciones ideológico-programáticas de los políticos y los partidos en Ecuador." Paper delivered at the seminar "Party Politics in Latin America," School of International Studies of the University of Miami, Miami, Florida. (2003). Jama, caleta y camello: Las estrategias de Abdalá Bucaram y el PRE para ganar las elecciones. Quito: Universidad Andina Simón Bolívar.

Freidenberg, Flavia, and Manuel Alcántara (2001). "Cuestión regional y política en Ecuador: Partidos de vocación nacional y apoyo regional.” América Latina Hoy, no. 27, pp. 123-152.

Freidenberg, Flavia, and Francisco Sánchez López (2001). "Como se escolhe um candidato a presidente? Regras e práticas nos partidos políticos da América Latina." Opiniao Pública 8, no. 2, pp. 158-188.

Gabriel, K. Ruben (1971). "The Biplot-Graphic Display of Matrices with Application to Principal Component Analysis." Biometrika, no. 58, pp. 453-467.

Galindo, Purificación (1986). "Una alternativa de representación simultánea: HJbiplot." Questíio 10, no. 1, pp. 13-23.

Galindo, Purificación, and C. Cuadras (1986). "Una extensión del método biplot y su relación con otras técnicas." Publicaciones de Bioestadística y Biomatemática, no. 17.

Galindo, Purificación, M. J. Fernández, C. Ávila, A. Del Río, and M. Fernández (1999). "El análisis HJ-biplot como herramienta de un ecosistema acuático." Statistic and Environment, pp. 85-94.

Gangas, Pilar (2000). "Los diputados españoles (1977-1996).” In A. Martínez, ed., El Congreso de los Diputados en España: Funciones y rendimientos, pp. 271-294. Madrid: Tecnos.

García Díez, Fátima (2000). "Partidos políticos y reforma electoral en América Central y Panamá." Paper delivered at the LASA Congress, Miami, Florida. (2005). Procesos contemporáneos de reforma electoral en América Central y Caribe. Salamanca: AECI-Fundación General de la Universidad de Salamanca.

García Montero, Mercedes, and Patricia Marenghi (2003). "Entre lo que dicen y lo que hacen: La congruencia en la disciplina legislativa de los partidos latinoamericanos." Paper delivered at the VII Congreso de Ciencia Política y de la Administración, Barcelona, Spain.

Garretón, M. Antonio, ed. (2003). Latin America in the Twenty-First Century: Toward a New Sociopolitical Matrix. Miami: North/South Center Press.

Gibson, Edward (1996). Class and Conservative Parties: Argentina in Comparative Perspective. Baltimore: Johns Hopkins University Press.

Gil, Federico (1975). Latinoamérica y Estados Unidos: Dominio, cooperación y conflicto. Madrid: Tecnos.

Gilberg, Trond, ed. (1989). Coalition Strategies of Marxist Parties. Durham, N.C., and London: Duke University Press.

Gomà, Ricard (1998). "Rendimientos sustantivos: Políticas económicas y sociales en la CentroAmérica posrevolucionaria." In Ana S. Cardenal and Salvador Marti, eds., América Central las democracias inciertas. Madrid: Tecnos.

Gomà, Ricard, and Jacint Jordana, eds. (2004). Descentralización y políticas sociales en América Latina. Barcelona: Fundació CIDOB.

Goodman, Louis (1990). "Political Parties and the Political Systems of Central America." In L. Godman, W. M. Leogrande, and J. Mendelson Forman, eds., Political Parties and Democracy in Central America, pp. 3-16. Boulder, Colo.: Westview Press.

Gray, John (2000). Falso amanecer: Los engaños del capitalismo global. Barcelona: Paidós. 
Grayson, George (1968). El Partido Demócrata Cristiano chileno. Buenos Aires: Editorial Francisco de Aguirre.

Gutiérrez Saxe, M., and J. Vargas Cullell (1998). "Auditoría Ciudadana sobre la calidad de la democracia: Propuesta para su ejecución en Costa Rica." Costa Rica: Iniciativa del Proyecto "Estado de la región en desarrollo humano sostenible," PNUD and European Union.

Habermas, Jürgen (1998). Facticidad y validez. Madrid: Trotta.

Hagopian, Frances (2005). "Conclusions: Government Performance, Political Representation, and Public Perceptions of Contemporary Democracy in Latin America." In Frances Hagopian and Scott Mainwaring, eds., The Third Wave of Democratization in Latin America: Advances and Setbacks, pp. 319-361. Cambridge: Cambridge University Press.

Hagopian, Frances, and Scott Mainwaring, eds. (2005). The Third Wave of Democratization in Latin America: Advances and Setbacks. Cambridge: Cambridge University Press.

Hallerbeg, Mark, and Patrick Marier (2001). "Executive Authority, the Personal Vote, and Budget Discipline in Latin American and Caribbean Countries." Working Paper no. 17. Bonn: Zentrum für Europäische Integrationsforschung, Rheinische Friedrich-Wilhelms Universität, Bonn, Germany.

Hawkins, Kirk, and Scott Morgenstern (2003). "Cohesion of Legislators in Latin America: Patterns and Explanations." Unpublished manuscript.

Held, David (2001). Modelos de democracia. Madrid: Alianza Editorial.

Held, David, Anthony McGrew, David Goldblatt, and Jonathan Perraton (1999). Global Transformations: Politics, Economics, and Culture. Cambridge, Eng.: Polity Press.

Hibbing, John R. (1991). "Congressional Careers: Contours of Life in the U.S. House of Representatives." Chapel Hill: University of North Carolina Press. - (1999). "Legislative Careers: Why and How We Should Study Them." Legislative Studies Quarterly 24, no. 2, pp. 149-171.

Higley, John, and Richard Gunther (1992). Elites and Democratic Consolidation in Latin America and Southern Europe. New York: Cambridge University Press.

Higley, John, Jan Pakulski, and Wlodzimierz Wesolowski, eds. (1998). Postcommunist Elites and Democracy in Eastern Europe. Houndmills, Eng.: Macmillan.

Hinich, M., and M. C. Munger (1996). Ideology and the Theory of Democratic Choice. Ann Arbor: University of Michigan Press.

Hinzpeter, Ximena, and Carla Lehmann, S.B. (1999). "Las alas de la DC: La fuerte tensión interna del principal partido." Puntos de Referencia, no. 211.

Holmberg, Soren (1989). "Political Representation in Sweden." Scandinavian Political Studies, no. 12, pp. 1-36.

- (1999). "Collective Policy Congruence Compared." In Warren Miller et al., Policy Representation in Western Democracies. Oxford: Oxford University Press.

(2000). "Issue Agreement." In Peter Esaiasson and Knut Heidar, Beyond Westminster and Congress: The Nordic Experience. Columbus: Ohio State University Press.

Hunneus, Carlos (2003). "A Highly Institutionalized Political Party: Christian Democracy in Chile.” In Scott Mainwaring and Timothy Scully, eds., Christian Democracy in Latin America: Electoral Competition and Regime Conflicts, pp. 121-161. Stanford, Calif.: Stanford University Press. 
Huntington, Samuel (1965). "Political Development and Political Decay." World Politics, no. 17, pp. 386-430.

(1991). La Tercera Ola: La democratización a finales del siglo XX. Mexico City: Paidós.

Ibarra, Pedro, Salvador Martí, and Ricard Gomà, eds. (2002). Creadores de democracia radical: Movimientos sociales y redes de políticas públicas. Barcelona: Icaria.

IDD-Lat (2004). Índice de desarrollo democrático. Buenos Aires: Konrad Adenauer Stiftung.

Inglehart, Ronald (1984). "The Changing Structure of Political Cleavages in Western Society." In Russell J. Dalton, Scott Flanagan, and Paul Allen Beck, eds., Electoral Change in Advanced Industrial Democracies: Realignment or Dealignment? pp. 25-69. Princeton, N.J.: Princeton University Press.

Irwin, Galen, and Jacques Thomassen (1975). "Issue-Consensus in a Multi-Party System: Voters and Leaders in the Netherlands." Acta Politica, no. 10, pp. $389-420$.

Iturrieta, Anibal (1994). "El primer nacionalismo argentino." In Aníbal Iturrieta, ed., El pensamiento político argentino contemporáneo. Buenos Aires: Grupo Editor Latinoamericano.

Janda, Kenneth (1993). "Comparative Political Parties: Research and Theory.” In A. W. Finifter Political Science: The State of the Discipline II, pp. 163-191. Washington, D.C: American Political Science Association.

Jerez, Miguel (1997). "La élite parlamentaria." In M. Ramírez, ed., El parlamento a debate. Madrid: Trotta.

Jones, Mark P. (1995). Electoral Laws and the Survival of Presidential Democracies. Notre Dame, Ind.: University of Notre Dame Press. - (2001). "Carreras políticas y disciplinas partidarias en la Cámara de Diputados argentina." POSTData, no. 7, pp. 189-230.

- (2002). "Legislator Behaviour and Executive-Legislative Relations in Latin America." Latin American Research Review 37, no. 3, pp. 176-188.

- (2007). "The Recruitment and Selection of Legislative Candidates in Argentina." In Morgenstern and Siavelis, eds., Pathway to Power.

Jones, Mark P., Sebastian Saiegh, Pablo T. Spiller, and Mariano Tommasi (2002). "Amateur Legislators-Professional Politicians: The Consequences of PartyCentered Electoral Rules in a Federal System." American Journal of Political Science 46, no. 3, pp. 656-669.

Jordana, Jacint (2005). "Agencias reguladoras no tan inocentes." La vanguardia (Barcelona). May 26.

Katz, Jonathan N., and Brian R. Sala (1996). "Careerism, Committee Assignments, and the Electoral Connection." American Political Science Review 90, no. 1, pp. 21-33.

Katz, Richard (1997). "Representational Roles." European Journal of Political Research 32.

Kinder, Donald R. (1983). Presidential Traits: Report to the NES Board of Overseers. Ann Arbor: Center for Political Studies, University of Michigan.

Kirchheimer, Otto (1966). "The Transformation of the Western European Party Systems." In J. Lapalombara and M. Weiner, eds., Political Parties and Political Development, pp. 177-200. Princeton, N.J.: Princeton University Press.

Kitschelt, Herbert (2000). "Party Cohesion, Accountability and Responsiveness: Democratic Institutions and Political-Economic Change." Paper delivered at the meeting of the American Political Science Association, Washington, D.C. 
(2001). "Panoramas de intermediación de intereses políticos: Movimientos sociales, grupos de interés y partidos a comienzos del siglo XXI." In R. Maiz, ed., Construcción de Europa, Democracia y Globalización. Vol. 1. Santiago de Compostela, Spain: Universidade de Santiago de Compostela.

Kitschelt, Herbert, Zdenka Mansfeldova, Radoslaw Markowski, and Gabor Toka (1999). Post-Communist Party Systems: Competition, Representation and Inter-Party Cooperation. New York: Cambridge University Press.

Kitschelt, Herbert, and Elizabeth Zechmeister (2003). Patterns of Party Competition and Electoral Accountability in Latin America. Paper delivered at the annual meeting of the American Political Science Association, Philadelphia, Pennsylvania.

Klingemann, Hans-Dieter, Richard Hofferbert, and Ian Budge (1993). Parties, Policies and Democracy. Boulder, Colo.: Westview Press.

Kornberg, Allan, and Norman Thomas (1965). "The Political Socialization of National Legislative Elites in the United States and Canada." Journal of Politics 27, no. 4, pp. 761-775.

Kousser, Thad (2005). Term Limits and the Dismantling of State Legislative Professionalism. New York: Cambridge University Press.

Kreft, Ita, and Jan De Leeuw (1998). Introducing Multilevel Modeling. London: Sage.

Krehbiel, Keith (2004). "Legislative Organization." Journal of Economic Perspectives 18, no. 1, pp. 113-128.

Langston, Joy. (2007). "Legislative Recruitment in Mexico." In Morgenstern and Siavelis, eds., Pathway to Power: Political Recruitment and Candidate Selection in Latin America. University Park: Penn State University Press.

Leiras, Marcelo (2002). "Instituciones de gobierno, partidos y representación política en las democracias de América Latina: Una revisión de la literatura reciente." Contribuciones 1 , no. 73, pp. 7-57.

Leoni, Eduardo, Carlos Pereira, and Lucio Renno (2004): "Political Survival Strategies: Political Career Decisions in the Brazilian Chamber of Deputies." Journal of Latin American Studies, 36, no. 1, pp. 109-130.

Levitsky, Steven (1998). "Institutionalization and Peronism: The Concept, the Case and the Case for Unpacking the Concept." Party Politics 4, no. 1, pp. 77-92.

(2003). Transforming Labor-Based Parties in Latin America: Argentine Peronism in Comparative Perspective. New York: Cambridge University Press.

Limongi, Fernando, and Argelina Figueiredo (1995). "Partidos políticos na Camara dos Deputados: 1989-1994." Dados 38, no. 3, pp. 497-527.

Linz, Juan J. (2002). "Parties in Contemporary Democracies: Problems and Paradoxes." In R. Gunther, J. R. Montero, and J. J. Linz, eds., Political Parties: Old Concepts and New Challenges, pp. 292-317. Oxford: Oxford University Press.

Linz, Juan J., and Alfred Stepan (1996). Problems of Democratic Transition and Consolidation: Southern Europe, South America and Post-Communist Europe. Baltimore, Md., and London: Johns Hopkins University Press.

Linz, Juan J., and Arturo Valenzuela (1994). The Failure of Presidential Democracy. 2 vols. Baltimore, Md.: Johns Hopkins University Press.

Lipset, Seymour Martin (1959). "Some Social Requisites of Democracy: Economic Development and Political Legitimacy." American Political Science Review 53, pp. 69-105.

Lipset, Seymour A., Paul Lazarsfeld, Allen Barton, and Juan Linz (1954). "The Psychology of Voting: An Analysis of Political Behaviour." In Lindzey Garden, ed., Handbook of Social Psychology II, pp. 1124-1177. Cambridge, Mass.: Addison Wesley. 
Lipset, Seymour Martin, and Stein Rokkan (1967). Party Systems and Voter Alignments: Cross-National Perspectives. New York: Macmillan.

Lipset, Seymour M., and Aldo Solari, eds. (1967). Elites in Latin America. New York: Oxford University Press.

Llamazares, Iván, and Rickard Sandell (2000). "Partidos politicos y dimensiones ideológicas en Argentina, Chile, México y Uruguay: Esbozo de un análisis espacial." Polis, pp. 43-69.

Llanos, Mariana, and Francisco Sánchez López (2004). “Councils of Elders? The Senates and Its Members in the Southern Cone.” Working Paper no. 17. Institut für Iberoamerika-Kunde, Hamburg, Germany.

Loaeza, Soledad (1999). El Partido Acción Nacional: La larga marcha, 1939-1994; Oposición leal y partido de protesta. Mexico City: Fondo de Cultura Económica.

Londegran, John, and Keith Poole (1996). “Does Income Promote Democracy?" World Politics 49, pp. 1-30.

Loveman, Brian, and Thomas M. Davies, Jr. (1989). The Politics of Antipolitics: The Military in Latin America. 2nd ed. Lincoln: University of Nebraska Press.

Lujambio, Álonso (1993). "Presidentes y congresos: Estados Unidos, la experiencia latinoamericana y el futuro mexicano." Foro Internacional, no. 33, pp. 87-121.

Luke, Douglas A. (2004). Multilevel Modeling: Quantitative Applications in the Social Sciences. Thousand Oaks, Calif.: Sage.

Luna, Juan Pablo, and Elizabeth Zechmeister (2003). "Estructuración ideológica e izquierda en los sistemas de partidos latinoamericanos circa 1996-1998." In Jorge Lanzaro, ed., La izquierda latinoamericana. Buenos Aires: CLACSO. - (2005). "Political Representation in Latin America: A Study of Elite-Mass Congruence in Nine Countries." Comparative Political Studies, no. 38, pp. 388-416.

Maddox, Jerome (2002). "Working Outside of the House (and Senate): Outside Careers and Partisan Bias in Professionalized State Legislatures." Paper delivered at the meeting of the Annual American Political Science Association, Boston, Massachusetts.

Madeira, Rafael Machado (2003). "O padrao de carreira politica dos deputados federais da arena baiana: Trajetorias estaveis e lealdades pessoais." Revista Mediacoes 8, no. 2, pp. 83-117.

Maestas, Cherie (2000). "Professional Legislatures and Ambitious Politicians: Policy Responsiveness of State Institutions." Legislative Studies Quarterly 25, pp. 663-690.

_ (2003). "The Incentive to Listen: Progressive Ambition, Resources and Opinion Monitoring Among State Legislators.” Journal of Politics 65, no. 2, pp. $439-456$.

Maiguashca, Juan, ed. (1994). Historia y región en el Ecuador: 1830-1930. Quito: FLACSO-CEN.

Mainwaring, Scott (1998). "Party Systems in the Third Wave." Journal of Democracy 9, no. 3, pp. 67-82. (1999). Rethinking Party Systems in the Third Wave of Democratization: The Case of Brazil. Stanford, Calif.: Stanford University Press.

Mainwaring, Scott, Daniel Brinks, and Aníbal Pérez-Liñán (2001). "Classifying Political Regimes in Latin America, 1945-1999.” Studies in Comparative International Development 36, no. 1, pp. 37-65.

Mainwaring, Scott, and Aníbal Pérez-Liñán (1997). "Party Discipline in the Brazilian Constitutional Congress.” Legislative Studies Quarterly, no. 4, pp. 453-483. 


\section{BiBLIOGRAPHY}

(2004a). "Nivel de desarrollo y democracia: El excepcionalismo latinoamericano (1945-1996)." América Latina Hoy 36, pp. 189-248.

(2004b). "Regional Effects and Region-wide Diffusion of Democracy: Why Regions of the World Are Important in Comparative Politics." Paper delivered at the meeting of the American Political Science Association, Chicago, Illinois. - (2005). "Latin American Democratization Since 1978: Democratic Transitions, Breakdowns, and Erosions." In Frances Hagopian and Scott Mainwaring, ed., The Third Wave of Democratization in Latin America: Advances and Setbacks, pp. 14-61. Cambridge: Cambridge University Press.

Mainwaring, Scott, and Timothy Scully, eds. (1995). Building Democratic Institutions: Party Systems in Latin America. Stanford, Calif.: Stanford University Press.

(2003). Christian Democracy in Latin America: Electoral Competition and Regime Conflicts. Stanford, Calif.: Stanford University Press.

Mainwaring, Scott, and Matthew Shugart, eds. (1997). Presidentialism and Democracy in Latin America. New York: Cambridge University Press.

Mainwaring, Scott, and Mariano Torcal (2005). "La institucionalización de los sistemas de partidos y la teoría del sistema partidista después de la tercera ola democratizadora." América Latina Hoy, no. 41, pp. 141-173.

Manin, Bernard (1998). Los principios del gobierno representativo. Madrid: Alianza Editorial.

Maor, Moshe (1997). Political Parties and Party Systems: Comparative Approaches and the British Experience. London: Routledge.

Maravall, José María (1995). Los resultados de la democracia. Madrid: Alianza Editorial. - (2003). El control de los políticos. Madrid: Taurus.

March, James G., and Johan P. Olsen (1984). "The New Institutionalism: Organizational Factors in Political Life." American Political Science Review 78, no. 3, pp. 734-749.

Marenco dos Santos, Andre (2001). "Sedimentacao de lealdades partidarias no Brasil: Tendencias e descompasaos." Revista Brasileira de Ciencias Sociais 16, no. 45 , pp. 69-83.

Marenghi, Patricia. (2001). "Anexo: Organización de los partidos políticos; Dimensiones comparadas." In Manuel Alcántara and Flavia Freidenberg, eds., Partidos políticos de América Latina. Salamanca: Ediciones Universidad de Salamanca.

Martí, Salvador (2001). "¿Y después de las transiciones qué? Un balance y análisis de las teorías del cambio político." Revista de Estudios Políticos, no. 113, pp. 101-124.

Martínez, Rafael, ed. (2004). La elección presidencial mediante doble vuelta en Latinoamérica. Barcelona: ICPS.

Martínez Barahona, Elena (2000). "La democracia interna en los partidos centroamericanos." Paper delivered at the seminar "Political Parties in Latin America," Institute of Latin American Studies (ILAS), London, England.

Martínez Rodríguez, Antonia (1997). "Cultura política, gobernabilidad y elites parlamentarias en América Latina." Revista Mexicana de Sociología 59, no. 1, pp. 89-115.

Martínez Rosón, Mar (2004). "El concepto de profesionalización parlamentaria y su aplicación en los parlamentos centroamericanos." Paper delivered at the II Congreso de la Asociación Latinoamericana de Ciencia Política (ALACIP), Mexico City. 
Mascott, María de los Ángeles (2004). "Representantes y representados en México: ¿Mandato o delegación?” Metapolítica 8, pp. 30-42.

Matthews, Donald, and Henry Valen (1999). Parliamentary Representation: The Case of the Norwegian Storting. Columbus: Ohio State University Press.

May, John D. (1973). "Opinion Structure of Political Parties: The Special Law of Curvilinear Disparity." Political Studies, no. 21, pp. 135-151.

Mayhew, David (1974). Congress: The Electoral Connection. New Haven, Conn.: Yale University Press.

McAllister, Ian (1991). "Party Elites, Voters and Political Attitudes: Testing Three Explanations of Mass-Elite Differences." Canadian Journal of Political Science, no. 24, pp. 237-268.

McCoy, Jennifer L., ed. (2000). Political Learning and Redemocratization in Latin America: Do Politicians Learn from Political Crises? Miami: North/South Center Press.

McCurley, Carl, and Jeffrey J. Mondak (1995). "The Influence of Incumbents, Competence, and Integrity in U.S. House Elections." American Journal of Political Science 39, no. 4, pp. 864-885.

McDonald, Ronald H., and Mark Ruhl (1989). Party Politics and Elections in Latin America. Boulder, Colo.: Westview Press.

Mendez Lago, Mónica, and Antonia Martinez Rodríguez (2002). "Political Representation in Spain: An Empirical Analysis of the Perception of Citizens and MPs." Journal of Legislative Studies 8, no. 1, pp. 63-90.

Meseguer, Covadonga (2004). La difusión de las privatizaciones en la OCDE y en América Latina: Un proceso de aprendizaje? Working Paper no. 1. CIDOB, Barcelona, Spain.

Michels, Robert (1991 [1st ed., 1915]). Los partidos políticos: Un estudio sociológico de las tendencias oligárquicas de la democracia moderna. Buenos Aires: Amorrortu Editores.

Middlebrook, Kevin J., ed. (2000a). Conservative Parties, the Right, and Democracy in Latin America. Baltimore, Md.: Johns Hopkins University Press. (2000b). Introduction. In Middlebrook, ed., Conservative Parties, the Right and Democracy.

Miguel, Luis Felipe. (2003). "Capital politico e carreira eleitoral: Algumas varia veis na eleicao para o Congresso brasileiro." Revista de Sociologia e Politica 20, pp. $115-134$.

Miller, Warren, ed. (1999). Policy Representation in Western Democracies. Oxford: Oxford University Press.

Miller, Warren, and Donald Stokes (1963). "Constituency Influence in Congress." American Political Science Review 57, no. 1, pp. 165-177.

Molina, José Enrique (2000). "Los sistemas electorales de América Latina." Cuadernos de Capel 45.

Molinelli, Guillermo (1991). Presidentes y Congresos en Argentina: Mitos y realidades. Buenos Aires: Grupo Editor Latinoamericano.

Moncrief, Gary F. (1999). "Recruitment and Retention in U.S. Legislatures." Legislative Studies Quarterly 24, no. 2, pp. 173-208.

Moncrief, Gary F., Peverille Squire, and Malcom E. Jewell (2001). Who Runs for the Legislature? Upper Saddle River, N.J.: Prentice Hall.

Mondak, Jeffrey J. (1995). "Competence, Integrity, and the Electoral Success of Congressional Incumbents.” Journal of Politics 57, no. 4, pp. 1043-1069.

Montero, José Ramón, and Richard Gunther (2002). "Reviewing and Reassessing Parties." Introduction to Richard Gunther, José Ramón Montero, and Juan J. 
Linz, eds., Political Parties: Old Concepts and New Challenges, pp. 1-38. Oxford: Oxford University Press.

Moraes, Juan Andrés. (2007). "Why Factions? Candidate Selection and Legislative Politics in Uruguay." In Morgenstern and Siavelis, eds., Pathway to Power: Political Recruitment and Candidate Selection in Latin America. University Park: Penn State University Press.

Morán, Maria Luz (1997). "Elites y cultura política en la España democrática." In Pilar del Castillo and Ismael Crespo, eds., Cultura política: Enfoques teóricos y análisis empíricos. Valencia, Spain: Tirant lo Blanch.

Moreno, Alejandro (1999). Political Cleavages, Issues, Parties and the Consolidation of Democracy. Boulder, Colo.: Westview Press.

- (2004). El público y sus representantes: Opiniones de las elites y la sociedad en México." Metapolítica 8, pp. 30-42.

Morgenstern, Scott (2000). "Explaining Voting Unity in the Legislatures of the United States and Latin America." Paper delivered at the meeting of the American Political Science Association, Washington, D.C.

- (2001). "Organized Factions and Disorganized Parties: Electoral Incentives in Uruguay." Party Politics 7, no. 2, pp. 265-286.

- (2003). "Explicando la unidad de los parlamentarios en el Cono Sur." In M. Alcántara and Elena Martínez-Barahona, eds., Política, dinero e institucionalización partidista en América Latina, pp. 357-388. Mexico DF: Universidad Iberoamericana.

Morgenstern, Scott, and Benito Nacif, eds. (2002). Legislative Politics in Latin America. Cambridge: Cambridge University Press.

Morgenstern, Scott, and Peter M. Siavelis (forthcoming 2007). Pathway to Power: Political Recruitment and Candidate Selection in Latin America. University Park: Penn State University Press.

Moureau, Defargues (2003). La Mondialisation. Paris: Presses Universitaires de France.

Muller, Edward N., and Mitchell A. Seligson (1994). "Civil Culture and Democracy: The Question of Causal Relationships." American Political Science Review 82, no. 3, pp. 635-652.

Muller, Wolfang C., and Kaare Strom (1999). "Conclusions: Party Behavior and Representative Democracy." In Wolfgang C. Muller and Kaare Strom, eds., Policy, Office or Votes? How Political Parties in Western Europe Make Hard Decisions, pp. 279-310. Cambridge: Cambridge University Press.

Nacif, Benito (2002). "Para comprender la disciplina de partido en la Cámara de Diputados de México: El modelo de partido centralizado." Foro Internacional 42, no. 1, pp. 5-38.

Navia, Patricio (2007). "Legislative Candidate Selection in Chile." In Morgenstern and Siavelis, eds., Pathway to Power: Political Recruitment and Candidate Selection in Latin America. University Park: Penn State University Press.

Nilsson, Martin (2003). "Left Parties and Democratic Consolidation in Latin America." Paper from the ECPR-Joint Sessions of Workshops, University of Edinburgh, Edinburgh, Scotland.

Norden, Deborah L. (1998). "Party Relations and Democracy in Latin America." Party Politics 4, no. 4, pp. 423-443.

Norris, Pippa (1996). "Legislative Recruitment." In Lawrence LeDuc, Richard Niemi, and Pippa Norris, eds., Comparing Democracies: Elections and Voting in Global Perspective. London: Sage Publications.

- ed. (1997). Passages to Power: Legislative Recruitment in Advanced Democracies. Cambridge: Cambridge University Press. 
O’Donnell, Guillermo (1994). "Delegative Democracy?” Journal of Democracy 5, no. 1 , pp. 55-69. (1999a). "Horizontal Accountability and New Polyarchies." In Andreas Schedler, Larry Diamond, and Marc F. Plattner, eds., The Self-Restraining State: Power and Accountability in New Democracies, pp. 29-52. Boulder and London: Lynne Rienner Publishers.

(1999b). "Polyarchies and the (Un)Rule of Law in Latin America: A Partial Conclusion." In Juan E. Méndez, G. O’Donnell, and P. S. Pinheiro, eds., The (Un)Rule of Law and the Underprivileged in Latin America, pp. 303-339. Notre Dame, Ind.: University of Notre Dame Press.

- (2002). "Ilusiones sobre la consolidación." Nueva Sociedad, no. 180-181, pp. 311-332.

O’Donnell, Guillermo, Philippe Schmitter, and Laurence Whitehead (1986). Transiciones desde un gobierno autoritario. 4 vols. Buenos Aires: Paidós.

O'Donnell, Guillermo, Jorge Vargas Cullell, and Osvaldo M. Iazzetta, eds. (2004). The Quality of Democracy: Theory and Applications. Notre Dame, Ind.: University of Notre Dame Press.

Otero, Patricia (2004). "Partidos y sistemas de partidos en Panamá: Un estudio de la estructuración ideológica." Paper delivered at the X encuentro de Latinoamericanistas Españoles, Salamanca, Spain.

Pachano, Simón (1996). Democracia sin sociedad. Quito: ILDIS.

Padró i Miquel, Gerard, and James M. Snyder (2004). "Legislative Effectiveness and Legislative Life." Working Paper no. 04-28. Department of Economics, MIT, Cambridge, Massachusetts. Available at http://ssrn.com/abstract= 576406.

Pan American Health Organization (PAHO) (2004). PAHO Regional Mortality Database. Estimates based on world population prospects, 2004 revision. Available at www.paho.org.

Panebianco, Angelo (1988). Political Parties: Organization and Power. Cambridge: Cambridge University Press.

Payne, J. Mark, Daniel Zovatto, Fernando Carrillo, and Andrés Allamand (2002). Democracies in Development: Politics and Reform in Latin America. Washington, D.C.: Inter-American Development Bank.

PELA (Proyecto Elites Parlamentarias en América Latina) (1994-2005). Salamanca: Universidad de Salamanca.

Pharr, Susan J., and Robert Putnam (2000). Disaffected Democracies: What's Troubling the Trilateral Countries? Princeton, N.J.: Princeton University Press.

PNUD (Programa de las Naciones Unidas para el Desarrollo) (2004). La Democracia en América Latina: Hacia una democracia de ciudadanas y ciudadanos. New York: United Nations.

Polsby, Nelson W. (1968). "The Institutionalization of the US House of Representatives." American Political Science Review 62, pp. 144-168.

Powell, Bingham (2001). "Democratic Representation: Two Contributions from Comparative Politics." Paper delivered at the annual meeting of the American Political Science Association, San Francisco, California.

Powell, Bingham, and Guy Whitten (1993). "A Cross-National Analysis of Economic Voting: Taking Account of Political Context." American Journal of Political Science, no. 37, pp. 391-414.

PPAL (Proyecto Partidos Políticos en América Latina) (1999-2001). Salamanca: Universidad de Salamanca.

Przeworski, Adam, and Fernando Limongi (1997). "Modernization: Theories and Facts." World Politics 49, pp. 155-183. 
Przeworski, Adam, Susan Carol Stokes, and Bernard Manin, eds. (1999). Democracy, Accountability, and Representation. Cambridge: Cambridge University Press.

Putnam, Robert D. (1973). The Beliefs of Politicians: Ideology, Conflict and Democracy in Britain and Italy. New Haven, Conn.: Yale University Press.

Quintero, Rafael, ed. (1991). La cuestión regional y el poder. Quito: Corporación Editora Nacional.

Ranney, Austin (1962). The Doctrine of Responsible Party Government: Its Origins and Present State. Urbana: University of Illinois Press.

Reiser, Marion (2003). "From Political Amateurs to Professional Politicians? An Analysis of Councilors in Four German Cities." Paper delivered at the meeting of the American Political Science Association, Philadelphia, Pennsylvania.

Reveles, Francisco (2003). El PAN en la oposición. Mexico City: Ediciones Gernika.

Rittberger, Volker, ed. (1993). Regime Theory and International Relations. London: Clarendon Press.

Rohrschneider, Robert (1994). "Report from the Laboratory: The Influence of Institutions on Political Elites' Democratic Values in Germany." American Political Science Review 88, no. 4, pp. 927-941.

Rosas, Guillermo (2001). "Policy Preferences, Ideology, and Political Competition in Latin American Legislatures." Paper delivered at the meeting of the American Political Science Association, Washington, D.C.

Rosenbaum, Walter (1975). Political Culture. London: Thomas Nelson \& Son.

Ruiz Rodríguez, Leticia (2000). "Clivajes y competencia partidista en Chile (1990-1999)." In Nuevo gobierno: Desafios de la reconciliación; Chile 1999-2000, pp. 159-190. Santiago: FLACSO-Chile.

- (2003a). La coherencia de los partidos políticos: Estructuración interna de la élite parlamentaria latinoamericana. Doctoral dissertation, Departamento de Derecho Pulbico General, Universidad de Salamanca, Salamanca, Spain. (2003b). "Polarización en el Chile post-autoritario: Elites partidistas." In Manuel Alcántara and Elena Martínez Barahona, eds., Política, dinero e institucionalización partidista en América Latina. Mexico DF: Universidad Iberoamericana.

- (2004). "Rendimiento electoral y coherencia partidista en América Latina: El desacuerdo exitóso." In Consejo Español de Estudios Iberoamericanos, Actas X encuentro de Latinoamericanistas españoles, Salamanca, Spain.

- (2006). "Coherencia partidista: La estructuración interna de los partidos políticos en América Latina." Revista Española de Ciencia Política, no. 14, pp. 87-114.

(2007). Partidos y coherencia: Parlamentarios en América Latina. Madrid: Centro de Estudios Políticos y Constitucionales.

Ruiz Rodríguez, Leticia, and Mercedes García Montero (2003). "Coherencia partidista en las élites parlamentarias latinoamericanas." Revista Española de Ciencia Política, no. 8, pp. 71-102.

Sabsay, Daniel Alberto (1991). "El ballotage: Su aplicación en América Latina y la gobernabilidad." Cuadernos de Capel 34.

Samuels, David (2003). Ambition, Federalism, and Legislative Politics in Brazil. Cambridge: Cambridge University Press.

(2007). "Political Ambition, Candidate Recruitment, and Legislative Politics in Brazil." In Morgenstern and Siavelis, eds. Pathway to Power: Political Recruitment and Candidate Selection in Latin America. University Park: Penn State University Press. 
Sanbonmatsu, Kira (2002). "Political Parties and the Recruitment of Women to State Legislatures." Journal of Politics 64, no. 3, pp. 791-809.

Sani, Giacomo, and José Ramón Montero (1986). "El espectro político: Izquierdaderecha y centro.” In Juan J. Linz and José Ramón Montero, eds., Crisis y cambio: Electores y partidos en la España de los años ochenta, pp. 155-200. Madrid: Centro de Estudios Constitucionales.

Sani, Giacomo, and Giovanni Sartori (1983). "Polarization, Fragmentation and Competition in Western Democracies." In P. Daadler and P. Mair, eds., Western European Party Systems, pp. 307-340. Beverly Hills, Calif.: Sage.

Santos, Fabiano, and Lucio Renno (2004). "The Selection of Committee Leadership in the Brazilian Chamber of Deputies." Journal of Legislative Studies 10, no. 1, pp. 50-70.

Sartori, Giovanni (1994). Comparative Constitutional Engineering: An Inquiry into Structures, Incentives and Outcomes. New York: New York University Press.

Editorial.

Scarrow, Susan (2000). "Parties Without Members? Party Organization in a Changing Electoral Environment." In R. J. Dalton and M. P. Wattenberg, eds., Parties Without Partisans: Political Change in Advanced Industrial Democracies, pp. 79-101. Oxford: Oxford University Press.

Schattschneider, Elmer (1942). Party Government. New York: Rinehart and Winston.

Schedler, Andreas (1995). "Under- and Overinstitutionalization: Some Ideal Typical Propositions Concerning Old and New Party Systems.” Working Paper no. 213. Kellogg Institute for International Studies, University of Notre Dame, Notre Dame, Indiana.

Schmitt, Hermann, and Jacques Thomassen (1999). Political Representation and Legitimacy in the European Union. Oxford: Oxford University Press.

Schmitter, Philippe (1995). "The Consolidation of Political Democracies." In Geoffrey Pridham, ed., Transitions to Democracy: Comparative Perspectives from Southern Europe, Latin America, and Eastern Europe. Aldershot: Ashgate Publishing.

Scott, Robert E. (1967). "Political Elites and Political Modernization: The Crisis of Transition." In Seymour M. Lipset and Aldo Solari, eds., Elites in Latin America, pp. 117-145. New York: Oxford University Press.

Searing, Donald (1985). "The Role of the Good Constituency Member and the Practice of Representation in Great Britain." Journal of Politics 47, no. 2, pp. 348-381.

(1987). "New Roles for Postwar British Politics: Ideologues, Generalists, Specialists, and the Progress of Professionalization in Parliament." Comparative Politics 19, no. 4, pp. 431-442.

(1994). Westminster's World: Understanding Political Roles. Cambridge: Cambridge University Press.

Shepsle, Kenneth A., and Mark S. Bonchek (2005). Las formulas de la política: Instituciones, racionalidad y comportamiento. Mexico DF: TaurusCIDE.

Shin, Doh Chill (1994). "On the Third Wave of Democratization: A Synthesis and Evaluation of Recent Theory and Research." World Politics 47, no. 1, pp135-170.

Shugart, Matthew Søberg, Melody Ellis Valdini, and Kati Suominen (2005). "Looking for Locals: Voter Information Demands and Personal Vote-Earning 
Attributes of Legislators Under Proportional Representation." American Journal of Political Science 49, no. 2, pp. 437-449.

Siavelis, Peter (2005). "La lógica oculta de la selección de candidatos en las elecciones parlamentarias chilenas." Estudios Públicos 98, pp. 189-225.

Snijders, Tom, and Roel Bosker (1999). Multilevel Analysis. London: Sage.

Soule, John W. (1969) "Future Political Ambitions and the Behavior of Incumbent State Legislators." Midwest Journal of Political Science 13, no. 3, pp. 439-454.

Squire, Peverill (1993). "Professionalism and Public Opinion in State Legislatures." Journal of Politics 55, no. 2, pp. 479-491.

(1998). "Membership Turnover and the Efficient Processing of Legislation." Legislative Studies Quarterly 23, no. 1, pp. 23-32.

Squire, Peverill, and Keith E. Hamm (2005). 101 Chambers: Congress, State Legislatures, and the Future of Legislative Studies. Columbus: Ohio State University Press.

Steenbergen, Marco, and Bradford S. Jones (2002). "Modeling Multilevel Data Structures." American Journal of Political Science 46, no. 1, pp. 218-237.

Stokes, Susan (1999). "What Do Policy Switches Tell Us About Democracy?" In Adam Przeworski, Susan Carol Stokes, and Bernard Manin, eds., Democracy, Accountability, and Representation. Cambridge: Cambridge University Press. - (2001). Mandates and Democracy: Neoliberalism by Surprise in Latin America. Cambridge: Cambridge University Press.

Stone, Walter J., L. Sandy Maisel, and Cherie D. Maestas (2004). "Quality Counts: Extending the Strategic Politician Model of Incumbent Deterrence." American Journal of Political Science 48, no. 3, pp. 479-495.

Studlar, Donley, and Ian Mcallister (1996). "Constituency Activity and Representational Roles Among Australian Legislators." Journal of Politics 58, no. 1, pp. 69-90.

Thelen, Kathleen, and Sven Steinmo (1992). "Institutionalism in Comparative Politics." In Sven Steinmo, Kathleen Thelen, and Frank Longstreth, eds., Structuring Politics: Historical Institutionalism in Comparative Analysis. New York: Cambridge University Press.

Thomassen, Jacques (1994). "Empirical Research into Political Representation: Failing Democracy or Failing Models?" In Kent Jennings and Thomas Mann, eds., Elections at Home and Abroad: Essays in Honor of Warren E. Miller. Ann Arbor: University of Michigan Press.

Torcal, Mariano (2001). Political Disaffection and Democratization History in New Democracies. Working Paper no. 308. Kellogg Institute, University of Notre Dame, Notre Dame, Indiana.

Tsebelis, George (1997). "Processo decisorio en sistemas políticos: Veto players no presidencialismo, parlamentarios, multicameralismo e pluripartidismo." Revista Brasileira de Ciencias Sociais 12, no. 34.

- (2000): "Veto Players and Institutional Analysis." Governance, no. 13, pp. 441-474.

Ugalde, Luis Carlos (2002). "La disciplina partidista en México." Paper delivered at the El Gobierno Dividido en México, Riesgos y Oportunidades, Mexico DF, Mexico.

Uriarte, Edurne (1997). "El análisis de las elites políticas en las democracias." Revista de Estudios Políticos, no. 9, pp. 249-275.

(2000). "La política como profesión y vocación: Análisis de las motivaciones y de la carrera política de los diputados españoles." Revista Española de Ciencia Política, no. 3, pp. 97-124. 
Von Beyme, Klaus (1995). La clase política en el estado de partidos. Madrid: Alianza Editorial.

Vowles, Jack, Peter Aimer, Susan Banducci, and Jeffrey Karp (1998). Voters' Victory? New Zealand's First Election Under Proportional Representation. Auckland: University of Auckland Press.

Weissberg, Robert (1978). "Collective Versus Dyadic Representation in Congress." American Political Science Review 72, no. 2, pp. 535-547.

Wolinetz, Steven B. (2002). "Beyond the Catch-All Party: Approaches to the Study of Parties and Party Organization in Contemporary Democracies." In R. Gunther, J. R. Montero, and J. J. Linz, eds., Political Parties: Old Concepts and New Challenges, pp. 136-165. Oxford: Oxford University Press.

World Bank (2005). World Development Indicators [CD-ROM]. Washington, D.C.: Development Data Group.

Wright Mills, Charles (1981). Poder, política, pueblo. Mexico DF: Fondo de Cultura Económica. 


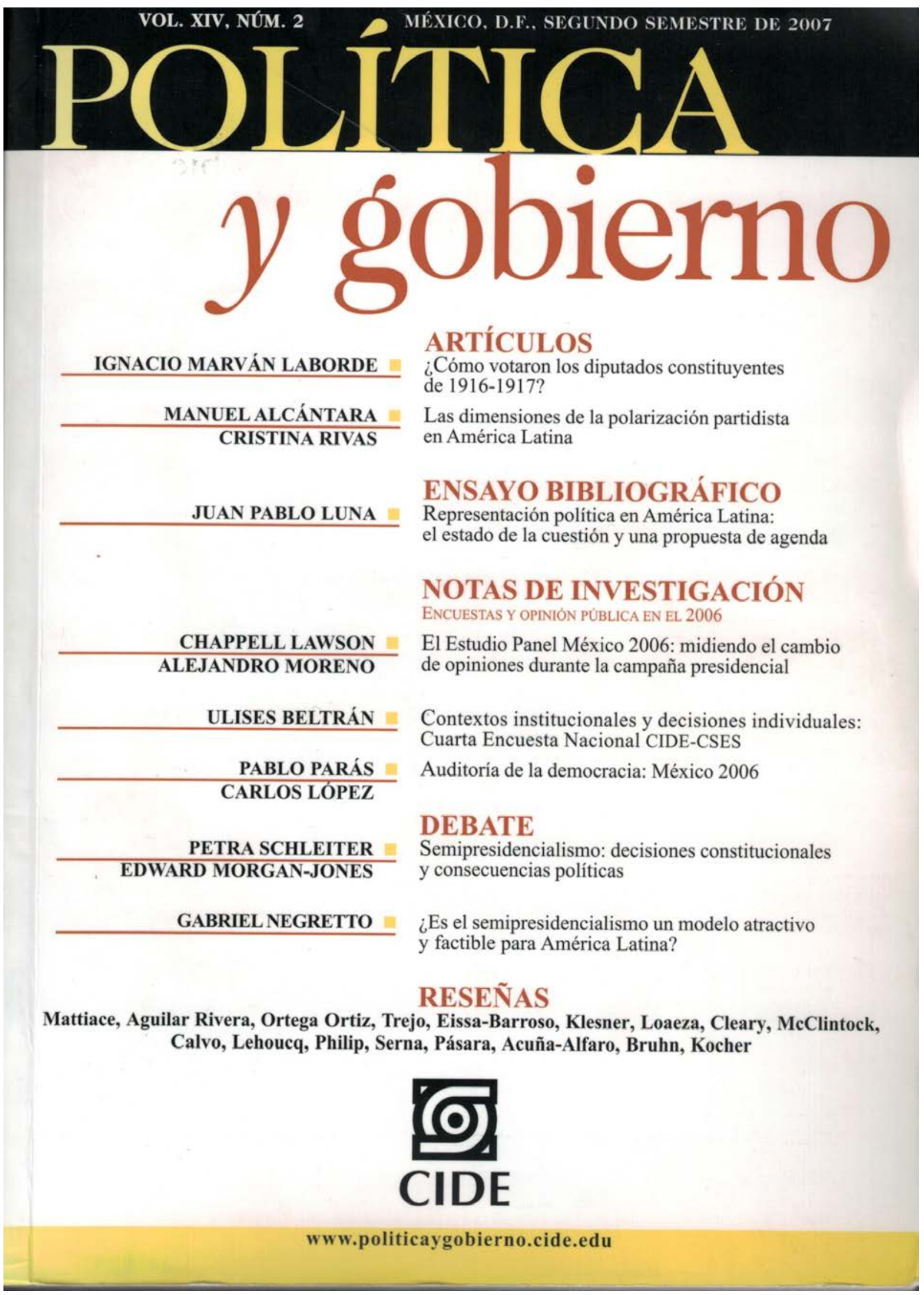




\title{
Las dimensiones de la polarización partidista en América Latina
}

\author{
Manuel Alcántara y Cristina Rivas*
}

Resumen: El presente artículo ofrece un análisis empírico de la división izquierda-derecha entre partidos políticos en América Latina a partir de la información del proyecto de investigación Élites Parlamentarias Latinoamericanas de la Universidad de Salamanca. Para ello se identifican los ejes de polarización con dicha división (intervención estatal, valores, imagen de Estados Unidos, Fuerzas Armadas y democracia). Para ello se utiliza el Hj-Biplot, una técnica estadística que permite representar de manera simultánea los ejes de polarización y la posición específica de los partidos respecto a ellos. Los resultados del análisis indican que la imagen de los Estados Unidos, los valores y la proclividad democrática constituyen los principales ejes de polarización entre los partidos con representación parlamentaria analizados.

Palabras clave: clivajes políticos, polarización partidista, izquierda y derecha, representación biplot, América Latina.

\section{The Spatial Dimensions of Left-Right Polarization in Latin America}

Abstract: This article uses the interview data from the Parliamentary Elites Project of the University of Salamanca to measure left-right divisions of Latin American political parties. It identifies the dimensions of left-right polarization (state intervention, values, images of the United States, the armed forces, and democracy). It relies upon Hj-Biplot, a statistical technique that permits simultaneously representing the dimensions of polarization and their particular weight in left-right cleavages. The article concludes that images of the United States, values, and support for democracy are the principal dimensions of polarization between legislative parties in selected Latin American countries.

Keywords: political cleavages, party polarization, left and right, biplot representation, Latin America.

* Manuel Alcántara es catedrático en el Área de Ciencia Política de la Universidad de Salamanca, Campus Miguel de Unamuno, 37071, Salamanca, España. Correo electrónico: malcanta@usal.es. Cristina Rivas es investigadora contratada del Instituto de Iberoamérica de la Universidad de Salamanca, Hospedería Fonseca, 37071 Salamanca, España. Correo electrónico: crisrivas@usal.es.

El artículo se recibió en septiembre de 2006 y fue aceptado para su publicación en marzo de 2007. 


\section{Introducción}

En los países europeos se ha desarrollado en los últimos cuarenta años un Egran número de estudios que se esfuerzan en determinar qué factores permiten explicar, de la mejor manera posible, el espacio en el que compiten los partidos políticos. En países con una larga trayectoria partidista el estudio de las líneas de división que estructuran la competencia de partidos permite sostener que los clivajes políticos permanecen vigentes y/o conviven con nuevas divisiones o conflictos sociales (Lipset y Rokkan, 1967; Inglehart, 1984).

La democratización y consolidación democrática de los países latinoamericanos supone la vuelta de los partidos a la arena política y con ello un incremento de los estudios de los sistemas de partidos en la región. Frecuentemente, se ha prestado especial atención a tres características fundamentales del sistema de partidos: la fragmentación, la volatilidad política y el número de partidos. Sin embargo, y tal y como señala Coppedge (1997), se ignoran otros aspectos importantes de los sistemas partidistas que constituyen la base de la competición política (la ideología, los intereses políticos, ideales, valores, así como los clivajes o líneas de división).

En América Latina los estudios sobre clivajes son escasos si bien, en la última década autores como Moreno (1999), Ruiz Rodríguez (2000), Alcántara (2004), Jones (2005) y Rivas (2006), entre otros, han realizado estudios sobre este tema con aportación empírica, ya sea a nivel de las élites políticas o de la ciudadanía. La incorporación del modelo de clivajes al contexto latinoamericano para explicar el origen y evolución del sistema de partidos ha dado lugar a una gran confrontación teórica acerca de la idoneidad o no de su uso en esta región (Dix, 1989; Ruiz Rodríguez, 2000; Mainwaring y Torcal, 2003), existiendo una cierta reticencia a su inclusión en los análisis de los sistemas partidistas latinoamericanos. Si los clivajes son entendidos como "pautas relativamente estables de polarización por las que determinados grupos apoyan determinadas políticas o partidos, mientras que otros apoyan políticas opuestas o a partidos opuestos" (Inglehart, 1984, p. 25) su aplicación en la política latinoamericana está justificada.

En esta línea, el concepto de clivaje que se utiliza en este trabajo hace referencia a las dimensiones de polarización programática que acercan o separan a los partidos políticos latinoamericanos etiquetados como partidos derechistas o izquierdistas, entendiendo la polarización como la dis- 
tancia entre la izquierda y la derecha con relación a preferencias ideológicas respecto a temas concretos de interés político.

Este trabajo trata de identificar las principales líneas de división ideológica entre once partidos políticos latinoamericanos ubicados, por sus propios diputados, en los extremos de la escala izquierda-derecha así como la formación de familias partidistas a partir de la clasificación de las posiciones medias de los representantes en las dimensiones de polarización ideológica obtenidas. Seguidamente, se analiza cuál ha sido la evolución de esos partidos políticos en dos periodos legislativos consecutivos. Con ello se profundiza en las diferencias entre los partidos de izquierda y de derecha en América Latina con base en los clivajes definidos por las dimensiones extraídas a partir de una serie de variables relativas a cuestiones económicas, políticas, religiosas y sociales y si estas divisiones se mantienen en el tiempo. Pero también si existen cambios significativos al interior de cada partido en las dos legislaturas estudiadas.

En este trabajo se han llevado a cabo dos tipos de análisis estadísticos multivariantes: un análisis factorial y una representación HJ-biplot de las medias de los factores, obtenidos en el análisis factorial, y de los partidos políticos en los actuales parlamentos latinoamericanos seleccionados. El objetivo del análisis factorial en este caso es encontrar, a partir de un amplio número de variables observables, un número relativamente pequeño de factores que puedan ser utilizados para interpretar la relación entre dichas variables y, de este modo, obtener las dimensiones de polarización ideológica en los actuales parlamentos latinoamericanos. Una vez conocidas las líneas de división entre los partidos de izquierda y derecha, el interés se centra en conocer qué dimensiones son las que más polarizan a los partidos políticos y qué familias ideológicas se forman con base en cada uno de los clivajes encontrados. Con este fin se ha utilizado la representación HJ-Biplot, un análisis que permite representar simultáneamente las dimensiones ideológicas y los partidos políticos en un espacio de dimensión reducida, de forma que no sólo se puede conocer la configuración de los partidos políticos sino qué dimensiones son las responsables de dicha configuración.

Para dar respuesta a la segunda parte de este trabajo, la continuidad o el cambio ideológico de los partidos políticos en dos legislaturas consecutivas, se han repetido los mismos análisis estadísticos, pero en esta ocasión incluyendo los datos de las formaciones políticas en ambas legislaturas.

Finalmente, la comparación de los dos análisis HJ-Biplot realizados en este trabajo (el primero con los datos correspondientes a la legislatura ac- 
tual y el segundo con los datos tanto de ésta como de la anterior) deja entrever, a pesar del corto periodo de tiempo considerado, que la capacidad discriminante de las dimensiones ideológicas se mantiene en el periodo analizado para la práctica totalidad de los clivajes. ${ }^{1}$

\section{Izquierda y derecha, el reto de su medición}

Los conceptos "izquierda" y "derecha" son funcionales en la medida en que simplifican los programas y posiciones de los partidos políticos así como por su capacidad de nombrar a temas políticos relevantes en un momento dado (Knutsen, 1998).

Sin embargo, el uso de los términos "izquierda" y "derecha" en una región tan heterogénea como América Latina ha sido históricamente estéril y poco esclarecedor de la vida política. A las frecuentes interrupciones de los procesos democráticos, en los que el juego izquierda-derecha cobra un especial significado, se le sumó el imperio del populismo que durante décadas definió la política latinoamericana y que en su configuración de un universo político globalizador de características movimientistas confundía la relación izquierda-derecha hasta llegar a su plena disolución (Alcántara, 1991). No obstante, la recuperación del juego democrático ampliamente extendido a la gran mayoría de países de la región a lo largo del último cuarto de siglo ha posibilitado la reconfiguración de la liza partidista en el eje izquierda-derecha. La continuidad de la vida política democrática durante este lapso ha consolidado antiguos esquemas de confrontación ideológica, como sucede en Chile y Uruguay, y ha abierto otros nuevos como es el caso de Ecuador, El Salvador, México o Nicaragua. Esta confrontación ha podido ser medida eficazmente gracias al posicionamiento de los actores en el continuo izquierda-derecha dando cierto sentido al antagonismo político. Estudios recientes han puesto de manifiesto la necesidad de llevar a cabo trabajos empíricos comparativos, a fin de determinar el grado en el que la dimensión izquierda-derecha permite capturar características de la vida política y partidaria de cada país latinoamericano (Coppedge, 1998).

\footnotetext{
${ }^{1}$ El empleo de la misma técnica multivariante de análisis estadístico asegura que los resultados obtenidos van ligados a las opiniones de los parlamentarios entrevistados (teniendo en cuenta que se trata de muestras representativas) y no a la metodología utilizada.
} 
La ubicación ideológica, cuyo significado ha sido fundamentalmente aplicado para el estudio de los sistemas políticos y de partidos (Sartori, 1976), se va a aplicar, en el presente trabajo, a los partidos como unidades de análisis aisladas con el fin, no tanto de medir la competencia partidista como de etiquetar a los partidos políticos para poder establecer grupos de partidos según las dimensiones ideológicas consideradas (Alcántara, 2004).

La escala izquierda-derecha es un mecanismo de medición y, sobre todo, de ubicación en un eje especialmente simbólico que se encuentra aceptado ampliamente en las ciencias sociales. A partir de la ubicación ideológica de sus miembros es posible conocer qué partidos políticos están más cercanos y cuáles más distantes, y hasta qué punto la proximidad entre partidos implica similaridad (Sani y Sartori, 1983). Mair (1997) refiriéndose a Europa Occidental indica que la izquierda y la derecha no solamente continúan siendo los mayores principios de organización en la política sino que también ayudan a crear unos cimientos uniformes en las pautas contemporáneas de la competición política. Por iguales términos aboga Imbeau (2001). Algo similar cabe contemplar para América Latina. Distintas contribuciones empíricas y comparadas sobre la realidad política latinoamericana (Coppedge, 1998; Alcántara, 1991, 1995, 1999 y 2004; Ruiz Rodríguez, 2003; Colomer y Estabel, 2005; Jones, 2005; Freidenberg, García Díez y Llamazares, 2006 y Rivas, 2006, entre otros) han mostrado que a pesar de las diferencias existentes en cada contexto nacional, la dimensión izquierda-derecha es empleada de forma habitual por los políticos latinoamericanos ayudando de esta forma a predecir la pertenencia partidista de los legisladores y los políticos, además de ir asociada a determinadas actitudes y opiniones políticas (Alcántara y Llamazares, 2006). Los actores se autoubican, ubican a sus partidos y a las formaciones competidoras en el referido continuo y muestran sus preferencias en cuestiones políticas diferentes que pueden ser transferidas a escalas facilitando análisis estadísticos, y garantizando la validez de dichos indicadores. Dentro del universo partidista los legisladores son miembros relevantes por su influencia en el curso de los procesos políticos y su papel clave en la conformación de la cultura política de un país, además se tiene fácil acceso a ellos y su número, relativamente pequeño frente a otros tipos de integrantes del partido, permite obtener muestras representativas de unidades de información y observación. García Díez y Mateos Díaz (2006) analizan la adecuación e importancia de profundizar en el conocimiento de las actitudes, opiniones y valores de la élite parlamentaria latinoamericana, lo 
que no impide que deban realizarse análisis contextuales más complejos en los que se tengan en cuenta otros colectivos políticos. Con este referente, los legisladores latinoamericanos vienen siendo entrevistados desde 1994 bajo la inspiración de un proyecto de investigación ${ }^{2}$ que permite clasificar a los partidos políticos ideológicamente, así como obtener datos de su valoración y opinión sobre distintas cuestiones de la realidad política representativas de la polarización ideológica.

Los once partidos políticos seleccionados cumplen dos tipos de requisitos: cuentan con representación legislativa a lo largo de la última década en los Congresos latinoamericanos, y han sido ubicados por sus propios diputados en los extremos de la escala izquierda-derecha. Aun cumpliendo estos dos requisitos, no han sido considerados los partidos con menos de cinco diputados entrevistados, es el caso de Unión por el Perú (UPP). Del mismo modo, se ha limitado el estudio a un máximo de dos partidos políticos por país (uno de derecha y otro de izquierda, siempre que esto sea posible). En los países donde existe más de un partido de izquierda o de derecha que cumple los criterios establecidos, se ha seleccionado el partido con la media de ubicación más extrema (ya sea a la derecha o a la izquierda). Es el caso en Ecuador de Izquierda Democrática (ID) y Movimiento Unidad Plurinacional Pachakutik-Nuevo País (MUPP-NP).

En el cuadro 1 se presentan las medias de ubicación ideológica de todos los partidos políticos latinoamericanos con representación parlamentaria en las dos últimas legislaturas. Para este análisis se han seleccionado sólo los partidos con medias de ubicación más extremas. Así, en una escala de 1 a 10, donde 1 significa "izquierda" y 10 "derecha", se ha considerado como de izquierda aquel que obtiene una media, en una de las dos legislaturas analizadas, menor o igual a 3.5 en la escala de ubicación ideológica del partido, y como de derecha aquel con una media mayor o igual a 7.5 en dicha escala. Se es consciente de la limitación que puede suponer para el estudio el considerar como criterio de selección de los partidos políticos su ubicación ideológica puesto que, para los estudiosos del tema, es fácil que hayan quedado fuera de este marco de análisis partidos que, a la vista de todos, defienden políticas características de la izquierda o de la derecha. Pero como se ha mencionado anteriormente parece demostrado empíricamente la validez de su utilización y el hecho de que un $98 \%$ de los legisladores entrevistados en

${ }^{2}$ El proyecto es conocido con el nombre de PELA y se lleva a cabo en la Universidad de Salamanca. 
este estudio sea capaz de ubicar a su propio partido político en la escala ideológica justifica la utilización del continuo izquierda-derecha como criterio sólido de clasificación de los partidos políticos latinoamericanos.

Los partidos analizados, que cumplen este criterio espacial, son el Partido Socialista (PS) y la Unión Democrática Independiente (UDI) en Chile, el Movimiento Unidad Plurinacional Pachakutik-Nuevo País (MUPP-NP) y el Partido Social Cristiano (PSC) en Ecuador, el Partido Nacional Hondureño (PNH) en Honduras, el Partido de la Revolución Democrática (PRD) en México, el Frente Sandinista de Liberación Nacional (FSLN) en Nicaragua, el Partido Reformista Social Cristiano (PRSC) en República Dominicana, el Frente Farabundo Martí para la Liberación Nacional (FMLN) y la Alianza Republicana Nacionalista (ARENA) en El Salvador y el Frente Amplio-Encuentro Progresista (FA-EP) en Uruguay. La selección de casos bajo este criterio facilita la identificación de los elementos diferenciadores y constitutivos de dicha polarización, frente a otros partidos cuya distancia ideológica y, por consiguiente, su polarización es menor. ${ }^{3}$

\section{Principales dimensiones de la polarización en los actuales Parlamentos latinoamericanos}

Las cinco dimensiones ideológicas son el resultado de la aplicación de un análisis factorial exploratorio con rotación varimax, ${ }^{4}$ basado en las respuestas de los diputados de los actuales parlamentos latinoamericanos a una serie de preguntas que miden sus posiciones ante cuestiones económicas, políticas, religiosas y sociales y proporcionan información sobre las divisiones políticas de los miembros de los distintos partidos analizados en torno a cuestiones concretas. La selección de las variables incluidas en el análisis

\footnotetext{
${ }^{3}$ Una observación a tener en cuenta es que los análisis de este trabajo están basados en las percepciones y evaluaciones de los legisladores, lo cual no significa que coincidan con las posiciones estratégicas que los partidos adoptan en el parlamento. No obstante, se asume que existe una asociación importante entre las posiciones y actitudes ante distintos temas de los miembros de un partido y su propio partido.

${ }^{4}$ Los resultados obtenidos cumplen los supuestos necesarios para la realización de un análisis factorial, con un valor de la medida de adecuación muestral Kaiser Meyer Olkin igual a 0.754. Con la extracción de los cinco primeros factores se obtiene un modelo factorial que explica el $56.58 \%$, porcentaje aceptable si se tiene en cuenta el número de casos de los que se dispone ( $\mathrm{N}=298)$ y de la reducción de la dimensión conseguida (se pasa de 19 variables a 5).
} 


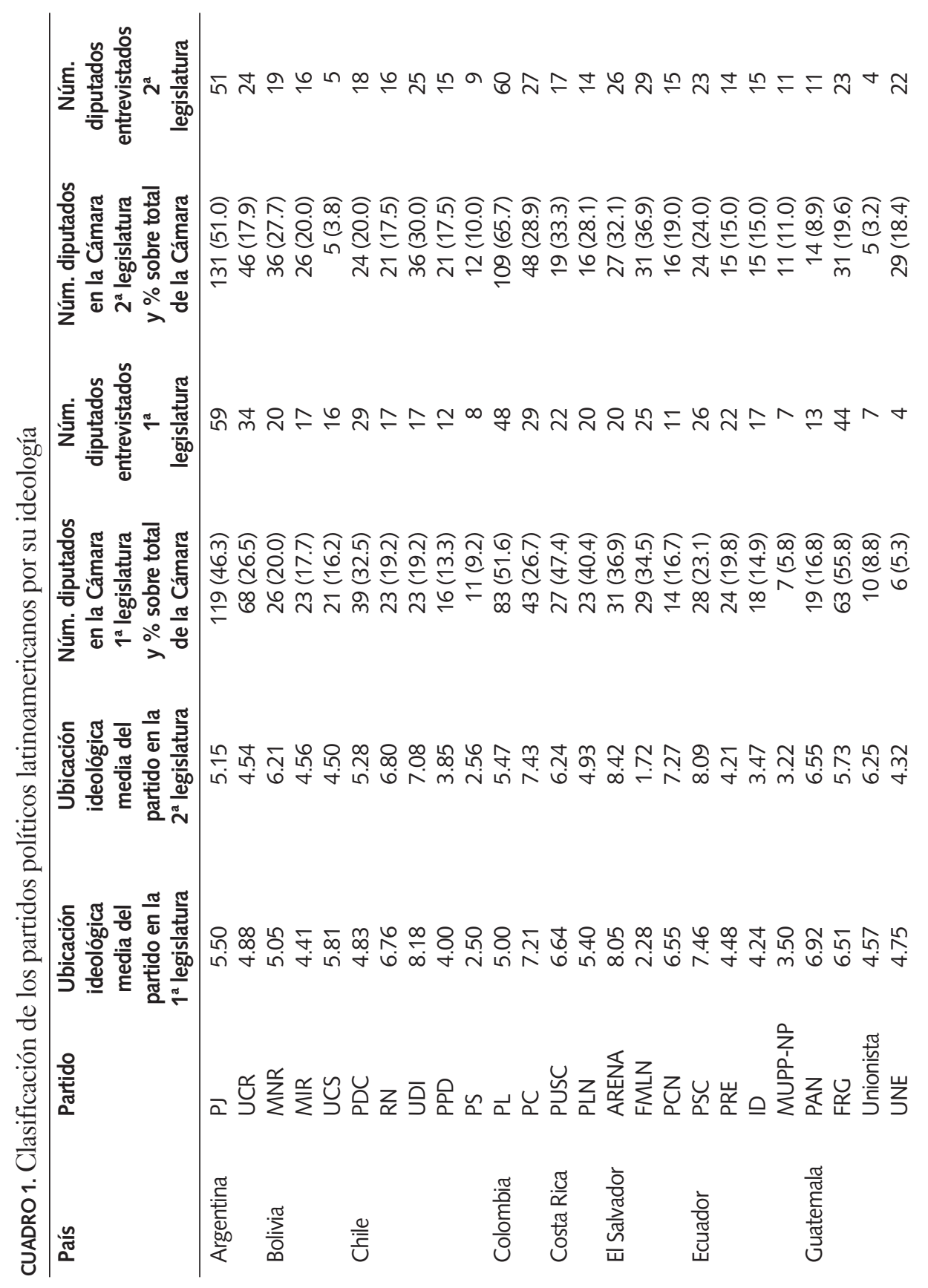




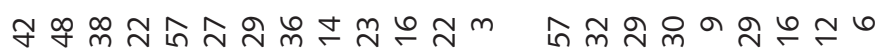

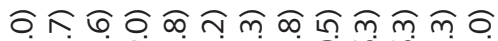

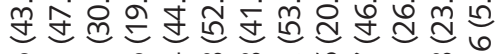

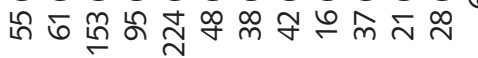

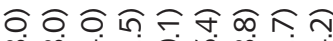

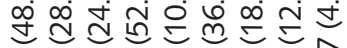

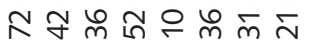

ஸิm

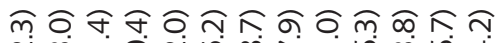

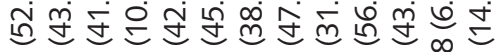

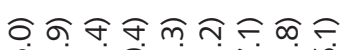

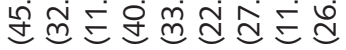

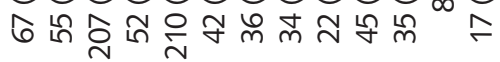

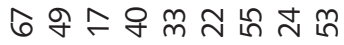

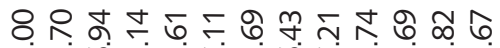
เ $N$ m

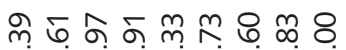
ช่

ํ. क 约 チं

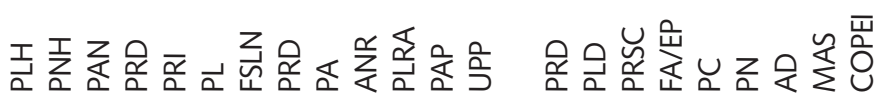

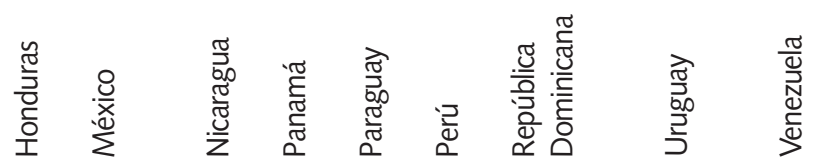

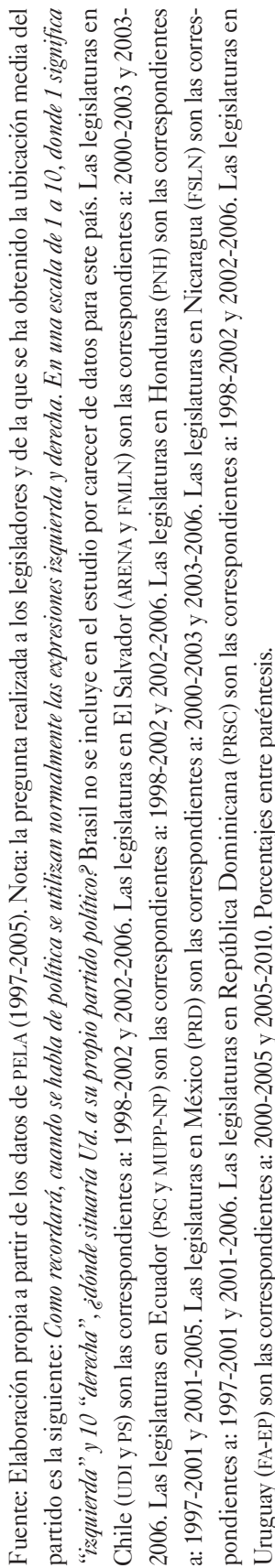


CUADRO 2. Variables en el análisis

- Evaluación de la democracia en el país

- Valoración del papel de las Fuerzas Armadas en la actualidad

- Opinión personal con respecto al aborto

- Las relaciones con las Fuerzas Armadas como problema para la consolidación democrática

- Papel de las elecciones (como mecanismo para la representación política)

- Preferencia de Estados Unidos como socio comercial

- Preferencia de Estados Unidos como socio inversor

- Papel de los partidos políticos

- Las relaciones entre las Fuerzas Armadas y el gobierno como amenaza para la estabilidad de la democracia

- Grado de intervención estatal en subvencionar la vivienda al ciudadano

- Grado de intervención estatal en generar trabajo

- Grado de intervención estatal en dar cobertura general sanitaria

- Grado de intervención estatal en garantizar una educación universitaria general y gratuita

- Grado de intervención estatal en dar cobertura de seguro de desempleo

- Grado de intervención estatal en proteger el medio ambiente

- Grado de intervención estatal en cubrir las necesidades básicas de todos los ciudadanos

- Grado de religiosidad y práctica religiosa

- Opinión personal con respecto al divorcio

- Interés por pertenecer en un futuro al ALCA

Fuente: Elaboración propia a partir del cuestionario de PELA (1997-2005).

(véase cuadro 2), frente a otro conjunto de posibles indicadores, ha estado basada en criterios que siguen en gran medida lo avanzado por Alcántara (2004).

La finalidad de este análisis es la identificación de estructuras latentes que permitan establecer cuáles son los principales ámbitos de diferenciación de la derecha y la izquierda latinoamericanas a partir de las opiniones y preferencias de sus parlamentarios. Se obtienen cinco factores que explican el $56.6 \%$ de la varianza total.

El primer factor, el de mayor poder explicativo (17.3\%) lo componen variables relacionadas con la intervención estatal en políticas públicas. El segundo factor extraído, $11.6 \%$ de varianza total, está compuesto por variables que tienen que ver con valores. El tercero es el relativo a la imagen que los parlamentarios latinoamericanos tienen de Estados Unidos y explica el 9.7\% de la varianza. El cuarto factor está integrado por variables relativas al papel que las Fuerzas Armadas juegan en la actualidad en América Latina. Y, finalmente, el último factor es el relacionado con la proclividad democráti- 
ca y está formado por las variables relativas al papel de los partidos políticos y de las elecciones como mecanismo para la representación política, así como el grado de democracia existente en su país (véase cuadro 3).

De los resultados anteriores es posible establecer cinco grandes clivajes de polarización programática en los Parlamentos latinoamericanos: "Intervención estatal", "Valores", "Imagen de Estados Unidos", "Fuerzas Armadas" y "Democracia".

Estos factores permiten obtener un mismo sistema de referencia para el conjunto de partidos políticos latinoamericanos seleccionados, a partir del cuál se puede conocer la importancia relativa de los clivajes de polarización ideológica.

Tras extraer las cinco dimensiones en las que los partidos políticos objeto de estudio muestran posiciones claramente diferenciadas, se pretende conocer cuáles de estas líneas de división son las que establecen mayor polarización entre las formaciones de izquierda y de derecha aquí abordadas y cuál es el posicionamiento de los partidos en torno a estas dimensiones.

Para dar respuesta a todos estos interrogantes, y de manera complementaria, se realiza un análisis multivariante poco utilizado en el campo de la ciencia política, el HJ-Biplot (Galindo, 1986), extensión de los métodos Biplot de Gabriel. Las variables utilizadas en esta representación HJ-Biplot son las medias de las puntuaciones factoriales (para cada uno de los partidos políticos considerados) obtenidas en el análisis factorial. Las representaciones que comprenden el análisis simultáneo de casos (partidos) y de variables son interesantes, ya que no sólo permiten conocer la configuración de los partidos políticos sino también qué variables son responsables de la configuración de los mismos (para una mejor comprensión de esta técnica multivariante ver apéndice metodológico).

Antes de interpretar los gráficos biplot habría que tener en cuenta una serie de aspectos importantes del análisis. Por un lado, la bondad de ajuste de la representación biplot en el subespacio de máxima inercia (es decir, conocer cuál es la cantidad de información retenida en el análisis). Y por otro, la parte de variabilidad de cada una de las variables explicadas por el factor y la calidad de representación de los partidos políticos en los gráficos. ${ }^{5}$

${ }^{5}$ Dado que la variabilidad total de los datos no puede ser recogida en un solo gráfico, puesto que no se trata de un fenómeno bidimensional, se han retenido los tres primeros ejes factoriales del HJ-Biplot. La tasa de inercia en el primer plano factorial (es decir, la cantidad de infor- 


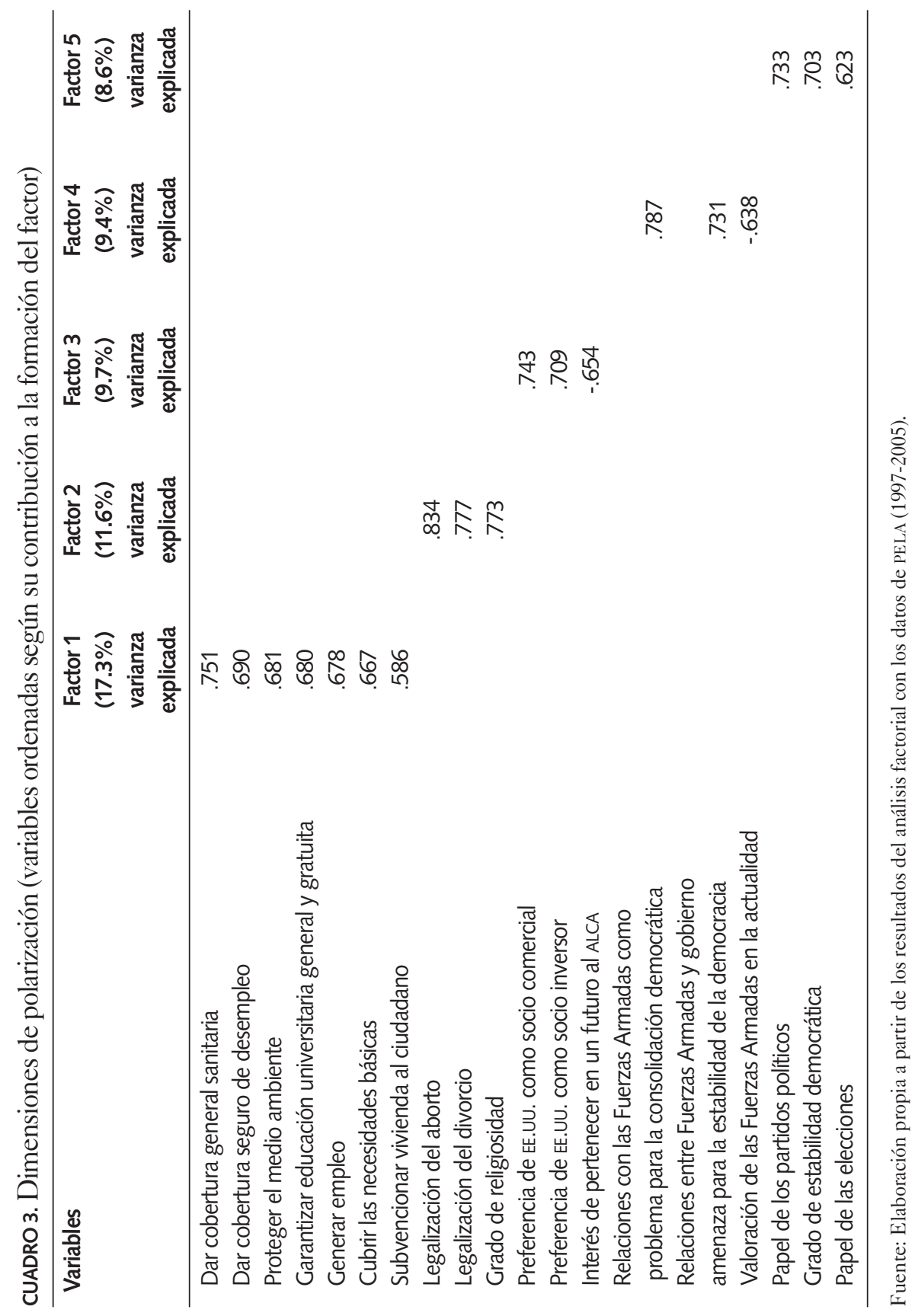


El análisis de la representación biplot pone de manifiesto que las dimensiones ideológicas con mayor variabilidad y, por tanto, con mayor capacidad discriminatoria son dos: "Imagen de Estados Unidos" y "Valores". Si bien, la "Democracia" y el papel de las "Fuerzas Armadas" tienen una aportación importante a la hora de discriminar a la izquierda y la derecha en América Latina. La "Intervención estatal" es el clivaje que presenta la variabilidad más baja en el plano factorial ${ }^{6}$ (véase figuras 1 y 2 , y cuadro 2 del apéndice metodológico).

La calidad de representación en los gráficos biplot para la práctica totalidad de nuestros casos es buena o aceptable. De modo que es posible extraer conclusiones fiables respecto a las proyecciones de los partidos políticos sobre las dimensiones de polarización programática para todas las formaciones políticas excepto para el PSC en Ecuador, dada su baja contribución a la formación de las dimensiones programáticas en este plano (y que supone que su posición en el espacio de dimensión reducida pueda ser aparente) y el FMLN en El Salvador. En este último caso hay que ser cautos a la hora de extraer conclusiones definitivas. ${ }^{7}$

Los gráficos biplot (véase figuras 1 y 2) muestran cómo las fuerzas de izquierda y de derecha en los actuales Congresos latinoamericanos quedan claramente divididas por las dimensiones de polarización ideológica obtenidas en el análisis factorial. Los partidos de derecha se sitúan gráficamente a la izquierda en el primer y segundo plano factorial, mientras que los de iz-

mación retenida), formado por el eje 1 y 2 , alcanza el $61.1 \%$, consiguiéndose en el espacio, formado por los tres primeros ejes (1, 2 y 3), el 79.6\% de la variabilidad total en los datos, es decir, se pueden interpretar las posiciones de los partidos y de las dimensiones ideológicas con una pérdida de información relativamente pequeña (un 20\% sobre el total), lo que garantiza la fiabilidad de la interpretación de los datos (véase cuadro 1 del apéndice metodológico).

${ }^{6}$ Un análisis más detallado, implica conocer a qué se debe esa menor contribución. Una posible interpretación está en la presencia de posiciones medias de los parlamentarios entrevistados para las variables que componen esta dimensión y, por consiguiente, la no relación entre ésta y la pertenencia a un partido político (medido a partir del continuo izquierda-derecha). O bien, que esta dimensión esté mejor representada en otros planos factoriales aquí no considerados. En este caso habría que buscar en los planos formados por los ejes 1 y 4,2 y 4 o 3 y 4 para confirmarlo, ya que queda un $20 \%$ de variabilidad total no explicada por los tres ejes retenidos. No obstante, y como se demostrará en páginas posteriores, esta dimensión permite distinguir igualmente entre fuerzas políticas de izquierda y de derecha.

${ }^{7}$ La calidad de representación del PSC en el plano factorial formado por los ejes 1, 2 y 3 es de 134 sobre 1.000 siendo la del FMLN de 325 sobre 1.000 (véase cuadro 3 del apéndice metodológico). 
quierda (bien representados en el eje 1-2) aparecen posicionados en la parte derecha del primer plano factorial (figura 1). Por otra parte, dentro de la izquierda se observan dos grupos claramente diferenciados, por un lado, aquellos situados en el cuadrante inferior derecho (FSLN, FMLN, PRD y MUPPNP) que representan una izquierda de carácter revolucionario ${ }^{8}$ y, por otro, una izquierda más moderada, en términos ideológicos y programáticos, ${ }^{9}$ ubicada en el cuadrante superior derecho (F//EP y PS).

Esto implica que el primer plano factorial (figura 1) separa, por un lado, a aquellos partidos políticos proclives a una mayor participación estatal en políticas públicas, con un bajo componente de sus valores y que evalúan negativamente el papel de las Fuerzas Armadas en el momento de la realización de la encuesta, todos ellos posicionados en la parte derecha del gráfico, frente a los neoliberales en términos económicos, conservadores en sus valores y que consideran positivo el papel de las Fuerzas Armadas, situados en la parte izquierda del gráfico. Por otro lado, también separa a aquellos partidos con una imagen positiva y favorable a la firma de acuerdos con Estados Unidos, menos proclives a la democracia en el país (parte inferior del gráfico) de los que manifiestan un claro rechazo a estrechar relaciones con los Estados Unidos y apuestan por un modelo de democracia en el que partidos políticos y elecciones son esenciales para el funcionamiento del sistema político (parte superior del gráfico).

Es significativo que algunas de estas dimensiones ideológicas no sólo separen a la derecha de la izquierda sino que permiten establecer diferencias dentro del conjunto de partidos de derecha o de izquierda, tal es el caso de los clivajes "Intervención estatal" e "Imagen de Estados Unidos", principalmente.

\footnotetext{
${ }^{8}$ Desde sus orígenes, el FSLN se caracterizó por su identidad antiimperialista, revolucionaria y marxista. El FMLN recoge en sus Estatutos su definición como "partido democrático, revolucionario y socialista" y el PRD en su Declaración de Principios dice que "Asume las tradiciones históricas que dieron origen a las grandes revoluciones de México: la Independencia, la Reforma y la Restauración de la República y la Revolución de 1910. (...) se identifica con las revoluciones socialistas, los movimientos de liberación nacional y la izquierda mundial".

${ }^{9}$ En el caso del FA, durante la segunda mitad de la década de 1980 y principios de 1990, tuvo que adaptarse y organizarse para ser una opción política viable. La moderación, ideológica como programática, fue pieza clave en dicho proceso, principalmente para la formación de alianzas con otros partidos ubicados más hacia el centro (Yaffé, 2006). Algo similar le sucede al ps en Chile, miembro de la Concertación de Partidos por la Democracia (junto al Partido por la Democracia, PPD, el Partido Radical Social Demócrata, PRSD, y la Democracia Cristiana, PDC), coalición que ha llevado a cabo el proceso de transición y que ha elegido ya cuatro gobiernos desde el término de la dictadura de Pinochet (Bianchini, 2006).
} 
Si bien, no será posible extraer conclusiones fiables de estas formaciones políticas para la dimensión "Democracia" e "Imagen de Estados Unidos", ya que en el eje 1-3 estas dimensiones tienen una pésima calidad de representación en la medida en que la contribución relativa de los ejes a ambas dimensiones es muy baja (véase cuadro 3 del apéndice metodológico).

Una vez conocidas las dimensiones ideológicas que tienen mayor poder discriminante entre los partidos políticos, se aborda el estudio de las posibles familias partidistas formadas a partir de cada una de estas dimensiones. ${ }^{10}$

\section{Clasificación de los partidos políticos en las principales dimensiones ideológicas: intervención estatal}

Las transformaciones estructurales asociadas a un modelo de desarrollo centrado en el mercado y en políticas neoliberales se han convertido en otro escenario de competencia para los partidos políticos latinoamericanos. Con frecuencia se han asociado políticas económicas neoliberales y de mercado con fuerzas políticas de derecha, y las posiciones a favor de aumentar la capacidad de intervención del Estado en la esfera económica-social con partidos de izquierda. La confrontación entre mercado-estado viene articulando la política latinoamericana desde la mitad de la década de 1980 y, pese a que en la actualidad este binomio no tenga la misma capacidad discriminatoria que en décadas pasadas, sigue siendo una de las principales líneas de competencia partidista entre la izquierda y la derecha latinoamericana.

La dimensión "Intervención estatal", como se vio al interpretar el análisis factorial, está formada por aquellas variables relacionadas con la intervención del Estado en diferentes políticas públicas (salud, vivienda, medio ambiente, educación universitaria, trabajo, seguro de desempleo o cubrir las necesidades básicas de todos los ciudadanos). Así, proyectando en las figuras 1 y 2 cada uno de los partidos políticos de forma perpendicular al vector que representa al clivaje "Intervención estatal" se obtiene la clasificación de los mismos. De modo que todos aquellos partidos posicionados cerca de la punta de la flecha de este vector estarán a favor de una intervención estatal en este tipo de políticas públicas, principalmente de carácter social, lo

${ }^{10}$ La relación partido político-dimensiones ideológicas se estudia a través de la proyección perpendicular de los puntos que encarnan a los partidos sobre los vectores que representan a las dimensiones programáticas obtenidas en el análisis factorial, lo que permite determinar cuáles son los clivajes que más diferencian subconjuntos de partidos. 
FIGURA 1. Representación HJ-Biplot de la matriz de datos (eje 1 y 2 )

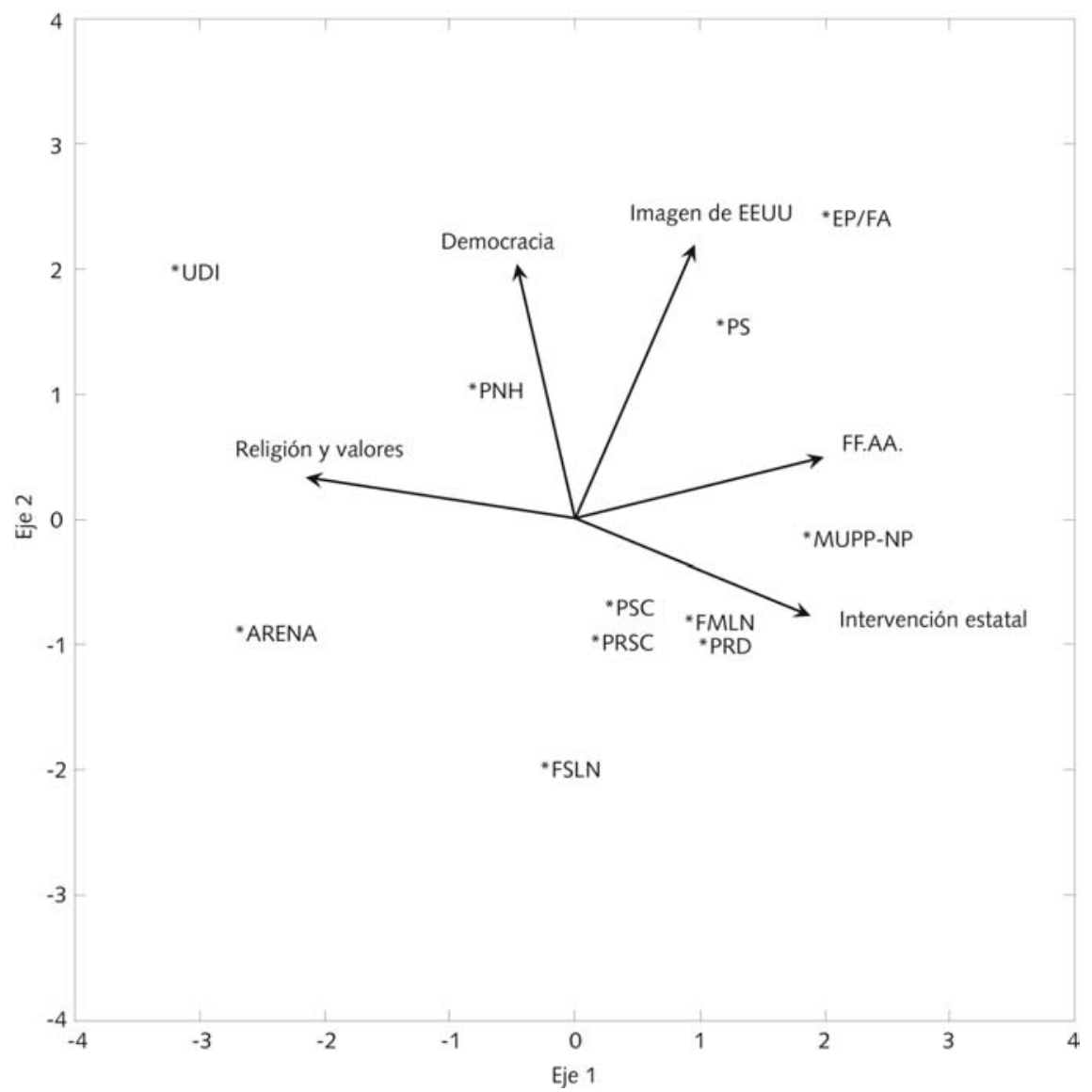

Fuente: Resultados obtenidos del HJ-Biplot a partir de los datos de PELA (1997-2005).

que definiría una situación "estatista", mientras que los situados en el extremo opuesto del vector, que defienden una menor intervención del Estado en la esfera económica-social estarán a favor de un modelo neoliberal en la economía.

Los resultados recogidos en el cuadro 4 ponen de manifiesto que el polo estatista atrae a un mayor número de partidos que el neoliberal reflejando, posiblemente, el cambio acontecido desde principios de la presente década como reacción a las políticas de ajuste estructural diseminadas por la región 
FIGURA 2. Representación HJ-Biplot de la matriz de datos (eje 1 y 3 )

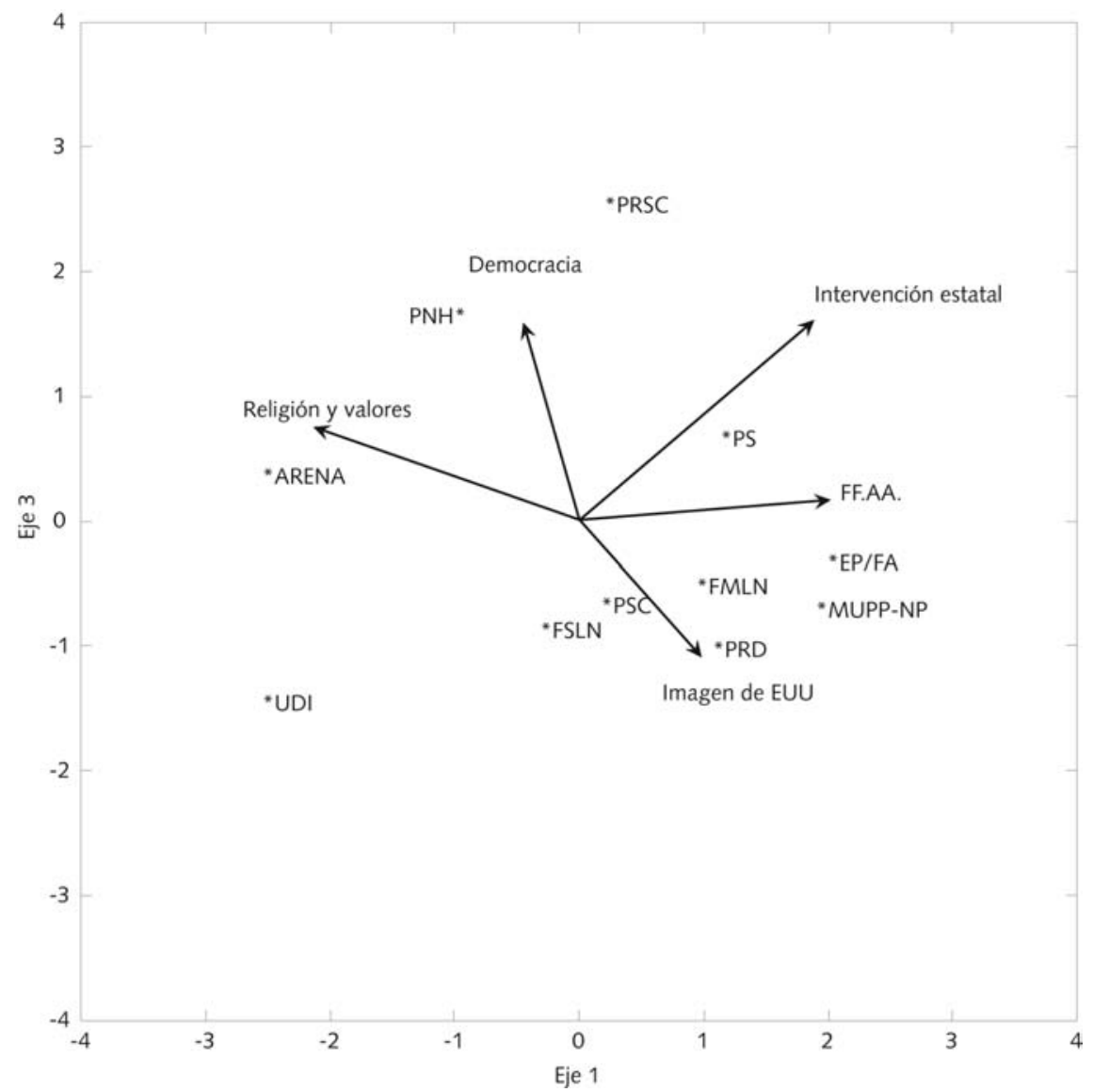

Fuente: Resultados obtenidos del HJ-Biplot a partir de los datos de PELA (1997-2005).

desde la segunda mitad de la década de 1980. El predominio de la vertiente estatista es una muestra de pervivencia, al menos en la opinión de los entrevistados, de "programas clásicos de defensa de la matriz estadocéntrica" (Alcántara, 2004, p. 140). Los partidos estatistas son claramente de izquierda: MUPP-NP, PRD, FA/EP, FMLN, PS y FSLN, pero también los hay de derecha como es el caso del PRSG y PNH (véase figuras 1 y 2). Son, principalmente, el MUPP-NP, el PRD y el FMLN (si bien la posición de este último debe tomarse con mucha precaución dada su baja calidad de representación) quienes 
plantean un rechazo claro a las políticas neoliberales en la economía otorgándole al Estado un papel más activo en lo económico y social. Para todos ellos puede mantenerse que existe una gran coherencia entre los resultados obtenidos y los programas o estatutos partidistas (Alcántara y Freidenberg, 2001). Resulta llamativo el posicionamiento del PS chileno y el FSLN nicaragüense en este clivaje con una posición más moderada dentro del polo estatista, lo que demuestra que no siempre los programas y discursos de los partidos coinciden con sus posiciones ideológicas. El PS en su Declaración de Principios establece en el art. 3 que "(...) Rechazan los comportamientos egoístas y excluyentes que la lógica del sistema capitalista impone a los seres humanos". En el caso del FSLN su oposición al neoliberalismo es la base de su programa político. Sus estatutos indican que "El Frente Sandinista de Liberación Nacional es un partido Revolucionario, socialista, democrático y antiimperialista" (Alcántara, 2004, pp.143, 145). No obstante, hay que tener en cuenta la diversidad de los ámbitos de intervención estatal que componen esta dimensión de polarización puesto que, tal y como se ha demostrado en otros estudios, la opinión de la izquierda latinoamericana respecto al papel del Estado en cuanto ente regulador del mercado y la provisión de bienes y servicios difiere de unos partidos a otros según el ámbito y área de intervención del que se trate (Martí Puig y Santiuste Cué, 2006, pp. 339340), coincidiendo, en buena medida, la clasificación de los partidos de izquierda realizada en dichos estudios con los resultados aquí presentados. Esto puede justificar la posición moderada de estos dos partidos políticos en esta dimensión.

En el ámbito neoliberal y pro mercado, queda constancia de la casi exclusiva presencia de dos fuerzas políticas de derecha: UDI y ARENA. Dentro del grupo conservador, la UDI se perfila como la fuerza política, con diferencia, más favorable a una política de mercado en la economía. ${ }^{11}$

\footnotetext{
${ }^{11}$ En el art. 16 de la Declaración de Principios se defienden las políticas neoliberales al establecer que "la experiencia demuestra que los sistemas económicos que estimulan en cada persona la capacidad generadora de riqueza, obtienen un desarrollo económico y un bienestar social muy superiores a los colectivismos planificados por la burocracia estatal (...) cuanto más se acerque el Estado a ser el único empleador o fuente de ingresos para las personas, más próximo se estará al control de éstas por los detentadores del poder político" (http://www.udi.cl/udi/principios).
} 
CUADRO 4. Clasificación de los partidos políticos en la dimensión intervención estatal

\begin{tabular}{lc}
\hline Dimensión intervención estatal & Partidos políticos * \\
\hline Estatismo & MUPP-NP, PRD, FMLN, FA/EP, PS, FSLN, PRSC, PNH \\
Neoliberalismo & UDI, ARENA \\
\hline
\end{tabular}

Fuente: Elaboración propia a partir de los gráficos HJ-Biplot. * Los partidos políticos no incluidos en el cuadro es porque tienen una calidad de representación mala en esta dimensión y, por tanto, su clasificación en un grupo u otro puede ser sólo aparente.

Clasificación de los partidos políticos en las principales dimensiones ideológicas: democracia

El clivaje autoritarismo-democracia no ha ocupado un lugar predominante en la estructuración de los sistemas de partidos de muchos países latinoamericanos a pesar de haber estado marcados por la experiencia política autoritaria de las décadas de 1970 y 1980. En gran medida las transiciones a la democracia tuvieron éxito precisamente por la adopción del credo democrático sin restricciones por parte de la clase política. Sin embargo, tras varios lustros de funcionamiento de las instituciones democráticas se pueden encontrar matices que diferencian a los partidos según su mayor o menor proclividad democrática y más concretamente sobre su idea de cómo debe desarrollarse la democracia.

Las variables que componen el clivaje de "Democracia" son las relativas al reconocimiento del papel de los partidos políticos y de las elecciones como mecanismos para la representación política, así como la evaluación de la estabilidad democrática en el país. Este clivaje divide a las formaciones políticas en dos polos bien diferenciados: por un lado, las que valoran la democracia en el país y apuestan por un modelo de democracia en el que se incluya a los partidos políticos y las elecciones como aspectos esenciales de la democracia liberal, lo que definiría una situación de "mayor proclividad democrática" (las proyectadas en la figura 1 cerca de la punta de la flecha que representa a esta dimensión) y por otro, aquellas que opinan que los partidos y las elecciones no son ingredientes básicos para el funcionamiento de la democracia, que representaría el polo de "menor proclividad democrática”.

Así todo, el grupo de partidos con mayor proclividad democrática está formado básicamente por la UDI y PS chilenos y el FA/EP uruguayo, lo que 
CUADRO 5. Clasificación de los partidos políticos en la dimensión democracia

\begin{tabular}{lc}
\hline Dimensión democracia & Partidos políticos * \\
\hline Menor proclividad democrática & MUPP-NP, FMLN, FSLN, PRD, ARENA \\
Mayor proclividad democrática & UDI, PS, FA/EP \\
\hline
\end{tabular}

Fuente: Elaboración propia a partir de los gráficos HJ-Biplot. ${ }^{*}$ Los partidos políticos no incluidos en el cuadro es porque tienen una calidad de representación mala en esta dimensión y, por tanto, su clasificación en un grupo u otro puede ser sólo aparente.

evidencia el peso de la historia y de condicionantes sistémicos. La clasificación de partidos de menos proclividad democrática la encabezan el FSLN, el PRD y el FMLN, seguidos del MUPP-NP, fuerzas políticas presentes en sistemas de muy poca tradición democrática. En este sentido hay que tener en cuenta que tanto el FSLN como el FMLN surgieron para combatir la dictadura de Somoza, en el primer caso, y la salvadoreña en el segundo, pero su forma de expresión política no fue la democrática sino la violenta. A estos partidos de izquierda con menor proclividad democrática se le une la derecha salvadoreña, ARENA, que pese a adoptar una posición más moderada que el resto de partidos en este polo está más próxima a este grupo que al de sus homólogos de derecha.

La clasificación de los partidos políticos en esta dimensión pone de manifiesto que el clivaje de democracia no discrimina tanto a las formaciones políticas de derecha e izquierda como a la propia izquierda en sí misma. De modo que es posible hablar de una izquierda democrática que acepta los mecanismos formales de representación, como pueden ser los partidos y las elecciones, y con una mayor tradición democrática constituida por el PS chileno y el FA/EP uruguayo; y una izquierda que concede menor importancia a instituciones clave en el juego democrático como son los partidos políticos y las elecciones; los casos más claros son los frentistas, el FSLN y FMLN, o puede ser el caso del MUPP-NP, por su origen social e indigenista que "apueste por un modelo de democracia participativa que vaya más allá de los mecanismos formales de representación de la democracia liberal" (Martí Puig y Santiuste Cué, 2006, p. 322).

Tampoco se puede olvidar el legado autoritario de cada uno de los países aquí contemplados que aproxima las posiciones de los partidos de derecha e izquierda de un mismo sistema político en esta dimensión. Un ejemplo de ello es El Salvador con ARENA y FMLN situados en el polo de menor proclividad democrática y Chile con UDI y PS en el polo opuesto. 
La baja calidad de representación del PNH y del PRSG en este binomio impide extraer conclusiones claras sobre su posicionamiento en el mismo.

Clasificación de los partidos políticos en las principales dimensiones ideológicas: valores

El clivaje religioso ha sido durante mucho tiempo uno de los principales ejes de división social y política tanto en Europa como en América Latina. Tradicionalmente, hablar de religión suponía hablar de la Iglesia católica, una institución elitista, conservadora y antidemocrática claramente identificada con el Estado y el poder (Levine, 2005). La existencia de un pluralismo religioso que, aunque de manera lenta sigue creciendo, ha supuesto el debilitamiento del monopolio de la Iglesia católica que, no obstante, goza todavía de un lugar privilegiado en la sociedad latinoamericana y su influencia, hoy por hoy, sigue siendo relevante, aunque no sea exactamente el caso de los países centroamericanos.

El proceso de secularización que la sociedad latinoamericana ha experimentado varía de unos países a otros lo que implica que la importancia de la dimensión "Valores" no sea la misma en todos ellos. Pero tal y como se ha visto en páginas anteriores, pese a que el nuevo panorama religioso en América Latina indica que hay un declive del catolicismo (Parker, 2005, p. 52), la religión sigue siendo una línea de división importante entre partidos de izquierda y de derecha en los actuales congresos latinoamericanos. El papel jugado por la Iglesia católica en el nacimiento de algunos partidos políticos latinoamericanos, tal y como señala Alcántara (2004), es un aspecto fundamental a tener en cuenta a la hora de interpretar este clivaje. Pero la dimensión religiosa no sólo se manifiesta a través de una adscripción religiosa en particular sino también por las actitudes en relación a cuestiones morales que han jugado un papel importante en el conflicto iglesia(s)-Estado (sobre todo la católica), no sólo en América Latina sino también en toda Europa Occidental.

Las variables que forman esta dimensión ideológica son fundamentalmente tres: grado de religiosidad de los parlamentarios latinoamericanos y su postura ante la legalización del aborto y el divorcio. La clasificación de las fuerzas políticas de izquierda y de derecha en este clivaje permite hablar de dos grupos bien diferenciados (véase cuadro 6). Por un lado, un polo "conservador" caracterizado por un alto grado de religiosidad y poco tolerante. Y por otro, un polo "progresista" menos religioso, con menor presencia de los valores tradicionales y defensor de las libertades individuales. 
CUADRO 6. Clasificación de los partidos políticos en la dimensión valores

\begin{tabular}{lc}
\hline Dimensión valores & Partidos políticos * \\
\hline Conservador & UDI, ARENA, PNH, PRSC \\
Progresista & MUPP-NP, FA/EP, PS, FMLN, PRD, FSLN \\
\hline
\end{tabular}

Fuente: Elaboración propia a partir de los gráficos HJ-Biplot. * Los partidos políticos no incluidos en el cuadro es porque tienen una calidad de representación mala en esta dimensión y, por tanto, su clasificación en un grupo u otro puede ser sólo aparente.

Las diferencias entre la derecha y la izquierda en cuanto a sus creencias y valores en relación a temas morales son muy claras. Por parte del grupo conservador la UDI se perfila como el partido con diputados más religiosos y contrarios a la legalización del divorcio y, sobre todo, del aborto, seguido de ARENA, ${ }^{12}$ PNH y PRSC. En el extremo opuesto de esta dimensión se encuentran todos los partidos de izquierda: MUPP-NP, FA/EP, FMLN, PS y PRD como las formaciones más progresistas, coherentes con la tradición secular y liberal de los partidos de izquierda. El FSLN mantiene una postura más moderada; su posición ante la legalización del aborto, principalmente, continúa siendo algo conservadora.

\section{Clasificación de los partidos políticos en las principales dimensiones ideológicas: imagen de los Estados Unidos}

En la celebración de la IV Cumbre de las Américas, en Mar de Plata, en noviembre de 2005, buena parte del debate se centró en la conformación de manera rápida del Área de Libre Comercio de las Américas (ALCA), que suponía para Estados Unidos un modo de reafirmar su presencia en la región latinoamericana. Sin embargo, tal y como quedó de relieve en dicha Cumbre, a través de los Jefes de Estado, las diferencias de opinión entre países son notables y la llegada a un acuerdo parece caer en un punto muerto.

La falta de interés hacia América Latina, el fracaso de las reformas económicas neoliberales impulsadas desde Washington, así como la incapacidad de Estados Unidos para diseñar una política regional convincente, han hecho que las relaciones bilaterales entre Estados Unidos y muchos países

${ }^{12}$ El apoyo de ARENA a proyectos conservadores católicos ha estado presente desde sus inicios. En los últimos años ha mostrado su apoyo a las propuestas antiaborto de la "Fundación Sí a la Vida” encabezada por Julia Regina de Cardenal. 
latinoamericanos se hayan deteriorado y que cada vez se haga más visible el surgimiento de un sentimiento anti-estadounidense en Latinoamérica. Son cada vez más los países latinoamericanos, en especial los que integran el MERCOSUR, Brasil, Argentina, Uruguay y Paraguay, que buscan en la Unión Europea y en China nuevos mercados para sus productos y de este modo reducir la dependencia con respecto a Estados Unidos (Kern, 2005, p. 8).

El clivaje "Imagen de Estados Unidos" está compuesto por tres variables relativas a las relaciones político-económicas con el país: la preferencia de tener a Estados Unidos como socio comercial, como socio inversor y el grado de interés de los parlamentarios latinoamericanos en que su país pertenezca en un futuro al ALCA. Esta dimensión ideológica divide a los partidos políticos en dos grupos bien distintos, aunque las diferencias entre la izquierda y la derecha no son tan claras, primando más la variable país que el partido político o la ideología. Así todo, los partidos más proclives a fomentar las relaciones con Estados Unidos, con el fin de favorecer sus propios intereses económicos y geoestratégicos, definen el polo "pro-estadounidense", formado principalmente por ARENA, la izquierda nicaragüense, mexicana y salvadoreña. El FSLN y ARENA se erigen como los partidos más favorables a la firma del ALCA y a tener a Estados Unidos como principal socio comercial e inversor. No en vano, tanto El Salvador como Nicaragua han firmado acuerdos comerciales con Estados Unidos. A la firma del Tratado de Libre Comercio entre Centroamérica, la República Dominicana y Estados Unidos (DR-CAFTA) se añade, además, la firma de acuerdos en el marco de la Cuenta para el Desafío del Milenio (MCA) que contribuyen a consolidar aún más la orientación exportadora de la región (Sánchez Ancochea, 2006, p. 2). En el polo opuesto, se encuentran el resto de formaciones políticas de izquierda menos favorables a impulsar las relaciones político-económicas con Estados Unidos, definiendo de este modo el polo "anti-estadounidense". El FA/EP y el PS chileno se presentan como las fuerzas políticas más contrarias a la firma de acuerdos con Washington, mientras que el MUPP-NP, se muestra mucho más moderado al respecto, ocupando posiciones medias en este tema. En una situación similar se encuentra la UDI, que es la única fuerza política de derecha reticente a estrechar relaciones con Estados Unidos. No se debe perder de vista el impacto de China en América Latina y más concretamente en Chile. China se ha convertido en uno de los principales socios comerciales de Chile y en noviembre de 2005 firmó un acuerdo de libre comercio con el país asiático (Sánchez Ancochea, 2006). 
CUADRO 7. Clasificación de los partidos políticos en la dimensión imagen de los Estados Unidos

\begin{tabular}{ll}
\hline Dimensión imagen de Estados Unidos & Partidos políticos * \\
\hline Pro-Estados Unidos & FSLN, FMLN, ARENA, PRD \\
Anti-Estados Unidos & FA/EP, PS, UDI, MUPP-NP \\
\hline
\end{tabular}

Fuente: Elaboración propia a partir de los gráficos HJ-Biplot. * Los partidos políticos no incluidos en el cuadro es porque tienen una calidad de representación mala en esta dimensión y, por tanto, su clasificación en un grupo u otro puede ser sólo aparente.

Este clivaje también divide no sólo a la izquierda y a la derecha latinoamericanas sino a las regiones del continente por un lado, Centroamérica y el Caribe como más próxima a Estados Unidos, algo de esperar si tenemos en cuenta las posibles consecuencias positivas en el desarrollo económico de los países centroamericanos de la firma del DR-CAFTA y, por otro, los países andinos y el Cono Sur menos proclives a fomentar las relaciones con Estados Unidos y con su punto de mira en el mercado europeo y asiático.

Clasificación de los partidos políticos en las principales dimensiones ideológicas: fuerzas armadas

Los partidos políticos en América Latina corrieron suerte muy distinta durante los años de autoritarismo y presencia de los regímenes militares por lo que es previsible que la dimensión "Fuerzas Armadas" los divida en grupos claramente diferenciados. El papel político que los militares jugaron en Chile y Uruguay no es el mismo que el desempeñado en México o Ecuador.

El clivaje relativo a las Fuerzas Armadas lo conforman tres variables: las relaciones entre éstas y el Gobierno como amenaza para la estabilidad democrática en América Latina, las relaciones con las Fuerzas Armadas como problema para la consolidación democrática del país, y la valoración de las mismas en el momento de realizar la encuesta. La clasificación de los partidos con base en esta dimensión ideológica de polarización separa, por un lado, a los partidos "más favorables a las Fuerzas Armadas", que consideran que las relaciones entre las Fuerzas Armadas y el Gobierno no suponen, hoy en día, una amenaza para la estabilidad democrática de los países latinoamericanos. Y, en el polo opuesto, a los "menos favorables a las Fuerzas Armadas", que cuestionan el papel de los militares en la actualidad y desconfían de su actuación en la vida pública de sus respectivos países. 
CUADRO 8. Clasificación de los partidos políticos en la dimensión fuerzas armadas

\begin{tabular}{lc}
\hline Dimensión fuerzas armadas & Partidos políticos * \\
\hline Más favorables a las Fuerzas Armadas & ARENA, UDI, PNH, FSLN \\
Menos favorables a las Fuerzas Armadas & FA/EP, PS, MUPP-NP, PRD, FMLN \\
\hline
\end{tabular}

Fuente: Elaboración propia a partir de los gráficos HJ-Biplot. * Los partidos políticos no incluidos en el cuadro es porque tienen una calidad de representación mala en esta dimensión y, por tanto, su clasificación en un grupo u otro puede ser sólo aparente.

En el primer grupo, los favorables a las Fuerzas Armadas, se encuentran básicamente las formaciones políticas de derecha (UDI, ARENA y PNH), algo de esperar teniendo en cuenta que durante las décadas de 1960 y 1980, la élite política de la derecha colaboró estrechamente con las Fuerzas Armadas en el poder (Alcántara y Llamazares, 2006, p. 347). Por ejemplo, la UDI en sus orígenes se mantuvo siempre próxima al legado autoritario, se mostró a favor de la continuidad de Pinochet al mando de la presidencia de Chile en el Plebiscito Nacional celebrado el 5 de octubre de 1988. En el caso de ARENA y el PNH, el liderazgo armado estuvo presente en sus orígenes. Junto a estos tres partidos se encuentra también el FSLN, cuya relación con las Fuerzas Armadas ha sido muy estrecha desde sus orígenes. El hecho de que las Fuerzas Armadas en Nicaragua durante una década llevasen el nombre de "sandinistas" favoreció esta situación (Alcántara, 2004).

El segundo grupo, menos favorable a las Fuerzas Armadas, lo constituyen partidos de izquierda, FA/EP, PS, MUPP-NP y PRD. Una actitud estrechamente vinculada con los enclaves autoritarios de cada país y la peculiar forma en que se llevó a cabo la transición política en ellos. No se puede olvidar que precisamente fueron las formaciones de izquierda de las más castigadas por los regímenes dictatoriales.

Destaca la evolución que ha experimentado el FMLN en este clivaje, quien a pesar de su origen armado, se sitúa en un lugar intermedio, próximo al polo menos militar. Esto es comprensible si tenemos en cuenta que en la década de 1980, el FMLN y las Fuerzas Armadas, eran contrincantes en el conflicto bélico (Corral y Otero, 2005). No obstante, no deben extraerse conclusiones definitivas sobre su posicionamiento en esta dimensión dada su baja calidad de representación. 


\section{Evolución de los partidos políticos en las principales dimensiones ideológicas respecto a la legislatura anterior}

A lo largo del periodo de democratización de los sistemas políticos latinoamericanos los partidos de la región han sufrido importantes cambios, en términos programáticos e ideológicos, tanto en temas de carácter políticoinstitucional como en cuestiones de contenido social o económico (Alcántara, 2004, p. 127). Un claro ejemplo de ello es el giro dado en torno al clivaje "estado-mercado", donde el papel activo del Estado en la economía como patrón indiscutible ha dejado de ser un tema de confrontación decisivo para la clasificación de la izquierda y la derecha latinoamericanas surgiendo otro tipo de divisiones relacionadas con la integración de los países latinoamericanos en la economía mundial o en cómo paliar los efectos del predominio de las políticas de libre mercado.

Para conocer de manera orientativa, dada la limitación del periodo de estudio (1997-2005), cuál ha sido la evolución de la izquierda y la derecha latinoamericanas, se ha hecho un nuevo análisis factorial, ${ }^{13}$ teniendo en cuenta a los partidos políticos tanto en la legislatura anterior como en la actual. ${ }^{14}$ De ese análisis factorial se han obtenido las cuatro dimensiones ideológicas analizadas previamente. ${ }^{15}$ A partir de ahí, se ha realizado un HJ-Biplot de medias cuyos resultados quedan representados en las figuras 3 y 4 donde puede interpretarse la posición de las cuatro dimensiones de polarización ideológica obtenidas: "Intervención estatal", "Democracia", "Fuerzas Armadas" y "Valores". Los tres primeros ejes de la representación biplot explican el $85.93 \%$ de la variabilidad total del plano, por lo que la pérdida de información es muy baja.

La interpretación del posicionamiento de los partidos políticos en las dimensiones de polarización ideológica es posible en la mayoría de los casos

${ }^{13}$ Las variables incluidas en este nuevo análisis factorial son las mismas que en el anterior a excepción de las relativas a Estados Unidos que no existen en los cuestionarios aplicados en la legislatura anterior. La medida de adecuación muestral de Kaiser Meyer Olkin es de 0.784, un coeficiente más que aceptable y el porcentaje de varianza total explicada por los cuatro factores resultantes es del $53.5 \%$.

${ }^{14}$ Para facilitar la lectura de datos en tablas como en gráficos posteriores, los partidos políticos van acompañados de un número que indica el periodo legislativo al que pertenece. Así, el 1 se refiere a la legislatura anterior y el 2 a la actual.

${ }^{15}$ Como acaba de señalarse, con excepción de la relativa a la imagen de Estados Unidos para la que no existe información en el periodo anterior. 
estudiados, a excepción del PRSC dominicano en las dos legislaturas analizadas, lo que implica no poder extraer conclusiones para este partido a lo largo del tiempo. El resto de las formaciones políticas tienen una calidad de representación aceptable en alguno de los planos factoriales extraídos. ${ }^{16}$

Los cambios ideológicos de los partidos políticos se muestran en las figuras 3 y 4, así como en el cuadro 8 que recoge, a modo de resumen, las posiciones de éstos en cada una de las dimensiones de polarización ideológica para caracterizarlos en su conjunto. Si se tiene en cuenta la dimensión "Intervención estatal", que es una de las principales líneas de división entre los partidos políticos latinoamericanos, la primera conclusión que se puede extraer es la existencia de una tendencia centrípeta de todas las fuerzas políticas, en especial de aquellas con posturas más neoliberales o más estatistas. Los casos más representativos son la UDI y el PS chileno. En dicho gráfico, proyectando de forma perpendicular el punto que representa a UDI1, UDI2, PS1 y PS2 sobre el vector que representa a la "Intervención estatal" se observa cómo, en la última legislatura, la UDI suaviza su postura antiestatista, consecuencia en buena medida del fracaso de las políticas neoliberales en América Latina, y el PS su posición proestatista, un hecho comprensible si se considera su condición de partido en el gobierno como integrante de la Concertación y los matices a la política de economía de libre mercado que Ricardo Lagos mantuvo durante su mandato presidencial. ${ }^{17}$

Esta tendencia se mantiene para todos los partidos analizados con excepción del MUPP-NP en Ecuador y ARENA en El Salvador, que en la última legislatura parecen haber intensificado su carácter estatista y antiestatista, respectivamente, si bien más pronunciado en el caso de Ecuador.

En cuanto a la dimensión "Democracia", la evolución de los partidos políticos en torno a ella ha sido muy distinta. Mientras que para la gran mayoría su posicionamiento en este clivaje no ha variado mucho, tal es el caso de la UDI, el PSC, el PNH, el FA/EP, el FSLN o el PRD. En otros partidos

\footnotetext{
${ }^{16}$ E1 FSLN2, MUPP-NP1 y PSC2, son característicos del eje 3, por tanto han de interpretarse teniendo en cuenta su posición en los planos factoriales formados por los ejes 1-3 (figura 4).

${ }^{17}$ En este nuevo análisis la posición del PS2 se ve modificada con respecto al análisis anterior en el que sólo se tenía en cuenta a los partidos políticos en los actuales parlamentos latinoamericanos. Si el PS2 en la figura 1 ocupaba una posición intermedia, en la figura 3 parece más clara su defensa de una intervención estatal en políticas públicas, aunque mucho más moderada que en el periodo 1998-2002. Esto se debe a la inclusión de un mayor número de partidos, con posiciones extremas de izquierda y derecha, que hace que su posición en esta nueva dimensión sea también más extrema.
} 
como ARENA, el desplazamiento a lo largo de esta dimensión del periodo 2000-2003 al de 2003-2006 ha sido más pronunciado: ha pasado de una proclividad democrática aceptable a posiciones próximas al polo de "menor proclividad democrática". Finalmente, para el MUPP-NP y el FMLN, el cambio de posición ha sido muy brusco. De tener el nivel de proclividad democrática menor en el periodo 2000-2003, el FMLN ocupa posiciones más moderadas en la siguiente legislatura, y lo mismo sucede con el MUPP-NP para quien el tiempo transcurrido entre una y otra legislaturas pone de relieve las situaciones tan diferentes en las que se encontraba en los momentos de realización de la encuesta. ${ }^{18}$

La evolución de las distintas formaciones políticas en la dimensión "Valores" no presenta cambios sustantivos en los partidos a lo largo del periodo analizado. En términos generales existe una ligera tendencia, como en el resto de los clivajes, a adoptar posiciones más centradas en torno a las cuestiones de carácter religioso y moral, excepto en el caso del MUPP-NP que en la legislatura actual se caracteriza por ser uno de los partidos políticos de América Latina menos religioso y más abierto. El FSLN, por su parte, continúa siendo la fuerza política de izquierda más moderada.

En cuanto al clivaje "Fuerzas Armadas", la tónica general de los partidos continúa siendo el abandono de las posiciones extremas. Los casos más característicos se encuentran en los partidos chilenos. La UDI se desplaza ligeramente hacia el centro a pesar de continuar siendo la fuerza política que mejor valora a las Fuerzas Armadas. En el polo opuesto se encuentra el PS, que si en el periodo 1998-2002, junto con el FA/EP, resultaba ser el menos favorable a las Fuerzas Armadas en la última legislatura experimenta un cambio significativo y, aunque su valoración continúa siendo poco positiva, su opinión ha mejorado notablemente. En línea con lo visto en el resto de dimensiones ideológicas, el MUPP-NP sigue siendo uno de los partidos que más cambios ha experimentado entre el periodo de 1998-2002 y el de 20022006, al igual que sucede con el PSC en esta dimensión. Así, mientras en 1998 el PSC tenía una opinión positiva sobre las Fuerzas Armadas, en la actualidad encabeza la lista de partidos contrarios a las mismas. ${ }^{19}$

\footnotetext{
${ }^{18}$ El periodo 1998-2002 coincidió con la preparación del golpe para derrocar a Jamil Mahuad por parte de Lucio Gutiérrez y que contó con el apoyo del MUPP-NP, y el segundo (2002-2006) coincidió con una mayor consolidación y madurez del partido, convertido en un actor estratégico clave para la gobernabilidad del país al inicio del periodo.

${ }^{19}$ Es posible que en ello tuviera influencia el hecho de que el entonces presidente y antagonista político, Lucio Gutiérrez fuera militar.
} 
FIGURA 3. Representación HJ-Biplot de la matriz de datos conjuntos (eje 1 y 2)

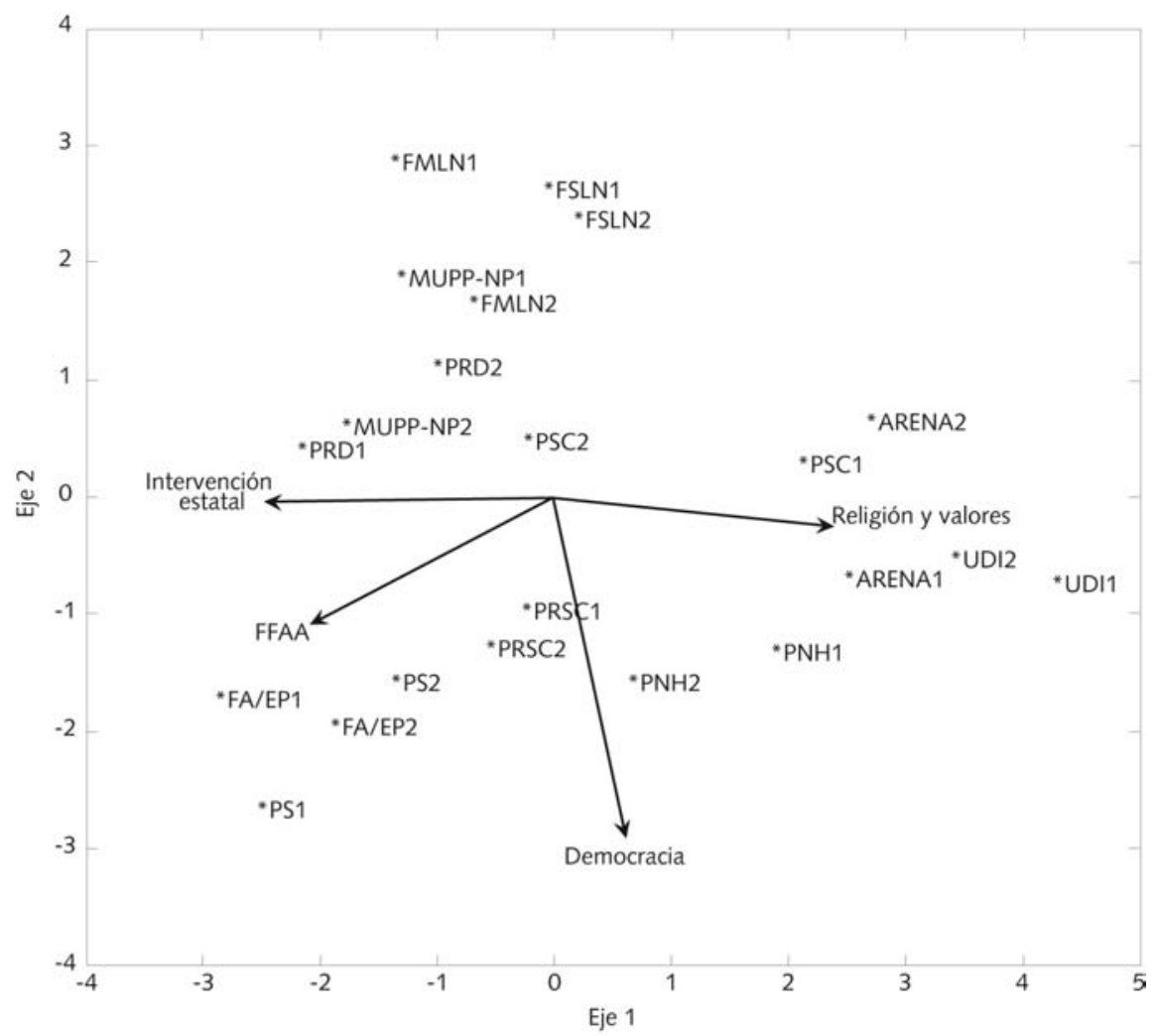

Fuente: Resultados obtenidos del HJ-Biplot a partir de los datos de PELA (1997-2005).

En el caso opuesto se encuentra el MUPP-NP, quien en la legislatura actual se muestra algo más positivo respecto al papel del ejército en Ecuador de lo que lo era en $1998 .{ }^{20}$ Lo mismo sucede con el PRD, mientras que en 2000-2003 adopta posiciones poco favorables al ejército, en la última legislatura su opinión sobre las Fuerzas Armadas mejora notablemente (véase figura 4 y cuadro 8). En cuanto al resto de formaciones políticas la evolución ha sido mínima.

${ }^{20} \mathrm{Al}$ principio de esa legislatura el MUPP-NP apoyaba sin reservas al gobierno del militar ex golpista Lucio Gutiérrez. 
FIGURA 4. Representación HJ-Biplot de la matriz de datos conjuntos (eje 1 y 3 )

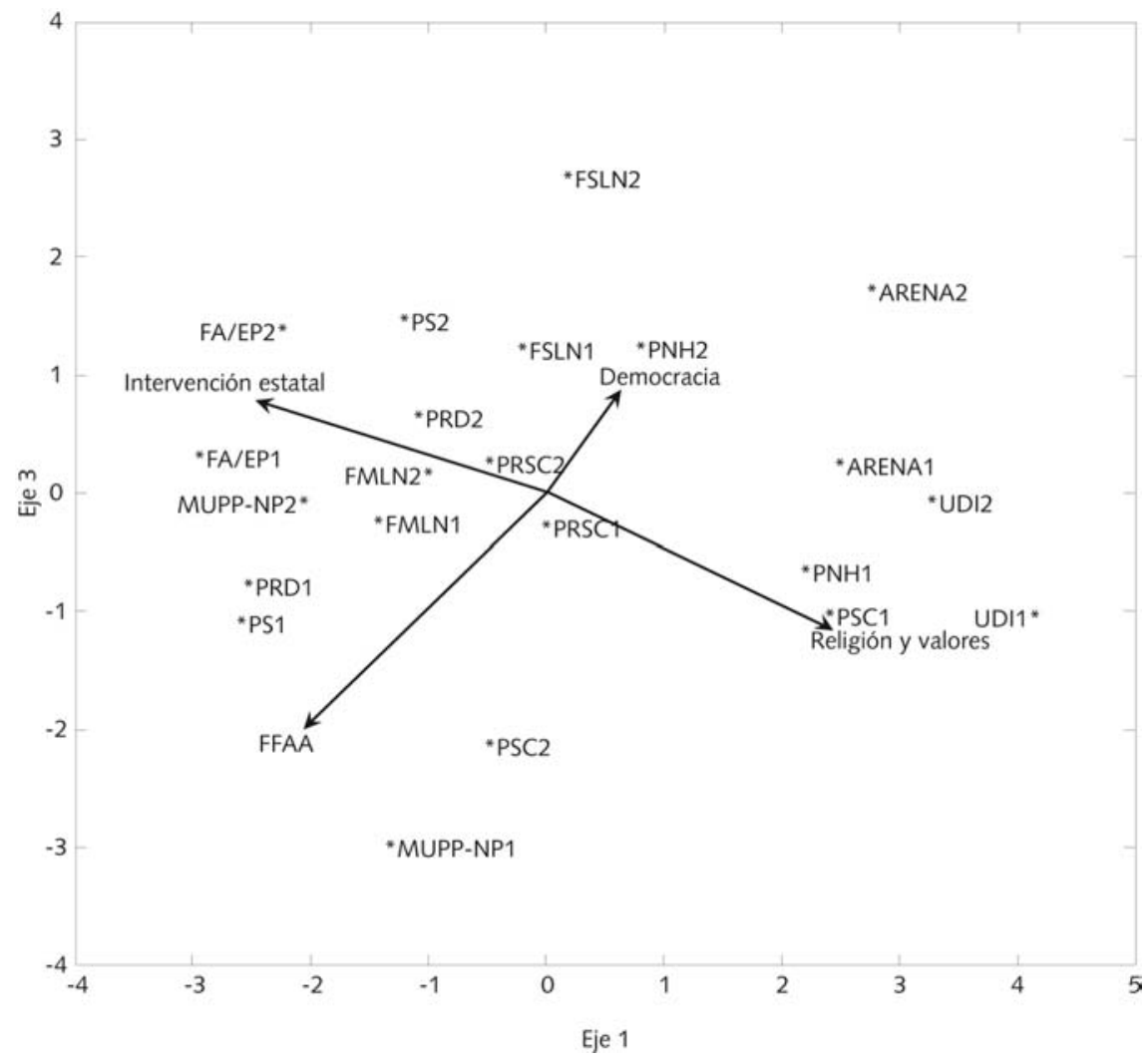

Fuente: Resultados obtenidos del HJ-Biplot a partir de los datos de PELA (1997-2005).

\section{Conclusiones}

Uno de los objetivos iniciales de este trabajo era construir y analizar las dimensiones de polarización ideológica que han constituido y constituyen el espacio de competencia entre la izquierda y la derecha en América Latina. El análisis de información relativa al periodo comprendido entre 1997-2005 permite vislumbrar la continuidad de las dimensiones ideológicas como ejes clave en la competencia partidista además de saber cuáles de esos clivajes han ido perdiendo importancia como espacios de confrontación entre la izquierda y la derecha. 


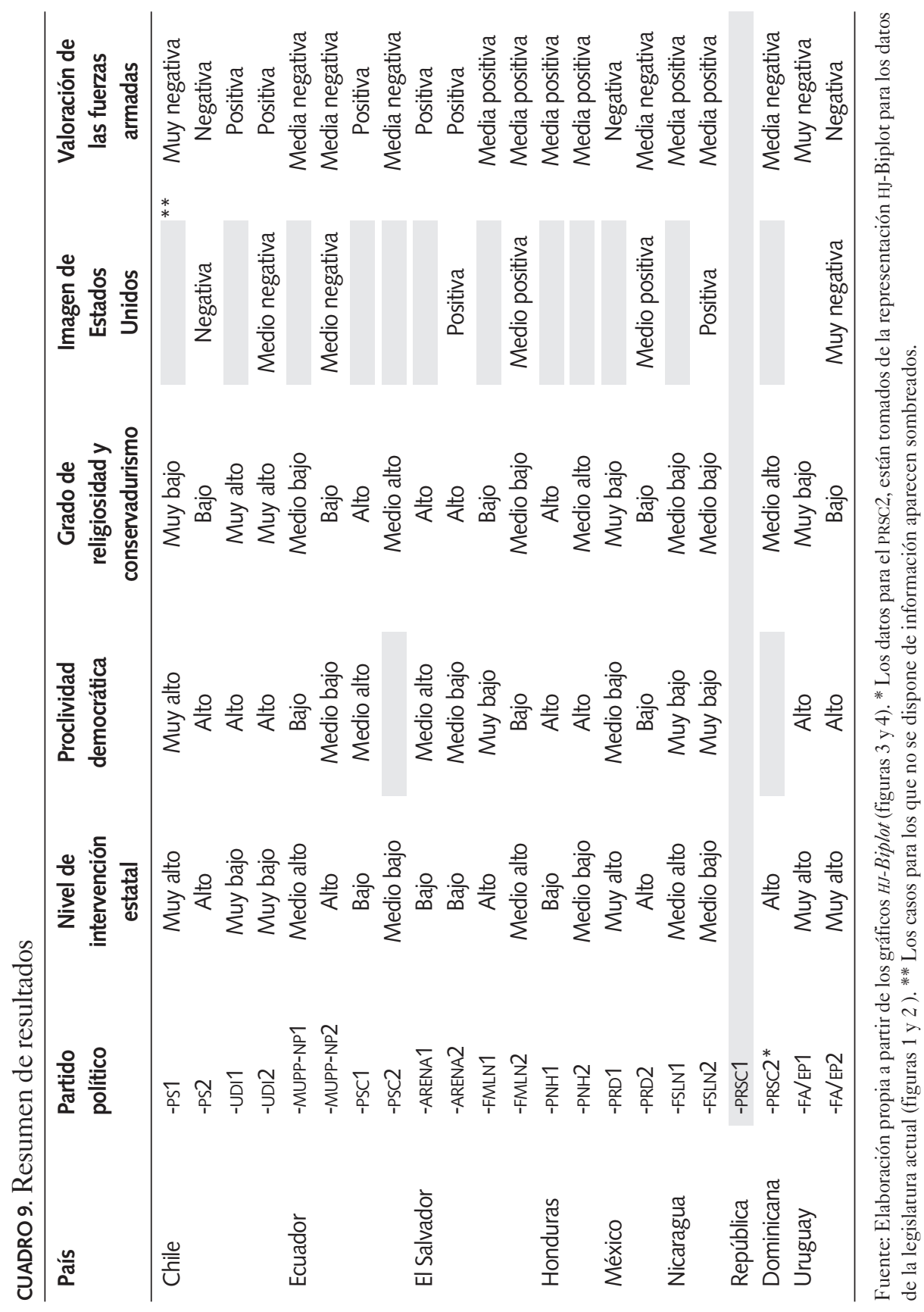


La primera conclusión que puede extraerse de estas páginas es que de las cinco líneas de competencia partidista en los actuales parlamentos latinoamericanos, "Intervención estatal", "Democracia", "Valores", "Imagen de Estados Unidos" y "Fuerzas Armadas", obtenidas a partir del análisis factorial, la simpatía/antipatía en términos económicos y estratégicos hacia Estados Unidos, el liberalismo/conservadurismo y la mayor o menor proclividad democrática de los diputados son los principales ejes de polarización entre los partidos con representación parlamentaria analizados.

En cambio, el clivaje estado/mercado importa menos y ha cedido ligeramente su puesto, en las legislaturas posteriores, a cuestiones como la imagen que los parlamentarios latinoamericanos tienen de los Estados Unidos, que se erige como uno de los temas principales de conflicto entre la izquierda y la derecha latinoamericana en la actualidad. ${ }^{21}$ La percepción de que la relación cívico-militar ha mejorado y la suposición de que ya no constituye una amenaza para la consolidación democrática continúa dividiendo a la izquierda y a la derecha. Al igual que asuntos como el divorcio y, sobre todo, el aborto, que siguen siendo cuestiones de confrontación.

Del análisis conjunto de los datos se puede extraer de manera orientativa, aunque no concluyente, la validez en el tiempo de las principales líneas de división entre la izquierda y la derecha latinoamericanas. Así pues, los clivajes "Democracia", "Valores" y "Fuerzas Armadas" prosiguen ejerciendo su papel polarizador entre formaciones políticas a lo largo de las dos legislaturas analizadas en cada país, mientras que el papel del Estado en la economía no es, en la actualidad, uno de los principales temas en la agenda política de muchos países de la región.

Otra de las conclusiones alcanzadas es que con el paso del tiempo los partidos son menos radicales en términos ideológicos. Como se ha visto existe una tendencia generalizada en las formaciones políticas analizadas a adoptar posiciones más centristas en todos los temas aquí abordados.

A modo de conclusión se puede decir que los partidos chilenos de izquierda y derecha presentan ciertas similitudes en cuanto a la valoración del papel de las reglas del juego democrático e imagen de los Estados Unidos se refiere. Tanto UDI como PS presentan índices elevados de proclividad democrática y tienen una visión algo negativa de Estados Unidos. Todos estos rasgos tienen que ver más con cuestiones sistémicas y con la situación po-

${ }^{21}$ Aunque al no tener referencia de este tema en torno a 1997 se impide conocer si esto ya era así en legislaturas anteriores. 
lítica y social del país que con características ideológicas de los partidos. El PS se caracteriza por ser un partido estatista, poco religioso y tolerante con la legalización del aborto y el divorcio, y escéptico en cuanto a las relaciones entre militares y gobierno y su posible amenaza para la consolidación democrática. Por su parte, la UDI se presenta como partido neoliberal, muy conservador y que valora positivamente el papel que las Fuerzas Armadas juegan en Chile sin suponer éstas una amenaza para la democracia.

En Ecuador, las diferencias entre el derechista PSC y el izquierdista MUPP-NP son patentes en la práctica totalidad de los clivajes analizados. Mientras que el MUPP-NP se caracteriza por estar a favor de la intervención estatal en políticas públicas, baja religiosidad, una imagen negativa de Estados Unidos, disconformidad con las Fuerzas Armadas y baja proclividad democrática, el PSC destaca por lo opuesto, aunque hubiese sido interesante comprobar si esos rasgos se mantienen constantes en la legislatura actual para las dimensiones de democracia e imagen de Estados Unidos, algo que no es posible dada la baja calidad de representación del PSC para este año en el eje 2. Teniendo en cuenta esto, se puede afirmar que el partido está más próximo a las ideas neoliberales que a las estatistas, es conservador y religioso, favorable a las Fuerzas Armadas (si bien en el periodo 2002-2006 esta opinión ha cambiado ligeramente) y defensor de los valores democráticos.

La izquierda y la derecha salvadoreña se muestran relativamente próximas en tres de las cinco dimensiones ideológicas analizadas. El punto más claro en el que ambos partidos coinciden es en la imagen positiva que sus diputados tienen de estrechar relaciones con Estados Unidos. De igual modo, parece existir un acercamiento entre ARENA y FMLN respecto a la posición que ocupan en la dimensión Fuerzas Armadas, si bien ARENA tiene una opinión más favorable hacia el ejército que el FMLN. Esto es comprensible si se tienen en cuenta los enclaves autoritarios en El Salvador y la forma en la que se llevó a cabo la transición política. También se da un acercamiento en lo que a la proclividad democrática de ambas fuerzas políticas se refiere. Si el FMLN se ha caracterizado en los dos periodos de tiempo analizados por ser uno de los partidos políticos latinoamericanos con menor proclividad democrática, ARENA en la legislatura 2003-2006 cuenta, también, con rasgos similares. En cambio, y pese a esta proximidad entre la izquierda y la derecha salvadoreña en estos aspectos, las distancias resultan insalvables cuando se tratan temas de intervencionismo estatal y valores. Mientras que ARENA es una fuerza política neoliberal y conservadora, el FMLN se identifica por lo contrario, es estatista y progresista. 
El PNH, para las dos legislaturas analizadas, confirma su perfil de partido de derecha, aunque mucho más moderado que el resto de fuerzas políticas de este grupo (está próximo a ideales de mercado, es conservador, con proclividad democrática alta y defensor del papel de las Fuerzas Armadas).

Algo similar sucede con el PRSC, aunque poca cosa se puede decir sobre su evolución en los clivajes dada su baja calidad de representación en los planos factoriales durante el periodo 1998-2002, no obstante, se descuelga del resto de formaciones políticas de derecha abogando por un aumento del papel del Estado en políticas públicas y su desconfianza del ejército del país.

En el caso del PRD se confirma su carácter estatista, cuenta con menor proclividad democrática, es progresista y poco religioso, poco favorable al ejército (aunque su opinión sobre las Fuerzas Armadas ha mejorado notablemente en la última legislatura) y considera positiva la firma de acuerdos comerciales e inversores con los Estados Unidos.

El FSLN es uno de los partidos que más constante se ha mantenido a lo largo del tiempo en términos ideológicos. Su perfil como fuerza de izquierda revolucionaria se hace evidente y, pese a mostrarse moderado en lo que respecta al intervencionismo estatal en políticas públicas, destaca por su menor proclividad democrática, su valoración positiva de las Fuerzas Armadas y su actitud pro-estadounidense. En cuanto a sus valores, no se muestra claramente definido, ya que si sus diputados mantienen posiciones muy alejadas de la práctica religiosa, el FSLN es mucho más conservador respecto a temas de fuerte contenido moral, por ejemplo la legalización del aborto, lo que hace que su posicionamiento en este clivaje no sea extremo.

Finalmente, está FA/EP que presenta rasgos muy similares al PS. En buena medida porque tanto Uruguay como Chile son países de una gran estabilidad democrática y una prosperidad económica superior a la del resto de los países latinoamericanos aquí analizados. El FA/EP se ha desmarcado de la izquierda revolucionaria latinoamericana, fundamentalmente de los frentes (FMLN y FSLN), presentándose como un partido altamente democrático, crítico del papel de las Fuerzas Armadas, en buena medida por la experiencia del régimen militar vivida, confrontador de Estados Unidos, progresista y liberal y defensor del papel del Estado en la economía.

Hoy las dimensiones ideológicas hacen posible seguir hablando de partidos de izquierda y de derecha, en los siete países latinoamericanos aquí examinados, con especificidades propias derivadas de características sui géneris de los sistemas políticos nacionales de los que forman parte. Sin embargo, el estudio de la polarización en la política latinoamericana analizando 
los partidos políticos extremos de izquierda y de derecha, lleva por otra parte, a reflexionar sobre las características del espacio de competición con la incorporación del centro ideológico latinoamericano, asunto que no ha sido abordado en este trabajo. $\mathbf{P}_{\mathbf{g}}$

\section{Referencias bibliográficas}

Alcántara Sáez, Manuel (1991), "La relación izquierda-derecha en la política latinoamericana”, Leviatán, núm. 43-44, pp. 73-92.

— (1995), "La élite parlamentaria latinoamericana y el continuo izquierdaderecha", en Wilhelm Hofmeister y Josef Thesing (eds.), La transformación de los sistemas políticos en América Latina, Bonn, Konrad Adenauer Stiftung, pp. 385-410.

— (1999), Sistemas políticos de América Latina, 2 vols., Madrid, Tecnos.

— y Freidenberg, Flavia (eds.) (2001), Partidos políticos de América Latina, 3 vols., Salamanca, Ediciones Universidad de Salamanca.

— (2004), ¿Instituciones o máquinas ideológicas? Origen, programa y organización de los partidos latinoamericanos, Barcelona, ICPS.

— y Llamazares Valduvieco, Iván (2006), "Los partidos de derecha en los legislativos latinoamericanos", en Manuel Alcántara (ed.), Políticas y políticos en América Latina, Madrid, Siglo XXI, pp. 343-363.

Bianchini, M. Chiara (2006), "Memoria histórica, democracia y desarrollo en Chile (1973-2003)", ponencia presentada en el XII Encuentro de Latinoamericanistas Españoles, Santander, pp. 316-330.

Colomer, Josep M. y Escatel, Luis E. (2005), "La dimensión izquierda y derecha en América Latina”, Desarrollo Económico, vol. 44, núm. 177, pp. 123-136.

Coppedge, Michael J. (1997), "A Classification of Latin American Political Parties”, Working Paper, núm. 24, Notre Dame, Kellogg Institute.

— (1998), "The Dynamic Diversity of Latin American Party Systems", Party Politics, vol. 4, núm. 4, pp. 547-568.

Corral, Margarita y Otero, Patricia (2005), "El desempeño de la izquierda centroamericana: los casos de Nicaragua y El Salvador", ponencia presentada en el XI Encuentro de Latinoamericanistas Españoles, Tordesillas, pp. 344-374.

Dix, Robert H. (1989), "Cleavage Structures and Party Systems in Latin America”, Comparative Politics, vol. 22, núm. 1, pp. 23-37. 
Freidenberg, Flavia; García Díez, Fátima y Llamazares Valduvieco, Iván (2006), "Instituciones políticas y cohesión ideológica. Un análisis multinivel de la heterogeneidad ideológica en los partidos latinoamericanos", en Manuel Alcántara (ed.), Políticas y políticos en América Latina, Madrid, Siglo XXI, pp. 255-280.

Gabriel, K. Ruben (1971), “The Biplot Graphic Display of Matrices with Application to Principal Component Analysis", Biometrika, vol. 58, núm. 3, pp. 453-467.

Galindo, M. Purificación (1986a), "Una alternativa de representación simultánea: HJ-Biplot”, Questiio, 10 (1), pp. 13-23.

— y Cuadras, Carles M. (1986b), "Una extensión del método biplot y su relación con otras técnicas", Publicaciones de Bioestadística y Biomatemática, núm. 17.

García Díez, Fátima y Mateos Díaz, Araceli (2006), "El Proyecto Élites Parlamentarias Latinoamericanas: continuidad y cambios (1994-2005)", en Manuel Alcántara (ed.), Políticas y políticos en América Latina, Madrid, Siglo XXI, pp. 3-25.

Imbeau, Louis M.; Pétry, François y Lamari, Moktar (2001), "Left-Right Party Ideology and Government Policies: A Meta-Analysis", European Journal of Political Research, núm. 40, pp. 1-29.

Inglehart, Ronald (1984), "The Changing Structure of Political Cleavages in Western Society", en Dalton, Flanagan y Beck (eds.), Electoral Change in Advanced Industrial Democracies: Realigment or Dealigment?, Princeton, Princeton Uni Press, pp. 25-69.

Instituto Internacional de Gobernabilidad de Cataluña (2005), Perfil de Gobernabilidad de la República de Ecuador.

Jones, Mark P. (2005), "The Role of Parties and Party Systems in the Policymaking Process", documento preparado para el Workshop on State Reform, Public Policies, and Policymaking Process, Inter-American Development Bank, Washington, D.C., febrero 28-marzo 2, pp. 1-74.

Kern, Sobren (1995), "¿Cuáles son los intereses de Estados Unidos en Latinoamérica?”, Análisis del Real Instituto (ARI), Madrid, pp. 1-10.

Knutsen, Oddbjorn (1998), "The Strength of the Partisan Component of Left-Right Identity. A Comparative Longitudinal Study of Left-Right Party Polarization in Eight West European Countries", Party Politics, vol. 4, núm. 1, pp. 5-31.

Levine, Daniel H. (2005), "Pluralidad, pluralismo y la creación de un vocabulario de derechos", América Latina Hoy, núm. 41, pp. 17-34. 
Lipset, Seymour M. y Rokkan, Stein (1967), Party Systems and Voter Alignments: Cross-National Perspectives, Nueva York, Mc Millan.

Mainwaring, Scott y Torcal, Mariano (2003), "El conflicto democracia/autoritarismo y sus bases sociales en Chile, 1973-1975: un ejemplo de redefinición política de un cleavage”, REIS, núm. 103, pp. 51-82.

Mair, Meter (1997), Party System Change. Approaches and Interpretations, Oxford, Clarendon Press.

Martí Puig, Salvador y Santiuste Cué, Salvador (2006), "La izquierda parlamentaria en América Latina”, en Manuel Alcántara (ed.), Políticas y políticos en América Latina, Madrid, Siglo XXI, pp. 311-342.

Moreno, Alejandro (1999), Political Cleavages. Issues, Parties and the Consolidation of Democracy, Boulder, Westview Press.

Parker, Cristián (2005), “¿América Latina ya no es católica? Pluralismo cultural y religioso creciente”, América Latina Hoy, núm. 41, pp. 35-56.

PELA (1994-2005), Salamanca, Instituto Interuniversitario de Iberomérica.

Rivas Pérez, Cristina (2006), "Las dimensiones de la polarización en los parlamentos", en Manuel Alcántara (ed.), Políticas y políticos en América Latina, Madrid, Siglo XXI, pp. 215-254.

Ruiz, Leticia M. (2000), "Clivajes y competencia partidista en Chile (19901999)", en Nuevo Gobierno: desafíos de la reconciliación. Chile 1999-2000, Chile, FLACSO-Chile, pp. 159-190.

— (2003), "Polarización en el Chile postautoritario", en Manuel Alcántara y Elena Martínez (eds.), Política, dinero e institucionalización partidista en América Latina, México, Universidad Iberoamericana, pp. 195-244.

Sánchez, Diego (2006), "Fortalezas y debilidades de la política comercial y de desarrollo de Estados Unidos: un análisis del caso centroamericano", Análisis del Real Instituto (ARI), Madrid, pp. 1-7.

Sani, Giacomo y Sartori, Giovanni (1983), "Polarization, Fragmentation and Competition in Western Democracies", en Hans Daadler y Meter Mair (eds.), Western European Party Systems: Continuity and Change, Londres, Sage. Sartori, Giovanni (1976), Parties and Party Systems. A Framework for Análisis, Cambridge, University Press.

Vicente, José Luis (2004), "Los métodos Biplot", documento de trabajo, Doctorado de Estadística Multivariante, Departamento de Estadística, Universidad de Salamanca (bienio 2004-2006).

Yaffé, Jaime (2006), "Institucionalización y adaptación partidaria. El caso del Frente Amplio (Uruguay)", ponencia presentada en el XII Encuentro de Latinoamericanistas Españoles, Santander, pp. 316-330. 


\section{Apéndice metodológico}

El $H J$-Biplot, aunque no reproduce los elementos de la matriz original, ${ }^{22}$ tiene la ventaja de que se trata de una representación simultánea en sentido estricto, de manera que los marcadores para los partidos políticos y para las dimensiones ideológicas son elegidos de forma que ambos puedan superponerse en el mismo sistema de referencia lográndose así una máxima calidad de representación, tanto para los partidos políticos como para las variables que definen los clivajes de la polarización.

Los métodos factoriales gráficos presentan los resultados en forma de diagramas de dispersión, generalmente en un subespacio de dimensión dos aunque la configuración inicial sea de dimensión mayor (generalmente un plano), por lo que se pierde algo de información a pesar de que se trabaje con aquel subespacio que retiene una mayor información, el de máxima inercia. Esto implica que sea necesario conocer la bondad de ajuste de la representación biplot en el subespacio de máxima inercia (es decir, conocer cuál es la cantidad de información retenida). Para ello se utiliza la tasa de absorción de inercia que se mide en términos de variabilidad explicada. Cuanta mayor variabilidad tenga un eje mayor información recoge, de modo que cuanto más se aproximen los valores de los ejes factoriales al valor 100 (la tasa de absorción de inercia varía entre 0 y 100) más fiable será la representación. Si el porcentaje de variaciones explicadas es alto (es decir, la tasa de absorción es próxima a 100) se supone que la configuración de la proyección de la hipernube refleja, con un alto grado de fiabilidad, la configuración de la nube en el hiperespacio (Vicente, 2004).

Tal y como se observa en el cuadro 1 , se han retenido los cuatro primeros ejes factoriales del HJ-Biplot realizado. ${ }^{23} \mathrm{El}$ primer eje factorial recoge la mayor parte de la información, absorbe el $35.1 \%$ de la variabilidad total; es de-

${ }^{22}$ A diferencia de los métodos Biplot propuestos por Gabriel en 1971, que permiten representar los datos de una matriz Xnxp (individuos por variables) en un espacio de dimensión reducida, sin más que elegir unos marcadores $a_{1}, a_{2}, \ldots a_{n}$ para sus filas (individuos) y $b_{1}, b_{2}, \ldots, b_{n}$ para sus columnas (variables), de forma que el producto interno $a_{i}{ }^{\prime} b_{i}$ reproduzca el elemento $x_{i j}$ de la matriz X.

${ }^{23}$ Cuando se habla de ejes factoriales se hace referencia a los ejes de la representación biplot y carecen de algún significado concreto. Los ejes factoriales son variables nuevas, combinaciones lineales de las variables de partida y lo que, en definitiva, permite representar más de dos variables en forma de diagrama de dispersión, generalmente en un subespacio de dimensión dos. Tendrán el significado de las variables que lo componen. 
CUADRO 1. Absorción de inercia

\begin{tabular}{lcc}
\hline & Inercia absorbida & Inercia acumulada \\
\hline Eje 1 & 35.05 & 35.05 \\
Eje 2 & 26.08 & 61.13 \\
Eje 3 & 18.45 & 79.58 \\
Eje 4 & 14.14 & 93.72 \\
\hline
\end{tabular}

Fuente: Resultados obtenidos del HJ-Biplot a partir de los datos de PELA (1997-2005).

cir, la dimensión o dimensiones ideológicas mejor representadas en el eje 1, serán los clivajes que más discriminan a los partidos políticos de izquierda y derecha en el primer plano factorial. El segundo eje, también aporta información importante, si bien algo menos que el primero (26.1\%). La tasa de inercia en el espacio formado por los tres primeros ejes (1, 2 y 3$)$ alcanza el $79.6 \%$ de la variabilidad total en los datos lo que garantiza la fiabilidad de la interpretación de los mismos. Esto justifica la decisión final de explicar sólo los tres primeros ejes en el análisis.

La identificación de aquellas dimensiones programáticas que determinan las diferencias entre los partidos políticos se realiza a través de los ejes factoriales. La medida de la relación entre los ejes de la representación biplot y cada una de las variables observadas se denomina Contribución Relativa del Factor al Elemento. ${ }^{24}$ Esta contribución permite saber cuáles son las líneas de división ideológica más directamente relacionadas con cada eje y, por tanto, conocer qué variables son responsables de la colocación de los partidos sobre las proyecciones perpendiculares a cada uno de los vectores en los ejes factoriales. ${ }^{25}$ De modo que si una dimensión recibe una alta contribución de uno de los ejes y baja de los demás (es decir, tiene valores altos en un eje y bajos en los demás), indica que ese elemento es una caracte-

${ }^{24}$ La contribución relativa del factor al elemento representa la parte de variabilidad de cada una de las variables explicada por el factor, y se interpreta de la misma manera que un coeficiente de determinación en regresión. Es decir, indica la contribución de cada uno de los ejes factoriales de la representación biplot a las dimensiones de polarización ideológica.

${ }^{25}$ Como los ejes son independientes, la contribución de cada uno de ellos a cada variable es independiente, por tanto, es posible calcular la contribución de un plano factorial sumando las contribuciones de los ejes que lo forman. Por ejemplo, la contribución del plano a la dimensión "Intervención estatal" sería el resultado de sumar la contribución del eje 1, eje 2 y eje 3 a esa dimensión, es decir, 469, 77 y 350. De modo que la contribución del plano a la dimensión "Intervención estatal" es de 896 (sobre 1.000). Véase cuadro 2. 
CUADRO 2. Contribuciones relativas para las dimensiones de polarización

\begin{tabular}{lcrr}
\hline Dimensiones programáticas & Eje 1 & Eje 2 & Eje 3 \\
\hline Intervención estatal & 469 & 77 & 350 \\
Valores & 608 & 15 & 76 \\
Imagen de Estados Unidos & 124 & 632 & 154 \\
Fuerzas armadas & 523 & 32 & 4 \\
Democracia & 28 & 548 & 340 \\
\hline
\end{tabular}

Fuente: Resultados obtenidos del HJ-Biplot a partir de los datos de PELA (1997-2005). Nota: Los datos que aparecen en negritas en el cuadro indican que la contribución que esas dimensiones reciben de los ejes es alta.

rística casi exclusiva de ese eje, y serán estas dimensiones programáticas las más importantes a la hora de interpretar un eje. ${ }^{26}$ Así, y en este caso concreto, las dimensiones características de eje 1 , es decir, aquellas que reciben valores altos del eje 1 y relativamente bajos de los demás son tres: "Valores", "Fuerzas Armadas" e "Intervención estatal". Por su parte, los clivajes, "Imagen de Estados Unidos" y "Democracia" obtienen los mayores valores del eje 2, por tanto dichas variables estarían definiendo este eje (véase cuadro 2).

En cuanto a los partidos, es más útil su interpretación en términos de calidad de representación y no tanto en términos de contribuciones relativas del factor al elemento (en este caso partido político). La calidad de representación puede interpretarse como la parte de la información de un partido, recogida por los ejes. La suma de las contribuciones relativas del factor al elemento proporciona información sobre la calidad de representación de los diferentes partidos en el subespacio de dimensión reducida. Así, cuanto más próximo a 1.000 sea el valor de un partido político en los ejes mejor será su calidad de representación en el plano factorial. ${ }^{27}$

\footnotetext{
${ }^{26}$ Aquellas variables que tienen valores similares en todos los ejes tienen una menor capacidad discriminatoria entre los partidos al poder ser interpretados indistintamente respecto a uno u otro eje (un ejemplo claro de ello es el de la dimensión "Intervención estatal").

${ }^{27}$ Por ejemplo, la calidad de representación del PS chileno en el plano factorial considerado sería el resultado de sumar la contribución recibida por ese partido del eje 1 , eje 2 y eje 3 , es decir, 242, 474 y 104 (véase cuadro 3). De modo que la calidad en el plano del PS es de 820 (sobre 1.000).
} 
CUADRO 3. Contribuciones relativas para los partidos políticos ${ }^{28}$

\begin{tabular}{lrrr}
\hline Partidos políticos & Eje 1 & Eje 2 & Eje 3 \\
\hline PS & 242 & 474 & 104 \\
UDI & $\mathbf{6 2 5}$ & 229 & 125 \\
MUPP-NP & $\underline{\mathbf{8 6 4}}$ & 10 & 98 \\
PSC & $\mathbf{9}$ & 71 & 54 \\
ARENA & $\underline{\mathbf{8 1 9}}$ & 97 & 20 \\
FMLN & 114 & 167 & 44 \\
PNH & 158 & 211 & 596 \\
PRD & 301 & 311 & 300 \\
FSLN & 13 & 496 & 86 \\
PRSC & 2 & 122 & $\mathbf{8 1 6}$ \\
FA/EP & 338 & 559 & 14 \\
\hline
\end{tabular}

Fuente: Resultados obtenidos del HJ-Biplot a partir de los datos de PELA (1997-2005).

Tal y como se observa en el cuadro 3 se puede afirmar que la calidad de representación en los gráficos biplot para la práctica totalidad de nuestros casos es buena o aceptable. No obstante, y aunque para el caso de los partidos políticos sea más útil su interpretación en términos de calidad, es interesante tener también en cuenta la contribución relativa de cada eje factorial a cada uno de los partidos para poder interpretar la discriminación de los ejes factoriales. ${ }^{29}$

Finalmente, y para una mejor interpretación de los gráficos HJ-Biplot presentados en este trabajo, hay que tener presente que las dimensiones programáticas se han representado mediante vectores (flechas) y los partidos políticos mediante puntos con sus correspondientes etiquetas. A la hora de interpretar los puntos (partidos políticos) hay que tener en cuenta su proyección perpendicular sobre el vector, de modo que los puntos que se proyectan cerca de la punta de la flecha tienen mayor magnitud que los que

\footnotetext{
${ }^{28}$ Los partidos que reciben una contribución relativamente alta de alguno de los ejes aparecen en el cuadro 3 en negrita y doble subrayado. Normalmente los partidos con bajas contribuciones en los tres ejes están cercanos al centro de gravedad y son aquellos que no pueden interpretarse por su mala calidad de representación.

${ }^{29}$ Su interpretación sería igual que para el caso de las dimensiones programáticas. Habría que tener en cuenta los valores de cada uno de los partidos políticos en los ejes factoriales, de modo que aquellos partidos con valores altos en uno de los ejes y bajos en los demás (valores que varían entre 0-1.000) se interpretarán teniendo en cuenta su proyección perpendicular sobre las variables características de ese eje.
} 
se proyectan en la prolongación. Además, los puntos que se proyectan por encima del centro de gravedad se corresponden con valores positivos mientras que por debajo del centro de gravedad tienen valores negativos. Cuanto más distantes aparezcan los puntos que representan a los partidos del centro de gravedad, más variabilidad habrán presentado esos partidos en el estudio. La proximidad entre los puntos que representan a los partidos políticos se interpreta como similitud entre partidos, de modo que dos partidos próximos en el plano factorial tendrán un comportamiento similar, mientras que cuanto más alejados estén en el plano mayores serán sus diferencias.

En cuanto a los vectores (o dimensiones ideológicas) han de tenerse en cuenta dos aspectos fundamentales: la longitud de los vectores que representan a las variables, que se interpreta en términos de variabilidad, y el ángulo que forma el vector con los ejes factoriales. Así, cuanto mayor sea la longitud del vector mayor variabilidad presenta ese clivaje en el análisis y cuanto menor sea el ángulo formado entre el vector y el eje factorial que lo representa mayor será su importancia en el estudio (Rivas, 2006). 